\title{
MONZOGRANITO DE RIONEGRO
}

\Cordillera Oriental

Departamentos de Santander y Norte de Santander

María Isabel Arango, Gabriel Rodríguez, Gilberto Zapata y Ana María Correa Martínez

Catálogo de las unidades litoestratigráficas de Colombia / Triásico-Jurásico

Citación: Arango, M. I., Rodríguez, G., Zapata, G. y Correa Martínez, A. M. (2020). Monzogranito de Rionegro. En Catálogos de las unidades litoestratigráficas de Colombia: Macizo de Santander. Vol. 1. Servicio Geológico Colombiano. https://doi.org/10.32685/9789585279445.5 


\section{Origen del nombre, distribución geográfica y reseña histórica El nombre de este cuerpo ígneo plutónico deriva de su composición modal dominante y de su localización geográfica cerca del municipio de Rionegro (Santander).}

\subsection{Distribución geográfica}

El Monzogranito de Rionegro tiene un área total aproximada de $1.445 \mathrm{~km}^{2}$ y está situado entre las planchas 86, 97 y 109. Es un cuerpo de forma alargada que se extiende en sentido NNW-SSE desde el flanco occidental de la cordillera Oriental, sobre los departamentos de Santander y Norte de Santander. Su parte más angosta se encuentra hacia el sur en la plancha $109(1,8 \mathrm{~km})$ y se amplía hasta 17,13 km hacia el norte de la plancha 97.

Por su parte, el cuerpo de granodiorita que fue cartografiado como una unidad aparte en la Plancha 109 (Ward et al., 1973), aflora en cercanías del municipio de Rionegro, en el extremo sur del Monzogranito de Rionegro, tiene un área de $36 \mathrm{~km}^{2}$ y se encuentra en la carretera que comunica el municipio de Rionegro con Santa Cruz. El cuerpo intrusivo tiene forma irregular alargada en sentido NE-SW (Ward et al., 1973).

El Monzogranito de Rionegro se encuentra limitado hacia el occidente por la falla de Bucaramanga, en contacto con la Formación Bocas y la Formación Girón. En cercanías del municipio de San Alberto se encuentra en contacto fallado e intrusivo con la unidad Ortoneis y con el Neis de Bucaramanga. Hacia el norte, el límite de la unidad es impreciso y ha sido incluido como parte del complejo extrusivo-intrusivo en la Plancha 76-Ocaña (Daconte y Salinas, 1980).

De acuerdo con la cartografía existente, el límite oriental del Monzogranito de Rionegro intruye la Formación Silgará y el Monzogranito de Cáchira, y en algunos sectores está limitado por la falla Veguitas y las fallas satélites de la falla de Cáchira.

Trabajos de campo, junto con análisis petrográficos y geocronológicos durante la ejecución del Proyecto Magmatismo Jurásico de Santander, permitieron delimitar el Monzogranito de Rionegro en su borde oriental, con una extensión menor que la presentada en las planchas 86 y 97 , en las que aparece como parte de este cuerpo intrusivo otro cuerpo que denominamos Monzogranito de
Cáchira (figura 1), que presentó una edad U/Pb en circones del Paleozoico, diferencias geoquímicas, textura granoblástica con contenidos mayores de moscovita y diques pegmatíticos de cuarzo y moscovita.

\subsection{Reseña histórica}

Esta unidad ha sido nombrada por Ward et al. (1973), teniendo en cuenta su diversidad litológica y su amplia distribución geográfica entre las planchas geológicas 86 (Ábrego), 97 (Cáchira) y 109 (Rionegro), Batolito de Rionegro, y está situada hacia el este del municipio de Rionegro, de donde toma su nombre en la plancha 109. En el norte, en cercanías del municipio de Ocaña, Arias y Vargas (1978) la nombraron Batolito de Ocaña, refiriéndose así a un conjunto de rocas intrusivas con similitudes composicionales al Batolito de Rionegro, junto con rocas extrusivas de composición riolítica, sin precisar límites cartográficos entre estas unidades.

Ward et al. (1973) definieron y separaron dos facies del Batolito de Rionegro: una facies principal de cuarzomonzonita (equivale a monzogranitos) localizada hacia el norte del municipio de Rionegro, en cercanías de la localidad de La Reforma; esta se extiende hacia el norte hasta el límite de las planchas 86 y 76, donde es cartografiada como complejo intrusivo-extrusivo (Daconte y Salinas, 1980). Posteriormente, esta facies es denominada unidad cuarzomonzonita (Arias y Vargas, 1978; Arias y Morales, 2003); unidad intrusiva cuarzomonzonita (Clavijo, 1994) y cuarzomonzonita-granito (Royero y Clavijo, 2001). En el empalme entre las planchas 97 (Cáchira) y 98 (Durania) no hay continuidad en la nomenclatura cartográfica del batolito, por lo que Fuquen et al., (2010), denominan el cuerpo intrusivo localizado al oeste de la plancha de Durania como Granito de Arboledas.

Subordinadamente, la facies granodiorítica está asociada en la literatura con la unidad granodiorita y granodiorita biotítica, que inicialmente correspondía a dos cuerpos: el primero de ellos, en la Plancha 86 (Arias y 


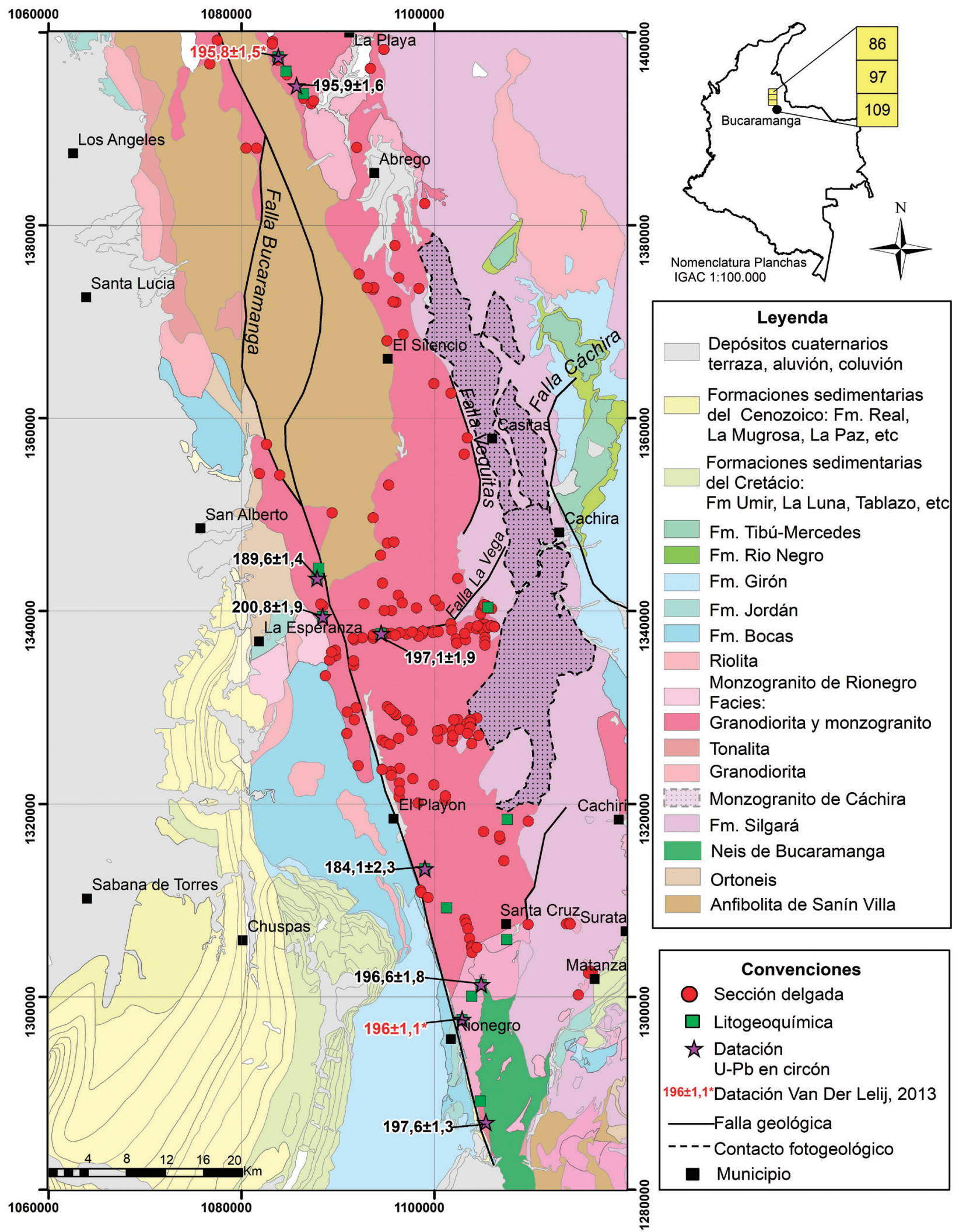

Figura 1. Localización de afloramientos del Monzogranito de Rionegro

Fuente: modificado a partir de Ward et al. (1973), Arias y Vargas (1978), Daconte y Salinas (1980), Arias y Morales (2003), Clavijo (1994) y Royero y Clavijo (2001) y este trabajo 
Vargas, 1978), y el otro, ubicado en la Plancha 109 (Ward et al., 1973).

Según Arias y Vargas (1978), estos dos cuerpos granodioríticos presentan similitudes entre sí; sin embargo, una edad reportada por Van der Lelij (2013) de 443,4 \pm $3,2 \mathrm{Ma}, \mathrm{U}-\mathrm{Pb}$ en circones para la unidad que aflora en la plancha 86 indica que se trata de un plutón diferente del Batolito de Rionegro y de la facies granodiorita que aflora al sur de este, localizada en cercanías del municipio de Rionegro y la población de Santa Cruz, en la Plancha 109 (Ward et al., 1973) (figura 1). La granodiorita que aflora en los alrededores de Rionegro debe ser tratada como una unidad aparte del Monzogranito de Rionegro, de acuerdo con la edad U/Pb en circones obtenida en este proyecto, de 21 4,5 $\pm 2,7 \mathrm{Ma}$, pues es anterior a la cristalización de las rocas del Monzogranito de Rionegro.

\section{Descripción geológica}

\subsection{Marco geológico}

El Macizo de Santander hace parte de un bloque regional de forma triangular conformado por las fallas de Santa Marta-Bucaramanga, al occidente, la falla de Oca-Ancón, al norte, y la falla de Boconó, en el lado oriental.

Las rocas más antiguas del Macizo de Santander comprenden unidades metamórficas como el Neis de Bucaramanga (Ward et al., 1973), denominado también complejo Bucaramanga (Clavijo, 1994). El Neis de Bucaramanga consiste de paragneises migmatíticos de alto grado considerados de edad Proterozoica, con un pico de metamorfismo de edad $1057 \pm 28 \mathrm{Ma}$ (U/Pb-SHRIMP en circón), relacionado con la orogenia grenvilliana (Goldsmith et al., 1971; Restrepo Pace et al., 1997; García y Ríos, 1999; Cordani et al., 2005; Ordóñez Cardona et al., 2006).

Edades publicadas por Van der Lelij (2013) y obtenidas durante el desarrollo del proyecto Magmatismo Jurásico del Macizo de Santander en unidades cartografiadas como el Neis de Bucaramanga y el Ortoneis por el método U-Pb LA-ICP-MS (laser ablation inductively-coupled plasma mass spectrometry -ablación láser inductivamente acoplada con un espectrómetro de masas con fuente de plasma-) en circones, arrojaron edades de metamorfismo y cristalización del Ordovícico.

El Neis de Bucaramanga subyace a la Formación Silgará, constituida por esquistos, filitas, metalodolitas, metaareniscas y escasos mármoles, y hace parte del basa- mento del Macizo de Santander (Ward et al., 1973; García y Ríos, 1999; Ríos et al., 2003; Mantilla et al., 2013 ; Mantilla et al., 2016). Presenta edades de metamorfismo del Ordovícico Inferior-Medio relacionadas con la orogenia caledoniana (Ríos et al., 2003; Ordóñez Cardona et al., 2006; Clavijo et al., 2008; Mantilla et al., 2013).

Algunas edades U-Pb en circón muestran magmatismo posterior y anterior al metamorfismo, representado por metavulcanitas y plutones que intruyen el basamento metamórfico, con edades U/Pb en circón del Silúrico, Devónico Inferior, Carbonífero y límite TriásicoJurásico.

Los plutones triásico-jurásicos del Macizo de Santander se consideraron emplazados en rocas metamorficas del Terreno Chibcha, de acuerdo con Restrepo y Toussaint (1988) y Restrepo et al., (2011), o del terreno Santander, según Etayo et al. (1985). Estos plutones están emplazados en rocas metamorficas ordovícicas relacionadas con la orogenia famatiniana, y probablemente no tienen relación con el arco continental más joven, Jurásico temprano a Medio, del Valle Superior del Magdalena, la serranía de San Lucas y la Sierra Nevada de Santa Marta, emplazado en basamento metamórfico grenvilliano, y donde no se han reportado rocas metamorficas relacionadas con la orogenia famatiniana.

Durante el límite Triásico-Jurásico se desarrolló un notable magmatismo de arco continental que produjo el emplazamiento de grandes batolitos, stocks graníticos y cuerpos riolíticos subvolcánicos localizados hacia la margen occidental del Macizo de Santander, en el basamento metamórfico paleozoico.

Unidades sedimentarias cretácicas reposan discordantes sobre el basamento metamórfico y los plutones. Con posterioridad a la sedimentación cretácica se dio escaso magmatismo durante el Mioceno, que emplazó pequeños cuerpos de pórfidos con mineralización de oro (Leal, 2011; Mantilla et al., 2013).

\subsection{Características macroscópicas}

Arias y Vargas (1978) describen la composición principal del Batolito de Rionegro como cuarzomonzonita, con un predominio de biotita y variaciones locales a granito, granodiorita y, en menor proporción, a tonalita. De acuerdo con Ward et al. (1973), la litología principal es leucocrática de color rosado a gris claro, con un índice de color de 15 a $20 \%$,y presenta texturas equigranulares 
a subporfiríticas con tamaño de grano medio. Estos autores indican variaciones litológicas, cerca de los bordes en contactos con la Formación Silgará, a un granito de color blanco a rosado.

A nivel macroscópico, según Daconte y Salinas (1980), las rocas intrusivas del Batolito de Ocaña exhiben una textura que varía de grano fino a grueso, con predominio del grano medio y escasas zonas pegmatíticas. Son rocas claras compuestas por feldespato rosado, cuarzo, plagioclasa y, en menor proporción, algún ferromagnesiano (biotita, clorita). La composición varía de granito a cuarzomonzonita.

El Monzogranito de Rionegro está compuesto por cristales subhedrales de plagioclasa, cristales de cuarzo anhedrales y feldespato que puede variar en su contenido a cristales anhedrales de tonalidad rosada. El mineral máfico que predomina es la biotita en láminas de color negro y, en menor proporción, cristales de hornblenda.

Macroscópicamente, las granodioritas corresponden a rocas faneríticas de color gris a gris verdoso, con tamaño de grano medio a ligeramente inequigranular y textura subporfirítica. Están compuestas por cuarzo, plagioclasa y feldespato potásico como minerales principales y biotita sectorizada. Se encuentran intruyendo la Formación Silgará; hacia el sur subyacen la Formación Girón y la Formación El Diamante (Arias y Vargas, 1978). Diques de cuarzomonzonita son abundantes en el norte del Monzogranito de Rionegro, al este de Bucaramanga. Sin embargo, diques y masas pequeñas están distribuidos en toda el área de afloramiento. En el Monzogranito de Rionegro son comunes los diques de composición félsica (riolitas, dacitas y aplitas) y máfica (andesitas,
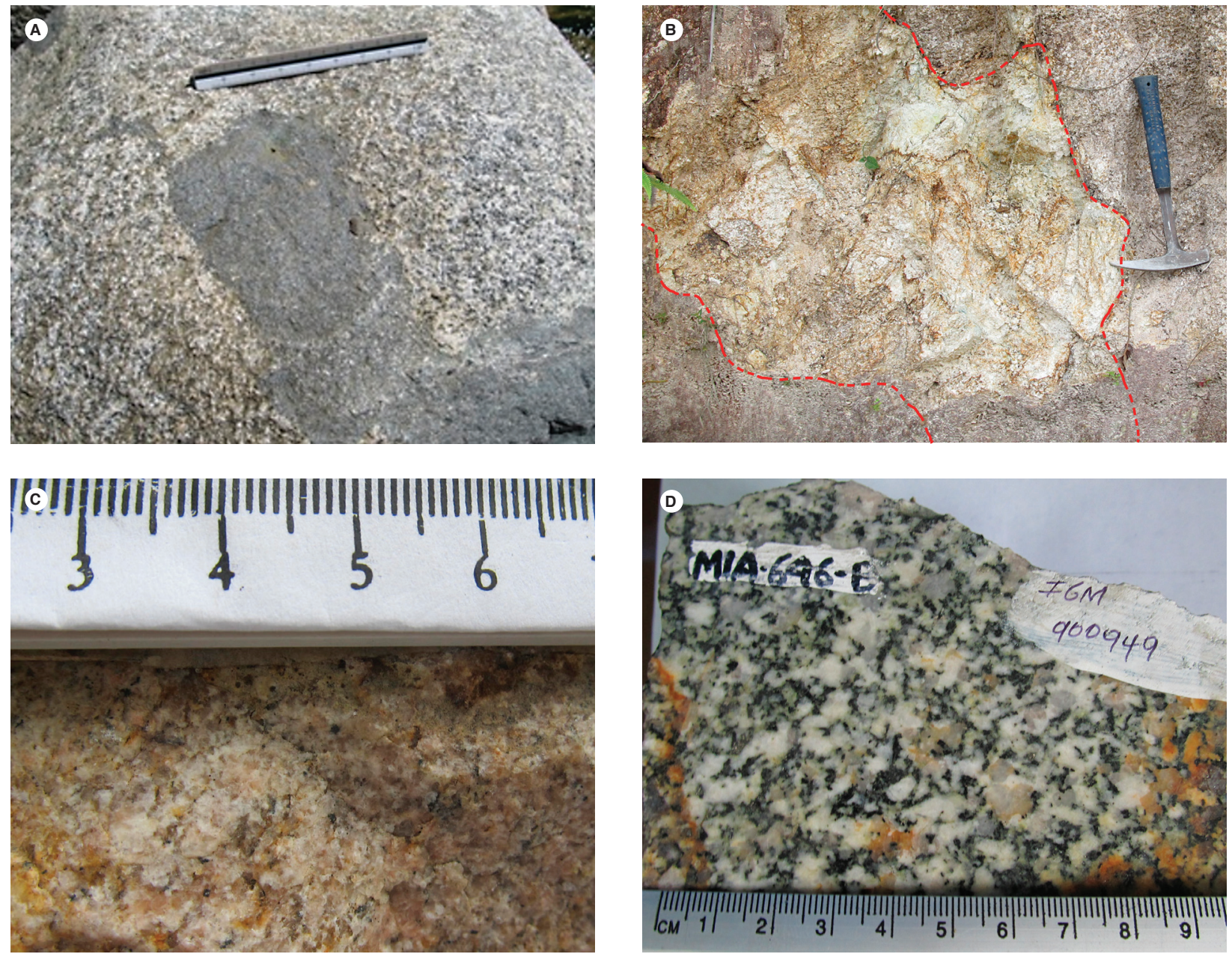

Figura 2. Aspecto macroscópico de rocas del Monzogranito de Rionegro. A) Enclave máfico en monzogranito. B) Saprolito de roca cortado por un dique félsico, GZ-6842. C) Monzogranito, IGM-900894. D) Granodiorita, IGM-900949 
microdioritas), con espesores decimétricos a centimétricos y con distribución irregular (figura 2). Asimismo, se presentan enclaves de composición básica diorítica, con bordes irregulares, netos a difusos, de tamaños que varían entre 5 y $20 \mathrm{~cm}$, compuestos por cristales finogranulares de biotita y plagioclasa.

En algunos sectores el cuerpo ígneo se encuentra meteorizado, y expone un saprolito de color crema, blanco a blanco amarillento, con textura granular gruesa, en el que se conservan cristales frescos de cuarzo y láminas lixiviadas de biotita.

Hacia el sector centro-occidental del plutón, en la vía que comunica los municipios de El Playón y San Alberto, en el cauce del río Cáchira y en la vereda Pueblo Nuevo se observan intrusiones locales del Monzogranito de Rionegro en un cuerpo de composición diorítica (figura 3), a manera de brechas intrusivas con abundancia de cristales de feldespato potásico y texturas pegmatíticas.

\subsection{Características microscópicas}

La descripción petrográfica del cuerpo principal, cuerpos menores asociados y diques se hace a partir del análisis de quince muestras de roca tomadas en este es- tudio. Además, se realizó la compilación y el análisis de 159 secciones delgadas existentes de estudios cartográficos anteriores (anexo 1).

Litológicamente predominan los monzogranitos, seguidos de sienogranitos, granodioritas, cuarzosienitas, tonalitas, cuarzomonzonitas, monzonitas y cuarzodioritas (figura 4). No hay una clara distribución espacial de los diferentes tipos de rocas en la unidad; por el contrario, se presentan dispersas a lo largo del cuerpo.

De acuerdo con Ward et al. (1973), el Batolito de Rionegro presenta textura general hipidiomorfa dada por una mineralogía principal de cuarzo (25 a 35\%), oligoclasa subhedral (25 a $45 \%$ ), microclina y micropertitas (20 a 40\%) y biotita (1 a 10\%). Como minerales accesorios se presentan circón, titanita, allanita, apatito y óxidos de hierro; como minerales de alteración tiene clorita, epidota y sericita.

Las granodioritas presentan una textura hipidiomorfa y están compuestas por plagioclasa, cuarzo, feldespato y biotita (Ward et al., 1973). Como minerales accesorios presentan titanita, apatito, allanita, magnetita y escaso circón y sericita. Clorita, productos arcillosos, calcita y epidota están presentes como minerales secundarios de alteración.
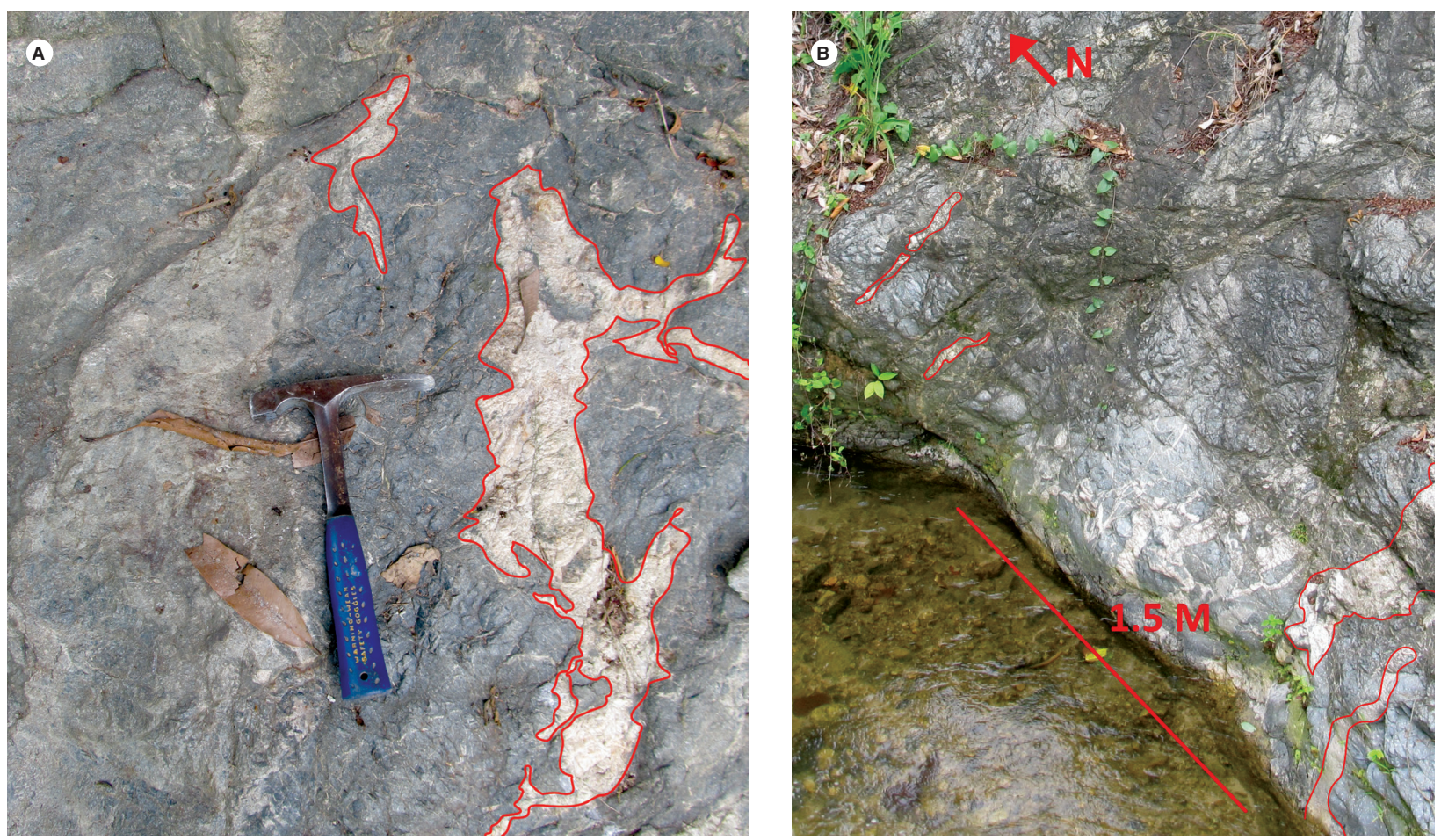

Figura 3. Intrusiones del Monzogranito de Rionegro en cuerpos de diorita en el borde occidental del plutón. A) TCR-387. B) Río Cáchira, estación TCR-387 


\section{A}

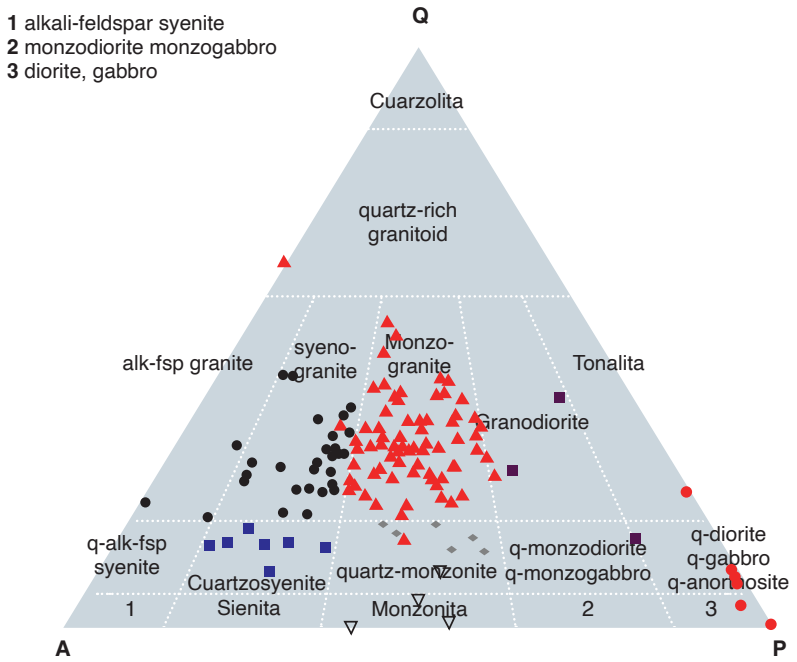

B

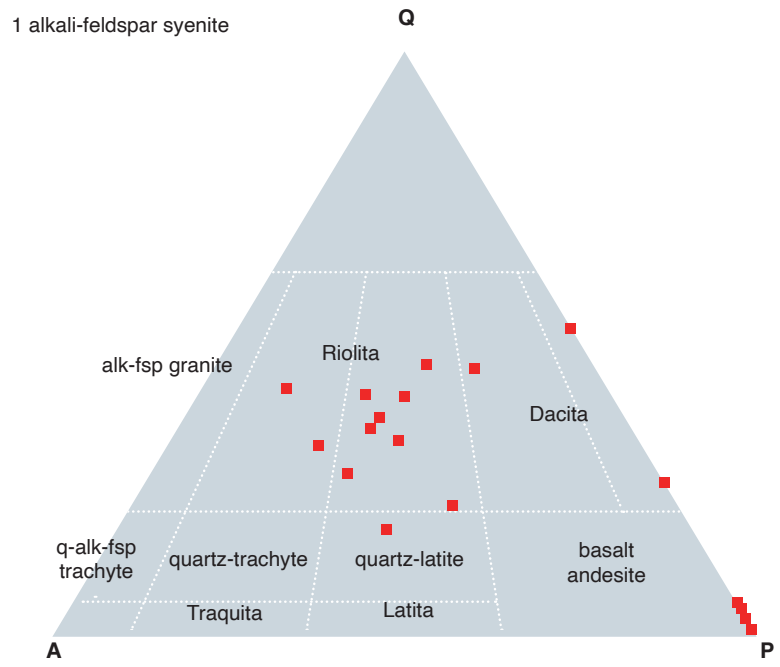

Figura 4. Composición modal del Monzogranito de Rionegro utilizando los diagramas de Streckeisen $(1976,1978)$. A) Distribución de rocas del Monzogranito de Rionegro en los campos de las rocas ígneas intrusivas, separando las muestras por color y símbolo según la clasificación. B) Composición modal de diques

De acuerdo con Daconte y Salinas (1980), las rocas del Batolito de Ocaña tienen texturas pertítica, hipidiomorfa a alotriomorfa y poiquilítica, con evidencias de cataclasis. Su composición incluye feldespato potásico (30 a $40 \%$ ) en cristales anhedrales con textura pertítica, a veces alterados a caolinita. La plagioclasa (30 a 40\%) varía de $A b_{70} a_{30}$, con maclas de albita y periclina. Algunos cristales presentan zonación. El cuarzo (20 a 30\%) se observa en cristales anhedrales con extinción débilmente ondulatoria y con inclusiones de plagioclasa y moscovita, a veces recristalizado. Los minerales accesorios son biotita, moscovita, magnetita y titanita. La moscovita es abundante en los contactos con la Formación Silgará.

El Monzogranito de Rionegro presenta una textura general alotriomorfa granular a hipidiomorfa, y comúnmente desarrolla texturas de intercrecimiento que varían entre mirmequíticas, micrográficas y simplectíticas (figura 5). De manera sectorizada se presentan texturas porfiríticas y granoblásticas a ligeramente orientadas; estas últimas evidencian sobreimposición de un metamorfismo dinámico asociado con el sistema de fallas de Bucaramanga y fallas menores.

Los monzogranitos se constituyen de cuarzo entre 20 y $54,3 \%$, plagioclasa entre 8,5 y $47,9 \%$ y feldespato potásico, que varía entre 22,2 y $65 \%$. El mineral máfico que más abunda es la biotita, que fluctúa entre 0,5 y $10 \%$, seguido de hornblenda en contenidos traza a 3,1\%; como minerales accesorios exhibe opacos (desde contenidos traza a $2 \%$ ), moscovita (menor de $1 \%$ ), titanita (hasta un $2 \%$ ), circón (hasta el 0,5\%) y apatito (0,5\%).

Los sienogranitos y cuarzo-sienogranitos presentan cantidades de cuarzo entre $15 y$ 45,1\%, plagioclasa entre el 6,9 y 22,9\%, y contenidos de feldespato potásico entre el 41 y el 70\%. Al igual que en los monzogranitos, el mineral máfico que predomina es la biotita, entre 0,5 y $7 \%$; como minerales accesorios, estas rocas tienen moscovita en cantidades menores del $1 \%$; en particular, en la roca IGM-10981 se encuentra granate en contenidos traza, opacos entre 0,1 y $2 \%$, apatito en cantidades menores de 0,2\%, circón entre el 0,2 y el 0,7\%, titanita entre 0,2 y $0,5 \%$, y allanita en un $0,5 \%$.

Las monzonitas se componen de cuarzo entre un 0,7 y $8 \%$, plagioclasa en un 35 a 40,5\%, y feldespato potásico entre 30 y 53,5\%. Como minerales máficos aparecen trazas de biotita y hornblenda; los minerales opacos alcanzan el $1 \%$. Presentan apatito y circón en cantidades trazas y titanita hasta en un $3 \%$.

Las granodioritas tienen contenidos modales de cuarzo entre 4,5 y 36,5\%, plagioclasa entre el 29 y 62,5\% y feldespato potásico entre 9,7 y 25\%. Se reporta la biotita como mineral máfico más común entre un 1 y 14,3\%. Por el contrario, la hornblenda es escasa y alcanza el $1 \%$, 

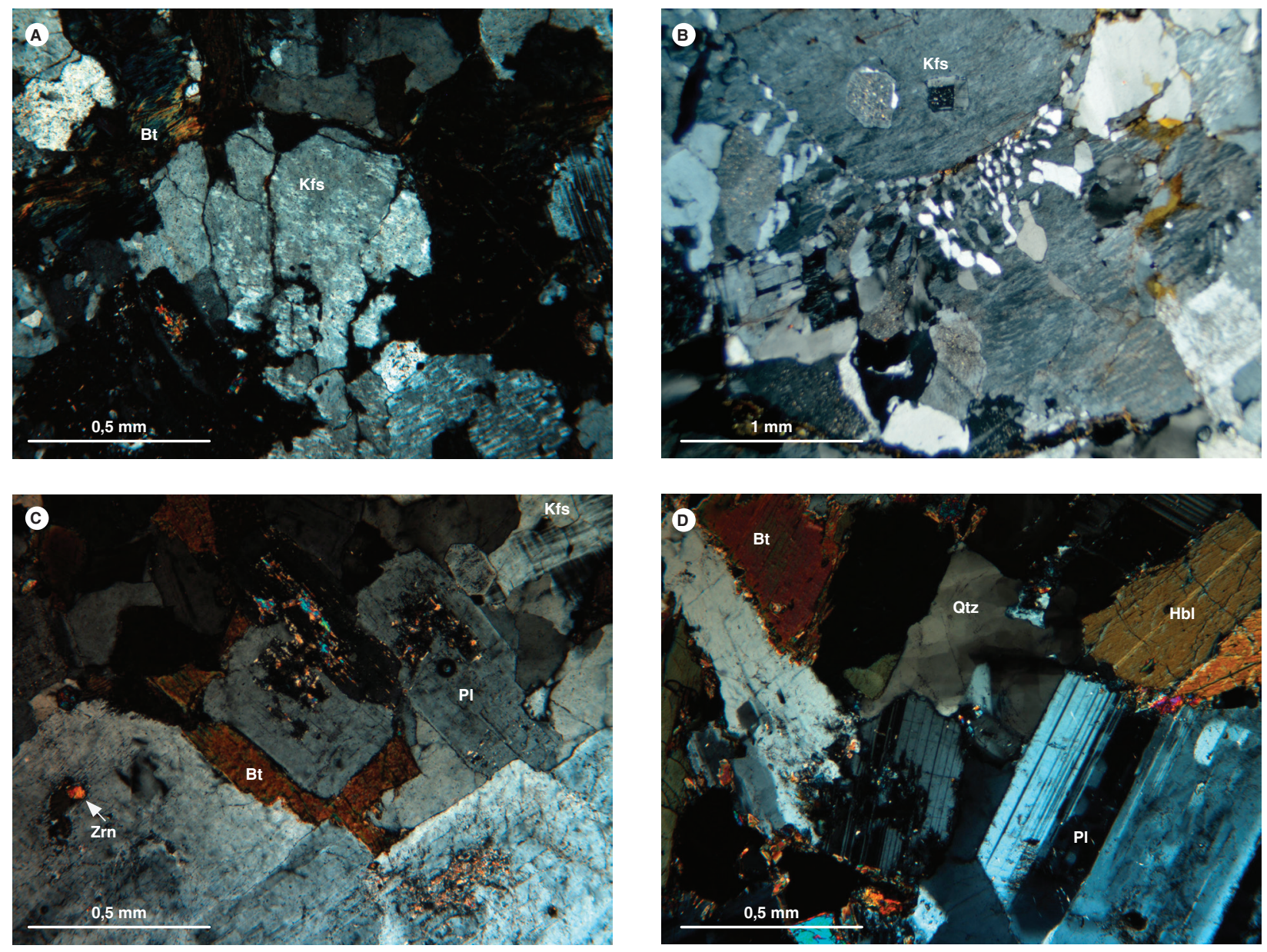

Figura 5. Texturas principales del Monzogranito de Rionegro (en nícoles cruzados). A) Pertitas en granodiorita, IGM-900985. B) Mirmequítica y pertítica en sienogranito, IGM-900950. C) Hipidiomorfa en granodiorita, IGM-901028. D) Hipidiomorfa en tonalita, IGM-31180

excepto en la roca IGM-90999, que tiene un contenido alto $(29 \%)$ y es clasificada como granodiorita con hornblenda. Estas rocas pueden presentar contenidos traza de moscovita, los opacos alcanzan en ellas hasta el $1 \%$; otros minerales accesorios, como el apatito y el circón, están en un $2 \%$ cada uno, y la titanita hasta en un 4,5\%.

Pocas rocas se clasifican como tonalitas, y las que lo hacen presentan cantidades de cuarzo entre el 21 y el $37,2 \%$, plagioclasa entre el 41 y el $54,5 \%$, y proporciones bajas de feldespato potásico, entre 0,8 y 4,5\%. La biotita aparece entre el 7,3 y $23 \%$, mientras que las cantidades de hornblenda oscilan del 9 al 12\%. Los minerales accesorios están en un $1 \%$ y corresponden a opacos, apatitos y circón, mientras que la titanita está entre un 0,2 y $2 \%$.

Las dioritas tienen una composición mineralógica de cuarzo entre 1,1 y $10 \%$, plagioclasa entre el 23,8 y $68 \%$, y escaso feldespato potásico (1\%). Algunas rocas presentan cantidades de piroxeno (clinopiroxeno entre $11 \% \mathrm{y}$
$15 \%$, y ortopiroxeno en $23,6 \%$ ), hornblenda entre 12 y $35 \%$, y biotita entre el 9 y el $13 \%$. Una roca de composición gabroica (IGM-31146) es clasificada como gabronorita piroxeno-hornbléndica, contiene clinopiroxeno augita en cantidades de $23,6 \%$, hornblenda en un $26,4 \%$, plagioclasa en $36,9 \%$ y cantidades menores de cuarzo $(1,1 \%)$ y feldespato $(0,6 \%)$ (figura 6$)$. El Monzogranito de Rionegro se caracteriza petrográficamente por contener cristales de cuarzo de formas xenomorfas, incoloros, con bordes irregulares y de aspecto limpio, con color de interferencia blanco del primer orden. Tienen extinción ondulatoria, inclusiones microcristalinas a manera de líneas e inclusiones de plagioclasa y feldespato, aparecen en tamaños de 0,4 a $1,5 \mathrm{~mm}$.

En granodioritas, monzogranitos, sienogranitos y tonalitas, la plagioclasa es de tipo andesina, y varía entre $\mathrm{An}_{34} \mathrm{y} \mathrm{An}_{36}$; solo en una roca clasificada como monzogranito (IGM-900997), la plagioclasa es de tipo oligoclasa 

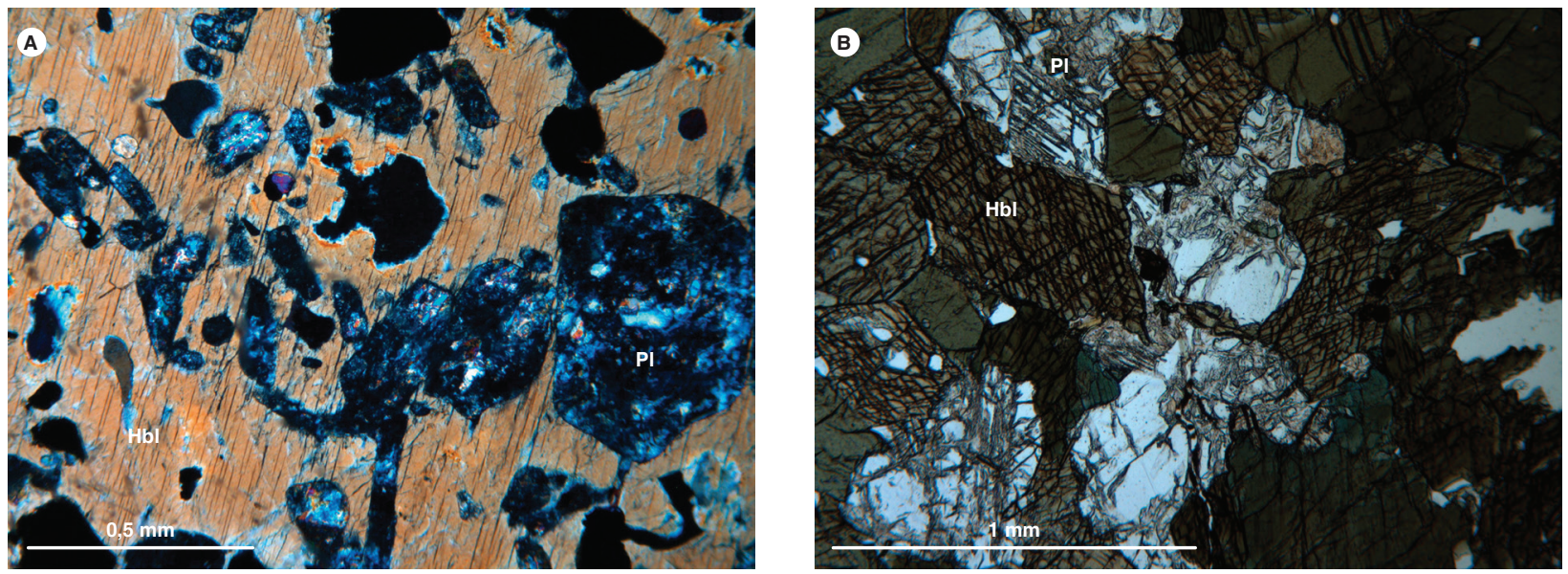

Figura 6. Litología inusual asociada con el Monzogranito de Rionegro. A) Gabronorita hornbléndica, IGM-31146. B) Diorita hornbléndica, IGM-31183

$\left(\mathrm{An}_{26}\right)$. En general, se presenta en cristales subidiomorfos tabulares con caras rectas a irregulares, por estar intercrecidos con cristales de feldespato y cuarzo. La plagioclasa se encuentra alterada moderadamente a sericita y saussurita, muestran maclas tipo albita y Carlsbad, zonaciones normales en las que los núcleos de los cristales se encuentran más alterados, en tamaños que varían de 0,7 a 2,5 mm; además, muestra inclusiones de hornblenda, biotita, circón, cuarzo, apatito, feldespato, titanita y opacos.

El feldespato potásico es principalmente ortosa, que en ocasiones pasa a microclina. Se presenta en cristales xenomorfos, incoloros, moderadamente alterados a caolín, con maclas incompletas en forma de parrilla y texturas pertíticas dada en parches y filoncillos de plagioclasa, además de textura poiquilítica dada por inclusiones de biotita, circón, opacos. Se presenta en tamaños que varían de 0,3 a $2,8 \mathrm{~mm}$.

El mineral máfico que más abunda es la biotita, presente en láminas subidiomorfas tabulares de tamaños que fluctúan entre 0,8 y 2,6 mm, de color castaño, pleocroicas X: verde amarillento, Y: pardo, y con birrefringencia del segundo orden, que exhibe colores de castaño a verde fuerte. Los cristales muestran extinción moteada, una dirección de clivaje en la que se hospedan agregados de titanita y magnetita residual. Son frecuentes las inclusiones de circón, apatito, opacos y titanita. Algunas láminas están alteradas moderadamente a clorita en agregados laminares de color verde claro y colores de interferencia púrpura a azul del segundo orden, $\mathrm{y}$ a epidota en agregados granulares verde amarillento de relieve alto y birrefringencia fuerte.
La hornblenda es escasa, se presenta en cristales subidiomórficos prismáticos, de colores verde claro, verde oscuro y verde amarillento. Tiene pleocroísmo y un relieve moderado, birrefringencia amarilla pálida de primer orden. Tiene dos direcciones de exfoliación a $54^{\circ} \mathrm{y}$ ángulo de extinción de $12^{\circ}$, cristales en tamaños de 0,5 a $2 \mathrm{~mm}$. Algunos cristales exhiben maclas polisintéticas. Presenta inclusiones de apatito y cuarzo, con opacos asociados y una leve alteración a epidota.

En las granodioritas aparecen esporádicamente núcleos de clinopiroxeno en hornblendas. El clinopiroxeno está en cristales xenomorfos, incoloros a amarillo pálido, birrefringencia fuerte de segundo orden con color de interferencia fucsia y alto relieve. Tiene un tamaño promedio de 0,5 mm y ángulo de extinción de $45^{\circ}$.

Como mineral accesorio se presenta la moscovita en cantidades menores del 1\%, en láminas subhedrales, incoloras, con birrefringencia alta y colores de interferencia azul a roja del segundo orden. Se encuentra asociada a láminas de biotita en tamaños de 0,3 a 0,5 mm.

Los minerales opacos son subidiomorfos, isotrópicos, con un tamaño promedio de $0,3 \mathrm{~mm}$, intersticiales, y se presentan como inclusiones en plagioclasa, cuarzo y ortosa. En luz reflejada se observan cristales correspondientes a pirita de color amarillo pálido, microfracturados, con superficies lisas; tienen inclusiones finas de calcopirita de color amarillo más intenso. Otros opacos corresponden a magnetita en cristales de color gris, con reflectancia baja; presentan texturas porosas.

La titanita se presenta en cristales intersticiales xenomorfos de color pardo, pleocroicos en tono castaño 
claro a medio. El color del mineral enmascara el color de interferencia del tercer orden. Aparece en tamaño de 0,2 mm asociada con los opacos.

Se presentan contenidos traza de allanita en cristales subidiomorfos de 0,5 a 1,3 mm, de color ocre, alto relieve, ligeramente pleocroicos y de color de interferencia castaño oscuro, que se encuentran asociados a epidota y clorita, y tienen inclusiones de opacos.

El circón se presenta en cristales incoloros con bordes ligeramente oscurecidos, subidiomorfos prismáticos alargados; algunos muestran microfracturas, con birrefringencia del fucsia al verde del tercer orden. Los cristales tienen tamaños de 0,05 a 0,2 mm y están asociados con opacos y biotitas.

El apatito se presenta como cristales de tamaños que varían entre 0,05 y 0,2 mm, subhexagonales, prismáticos e incoloros, y como inclusiones en biotita, hornblenda, cuarzo y plagioclasa.

El Monzogranito de Rionegro presenta rocas plutónicas afectadas por fases deformativas posteriores a su cristalización, asociadas a régimen dinámico frágil y que han sido clasificadas estructuralmente como cataclasi- tas. Las cataclasitas se caracterizan por presentar porfiroclastos de cuarzo, plagioclasa y feldespato con tamaños entre 0,5 y $5,5 \mathrm{~mm}$ en una matriz cuarzofeldespática finogranular.

Otras rocas han sido clasificadas como granofels cuarzofeldespáticos y se asocian con xenolitos que posiblemente son del Monzogranito de Cáchira (figura 7). Los granofels presentan una textura general granoblástica y texturas mirmequíticas, pertíticas y micrográficas. Mineralógicamente presentan feldespato potásico, cuarzo, plagioclasa, hornblenda y biotita, y como minerales accesorios presentan circón, opacos, titanita y moscovita.

Rocas de dique. Corresponden a riolitas, monzogranitos andesitas, dacitas, microdioritas y cuarzolatitas (tabla 1$)$.

En general, las rocas de dique presentan textura holocristalina porfídica, y como texturas particulares, microcristalina, micrográfica e intersectal dada por microlitos de plagioclasa entrecruzados con cuarzo, hornblenda y opacos. Localmente tienen textura glomeroporfídica.
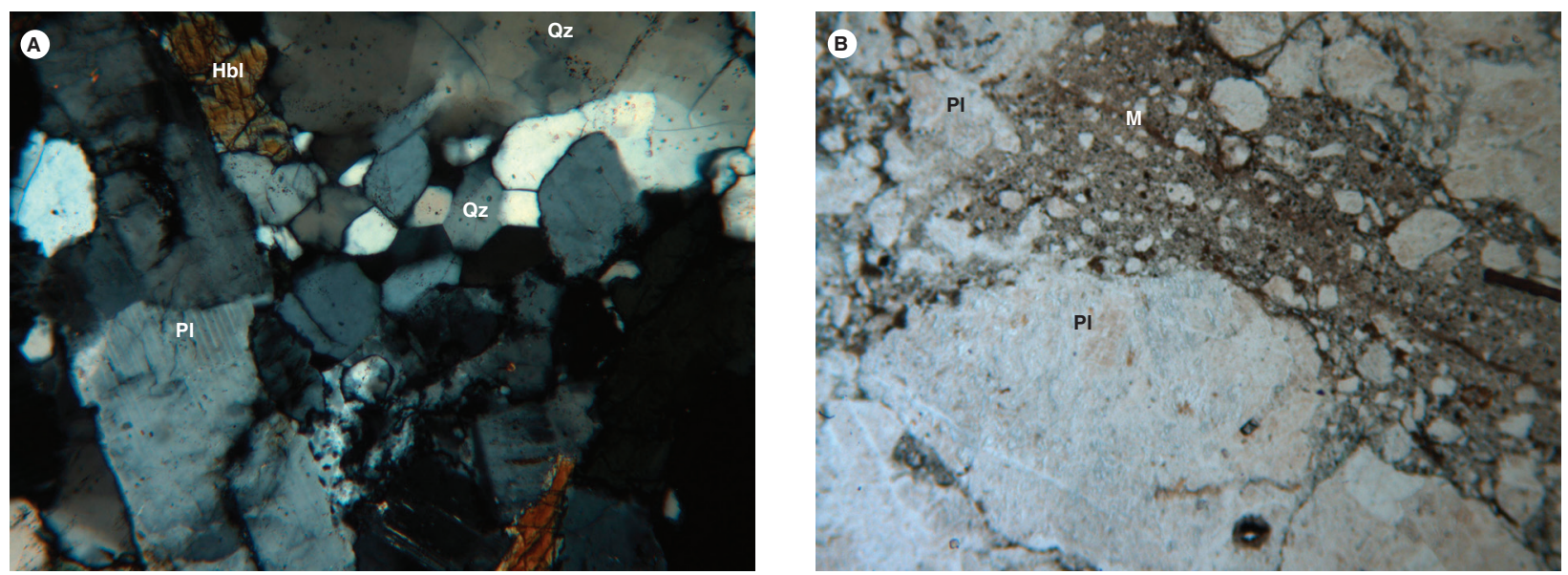

Figura 7. Aspecto microscópico de xenolitos dentro del Monzogranito de Rionegro. A) Textura granoblástica en granofels de cuarzo, feldespato y hornblenda, IGM-31178. B) Textura brechoide cataclástica (M: matriz), IGM-70839 
Tabla 1. Composición modal de rocas de dique

\begin{tabular}{|c|c|c|c|c|c|c|c|c|c|c|c|c|c|c|c|c|c|}
\hline IGM & w & $\mathbf{N}$ & Qtz & PI & Kfs & $\mathrm{Hbl}$ & Bt & Ms & $\mathrm{Chl}$ & Op & Ap & Zrn & Ttn & Ep & Matriz & Fenocristales & Clasificación \\
\hline 11176 & 1115982 & 1302479 & 19,6 & 60,7 & & & & & 16 & 1,8 & & & & $\mathrm{x}$ & & & Andesita \\
\hline 31145 & 1095735 & 1372096 & 1,8 & 93,6 & & & & & 1,7 & 2,9 & $\operatorname{Tr}$ & & $\operatorname{Tr}$ & & & & Andesita \\
\hline 31182 & 1083973 & 1354129 & 0,4 & 8,3 & & & & & & & & & & & 91,3 & & Andesita porfídica \\
\hline 11191 & 1109712 & 1307529 & 17,1 & 39,1 & 28 & & 3,6 & & & & & $\operatorname{Tr}$ & 1,2 & 11 & & & Andesita porfídica \\
\hline 72061 & 1100082 & 1341159 & & 70 & & 30 & & & 5 & & & & & & & & Basalto andesítico \\
\hline 74979 & 1093383 & 1396279 & 16 & 38 & 43 & & $\operatorname{Tr}$ & & & 1 & & & & & & & $\begin{array}{c}\text { Cuarzolatita } \\
\text { porfirítica }\end{array}$ \\
\hline 11175 & 1116182 & 1302679 & 39,5 & 34,9 & 16,3 & & 3,5 & 4,5 & & 1,4 & & & & $\mathrm{x}$ & & & Dacita \\
\hline 900998 & 1087836 & 1343412 & & 47 & & 35 & 10 & & & 4 & 1 & $\operatorname{Tr}$ & 3 & $\mathrm{x}$ & & & Diorita \\
\hline 900975 & 1086454 & 1393647 & 2,0 & 56,3 & & 34,4 & & & 1,3 & 6 & $\operatorname{Tr}$ & & $\operatorname{Tr}$ & & & & Microdiorita \\
\hline 900986 & 1094480 & 1337675 & 5 & 5 & & & & & 50 & & & & & 40 & & & Microdiorita \\
\hline 900906 & 1101270 & 1309253 & 38,6 & 30,6 & 30,8 & & $\operatorname{Tr}$ & & & $\operatorname{Tr}$ & & & & & & & Monzogranito \\
\hline 900953 & 1107525 & 1305963 & 23,8 & 26,5 & 41,9 & & 6,1 & $\mathrm{x}$ & $x$ & 1,2 & 0,5 & $\operatorname{Tr}$ & & $x$ & & & Monzogranito \\
\hline 900969 & 1107549 & 1318415 & 39,1 & 24,5 & 35,8 & & 0,7 & $\operatorname{Tr}$ & & $\operatorname{Tr}$ & $\operatorname{Tr}$ & $\operatorname{Tr}$ & & & & & Monzogranito \\
\hline 901010 & 1099016 & 1313299 & 34,5 & 28,1 & 35,3 & & 1,1 & & & 1 & $\operatorname{Tr}$ & $\operatorname{Tr}$ & & & & & Monzogranito \\
\hline 10871 & 1106762 & 1316699 & 31 & 33,1 & 35,3 & & 0,6 & & & $\operatorname{Tr}$ & $\operatorname{Tr}$ & $\operatorname{Tr}$ & $\operatorname{Tr}$ & & & & Riolita \\
\hline 10978 & 1091977 & 1388082 & 33 & 28 & 38 & & & & & $\operatorname{Tr}$ & & $\operatorname{Tr}$ & & 1 & & & Riolita \\
\hline 70862 & 1102317 & 1336679 & 43 & 30,5 & 24,5 & & 2 & & $\mathrm{x}$ & $\operatorname{Tr}$ & $\operatorname{Tr}$ & $\operatorname{Tr}$ & & & 50 & & Riolita \\
\hline 900951 & 1104858 & 1301287 & 28,2 & 20,2 & 43,3 & & 4,6 & & $\mathrm{x}$ & 2,2 & 1,5 & $\operatorname{Tr}$ & $\operatorname{Tr}$ & $\mathrm{x}$ & & & Riolita porfídica \\
\hline 74705 & 1094783 & 1398239 & 15,9 & 5,1 & 18,7 & & 0,3 & & $\mathrm{x}$ & & & & & & 60 & & Fenorriolita \\
\hline
\end{tabular}

Riolitas, dacitas y cuarzolatitas. Corresponden a los cuerpos de diques más comunes que atraviesan el Monzogranito de Rionegro. Están constituidas por una matriz de entre el 50 y el $75 \%$, y fenocristales entre el 25 y el $37 \%$.

La matriz presenta una textura granular fina xenomorfa, con tamaños de cristal de 0,05 a 0,2 mm. Está constituida por intercrecimientos entre cuarzo de aspecto limpio que contrasta en el relieve, con feldespato (microclina y ortosa), y en menor proporción, con plagioclasa. Intersticialmente se encuentran láminas de biotita y opacos. Se presentan abundantes texturas micrográficas y mirmequíticas; también es común la textura de reabsorción de la matriz en fenocristales de cuarzo y plagioclasa (figura 8).

Los fenocristales se componen de cuarzo en contenidos de $15,9 \%$, en cuarzolatitas, a $23 \%$ en riolitas y dacitas. Este mineral se manifiesta como cristales xenomorfos a subidiomorfos bipiramidales con caras cristalinas rectas, incoloros, de aspecto limpio, con extinción recta, algunos, microfracturados. Presentan texturas de reabsorción de la matriz y exhiben cristales de cuarzo con formas de bahía. Generan texturas micrográficas con el feldespato, con tamaños de 0,4 a $2 \mathrm{~mm}$.

La plagioclasa está en cantidades de hasta $5,1 \%$ en cuarzolatitas, y hasta $37 \%$ en riolitas. Corresponde a Andesina $\left(\mathrm{An}_{34}\right)$ en cristales subidiomorfos, tabulares, incoloros con color de interferencia gris del primer or- den. Presentan fuerte alteración a sericita, saussurita y epidota hacia el centro de los cristales. Exhiben zonación de tipo normal, pocos cristales con maclas tipo Carlsbad. Hacia los bordes de los cristales se desarrollan texturas mirmequíticas como entrecrecimientos alargados con cuarzo. Tienen inclusiones de opacos, cuarzo, apatitos y biotita con tamaños de 0,6 a $7 \mathrm{~mm}$.

El feldespato se presenta en contenidos de 16,3 y $43,3 \%$, tanto en fenocristales como en la matriz. Aparece en cristales xenomorfos, incoloros, frescos, y desarrolla maclas tipo Carlsbad y exsoluciones de plagioclasa, como pertitas en forma de hilillos, a mesopertitas. Algunos cristales están pasando a microclina con maclas incompletas tipo parrilla, o se presentan cristales zonados de tamaños entre 0,3 y 2,7 mm. Este mineral puede tener inclusiones de cuarzo y biotita.

La biotita se presenta en cantidades de hasta 4,6\% en láminas subidiomorfas de color pardo, con pleocroísmo $\mathrm{X}$ : verde pálido, Y: pardo fuerte, $\mathrm{y}$ colores de interferencia azul a amarillo del segundo orden con extinción moteada, algunas alteradas a clorita de color verde oliva y epidotizadas. Presentan una dirección de clivaje paralelo al eje más largo del cristal, donde se hospedan agregados finos de titanita y opacos. Tiene inclusiones de circón y apatitos en tamaños de 0,5 a 1,2 mm.

Los minerales accesorios están en contenidos menores a 2,2\%, siendo los minerales opacos los de mayor abundancia. Se presentan en cristales xenomorfos iso- 
trópicos de tamaños de grano fino $(0,01 \mathrm{~mm})$ dispersos en la matriz; otros, de tamaños de $0,3 \mathrm{~mm}$, con bordes rodeados por titanita, se encuentran junto a biotita. El circón está en cristales idiomorfos prismáticos alargados y cortos, incoloros, de relieve alto, con birrefringencia fuerte del tercer orden, con colores de interferencia que van de fucsia a azul, y extinción paralela. Cristales microfracturados con tamaños de $0,1 \mathrm{~mm}$ se presentan en la matriz junto a opacos y como inclusiones en biotitas.

Cristales de apatito se encuentran en tamaños que varían de 0,05 a 0,1 $\mathrm{mm}$ haciendo parte de la matriz y como inclusiones en biotitas. Son incoloros subidiomorfos con color de interferencia gris del primer orden, relieve alto y extinción recta. La titanita aparece en agregados xenomorfos finos de color pardo, rodeando los opacos y las biotitas.

Se presenta epidota como producto de alteración de plagioclasa y biotita en cristales xenomorfos de tamaños entre 0,05 y 0,2 mm, de color verde pálido, colores de interferencia entre amarillo y fucsia, del tercer orden. La allanita se manifiesta en cristales subidiomorfos tabulares de color pardo rojizo, fuertemente pleocroicos X: pardo rojizo, Y: pardo pálido, color de interferencia verde del tercer orden, y extinción recta. Su tamaño promedio es de 0,3 mm y presenta inclusiones de opacos y microfracturas.

Andesitas y microdioritas. Están compuestas por microcristales y microlitos de plagioclasa subidiomorfa, hornblenda en cristales subidiomorfos y cuarzo en cristales xenomorfos. En menor proporción, estos minerales aparecen en microfenocristales (figura 9). Presentan una matriz que varía entre el 50 y el 91,3\% del total de la roca.

Los microcristales se componen de plagioclasa en un 5 y $93,6 \%$, alterado a sericita-saussurita, que enmascaran las propiedades ópticas del mineral. Tienen tamaños menores de 0,5 mm y están en disposición entrecruzada con anfíbol y cuarzo intergranular.
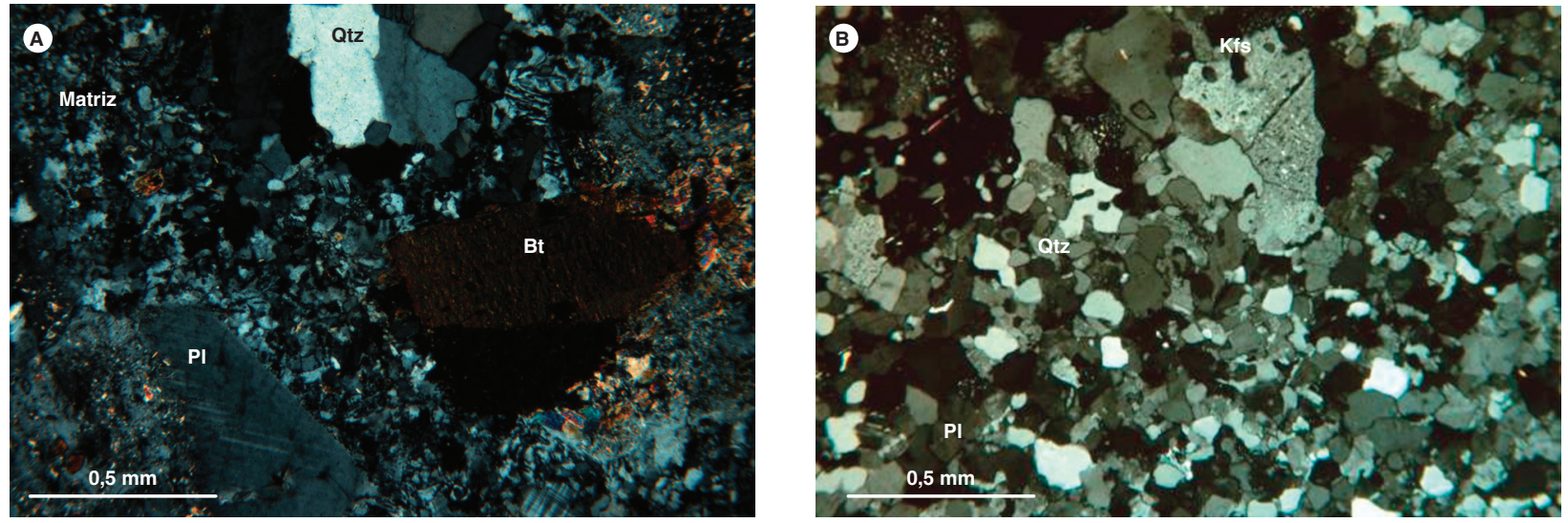

Figura 8. Diques de composición ácida en el Monzogranito de Rionegro. A) Riolita porfídica, IGM-900951. B) Dacita, IGM-11175
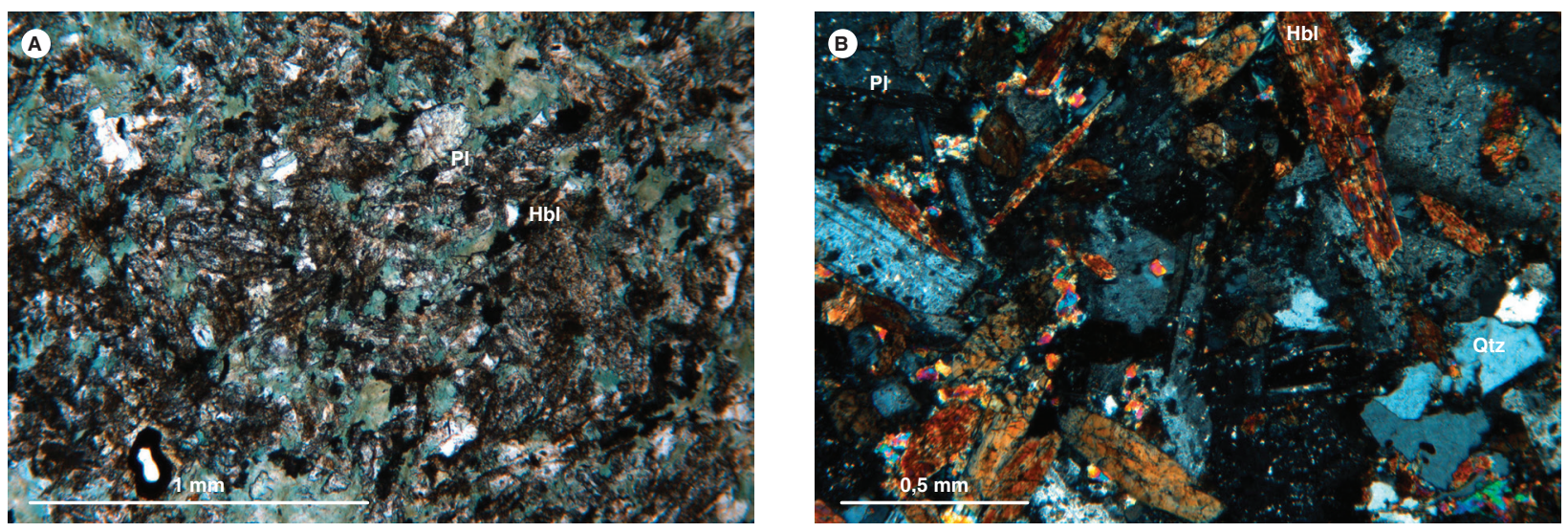

Figura 9. Diques básicos que atraviesan el Monzogranito de Rionegro. A) Microdiorita con alteración propilítica, IGM-900986. B) Microdiorita, IGM900975 


\section{Química mineral}

Los análisis de química mineral se llevaron a cabo en la microsonda electrónica de la Universidad Nacional de Colombia, sede Bogotá. El equipo usado es una microsonda JEOL JXA 8230, cuyas condiciones de operación fueron las siguientes: 1 a $10 \mu \mathrm{m}$ de diámetro del haz, tiempo en el pico de $20 \mathrm{~ms}$, intensidad de $20 \mathrm{nA}$ y voltaje de aceleración de $15 \mathrm{kV}$. Los conteos del instrumento son convertidos a porcentajes de óxidos mediante comparaciones con conteos de estándares naturales y sintéticos. Los datos se han tratado mediante la corrección ZAF (Z: número atómico; A: absorción de masas; F: fluorescencia) utilizando el programa de JEOL. La adquisición de los datos consistió en obtener imágenes de electrones retrodispersados de los cristales seleccionados para el análisis y en realizar los análisis puntuales.

Se realizaron análisis de química mineral del Monzogranito de Rionegro en las rocas 900952
(MIA-648B)-granodiorita y 900969 (GR-6736)-monzogranito. En la muestra 900952 (MIA-648B) se analizaron cristales de plagioclasa, feldespato, biotita y pirita, mientras que en la roca 900969 (GR-6736) se midieron composiciones de plagioclasa, feldespato, biotita, ilmenita y magnetita.

\subsection{Feldespato potásico}

En las imágenes de electrones retrodispersados, los feldespatos de ambas muestras exhiben texturas pertíticas en formas de lamelas, mientras que los cristales de plagioclasa muestran superficies moderadamente alteradas a finas láminas de mayor luminiscencia (figura 10).

Al graficar los resultados de los análisis de feldespato (tabla 2), en el diagrama de Smith y Brown (1988) estos resultan ser ortosa (Or) en cantidades que varían entre 90,03 y $94,22 \%$ mol, que se clasificaría en el campo de la ortosa pertítica (figura 11) y en albita (Ab) entre 5,72 y 9,96\%.
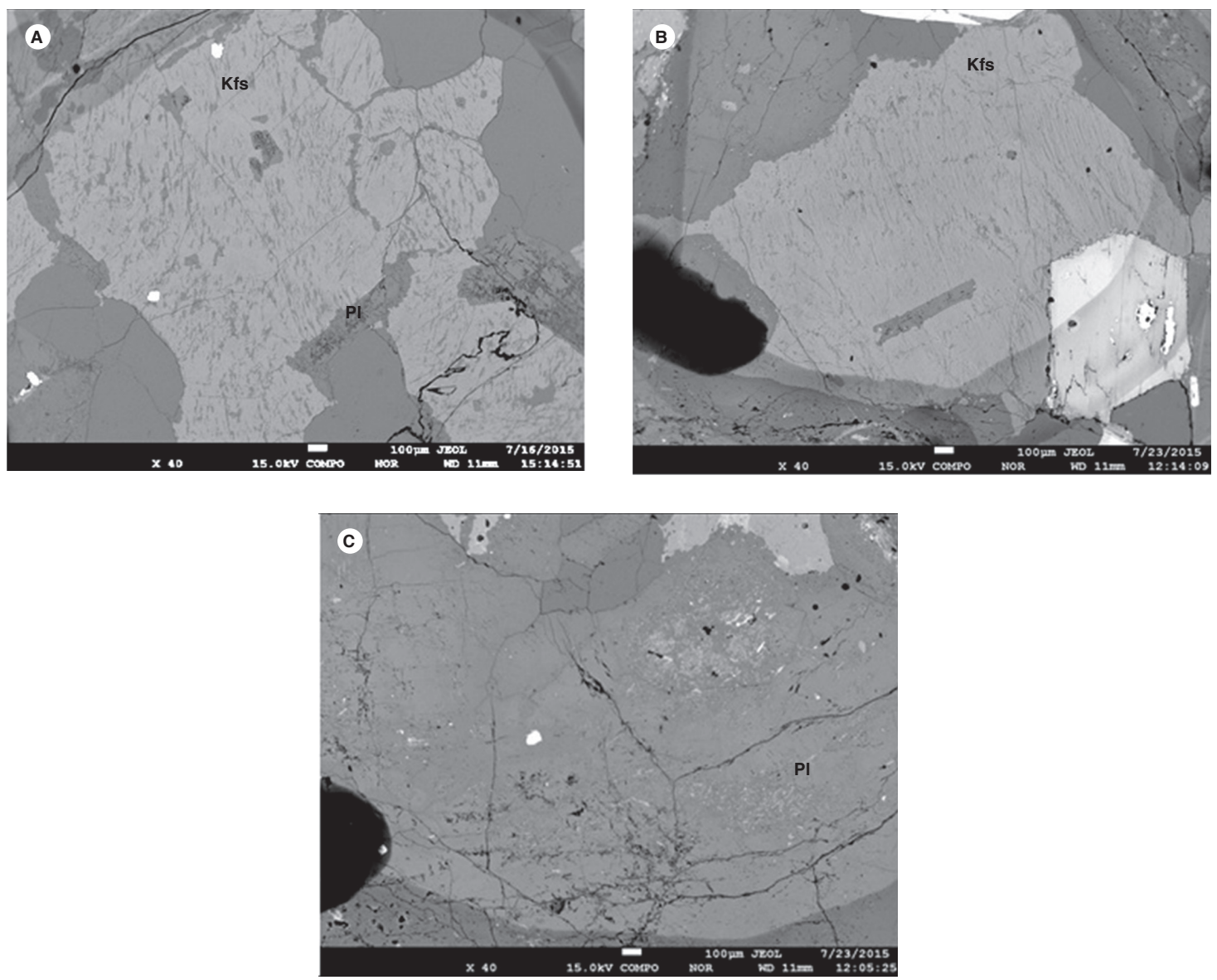

Figura 10. Imágenes de electrones secundarios retrodispersados (BSE) correspondientes a feldespato y plagioclasa. A) Feldespato potásico y plagioclasa en el campo de análisis C2 en la muestra GR-6736. B) Feldespato potásico en el campo de análisis C2 en la muestra MIA-648B. C) Plagioclasa en el campo C7 en la muestra MIA-648B 


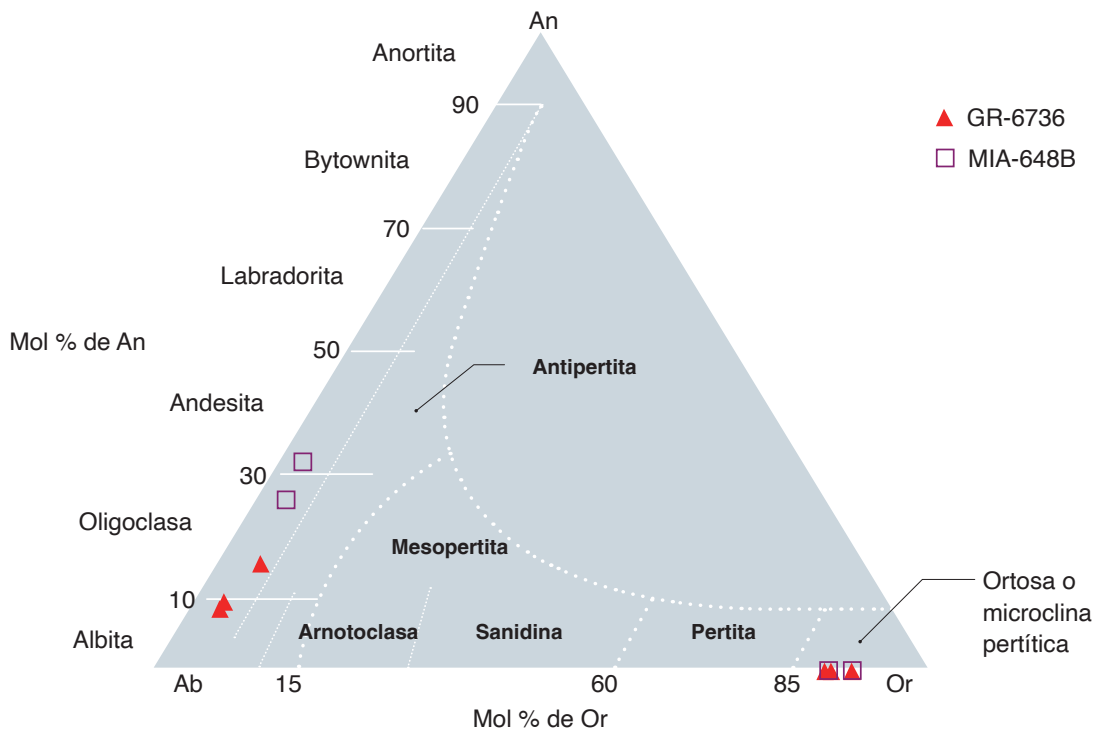

Figura 11. Análisis de microsonda electrónica correspondiente a las plagioclasas y los feldespatos del Monzogranito de Rionegro, graficados en el diagrama de Smith y Brown (1988)

Tabla 2. Análisis de microsonda electrónica correspondiente a las ortoclasas del Monzogranito de Rionegro

\begin{tabular}{|c|c|c|c|c|c|c|}
\hline Punto analizado & GR-6736-C2-Kfs-1 & GR-6736-C2-Kfs-2 & GR-6736-C2-Kfs-3 & GR-6736-C2-Kfs-4 & MIA-648B-C2-Kfs-2 & MIA-648B-C2-Kfs-3 \\
\hline $\mathrm{SiO}_{2}$ & 65,67 & 65,17 & 65,37 & 65,35 & 64,72 & 64,61 \\
\hline $\mathrm{TiO}_{2}$ & 0,01 & 0,02 & 0 & 0,01 & 0 & 0 \\
\hline $\mathrm{Al}_{2} \mathrm{O}_{3}$ & 18,43 & 18,49 & 18,67 & 18,59 & 18,33 & 18,36 \\
\hline $\mathrm{FeO}$ & 0,04 & 0,06 & 0,03 & 0,08 & 0,09 & 0,10 \\
\hline $\mathrm{MgO}$ & 0 & 0 & 0 & 0 & 0 & 0 \\
\hline $\mathrm{CaO}$ & 0 & 0,01 & 0,01 & 0 & 0 & 0 \\
\hline $\mathrm{Na}_{2} \mathrm{O}$ & 1,11 & 0,63 & 1,03 & 0,66 & 0,66 & 1,06 \\
\hline $\mathrm{K}_{2} \mathrm{O}$ & 15,20 & 15,76 & 15,30 & 15,80 & 16,00 & 15,17 \\
\hline Total (\% masa) & 100,46 & 100,13 & 100,41 & 100,48 & 99,79 & 99,29 \\
\hline $\mathrm{Si}$ & 12,026 & 12,001 & 11,985 & 11,994 & 11,988 & 11,989 \\
\hline $\mathrm{Al}$ & 3,977 & 4,012 & 4,034 & 4,021 & 4,002 & 4,015 \\
\hline $\mathrm{Fe}$ & 0,002 & 0,003 & 0 & 0,001 & 0 & 0 \\
\hline $\mathrm{Ti}$ & 0,004 & 0,006 & 0,003 & 0,008 & 0,009 & 0,011 \\
\hline $\mathrm{Mg}$ & 0 & 0 & 0 & 0 & 0 & 0 \\
\hline $\mathrm{Na}$ & 0,393 & 0,225 & 0,367 & 0,234 & 0,236 & 0,380 \\
\hline $\mathrm{Ca}$ & 0,001 & 0,002 & 0,002 & 0 & 0 & 0 \\
\hline $\mathrm{K}$ & 3,551 & 3,702 & 3,578 & 3,698 & 3,780 & 3,591 \\
\hline Total (cat) & 19,953 & 19,951 & 19,969 & 19,956 & 20,015 & 19,984 \\
\hline 0 & 32 & 32 & 32 & 32 & 32 & 32 \\
\hline z & 16,01 & 16,02 & 16,02 & 16,02 & 15,99 & 16,00 \\
\hline$x$ & 3,95 & 3,93 & 3,95 & 3,94 & 4,03 & 3,98 \\
\hline Or & 90,03 & 94,22 & 90,65 & 94,05 & 94,12 & 90,44 \\
\hline $\mathrm{Ab}$ & 9,96 & 5,72 & 9,29 & 5,95 & 5,88 & 9,56 \\
\hline $\mathrm{An}$ & 0,01 & 0,05 & 0,06 & 0 & 0 & 0 \\
\hline Total & 100 & 100 & 100 & 100 & 100 & 100 \\
\hline
\end{tabular}




\subsection{Plagioclasa}

Se hicieron análisis puntuales (tabla 3) de los cristales de plagioclasa que evidenciaron una composición entre albita (Ab 89,6-90,8, An 7,14-12,8, Or 1,21-1,27), oligoclasa (Ab 84,6, An 12,8, Or 2,53) y andesina (Ab 71,1 66,7, An 26,8-31,4, Or 2,0-1,75 (figura 11).

Tabla 3. Análisis de microsonda electrónica correspondiente a plagioclasas del Monzogranito de Rionegro

\begin{tabular}{|c|c|c|c|c|c|}
\hline Punto analizado & GR-6736-C2-PI-1 & GR-6736-C2-PI-2 & GR-6736-C2-PI-3 & MIA-648B-C7-PI-1 & MIA-648B-C7-PI-2 \\
\hline $\mathrm{SiO}_{2}$ & 65,63 & 64,73 & 65,99 & 61,37 & 59,55 \\
\hline $\mathrm{TiO}_{2}$ & 0,01 & 0,00 & 0,00 & 0,02 & 0,00 \\
\hline $\mathrm{Al}_{2} \mathrm{O}_{3}$ & 21,06 & 21,53 & 20,57 & 23,72 & 24,54 \\
\hline $\mathrm{FeO}$ & 0,04 & 0,05 & 0,06 & 0,19 & 0,23 \\
\hline $\mathrm{MgO}$ & 0 & 0 & 0 & 0 & 0,01 \\
\hline $\mathrm{CaO}$ & 2,03 & 2,83 & 1,77 & 5,65 & 6,77 \\
\hline $\mathrm{Na}_{2} \mathrm{O}$ & 11,01 & 10,32 & 11,24 & 8,28 & 7,95 \\
\hline $\mathrm{K}_{2} \mathrm{O}$ & 0,23 & 0,47 & 0,24 & 0,36 & 0,32 \\
\hline Total (\% masa) & 100,00 & 99,92 & 99,88 & 99,59 & 99,36 \\
\hline $\mathrm{Si}$ & 11,569 & 11,450 & 11,644 & 10,961 & 10,715 \\
\hline $\mathrm{Al}$ & 4,376 & 4,489 & 4,277 & 4,993 & 5,204 \\
\hline $\mathrm{Ti}$ & 0,002 & 0 & 0 & 0,003 & 0 \\
\hline $\mathrm{Fe}$ & 0,004 & 0,005 & 0,006 & 0,019 & 0,023 \\
\hline $\mathrm{Mg}$ & 0 & 0 & 0,001 & 0 & 0,001 \\
\hline $\mathrm{Na}$ & 3,762 & 3,539 & 3,846 & 2,867 & 2,772 \\
\hline $\mathrm{Ca}$ & 0,383 & 0,536 & 0,335 & 1,081 & 1,306 \\
\hline $\mathrm{K}$ & 0,051 & 0,106 & 0,054 & 0,082 & 0,073 \\
\hline Total (cat) & 20,147 & 20,125 & 20,164 & 20,005 & 20,094 \\
\hline 0 & 32 & 32 & 32 & 32 & 32 \\
\hline Z & 15,95 & 15,94 & 15,92 & 15,96 & 15,92 \\
\hline$x$ & 4,20 & 4,19 & 4,24 & 4,05 & 4,17 \\
\hline$A b$ & 89,65 & 84,64 & 90,81 & 71,14 & 66,79 \\
\hline An & 9,14 & 12,83 & 7,92 & 26,81 & 31,46 \\
\hline Or & 1,21 & 2,53 & 1,27 & 2,05 & 1,75 \\
\hline Total & 100 & 100 & 100 & 100 & 100 \\
\hline
\end{tabular}

\subsection{Micas}

En las imágenes BSE, las biotitas exhiben microfracturas que cortan el clivaje, inclusiones de opacos y áreas con tonalidades diferentes que indican cambios composicionales (ejemplo: punto Bt4 MIA-648B-C3), lo que pone en evidencia variaciones en los contenidos de Si y Fe (figura 12).

En la roca MIA-648B-C3, las micas tienen concentraciones de $\mathrm{SiO}_{2}$ (\%) entre 36,20 y 37,76; FeO entre 16,59 y 17,$92 ; \mathrm{Al}_{2} \mathrm{O}_{3}$ entre 13,43 y 13,9, y MgO entre 12,46 y 13,72. La roca GR-6736-C3 tiene mayor canti- dad de $\mathrm{SiO}_{2}(\%)$, entre 37,89 y 38,$74 ; \mathrm{Al}_{2} \mathrm{O}_{3}$ entre 13,59 y 14,15, y MgO entre 14,1 8 y 15,57, y presenta valores menores de FeO: 14,38 a 14,83. En el diagrama de Rieder(1998) se observa una dispersión entre estas dos rocas (figura 13, tabla 4). Las micas de la muestra MIA648B-C3 clasifican en el campo de biotita, mientras que las micas de la muestra GR-6736-C3 se distribuyen hacia el límite biotita-flogopita. Ambos conjuntos de micas se agrupan en suites de magmas calcoalcalinos orogénicos (Abdel Rahman, 1994). 

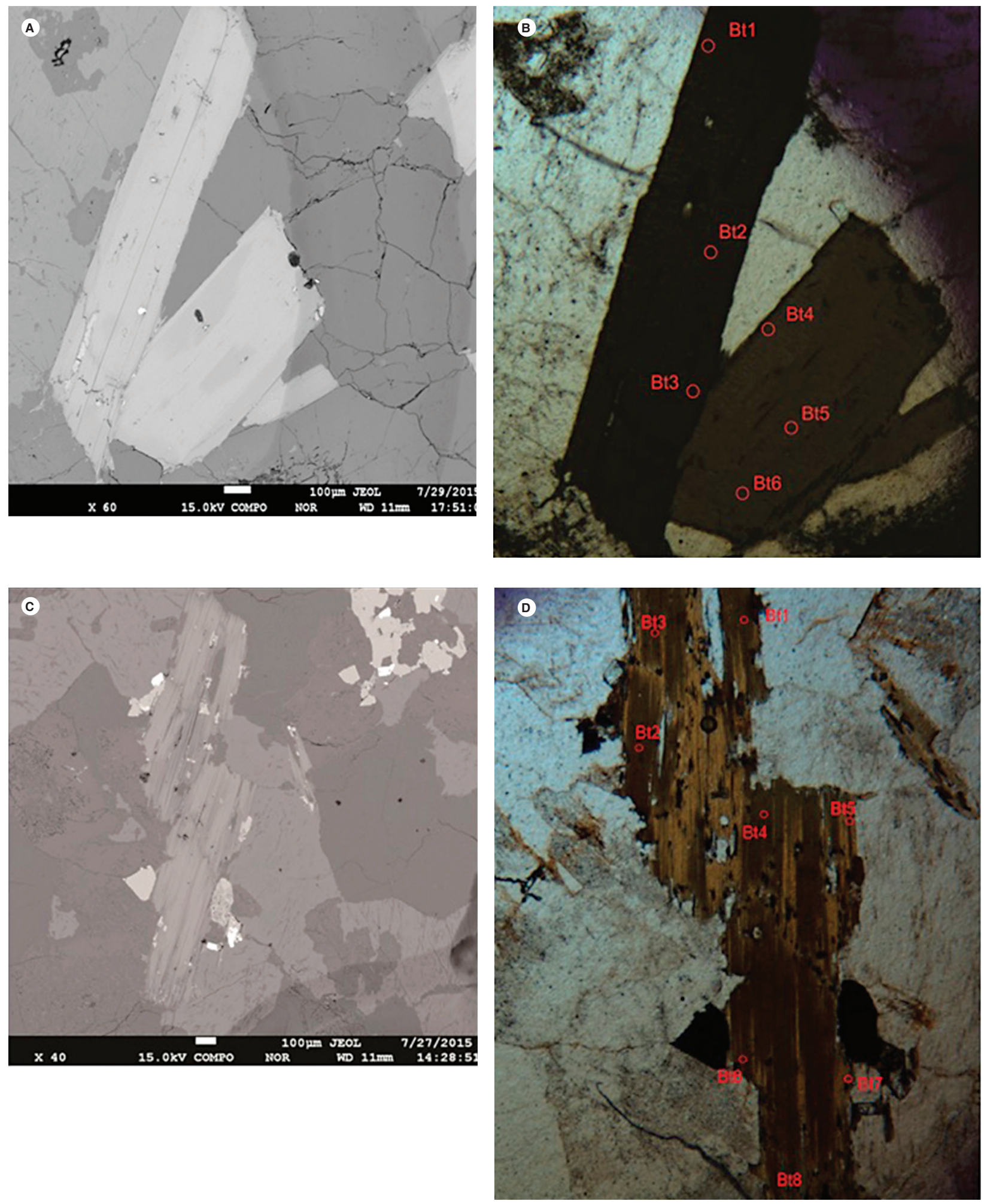

Figura 12. Imágenes de electrones secundarios retrodispersados (BSE) correspondientes a biotita e imágenes equivalentes obtenidas en microscopio petrográfico. A) Imagen BSE de biotita, muestra MIA-648B-C3. B) Puntos analizados de biotita en la roca MIA-648B, campo 3. Imagen obtenida en microscopio petrográfico con nícoles paralelos. C) Imagen BSE de biotita, muestra GR-6736-C3. D) Puntos analizados de biotita en la roca GR-6736, campo 3. Imagen obtenida en microscopio petrográfico con nícoles paralelos 
Tabla 4. Composición química de micas en las rocas 900952 (GR-6736) y 900969 (MIA-648B)

\begin{tabular}{|c|c|c|c|c|c|c|c|c|c|c|c|}
\hline Punto analizado & $\begin{array}{c}\text { MIA-648B- } \\
\text { C3-Bt-1 }\end{array}$ & $\begin{array}{c}\text { MIA-648B- } \\
\text { C3-Bt-2 }\end{array}$ & $\begin{array}{c}\text { MIA-648B- } \\
\text { C3-Bt-3 }\end{array}$ & $\begin{array}{c}\text { MIA-648B- } \\
\text { C3-Bt-4 }\end{array}$ & $\begin{array}{c}\text { MIA-648B- } \\
\text { C3-Bt-5 }\end{array}$ & $\begin{array}{c}\text { MIA-648B- } \\
\text { C3-Bt-6 }\end{array}$ & $\begin{array}{c}\text { GR-6736- } \\
\text { C3-Bt-1 }\end{array}$ & $\begin{array}{c}\text { GR-6736- } \\
\text { C3-Bt-2 }\end{array}$ & $\begin{array}{c}\text { GR-6736- } \\
\text { C3-Bt-4 }\end{array}$ & $\begin{array}{c}\text { GR-6736- } \\
\text { C3-Bt-6 }\end{array}$ & $\begin{array}{r}\text { GR-6736- } \\
\text { C3-Bt-7 }\end{array}$ \\
\hline $\mathrm{SiO}_{2}$ & 36,21 & 36,97 & 36,94 & 37,76 & 36,26 & 36,61 & 38,74 & 37,90 & 37,96 & 37,93 & 37,94 \\
\hline $\mathrm{TiO}_{2}$ & 3,14 & 3,08 & 3,12 & 2,80 & 3,20 & 3,00 & 1,82 & 2,21 & 1,99 & 2,42 & 2,17 \\
\hline $\mathrm{Al}_{2} \mathrm{O}_{3}$ & 13,75 & 13,88 & 13,88 & 13,47 & 13,82 & 13,98 & 13,85 & 13,85 & 13,60 & 14,16 & 14,03 \\
\hline $\mathrm{FeO}$ & 17,74 & 17,56 & 17,93 & 16,59 & 17,44 & 17,38 & 14,38 & 14,73 & 14,66 & 14,83 & 14,73 \\
\hline $\mathrm{MgO}$ & 12,47 & 12,61 & 12,52 & 13,72 & 12,56 & 12,64 & 15,58 & 14,70 & 15,06 & 14,19 & 14,69 \\
\hline $\mathrm{MnO}$ & 0,74 & 0,72 & 0,71 & 0,67 & 0,67 & 0,79 & 0,65 & 0,80 & 0,73 & 0,80 & 0,70 \\
\hline $\mathrm{CaO}$ & 0,00 & 0,00 & 0,00 & 0,00 & 0,00 & 0,00 & 0,00 & 0,02 & 0,00 & 0,00 & 0,00 \\
\hline $\mathrm{Na}_{2} \mathrm{O}$ & 0,13 & 0,15 & 0,13 & 0,16 & 0,16 & 0,17 & 0,13 & 0,25 & 0,26 & 0,27 & 0,21 \\
\hline $\mathrm{K}_{2} \mathrm{O}$ & 9,23 & 9,41 & 9,38 & 9,82 & 9,35 & 9,43 & 9,60 & 9,64 & 9,57 & 9,40 & 9,19 \\
\hline Total & 93,40 & 94,35 & 94,62 & 94,99 & 93,47 & 94,00 & 94,75 & 94,09 & 93,82 & 93,98 & 93,67 \\
\hline \multicolumn{12}{|c|}{ Fórmula basada en 220} \\
\hline $\mathrm{Si}$ & 5,629 & 5,674 & 5,665 & 5,735 & 5,627 & 5,646 & 5,808 & 5,753 & 5,774 & 5,755 & 5,763 \\
\hline AllV & 2,371 & 2,326 & 2,335 & 2,265 & 2,373 & 2,354 & 2,192 & 2,247 & 2,226 & 2,245 & 2,237 \\
\hline AIVI & 0,148 & 0,185 & 0,175 & 0,145 & 0,155 & 0,186 & 0,255 & 0,231 & 0,212 & 0,286 & 0,274 \\
\hline $\mathrm{Ti}$ & 0,367 & 0,355 & 0,360 & 0,320 & 0,373 & 0,347 & 0,205 & 0,253 & 0,227 & 0,276 & 0,248 \\
\hline $\mathrm{Mg}$ & 2,890 & 2,885 & 2,862 & 3,107 & 2,906 & 2,905 & 3,482 & 3,326 & 3,416 & 3,209 & 3,328 \\
\hline $\mathrm{Fe}^{2+}$ & 2,307 & 2,253 & 2,299 & 2,107 & 2,263 & 2,242 & 1,803 & 1,870 & 1,865 & 1,882 & 1,871 \\
\hline $\mathrm{Mn}$ & 0,097 & 0,094 & 0,092 & 0,086 & 0,089 & 0,103 & 0,082 & 0,103 & 0,094 & 0,102 & 0,090 \\
\hline $\mathrm{Ca}$ & 0,000 & 0,000 & 0,000 & 0,000 & 0,000 & 0,000 & 0,001 & 0,003 & 0,000 & 0,000 & 0,000 \\
\hline $\mathrm{Na}$ & 0,040 & 0,043 & 0,039 & 0,046 & 0,048 & 0,050 & 0,037 & 0,075 & 0,077 & 0,079 & 0,063 \\
\hline $\mathrm{K}$ & 1,830 & 1,842 & 1,836 & 1,902 & 1,851 & 1,856 & 1,835 & 1,867 & 1,857 & 1,819 & 1,781 \\
\hline Total & 15,680 & 15,658 & 15,663 & 15,713 & 15,685 & 15,689 & 15,700 & 15,726 & 15,747 & 15,653 & 15,655 \\
\hline $\mathrm{Fe} /(\mathrm{Fe}+\mathrm{Mg})$ & 0,444 & 0,439 & 0,445 & 0,404 & 0,438 & 0,436 & 0,341 & 0,360 & 0,353 & 0,370 & 0,360 \\
\hline
\end{tabular}

A

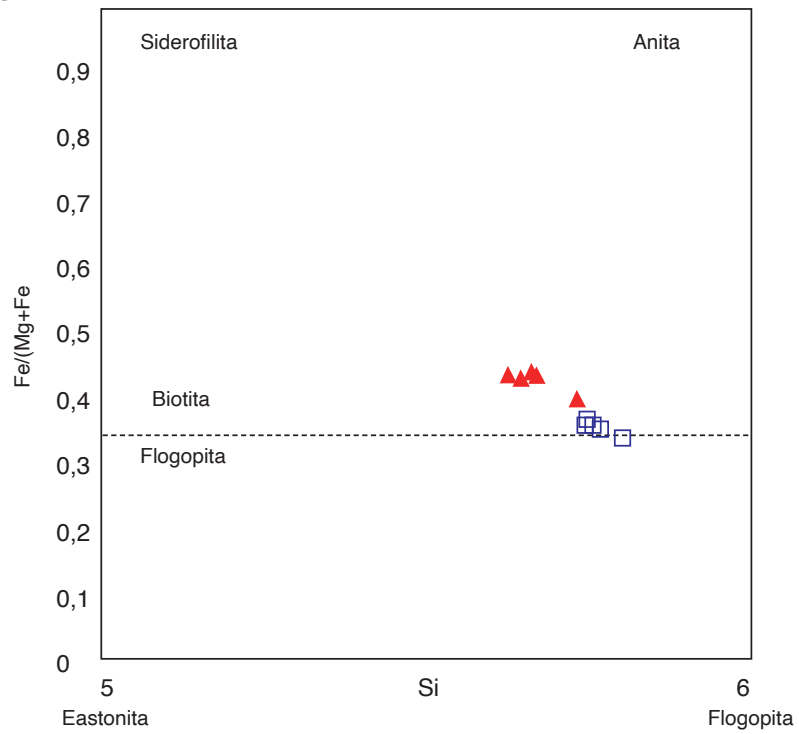

B

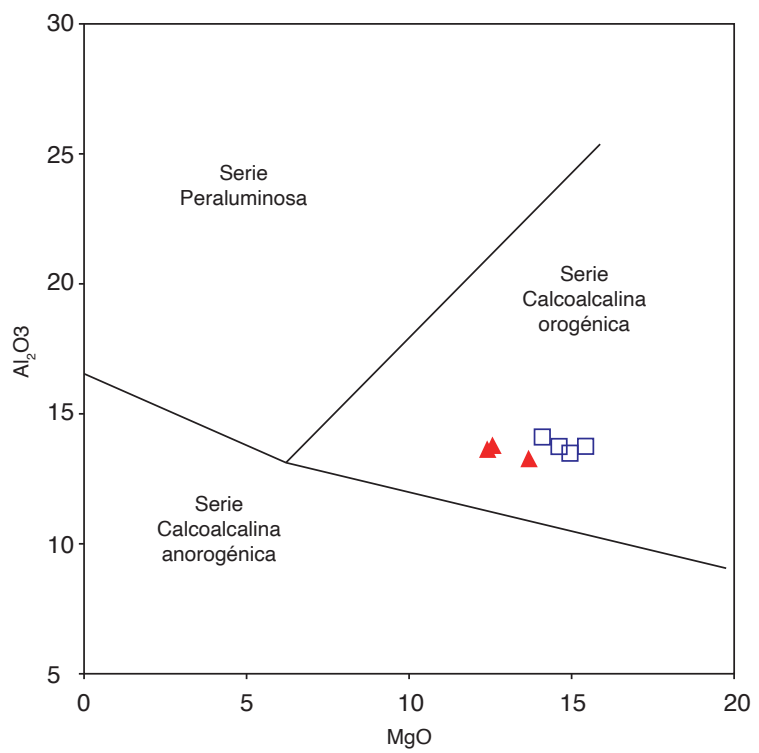

$\Delta$ MIA-648B

$\square$ GR-6736

Figura 13. Diagramas de clasificación correspondientes a micas del Monzogranito de Rionegro. A) Diagrama Rieder et al. (1998). B) Diagrama Abdel Rahman (1994) 


\subsection{Opacos}

El mineral opaco más abundante en las rocas MIA-648B y GR-6736 es la magnetita (tabla 5, figura 14.), con valores altos en $\mathrm{Fe}_{2} \mathrm{O}_{3}$ entre 53,46 y $54,18 \%$, y FeO entre 48,12 y 48,76\%, y concentraciones menores de $\mathrm{MnO}$ entre 0,02 y $0,10 \%, \mathrm{TiO}_{2}$ que alcanza hasta el $0,10 \%$ y $\mathrm{Al}_{2} \mathrm{O}_{3}$ hasta un $0,06 \%$. Las magnetitas son de color gris, luminiscentes, y presentan superficies homogéneas de aspecto liso.

La muestra GR-6736 tiene ilmenita, que se presenta con superficies porosas e irregulares, tiene altos contenidos de $\mathrm{TiO}_{2}$ (entre 45,92 y 47,46\%), FeO entre 30,79 y $31,70 \%, \mathrm{Fe}_{2} \mathrm{O}_{3}$ entre 11,41 y $14,16 \%$ y $\mathrm{MnO}$ entre 10,34 y $10,85 \%$. Presenta bajos contenidos de $\mathrm{MgO}$ (entre 0,02 y $0,04 \%$ ) tabla 6 .

La roca MIA-648B presenta pirita en cristales de forma anhedral diseminados en la roca. La pirita se encuentra asociada a bordes de magnetita e inclusiones finas de calcopirita. En la tabla 7 se muestran los elementos analizados en estos minerales. El azufre (S) y el hierro $(\mathrm{Fe})$ tienen concentraciones mayores en las piritas (entre 53,13 y $53,18 \%$, y entre 45,93 y $46,06 \%$, respectivamente), mientras que la calcopirita tiene mayor concentración de cobre $(\mathrm{Cu})$, en 31,78\%, y valores más bajos de hierro $(\mathrm{Fe})(32,47 \%)$ y azufre (S) $(34,22 \%)$.

Tabla 5. Composición química de magnetita en las rocas 900952 (GR-6736) y 900969 (MIA-648B)

\begin{tabular}{|c|c|c|c|c|c|c|}
\hline Punto analizado & GR-6736-C1-Mt-1 & GR-6736-C4-Mt-1 & GR-6736-C4-Mt-2 & GR-6736-C4-Mt-3 & MIA-648B-C5-Mt-1 & MIA-648B-C5-Mt-2 \\
\hline $\mathrm{SiO}_{2}$ & 0,00 & 0,02 & 0,00 & 0,00 & 0,00 & 0,00 \\
\hline $\mathrm{TiO}_{2}$ & 0,02 & 0,03 & 0,03 & 0,10 & 0,00 & 0,00 \\
\hline $\mathrm{Al}_{2} \mathrm{O}_{3}$ & 0,03 & 0,06 & 0,01 & 0,01 & 0,00 & 0,02 \\
\hline $\mathrm{Cr}_{2} \mathrm{O}_{3}$ & 0,01 & 0,03 & 0,04 & 0,01 & 0,01 & 0,00 \\
\hline $\mathrm{Fe}_{2} \mathrm{O}_{3}$ & 54,18 & 53,49 & 53,77 & 53,46 & 53,77 & 53,61 \\
\hline $\mathrm{FeO}$ & 48,76 & 48,12 & 48,40 & 48,16 & 48,31 & 48,15 \\
\hline $\mathrm{MnO}$ & 0,03 & 0,07 & 0,02 & 0,05 & 0,07 & 0,10 \\
\hline $\mathrm{MgO}$ & 0,00 & 0,01 & 0,00 & 0,00 & 0,01 & 0,00 \\
\hline $\mathrm{ZnO}$ & 0,00 & 0,00 & 0,00 & 0,00 & 0,00 & 0,00 \\
\hline $\mathrm{CaO}$ & 0,00 & 0,00 & 0,00 & 0,00 & 0,00 & 0,00 \\
\hline $\mathrm{V}_{2} \mathrm{O}_{3}$ & 0,00 & 0,00 & 0,00 & 0,00 & 0,00 & 0,00 \\
\hline $\mathrm{NiO}$ & 0,00 & 0,00 & 0,00 & 0,00 & 0,00 & 0,00 \\
\hline Total & 103,02 & 101,83 & 102,27 & 101,79 & 102,18 & 101,89 \\
\hline \multicolumn{7}{|c|}{ Fórmula basada en 320} \\
\hline $\mathrm{Si}$ & 0,000 & 0,007 & 0,001 & 0,000 & 0,000 & 0,000 \\
\hline $\mathrm{Ti}$ & 0,004 & 0,007 & 0,007 & 0,021 & 0,000 & 0,000 \\
\hline $\mathrm{Al}$ & 0,009 & 0,020 & 0,002 & 0,005 & 0,001 & 0,007 \\
\hline $\mathrm{Cr}$ & 0,003 & 0,007 & 0,009 & 0,002 & 0,003 & 0,001 \\
\hline v & 0,000 & 0,000 & 0,000 & 0,000 & 0,000 & 0,000 \\
\hline $\mathrm{Fe}^{3+}$ & 11,990 & 11,973 & 11,986 & 11,975 & 11,998 & 11,996 \\
\hline $\mathrm{Fe}^{2+}$ & 11,988 & 11,967 & 11,989 & 11,985 & 11,977 & 11,971 \\
\hline $\mathrm{Mg}$ & 0,000 & 0,003 & 0,000 & 0,000 & 0,003 & 0,000 \\
\hline $\mathrm{Mn}$ & 0,006 & 0,016 & 0,006 & 0,012 & 0,019 & 0,025 \\
\hline $\mathrm{Zn}$ & 0,000 & 0,000 & 0,000 & 0,000 & 0,000 & 0,000 \\
\hline $\mathrm{Ca}$ & 0,000 & 0,000 & 0,000 & 0,000 & 0,000 & 0,000 \\
\hline $\mathrm{Ni}$ & 0,000 & 0,000 & 0,000 & 0,000 & 0,000 & 0,000 \\
\hline Total & 24,000 & 24,000 & 24,000 & 24,000 & 24,000 & 24,000 \\
\hline $\mathrm{Mg} /\left(\mathrm{Mg}+\mathrm{Fe}^{2+}\right)$ & 0,000 & 0,000 & 0,000 & 0,000 & 0,000 & 0,000 \\
\hline $\mathrm{Cr} /(\mathrm{Cr}+\mathrm{Al})$ & 0,251 & 0,264 & 0,836 & 0,265 & 0,787 & 0,091 \\
\hline $\mathrm{Fe}^{2+} /\left(\mathrm{Fe}^{2+} \mathrm{Mg}\right)$ & 1,000 & 1,000 & 1,000 & 1,000 & 1,000 & 1,000 \\
\hline
\end{tabular}



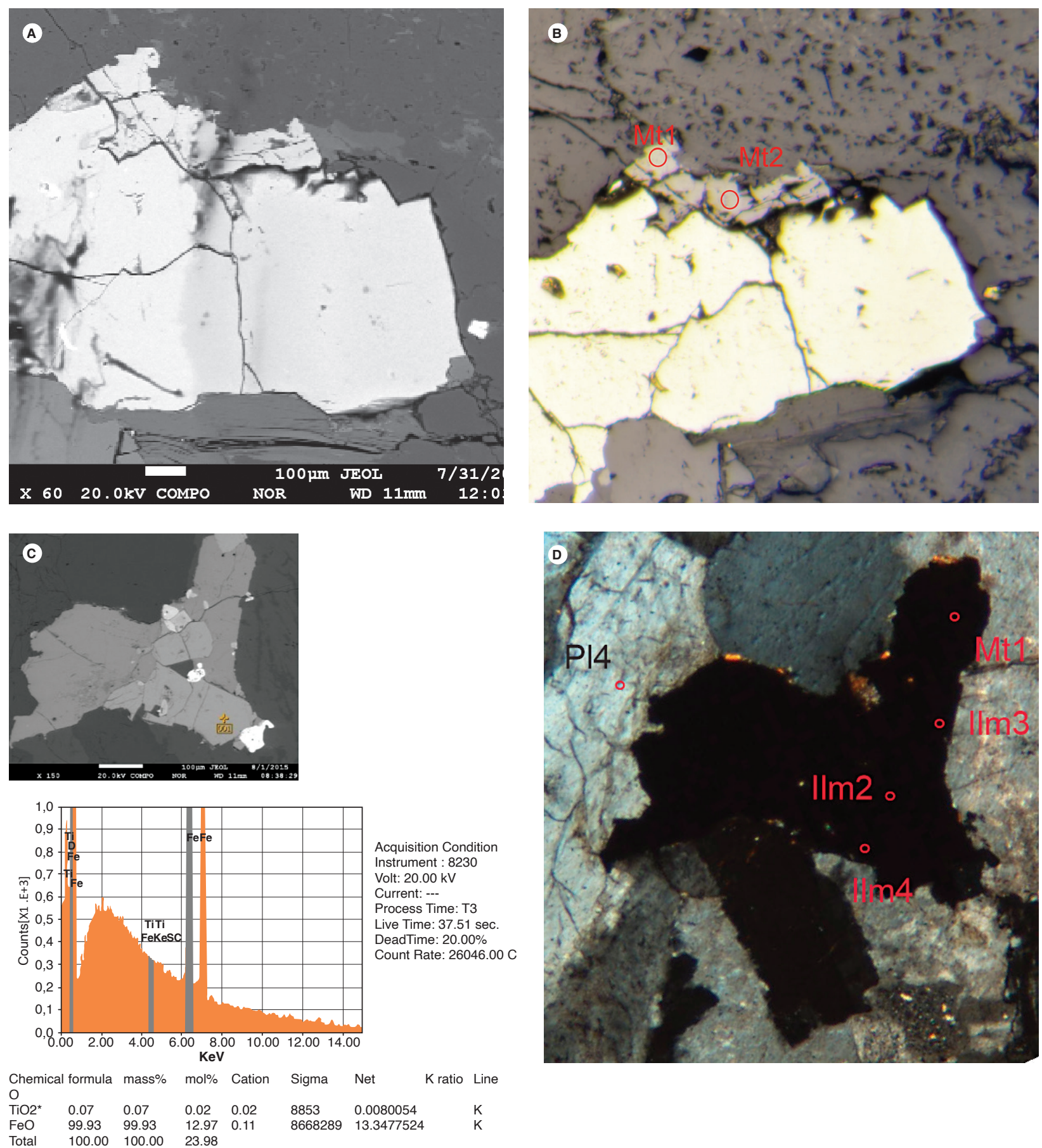

$\begin{array}{lllllllll}\text { Chemical formula } & \text { mass } \% & \text { mol\% } & \text { Cation } & \text { Sigma } & \text { Net } & \text { K ratio } & \text { Line } \\ \text { O } & & & & & & & \\ \mathrm{TiO}^{*} & 0.07 & 0.07 & 0.02 & 0.02 & 8853 & 0.0080054 & \mathrm{~K} \\ \mathrm{FeO} & 99.93 & 99.93 & 12.97 & 0.11 & 8668289 & 13.3477524 & \mathrm{~K} \\ \text { Total } & 100.00 & 100.00 & 23.98 & & & & \end{array}$

Figura 14. Imágenes de electrones secundarios retrodispersados (BSE) e imágenes de magnetita obtenidas en microscopio petrográfico. A) Imagen BSE del campo C5 de la roca MIA-648B. B) Puntos de análisis de magnetita en el C5 en MIA-648B. Imagen petrográfica de luz reflejada. C) EDS en C1 de la roca GR-6736, que arroja valores de magnetita. D) Minerales opacos en campo de análisis C1 en GR-6736. Imagen obtenida en microscopio petrográfico, nícoles cruzados 
Servicio Geológico Colombiano

Tabla 6. Composición química de ilmenita en la roca 900952 (GR-6736)

\begin{tabular}{|c|c|c|c|}
\hline Punto Analizado & GR-6736-C1-IIm-2 & GR-6736-C1-IIm-3 & GR-6736-C1-IIm-4 \\
\hline $\mathrm{TiO}_{2}$ & 45,9 & 47,46 & 46,85 \\
\hline \multicolumn{4}{|l|}{$\mathrm{SiO}_{2}$} \\
\hline $\mathrm{Fe}_{2} \mathrm{O}_{3}$ & 14,16 & 11,41 & 1,3 \\
\hline $\mathrm{Cr}_{2} \mathrm{O}_{3}$ & 0,00 & & 0,01 \\
\hline $\mathrm{Al}_{2} \mathrm{O}_{3}$ & & & 0,0 \\
\hline \multicolumn{4}{|l|}{$\mathrm{V}_{2} \mathrm{O}_{3}$} \\
\hline $\mathrm{FeO}$ & 30,79 & 31,70 & 31,33 \\
\hline $\mathrm{MnO}$ & 10,34 & 10,85 & 10,60 \\
\hline $\mathrm{MgO}$ & 0,0 & 0,00 & 0,04 \\
\hline $\mathrm{CaO}$ & 0,00 & 0,00 & 0,00 \\
\hline Total & 101,4 & 101,43 & 101,08 \\
\hline \multicolumn{4}{|c|}{ Cationes calculados a partir de 60} \\
\hline $\mathrm{Ti}$ & 1,733 & 1,785 & 1,768 \\
\hline $\mathrm{Si}$ & 0,000 & 0,000 & 0,000 \\
\hline $\mathrm{Fe}^{3+}$ & 0,535 & 0,429 & 0,46 \\
\hline $\mathrm{Cr}$ & 0,000 & 0,000 & 0,000 \\
\hline $\mathrm{Al}$ & 0,000 & 0,000 & 0,001 \\
\hline $\mathrm{v}$ & 0,000 & 0,000 & 0,000 \\
\hline $\mathrm{Fe}^{2+}$ & 1,9 & 1,326 & 1,315 \\
\hline $\mathrm{Mg}$ & 0,00 & 0,000 & 0,003 \\
\hline $\mathrm{Mn}$ & 0,439 & 0,460 & 0,451 \\
\hline $\mathrm{Ca}$ & 0,000 & 0,000 & 0,000 \\
\hline
\end{tabular}

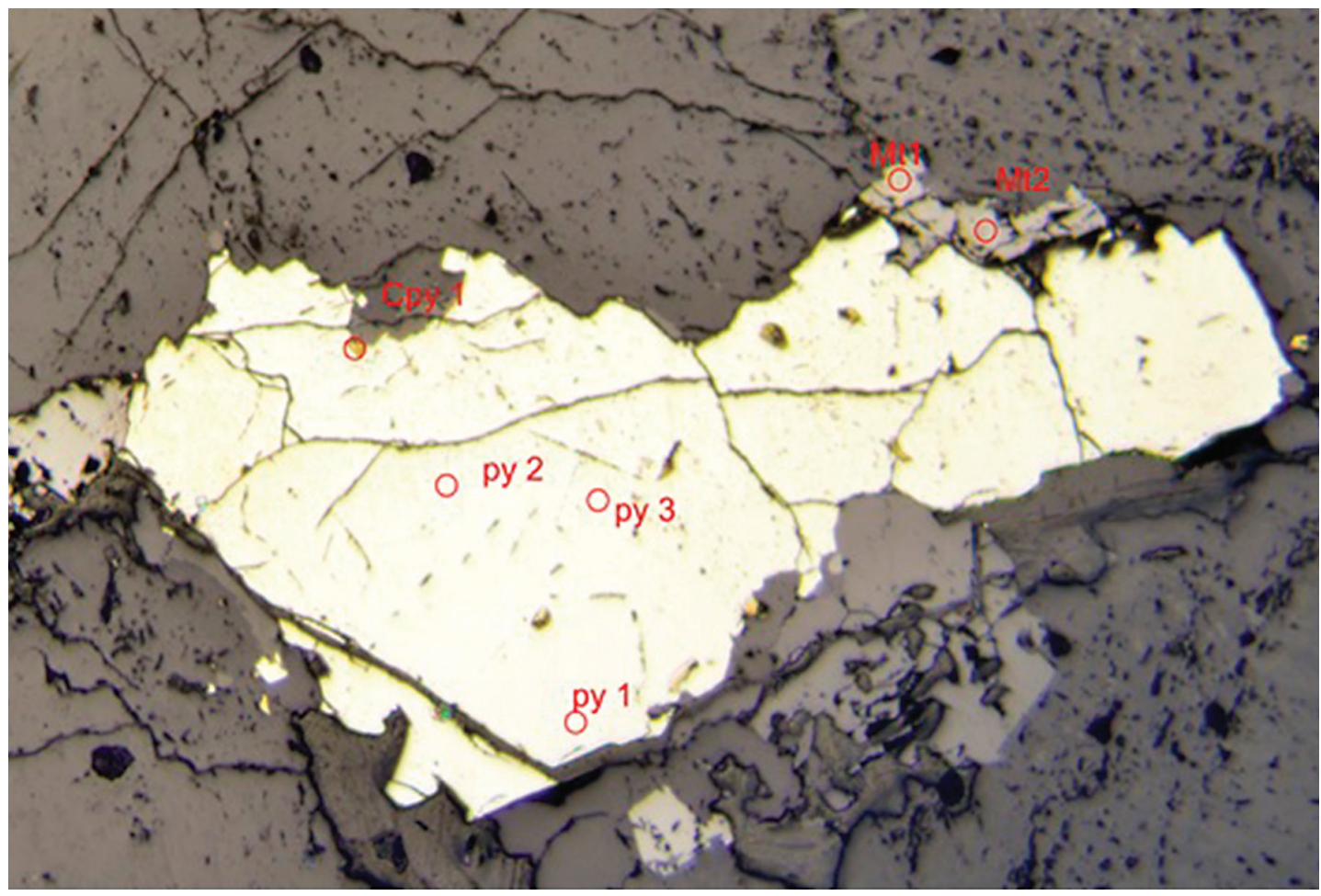

Figura 15. Imágenes de electrones secundarios retrodispersados (BSE) correspondientes a pirita y calcopirita. Pirita (Py) con inclusiones de calcopirita (Cpy) rodeada de magnetita $(\mathrm{Mt})$, roca MIA-648B 
Tabla 7. Composición química de calcopirita y pirita en la roca 900969 (MIA-648B)

\begin{tabular}{|c|c|c|c|}
\hline Punto Analizado & MIA-648B-C5-CPy-1 & MIA-648B-C5-Py-2 & MIA-648B-C5-Py-4 \\
\hline $\mathrm{Zn}$ & 0,05 & 0,00 & 0,01 \\
\hline As & 0,02 & 0,02 & \\
\hline$S$ & 34,22 & 53,13 & 53,18 \\
\hline $\mathrm{Fe}$ & 32,47 & 46,06 & 45,93 \\
\hline Co & 0,07 & 0,08 & 0,07 \\
\hline \multicolumn{4}{|l|}{$\mathrm{Ni}$} \\
\hline $\mathrm{Sb}$ & & & 0,01 \\
\hline $\mathrm{Cu}$ & 31,78 & & \\
\hline Total & 98,61 & 99,29 & 99,20 \\
\hline $\mathrm{Zn}$ & 0,0385 & 0,0017 & 0,0084 \\
\hline As & 0,0097 & 0,0126 & \\
\hline$S$ & 49,6225 & 66,7298 & 66,8198 \\
\hline $\mathrm{Fe}$ & 27,0243 & 33,2046 & 33,1232 \\
\hline Co & 0,0555 & 0,0514 & 0,0464 \\
\hline \multicolumn{4}{|l|}{$\mathrm{Ni}$} \\
\hline $\mathrm{Sb}$ & & & 0,0023 \\
\hline $\mathrm{Cu}$ & 23,2494 & & \\
\hline Total & 99,9614 & 99,9984 & 99,9917 \\
\hline
\end{tabular}

\section{Litogeoquímica}

Se realizaron once análisis geoquímicos de rocas intrusivas correspondientes a las litologías monzogranítica y granodiorítica, y diez análisis de rocas de diques ácidos y básicos, cuyos resultados se muestran en las tablas 8 y 9. Los valores de óxidos mayores se presentan en porcentaje en peso ( $\mathrm{wt} \%$ ), mientras que los elementos traza se presentan en partes por millón (ppm). Se utilizaron las técnicas de fluorescencia de rayos X para cuantificar óxidos mayores y los elementos traza Mo, V, Nb, Ta, W, $\mathrm{Zr}$ y Hf mediante un equipo marca Panalytical AXIOS Mineral para análisis elemental, configurado con software especializado para materiales geológicos. La cuantificación de los óxidos mayores se realizó en muestra fundida con metaborato y tetraborato de litio, y la cuantificación de elementos menores se realizó en muestra prensada.

Para el ploteo e interpretación de los óxidos mayores se realizó la corrección de los valores de volátiles (pérdidas por ignición-LOI).
Para el análisis de elementos traza de interés geoquímico en rocas se usó un espectrómetro de masas con plasma inductivamente acoplado, ICP-MS, Perkin Elmer Nexion. Para la disolución de la muestra se realizó un ataque por pasos utilizando ácidos inorgánicos fuertes ( $\mathrm{HF}, \mathrm{HNO}_{3}, \mathrm{HClO}_{4} \mathrm{y} \mathrm{HCl}$. El proceso se realizó en sistema abierto, empleando distintas rampas de temperatura y tiempos de calentamiento. La mayoría de los diagramas geoquímicos se generaron con el uso del GCDKit version 4.0 (Janoušek et al., 2006).

Van der Lelij (2013) presenta una caracterización litogeoquímica de algunos cuerpos ígneos del Macizo de Santander y de los Andes de Mérida, en Venezuela. Entre ellos hay un análisis del cuerpo Batolito de Ocaña (10VDL54) y otro del Batolito de Rionegro (10VDL59). Estos dos análisis, junto con un grupo de rocas colectadas en este estudio, se retoman con el fin de identificar sus firmas geoquímicas y examinar si existe relación entre estos dos cuerpos, como se plantea a partir de las similitudes petrográficas. 
Tabla 8. Datos de óxidos mayores del Monzogranito de Rionegro

\begin{tabular}{|c|c|c|c|c|c|c|c|c|c|c|c|c|}
\hline IGM & $\mathrm{SiO}_{2}$ & $\mathrm{TiO}_{2}$ & $\mathrm{Al}_{2} \mathrm{O}_{3}$ & $\mathrm{Fe}_{2} \mathrm{O}_{3}$ & MgO & $\mathrm{CaO}$ & $\mathrm{Na}_{2} \mathrm{O}$ & $\mathrm{K}_{2} \mathrm{O}$ & $\mathrm{P}_{2} \mathrm{O}_{5}$ & MnO & $\mathrm{FeO}$ & LOI \\
\hline \multicolumn{13}{|c|}{ Rocas graníticas } \\
\hline 900997 & 51,52 & 2,06 & 16,80 & 9,57 & 4,59 & 7,48 & 3,94 & 1,43 & 0,441 & 0,146 & 4,93 & 1,81 \\
\hline 900999 & 58,77 & 1,36 & 16,28 & 5,76 & 3,46 & 6,43 & 3,97 & 2,66 & 0,255 & 0,093 & 3,28 & 0,87 \\
\hline 900954 & 60,99 & 0,91 & 18,51 & 5,07 & 1,71 & 4,28 & 3,71 & 3,38 & 0,325 & 0,100 & & 0,67 \\
\hline 900949 & 62,83 & 0,82 & 17,65 & 4,74 & 1,48 & 4,16 & 4,09 & 2,75 & 0,244 & 0,114 & 2,44 & 0,74 \\
\hline 10VD659* & 64,1 & 0,7 & 17,6 & 4,2 & 1,3 & 3,8 & 4,0 & 3,0 & 0,2 & 0,101 & & 0,7 \\
\hline 900952 & 64,59 & 0,78 & 17,05 & 4,15 & 1,19 & 3,50 & 4,24 & 3,29 & 0,211 & 0,113 & & 0,62 \\
\hline 900950 & 66,73 & 0,56 & 16,49 & 3,73 & 1,13 & 3,44 & 3,93 & 3,03 & 0,176 & 0,090 & & 0,37 \\
\hline 900985 & 68,93 & 0,47 & 16,01 & 2,88 & 1,60 & 1,28 & 7,16 & 0,26 & 0,159 & 0,081 & 1,47 & 1,16 \\
\hline 900973 & 71,62 & 0,34 & 13,81 & 2,08 & 0,71 & 2,55 & 3,83 & 3,36 & 0,092 & 0,070 & 0,91 & 1,42 \\
\hline 900990 & 71,65 & 0,32 & 14,34 & 2,44 & 0,68 & 2,58 & 3,42 & 3,28 & 0,101 & 0,087 & 1,00 & 0,91 \\
\hline 900971 & 72,67 & 0,32 & 13,49 & 1,93 & 0,54 & 1,29 & 2,93 & 5,15 & 0,112 & 0,059 & 0,90 & 1,41 \\
\hline 900974 & 76,09 & 0,14 & 13,20 & 0,90 & 0,17 & 0,81 & 3,31 & 4,78 & 0,037 & 0,049 & 0,22 & 0,47 \\
\hline 10VDL54* & 76,9 & 0,1 & 12,9 & 0,7 & 0,1 & 0,3 & 3,5 & 4,8 & 0,0 & 0,040 & & 0,5 \\
\hline \multicolumn{13}{|c|}{ Rocas de dique } \\
\hline 900998 & 50,51 & 1,79 & 17,32 & 9,18 & 5,63 & 8,62 & 3,59 & 1,33 & 0,33 & 0,13 & 5,54 & 1,39 \\
\hline 900975 & 51,77 & 1,57 & 16,62 & 9,12 & 4,95 & 8,00 & 3,98 & 1,02 & 0,55 & 0,15 & 4,28 & 2,09 \\
\hline 900986 & 52,46 & 0,98 & 16,61 & 9,76 & 5,45 & 8,25 & 2,29 & 0,36 & 0,21 & 0,23 & 3,76 & 3,17 \\
\hline 900906 & 71,10 & 0,11 & 16,76 & 0,71 & 0,06 & 0,23 & 4,58 & 5,16 & & 0,02 & & 0,35 \\
\hline 900951 & 74,96 & 0,23 & 13,44 & 1,34 & 0,28 & 1,30 & 3,30 & 4,48 & 0,05 & 0,04 & & 0,39 \\
\hline MIA-646A & 76,42 & 0,10 & 13,11 & 0,62 & $<0,10$ & 0,87 & 2,86 & 5,64 & 0,04 & 0,03 & & 0,30 \\
\hline 900969 & 76,79 & 0,14 & 12,85 & 0,78 & $<0,10$ & 0,54 & 3,06 & 5,27 & $<0,024$ & 0,03 & 0,21 & 0,48 \\
\hline 900953 & 76,90 & 0,13 & 12,75 & 0,73 & $<0,10$ & 0,80 & 2,57 & 5,14 & $<0,024$ & 0,04 & & 0,69 \\
\hline 901011 & 77,42 & 0,06 & 12,71 & 0,71 & $<0,10$ & 0,72 & 3,29 & 4,68 & $<0,024$ & 0,044 & $<0,13$ & 0,31 \\
\hline 901010 & 77,47 & 0,07 & 12,87 & 0,67 & $<0,10$ & 0,62 & 3,65 & 4,35 & $<0,024$ & 0,02 & $<0,13$ & 0,21 \\
\hline
\end{tabular}

Fuente: *Van Der Lelij (2013) y este trabajo.

\section{1. Óxidos mayores}

Las rocas graníticas tienen un carácter intermedio a acido con rangos de $\mathrm{SiO}_{2}$ entre $61,61 \%$, en una granodiorita (IGM 900954), y 77,34\% en un granito alcalino (10VDL54). En general, las rocas presentan valores de $\mathrm{Na}_{2} \mathrm{O}$ entre 2,94 y $4,24 \%$ sin mayores cambios con el aumento de $\mathrm{SiO}_{2}$. Únicamente la muestra 900985 tiene un valor anormalmente alto: 7,16\%; el $\mathrm{K}_{2} \mathrm{O}$ varía entre 1,43 y $5,18 \%$, y aumenta con el contenido de $\mathrm{SiO}_{2}$ con un valor extremadamente bajo en la muestra 900985: $0,26 \%$ (figura 16).

$\mathrm{CaO}, \mathrm{Fe}_{2} \mathrm{O}_{3}, \mathrm{MgO}, \mathrm{MnO}, \mathrm{Al}_{2} \mathrm{O}_{3}, \mathrm{TiO}_{2}$, $\mathrm{Zr}$ y Ba disminuyen con el aumento de $\mathrm{SiO}_{2}$, como se muestra en la tabla 8 y la figura 16 . El CaO varía entre $0,34 \%$, en las rocas más ácidas, y 7,48\% en las intermedias; el MgO varía entre 0,08 y $1,72 \% ; \mathrm{el} \mathrm{Al}_{2} \mathrm{O}_{3}$ se presenta entre 13,01 y 18,70\%; hay valores menores $\mathrm{de}^{\mathrm{TiO}_{2}}$ (entre $0,11 \mathrm{y}$ $0,92 \%), \mathrm{Fe}_{2} \mathrm{O}_{3}$ entre 0,69 y $5,12 \%$, siendo mayor en las rocas granodioríticas.

Las rocas IGM 900997 e IGM 900999 muestran una composición mineralógica y geoquímica que difiere de la constitución promedio de la facies granodiorítica del
Monzogranito de Rionegro. Ambas rocas se localizan en el sector occidental del plutón donde se evidencian intrusiones del Monzogranito de Rionegro en un cuerpo cuarzomonzodiorítico. Las diferencias en contenidos modales y en el comportamiento químico sugieren que estas rocas representan a la unidad de cuarzomonzodiorita adyacente. Las muestras corresponden a rocas básicas con contenidos de $\mathrm{SiO}_{2}$ de 50,06 y 57,43\%, respectivamente, $\mathrm{Na}_{2} \mathrm{O}$ de $3,8 \%$ en ambas rocas y bajos contenidos de $\mathrm{K}_{2} \mathrm{O}$, de 1,39 y 2,6\%. El MgO está en contenidos de 4,46 a $3,38 \%, \mathrm{TiO}_{2}$ de 2,08 a $1,37 \%, \mathrm{Al}_{2} \mathrm{O}_{3}$ de 16,3 a 15,9\%; por otra parte, tienen valores de $\mathrm{CaO}$ altos: de 7,26 a 6,28\%; asimismo, el $\mathrm{Fe}_{2} \mathrm{O}_{3}$ es alto, pues se presenta en contenidos de 9,29 a $5,62 \%$.

Las rocas de diques básicos tienen cantidades $\mathrm{de}_{\mathrm{SiO}_{2}}$ entre 48,58 y $52,27 \%$, clasificadas petrográficamente como microdioritas (IGM 900998, 900975 y 900986), con cantidades de $\mathrm{Na}_{2} \mathrm{O}$ entre 2,28 y 3,90\%, $\mathrm{K}_{2} \mathrm{O}$ entre 0,36 y $1,28 \%$, y MgO entre 4,85 y $5,43 \%$. Los diques de composición ácida (monzogranitos, riolitas) tienen valores $\mathrm{de}_{\mathrm{SiO}}$ entre 72,02 y $77,70 \%, \mathrm{Na}_{2} \mathrm{O}$ entre 2,59 y $4,63 \%$, $\mathrm{K}_{2} \mathrm{O}$ entre 4,36 y $5,66 \%$, y valores bajos de MgO: 0,28\%. 

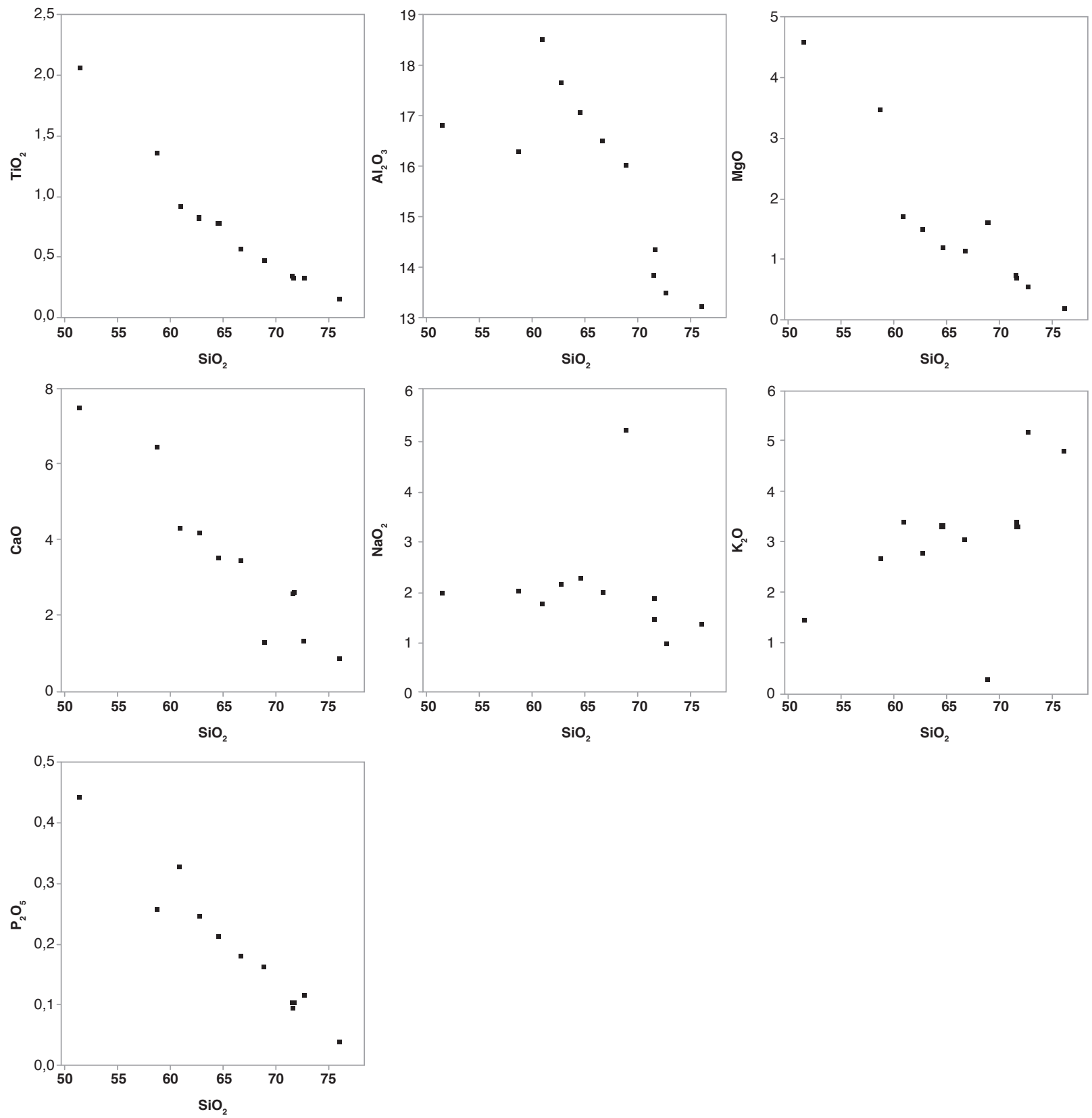

Figura 16. Diagramas de variación de Harker correspondientes a rocas graníticas del Monzogranito de Rionegro

En el diagrama de TAS (figura 17) las rocas se localizan en las series de cuarzomonzodiorita a granodiorita en las facies granodioríticas, y en el campo de granitos en la facies clasificada petrográficamente como monzogranitos. Las rocas IGM 900997 e IGM 900999 muestran una composición de monzodioritas y cuarzomonzodiorita concordante con la clasificación petrográfica. Los diques ácidos se localizan en el campo de riolitas, y los diques básicos hacia los campos de basaltos y basaltos andesíticos.

El Monzogranito de Rionegro muestra dispersión en cuanto a los contenidos de $\mathrm{K}_{2} \mathrm{O}$ vs. $\mathrm{SiO}_{2}$ (figura 18 ). Las rocas granodioríticas presentan menor contenido de sílice y se apartan de las rocas monzograníticas; sin embargo, todas las rocas tienen afinidad en las series calcoalcalina alta en K. La roca IGM 900985, clasificada como monzo- 
granito, muestra una baja concentración de $\mathrm{K}_{2} \mathrm{O}(0,26 \%$ $\mathrm{wt}$ ), que posiblemente corresponde a un error analítico.

Las rocas de dique se diferencian entre las muestras básicas con bajos contenidos de sílice y se dispersan en- tre las series calcoalcalinas altas en $\mathrm{K}$, calcoalcalinas $\mathrm{y}$ toleíticas. Por su parte, los diques de sienogranitos, monzogranitos y riolitas se agrupan en las series calcoalcalinas altas en $\mathrm{K}$.
(A)

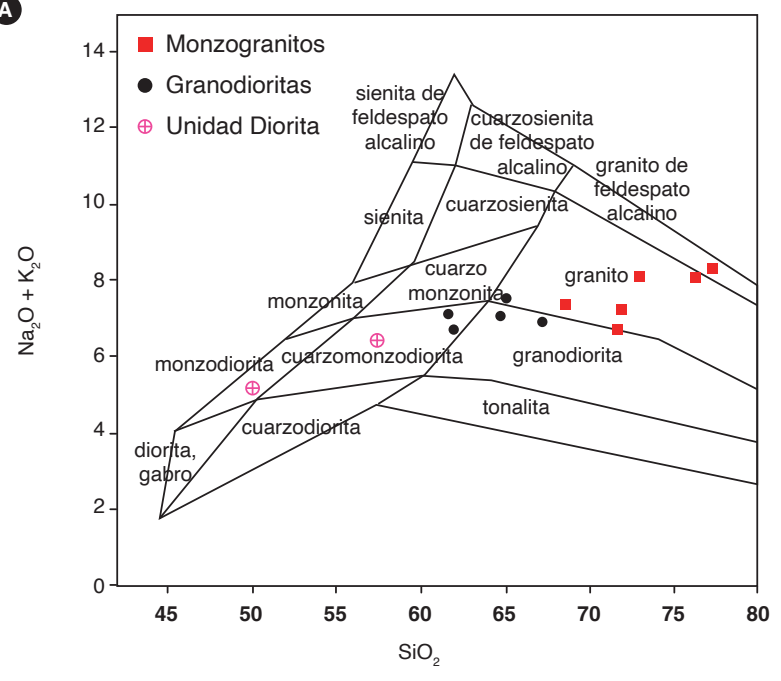

B

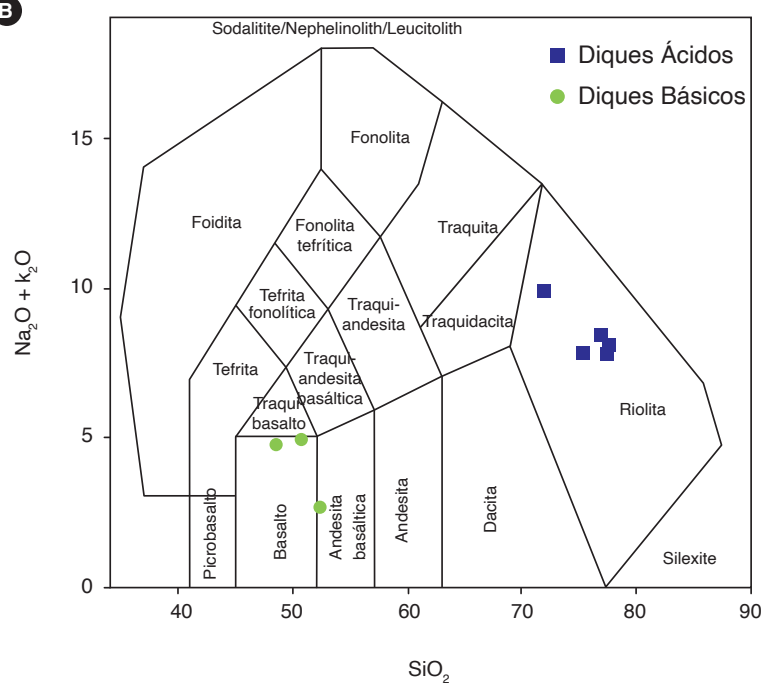

Figura 17. A) Diagramas TAS (Middlemost, 1985) correspondientes a rocas graníticas. B) TAS (Middlemost, 1994) correspondiente a rocas de dique
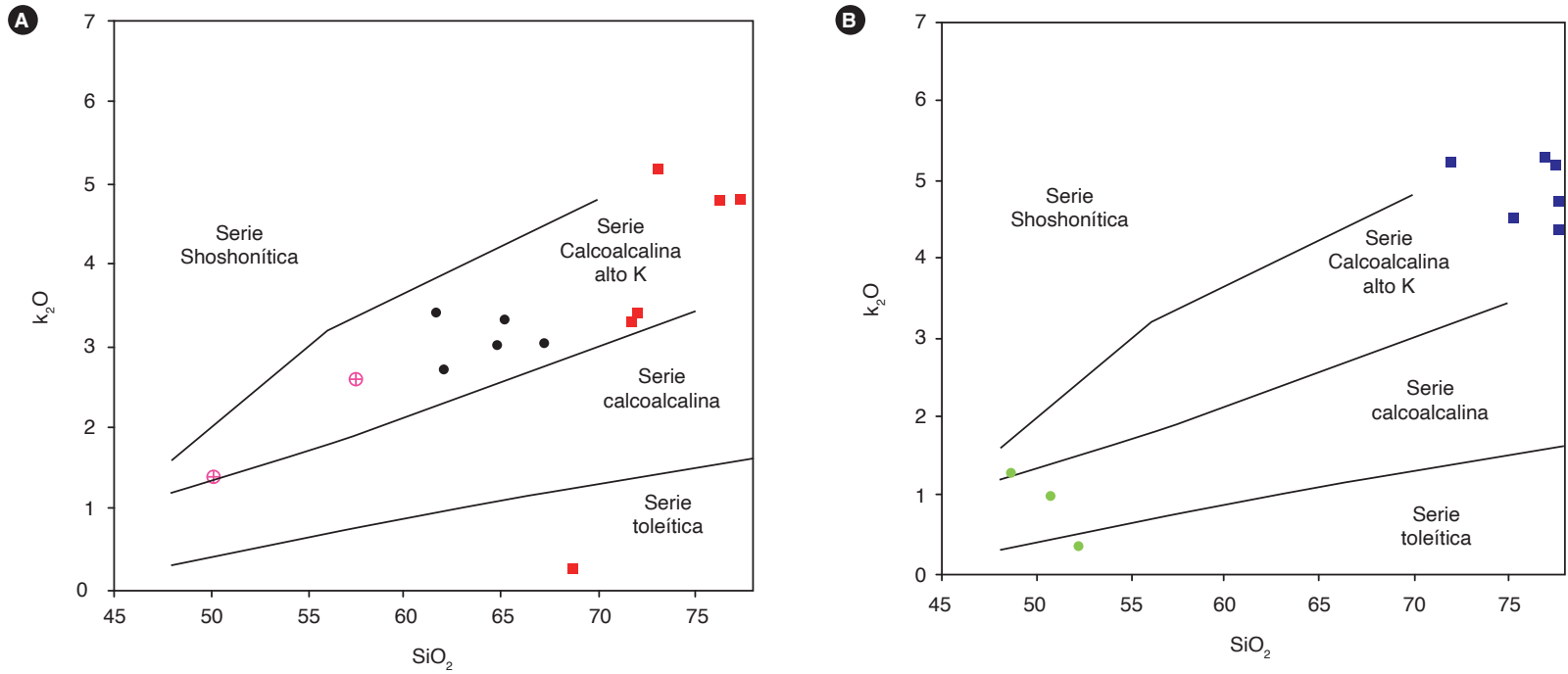

Figura 18. Diagrama de Peccerillo y Taylor (1976) correspondiente a rocas graníticas (A) y rocas de dique (B) Los símbolos deben interpretarse igual que en la figura 17 
Varios cuerpos ígneos del Macizo de Santander muestran un comportamiento metaluminoso a peraluminoso, con mayor afinidad hacia el campo peraluminoso. Van der Lelij (2013) sugiere que esta firma en las rocas posiblemente refleje el tipo de fuente del cual se derivó el magma de estos cuerpos intrusivos (magmas derivados de fuentes sedimentarias o de fuentes ígneas). Las variaciones de $\mathrm{Na}_{2} \mathrm{O}$ con respecto a $\mathrm{K}_{2} \mathrm{O}$ muestran el tipo de granito asociado (tipo $\mathrm{S}$ o tipo I). Las rocas del Monzogranito de Rionegro exhiben una tendencia hacia el campo peraluminoso (figura 19) con contenidos molares de A/CNK entre 1,009 y 1,115, excepto en la roca IGM 900973 , que tiene $\mathrm{A} / \mathrm{CNK}<1(0,948)$ y las dos rocas asociadas a la unidad de cuarzomonzodiorita.

Los diques básicos (IGM 900986, 900998 y 900975) se ubican en el campo metaluminoso con proporciones molares de A/CNK entre 0,74 y 0,86, mientras que las rocas de diques ácidos se ubican en el campo peraluminoso con relaciones molares de A/CNK entre 1,05 y 1,23 (figura 20).

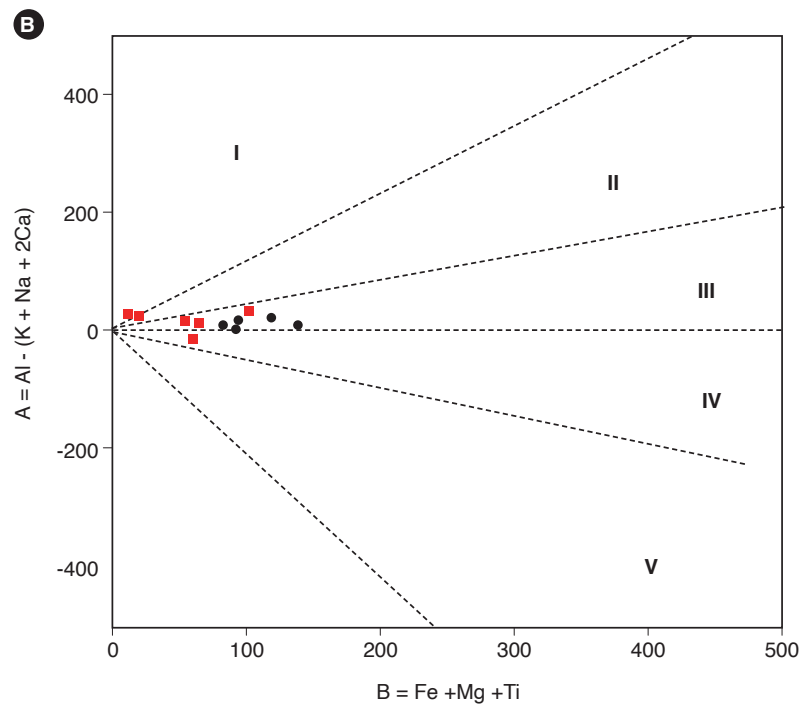

Figura 19. Diagramas de clasificación correspondientes a rocas graníticas del Monzogranito de Rionegro. A) Diagrama de Shand (1943). B) Diagrama de Debon y Le Fort (1983). La interpretación de los símbolos puede consultarse en la figura 17
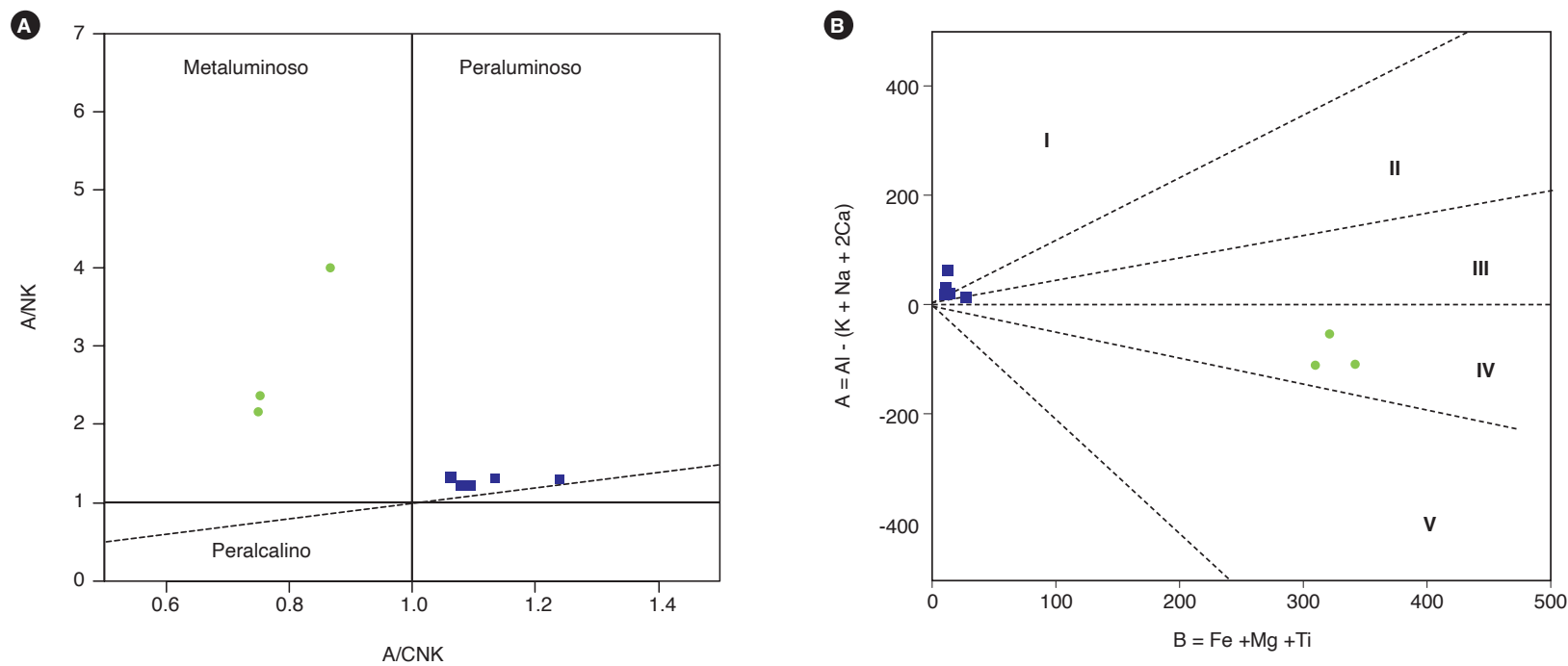

Figura 20. Diagramas de clasificación correspondientes a rocas diques del Monzogranito de Rionegro. A) Diagrama de Shand (1943). B) Diagrama de Debon y Le Fort (1983). La interpretación de los símbolos puede consultarse en la figura 17 


\subsection{Elementos traza y tierras raras}

Los contenidos de elementos traza y tierras raras del Monzogranito de Rionegro se presentan en la tabla 9, y los de rocas de diques en la tabla 10 .

Hay una clara diferenciación entre las facies granodiorita y monzogranito respecto a la relación de $(\mathrm{La} / \mathrm{Yb})_{\mathrm{N}}$ : valores entre 12,29 y 25,11 para las rocas clasificadas como granodioritas (IGM 900954, 900949, 900952, 900950 y 10 VDL59), mientras que en los monzogranitos estas relaciones son menores, entre 7,57 y 11,9 (IGM 900971, 900973, 900974, 900985 y 900990). Las rocas que corresponden a la unidad cuarzomonzodiorita (IGM 900997 y 900999), en la cual intruye el Monzogranito de Rionegro, exhiben relaciones $(\mathrm{La} / \mathrm{Yb})_{\mathrm{N}}$ entre 5,25 y 5,38 . Por su parte, la roca reinterpretada 10VDL54 (Van der Lelij, 2013) del Batolito de Ocaña, muestra una relación $(\mathrm{La} / \mathrm{Yb})_{\mathrm{N}}$ de 3,46 .

En las rocas de diques no se observa una diferenciación en lo que respecta al tipo de roca (ácido o básico) y la relación $(\mathrm{La} / \mathrm{Yb})_{\mathrm{N}}$. Los monzogranitos y riolitas tienen valores entre 4,29 y 27,07, mientras que los diques microdioríticos y andesíticos muestran valores entre 5,96 y 8,99.

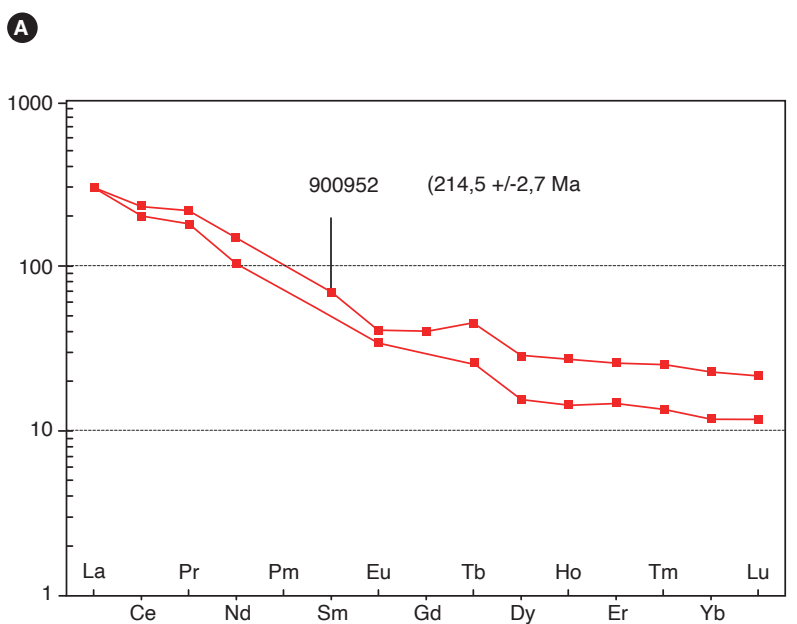

En los diagramas normalizados a condrito (Nakamura, 1974 y McDonough y Sun, 1995) (figura 21), las rocas del Monzogranito de Rionegro exhiben un enriquecimiento general en LREE (desde La a Sm) con distinción entre los trenes de las granodiorítas y los monzogranitos (figura 22).

Las granodioritas (10VDL59, 900949, 900954, 900952 y 900950) presentan valores de hasta quinientas veces el valor del condrito y valores de $\mathrm{Eu} / \mathrm{Eu}^{*}$ entre 0,66 y 1,091 .

Aunque desde las LREE hasta las HREE hay variaciones graduales en el contenido de las tierras raras, con entrecruzamientos en los trenes, se evidencian dos patrones con respecto al valor de $\mathrm{La}_{\mathrm{N}}$. Las rocas 1 OVDL59, 900949 y 900954 tienen valores altos de $\mathrm{La}_{\mathrm{N}}$ (entre $508,94$ y 549,78$)$ y se localizan hacia los bordes del cuerpo, mientras que las rocas 900952 y 900950 presentan valores de $\mathrm{La}_{\mathrm{N}}$ de 409,54 y 41 1,66 y se localizan en el interior de la unidad, con una diferencia de edad de cristalización marcada.

B

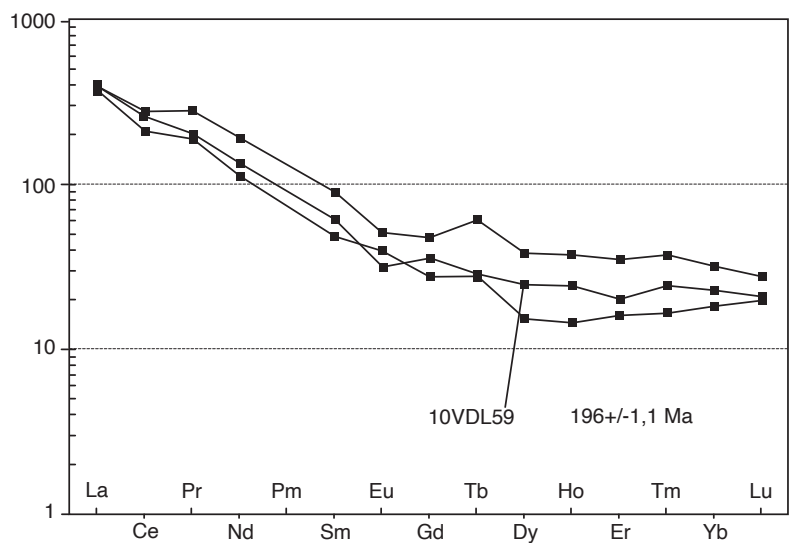

Figura 21. Diagrama REE correspondiente a rocas granodioríticas normalizado con respecto a la composición del condrito (Nakamura, 1974) La interpretación de los símbolos puede consultarse en la figura 17 
Tabla 9. Concentraciones de elementos traza y tierras raras del Monzogranito de Rionegro

\begin{tabular}{|c|c|c|c|c|c|c|c|c|c|c|c|c|c|}
\hline IGM & 900997 & 900999 & 900954 & 900949 & 10VDL59 & 900952 & 900950 & 900985 & 900973 & 900990 & 900971 & 900974 & 10VDL54 \\
\hline $\mathrm{Li}$ & 12 & 5,1 & 45 & 8,3 & & 18 & 22 & 17 & 4,3 & 12 & 10 & 6,9 & \\
\hline $\mathrm{Be}$ & 2,1 & 2,3 & 3,2 & 2,2 & 2,9 & 2,6 & 2,0 & 1,1 & 1,9 & 2,0 & 2,7 & 3,1 & 4,4 \\
\hline Sc & 29 & 23 & 20 & 13 & 8,3 & 17 & 9,5 & 6,4 & 5,4 & 6,0 & 6,9 & 5,1 & 5,9 \\
\hline v & 201 & 118 & 67 & 56 & 57 & 38 & 42 & 22 & 25 & 25 & 20 & 10 & 2,0 \\
\hline $\mathrm{Cr}$ & 64 & 56 & 12 & 4,2 & 5,0 & 8,0 & 7,8 & 3,5 & 3,8 & 2,5 & 4,3 & 1,4 & 6,0 \\
\hline $\mathrm{Mn}$ & 1161 & 734 & ** & ** & & ** & ** & 626 & 541 & 673 & 451 & 380 & \\
\hline Co & 33 & 26 & 19 & 20 & 6,1 & 15 & 17 & 16 & 13 & 20 & 16 & 13 & 0,5 \\
\hline $\mathrm{Ni}$ & 42 & 32 & 12 & 9,3 & 5,6 & 6,0 & 6,0 & 6,6 & 13 & 3,0 & 17 & 1,7 & 3,0 \\
\hline $\mathrm{Cu}$ & 38 & 29 & 23 & 13 & 6,8 & 10 & 10 & 6,8 & 30 & 5,2 & 7,8 & 4,6 & 3,7 \\
\hline $\mathrm{Zn}$ & 100 & 58 & 93 & 96 & 77,0 & 84 & 65 & 53 & 40 & 56 & 43 & 21 & 17,0 \\
\hline Ga & 22 & 17 & 26 & 27 & 23,7 & 22 & 20 & 15 & 15 & 16 & 16 & 15 & 16,5 \\
\hline As & 2,1 & 1,4 & 3,8 & 4,6 & 2,5 & 3,9 & 3,4 & 1,1 & 1,6 & 1,2 & 1,6 & 1,4 & 2,0 \\
\hline $\mathrm{Rb}$ & 24 & 29 & 168 & 104 & 66,1 & 113 & 93 & 10 & 98 & 97 & 206 & 220 & 174,0 \\
\hline $\mathrm{Sr}$ & 521 & 455 & 564 & 493 & 448,2 & 404 & 383 & 188 & 227 & 269 & 173 & 86 & 25,5 \\
\hline$Y$ & 31 & 18 & & & 43,6 & & & 24 & 19 & 19 & 21 & 18 & 32,8 \\
\hline $\mathrm{Cd}$ & 0,17 & 0,13 & 0,092 & 0,082 & & 0,095 & $<0,08$ & $<0,08$ & 0,086 & 0,082 & 0,15 & $<0,08$ & \\
\hline In & 0,080 & 0,049 & 0,074 & 0,050 & & 0,057 & 0,035 & 0,020 & 0,015 & 0,017 & 0,015 & 0,018 & \\
\hline Cs & 0,32 & 0,26 & 4,0 & 1,3 & 1,1 & 1,1 & 1,7 & 0,09 & 0,34 & 0,42 & 2,5 & 1,6 & 0,9 \\
\hline $\mathrm{Ba}$ & 420 & 335 & 2329 & 2693 & 1986,3 & 1979 & 2523 & 55 & 1074 & 1150 & 848 & 518 & 216,9 \\
\hline $\mathrm{La}$ & 24 & 13 & 121 & 127 & 130,3 & 98 & 97 & 25 & 35 & 32 & 29 & 21 & 20,9 \\
\hline $\mathrm{Ce}$ & 55 & 25 & 180 & 238 & 220,1 & 199 & 173 & 51 & 65 & 61 & 59 & 46 & 40,8 \\
\hline $\mathrm{Pr}$ & 7,4 & 3,5 & 21 & 31 & 22,6 & 24 & 20 & 5,9 & 7,3 & 6,7 & 6,6 & 5,6 & 4,7 \\
\hline $\mathrm{Nd}$ & 28 & 14 & 70 & 120 & 84,1 & 93 & 65 & 19 & 24 & 21 & 21 & 19 & 18,5 \\
\hline $\mathrm{Sm}$ & 6,5 & 3,2 & 9,6 & 18 & & 14 & 9,3 & 3,9 & 4,3 & 4,1 & 4,2 & 4,2 & 4,3 \\
\hline $\mathrm{Eu}$ & 2,0 & 1,2 & 3,0 & 3,9 & 2,4 & 3,1 & 2,6 & 1,00 & 1,2 & 1,3 & 1,1 & 0,67 & 0,4 \\
\hline $\mathrm{Gd}$ & 6,1 & 3,1 & 7,5 & 13 & 9,9 & 11 & 7,5 & 4,5 & 4,2 & 4,1 & 3,9 & 3,8 & 3,8 \\
\hline $\mathrm{Tb}$ & 1,0 & 0,54 & 1,3 & 2,8 & 1,3 & 2,1 & 1,2 & 0,73 & 0,60 & 0,58 & 0,62 & 0,57 & 0,8 \\
\hline Dy & 5,8 & 3,1 & 5,2 & 13 & 8,4 & 9,7 & 5,3 & 4,2 & 3,2 & 3,0 & 3,3 & 3,1 & 5,0 \\
\hline Ho & 1,2 & 0,63 & 1,0 & 2,6 & 1,7 & 1,9 & 1,0 & 0,89 & 0,67 & 0,63 & 0,72 & 0,60 & 1,2 \\
\hline $\mathrm{Er}$ & 3,4 & 1,9 & 3,6 & 7,8 & 4,5 & 5,8 & 3,3 & 2,6 & 2,1 & 1,9 & 2,2 & 1,8 & 3,4 \\
\hline $\mathrm{Tm}$ & 0,47 & 0,26 & 0,49 & 1,10 & 0,7 & 0,75 & 0,40 & 0,34 & 0,30 & 0,27 & 0,33 & 0,27 & 0,6 \\
\hline $\mathrm{Yb}$ & 3,1 & 1,7 & 4,0 & 7,0 & 5,0 & 5,0 & 2,6 & 2,1 & 2,1 & 1,8 & 2,2 & 1,9 & 4,1 \\
\hline $\mathrm{Lu}$ & 0,45 & 0,26 & 0,67 & 0,93 & 0,7 & 0,73 & 0,40 & 0,29 & 0,31 & 0,27 & 0,33 & 0,29 & 0,6 \\
\hline $\mathrm{TI}$ & 0,044 & 0,029 & 0,87 & 0,58 & & 0,61 & 0,50 & 0,048 & 0,53 & 0,52 & 1,3 & 1,2 & \\
\hline $\mathrm{Pb}$ & 6,4 & 6,3 & 13 & 11 & 7,9 & 12 & 10 & 4,1 & 9,5 & 9,9 & 39 & 20 & 23,6 \\
\hline $\mathrm{Bi}$ & $<0,05$ & $<0,05$ & 0,16 & $<0,05$ & 0,1 & $<0,05$ & $<0,05$ & $<0,05$ & $<0,05$ & $<0,05$ & 0,23 & 0,50 & 0,1 \\
\hline Th & 2,0 & 3,7 & 7,2 & 13 & 12,1 & 15 & 13 & 9,1 & 10 & 8,4 & 16 & 15 & 14,5 \\
\hline U & 0,50 & 1,3 & 2,2 & 0,94 & 1,4 & 2,1 & 1,2 & 1,4 & 1,4 & 2,3 & 4,6 & 3,8 & 3,8 \\
\hline $\mathrm{Zr}$ & 276 & 147 & 488 & 491 & 463,8 & 452 & 328 & 196 & 147 & 161 & 145 & 70 & 60,2 \\
\hline $\mathrm{Nb}$ & 18 & 14 & 16 & 20 & 15,1 & 20 & 15 & 13 & 14 & 13 & 17 & 20 & 21,1 \\
\hline W & 11 & 14 & 28 & 48 & 0,9 & 33 & 39 & 38 & 44 & 72 & 70 & 58 & 0,6 \\
\hline
\end{tabular}


Tabla 10. Concentraciones de elementos traza y tierras raras en rocas de dique

\begin{tabular}{|c|c|c|c|c|c|c|c|c|c|c|}
\hline IGM & 900998 & 900975 & 900986 & 900906 & 900951 & MIA-646A & 900969 & 900953 & 901011 & 901010 \\
\hline $\mathrm{Li}$ & 25 & 8,2 & 7,88 & 0,94 & 16 & 18 & 7,6 & 7,9 & 2,9 & 1,3 \\
\hline $\mathrm{Be}$ & 1,5 & 2,1 & 2,65 & 2,0 & 1,6 & 1,3 & 2,1 & 3,8 & 4,2 & 3,8 \\
\hline Sc & 25 & 2,1 & 5,84 & 4,3 & 28 & 24 & 6,1 & 5,4 & 3,6 & 6,6 \\
\hline $\mathrm{V}$ & 180 & 11 & 6,27 & 7,6 & 198 & 184 & 10 & 9,5 & 6,1 & 3,5 \\
\hline $\mathrm{Cr}$ & 138 & 6,5 & 2,43 & 1,6 & 99 & 103 & 3,5 & 5,4 & 2,4 & 0,76 \\
\hline $\mathrm{Mn}$ & 1793 & 287 & 339,10 & 200 & 1048 & 1153 & & 225 & 171 & 183 \\
\hline Co & 28 & 12 & 14 & 22 & 34 & 26 & 16 & 10 & 11 & 9,0 \\
\hline $\mathrm{Ni}$ & 111 & 3,7 & 1,9 & 1,635 & 63 & 45 & 3,8 & 3,7 & 1,1 & 1,2 \\
\hline $\mathrm{Cu}$ & 11 & 4,1 & 3,3 & 2,3 & 44 & 29 & 5,2 & 5,7 & 4,6 & 4,8 \\
\hline $\mathrm{Zn}$ & 134 & 15 & 18 & 15 & 91 & 87 & 27 & 109 & 11 & 6,9 \\
\hline $\mathrm{Ga}$ & 23 & 15 & 15 & 14 & 20 & 19 & 17 & 16 & 16 & 15 \\
\hline As & 2,1 & 0,91 & 0,53 & 1,2 & 1,5 & 2,0 & 1,8 & 1,4 & 0,74 & 1,2 \\
\hline $\mathrm{Rb}$ & 15 & 158 & 176 & 237 & 20 & 20 & 131 & 273 & 195 & 237 \\
\hline $\mathrm{Sr}$ & 887 & 213 & 66 & 85 & 501 & 436 & 173 & 67 & 19 & 36 \\
\hline$Y$ & 21 & & 11 & & 21 & 28 & & 21 & 12 & \\
\hline $\mathrm{Cd}$ & 0,17 & $<0,08$ & $<0,08$ & $<0,08$ & 0,15 & 0,15 & $<0,08$ & 0,20 & $<0,08$ & 0,19 \\
\hline In & 0,076 & 0,010 & 0,025 & 0,011 & 0,064 & 0,071 & 0,012 & 0,0057 & 0,012 & 0,050 \\
\hline Cs & 0,16 & 1,7 & 2,0 & 1,2 & 0,31 & 0,26 & 0,68 & 2,8 & 2,1 & 3,3 \\
\hline $\mathrm{Ba}$ & 149 & 2300 & 242 & 457 & 389 & 392 & 2051 & 231 & 40 & 142 \\
\hline $\mathrm{La}$ & 19 & 27 & 15 & 23 & 18 & 34 & 34 & 27 & 11 & 12 \\
\hline $\mathrm{Ce}$ & 43 & 39 & 23 & 45 & 39 & 74 & 68 & 48 & 22 & 22 \\
\hline $\mathrm{Pr}$ & 5,9 & 3,3 & 2,8 & 5,3 & 5,0 & 9,8 & 8,0 & 8,0 & 2,9 & 2,7 \\
\hline $\mathrm{Nd}$ & 23 & 7,7 & 8,7 & 18 & 19 & 39 & 28 & 27 & 11 & 7,7 \\
\hline $\mathrm{Sm}$ & 5,4 & 1,0 & 1,4 & 4,1 & 4,5 & 7,9 & 5,3 & 6,6 & 2,0 & 1,5 \\
\hline $\mathrm{Eu}$ & 1,6 & 1,5 & 0,38 & 0,7 & 1,6 & 2,3 & 1,8 & 0,68 & 0,32 & 0,17 \\
\hline $\mathrm{Gd}$ & 5,3 & 1,1 & 1,4 & 3,052 & 4,3 & 7,4 & 4,0 & 5,5 & 1,8 & 1,2 \\
\hline $\mathrm{Tb}$ & 0,81 & 0,16 & 0,20 & 0,71 & 0,70 & 1,1 & 0,80 & 0,77 & 0,28 & 0,23 \\
\hline Dy & 4,2 & 0,65 & 1,2 & 3,9 & 4,0 & 5,6 & 3,8 & 3,9 & 1,5 & 1,3 \\
\hline $\mathrm{Ho}$ & 0,84 & 0,15 & 0,27 & 0,79 & 0,81 & 1,1 & 0,78 & 0,74 & 0,33 & 0,35 \\
\hline $\mathrm{Er}$ & 2,3 & 0,54 & 0,99 & 2,5 & 2,3 & 3,2 & 2,3 & 2,3 & 1,1 & 1,3 \\
\hline $\mathrm{Tm}$ & 0,28 & 0,08 & 0,17 & 0,34 & 0,31 & 0,42 & 0,31 & 0,32 & 0,18 & 0,24 \\
\hline $\mathrm{Yb}$ & 1,7 & 0,67 & 1,4 & 2,2 & 2,1 & 2,6 & 2,1 & 2,2 & 1,4 & 1,8 \\
\hline $\mathrm{Lu}$ & 0,22 & 0,14 & 0,25 & 0,34 & 0,30 & 0,37 & 0,32 & 0,34 & 0,24 & 0,33 \\
\hline $\mathrm{TI}$ & 0,13 & 0,88 & 0,86 & 0,9 & 0,028 & 0,13 & 0,67 & 1,4 & 0,92 & 1,7 \\
\hline $\mathrm{Pb}$ & 7,4 & 13 & 24 & 25 & 4,7 & 5,1 & 14 & 28 & 27 & 17 \\
\hline $\mathrm{Bi}$ & 0,15 & $<0,05$ & $<0,05$ & $<0,05$ & $<0,05$ & $<0,05$ & $<0,05$ & $<0,05$ & $<0,05$ & 0,10 \\
\hline Th & 0,62 & 13 & 14 & 14 & 1,8 & 1,5 & 15 & 24 & 23 & 25 \\
\hline U & 0,47 & 2,0 & 3,4 & 3,1 & 0,42 & 1,8 & 2,0 & 7,6 & 3,1 & 4,6 \\
\hline $\mathrm{Zr}$ & 151 & 75 & 59 & 64 & 178 & 287 & 123 & 71 & 34 & 69 \\
\hline $\mathrm{Nb}$ & 6 & 6 & 13 & 6 & 12 & 16 & 15 & 22 & 18 & 22 \\
\hline W & 21 & 39 & 58 & 81 & 9 & 15 & 60 & 48 & 43 & 35 \\
\hline
\end{tabular}

Los monzogranitos (900971, 900985, 900990, 900973, 900974 y 1 0VDL54) muestran valores de hasta cien veces el condrito y valores de $\mathrm{Eu} / \mathrm{Eu}^{*}$ entre 0,51 y 0,97, que ponen en evidencia una anomalía negativa de Eu más fuerte que en las rocas granodioríticas, posiblemente como producto de la cristalización de plagioclasa (Winter, 2014).

De acuerdo con los valores de $\mathrm{La}_{\mathrm{N}}$, se distinguen dos patrones; sin embargo, las signaturas entre ellos tienden a ser paralelas hacia los HREE y no se observa diferenciación en la distribución geográfica dentro de la uni- dad. Las rocas 900973, 900990 y 900971 tienen $\mathrm{La}_{\mathrm{N}}$ entre 123,97 y 149,51, mientras que las rocas 900985

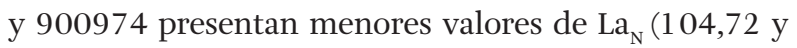
89,96 , respectivamente) y mayor anomalía negativa de Eu (figura 22), que podría estar relacionada con la cristalización fraccionada de plagioclasa. La roca 10VDL54 presenta una anomalía negativa del Eu aún más marcada, y en el comportamiento de los HREE se aparta del resto de las rocas, pues muestra mayores contenidos en un patrón plano. 


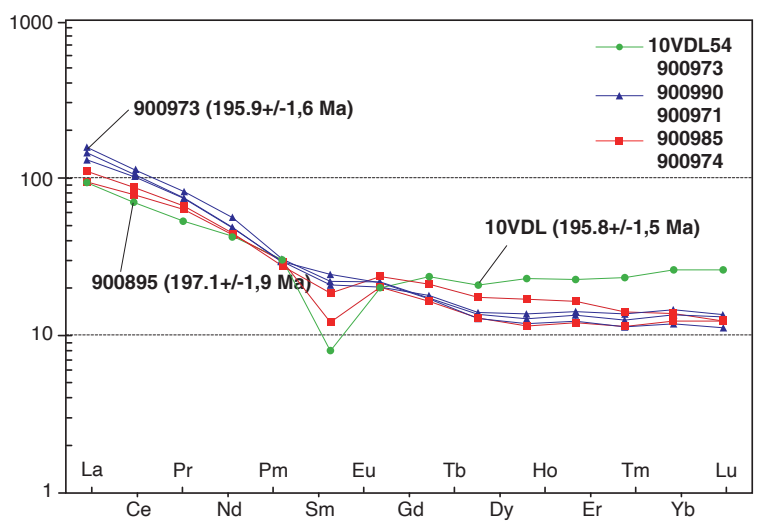

Figura 22. Diagrama REE correspondiente a rocas de la facies monzograníticas normalizado a condrito (McDonough y Sun, 1995)

En el diagrama de REE, las rocas de diques muestran al menos dos patrones (figura 23, patrones en verde y azul), con valores del condrito de ochenta a más de cien veces mayores en las rocas de la composición básica (andesitas y microdioritas). Con una edad asociada de 1 89,6 $\pm 1,4 \mathrm{Ma}$, las rocas se comportan paralelas entre ellas, $\mathrm{y}$ decaen progresivamente hacia la HREE, donde se cruza el patrón de las rocas ácidas. La roca 900969 exhibe una anomalía negativa en Eu.

Los diques de monzogranitos y riolitas muestran valores menores de ochenta veces el condrito; hacia las MREE tienen un comportamiento cóncavo, al tiempo que aumenta la concentración de HREE, posiblemente por la ausencia de anfíbol y la presencia de granate residual. La roca 900906 presenta anomalía negativa en Eu asociada a la cristalización de plagioclasa (Winter, 2014).

En los diagramas multielementales (o arañagramas) normalizados con respecto a los NMORB (Sun y McDonough, 1989) se presentan los patrones comparativos de las granodioritas y los monzogranitos (figura 24 A y B) del Monzogranito de Rionegro. En general, ambas fa-

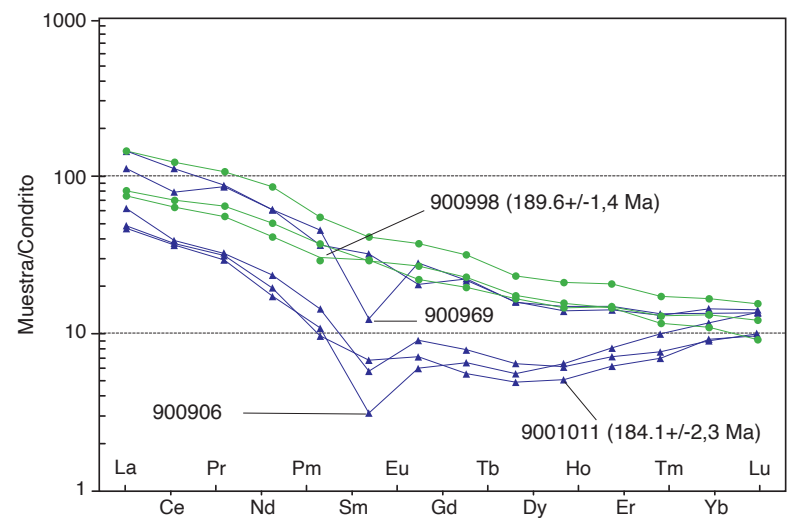

Figura 23. Diagrama REE correspondiente a rocas de diques normalizado a condrito. En verde, diques de composición andesítica-microdiorítica, y en azul, diques de composición granítica y riolítica.

Fuente: McDonough y Sun (1995) y este trabajo

cies muestran enriquecimientos en las LILE (Cs, Rb, Ba) y empobrecimientos hacia las HFSE (Ti, P), valores altos de $\mathrm{Ba}, \mathrm{K}$ y $\mathrm{Pb}$ y anomalías negativas de $\mathrm{P}$, Ti y Nb, asociadas con la insolubilidad de estos elementos ante fluidos hidratados que migran por la placa subducente (Best, 2003).

Las rocas monzograníticas muestran mayor dispersión en los elementos más móviles (Cs, Rb, Ba). Se observa que la roca IGM 900985 se aleja del patrón común de estas rocas, pues presenta valores bajos de los LILE y no exhibe un enriquecimiento en $\mathrm{K}$.

Los diques de composición ácida (monzogranitos y riolitas) tienen valores mayores de cien veces el condrito, y anomalía negativa de Ba, salvo la roca 900951, que muestra concentraciones menores de Cs y Rb. Hay fuertes anomalías negativas de $\mathrm{Nb}, \mathrm{La}, \mathrm{Ce}$, Sr y Ti y concentraciones mayores de Th, U, K y Pb (figura 25).

Por su parte, los diques de andesitas y microdioritas (en verde) tienen valores menores de cien veces el condrito, muestran ligeros empobrecimientos en Th, Nb, La, Ce y un tren continuo decreciente hacia las HREE (figura 25). 

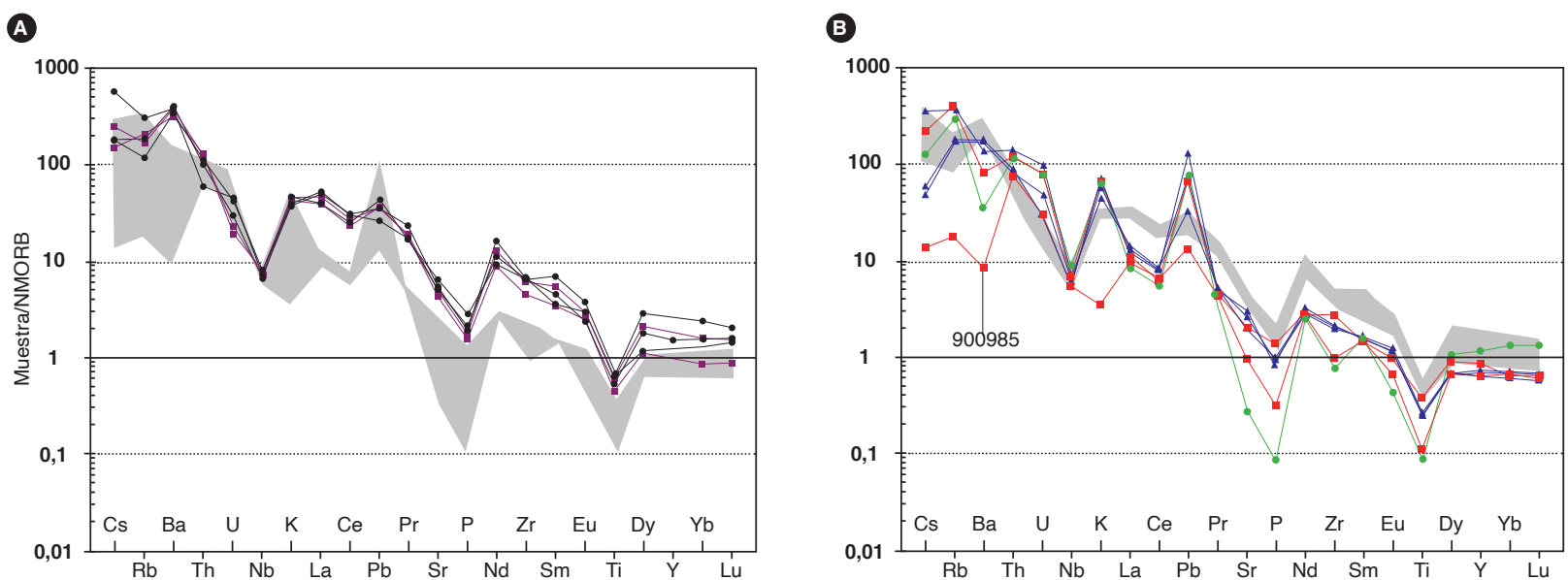

Figura 24. Diagramas multielementales (o arañagramas) normalizados con respecto a los NMORB (Sun y McDonough, 1989) correspondientes a rocas del Monzogranito de Rionegro. A) Rocas granodioríticas; en gris, patrón comparativo de las rocas monzograníticas. B) Rocas monzograníticas y tren comparativo, en gris, de las rocas granodioríticas

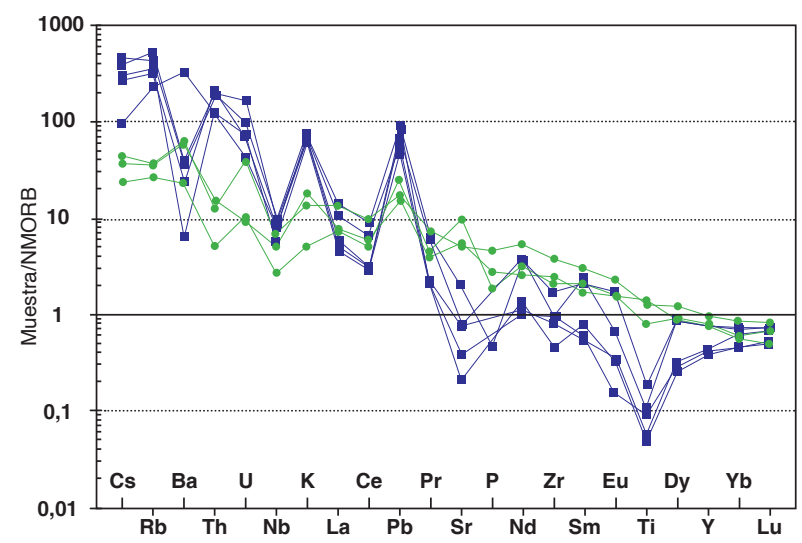

Figura 25. Diagrama NMORB correspondiente a rocas de dique del Monzogranito de Rionegro

\subsection{Discriminación de ambiente tectónico}

En los diagramas de Pearce (2008) y Harris et al. (1986) (figura 26), las rocas y diques se proyectan en el ambiente de arcos volcánicos. Las rocas graníticas y diques ácidos se concentran en un tren paralelo por encima de la zona MORB-OIB, en el campo asociado a zonas de subducción relacionadas con márgenes continentales. Cerca de la zona MORB-OIB se localizan rocas de diques básicos. La variación de patrones en las facies granodiorítica y monzogranítica y en los diferentes diques sugiere una posible generación de varios pulsos que en conjunto tienen una firma geoquímica predominantemente calcoalcalina alta en $\mathrm{K}$.
En los diagramas de Whalen et al. (1987) (figura 27A) y Chappell y White (1974) (figura 27B) las rocas se agrupan en los campos de magmas de tipo I. En el diagrama de Frost et al. (2001) (figura 27C) las muestras se localizan en el límite entre los grupos de magmas magnesianos y ferrosos; sin embargo, hay mayor afinidad del Monzogranito de Rionegro con los magmas de tipo magnesiano. Este tipo de magmas presentan una composición general calcoalcalina entre el rango de rocas tonalitas-granodioritas-granitos, entre las series metaluminosa y peraluminosa, están asociados a arcos y ambientes de poscolisión y se relacionan con un origen derivado de la fusión parcial de la corteza continental bajo condiciones oxidantes (Frost y Frost, 2008). 

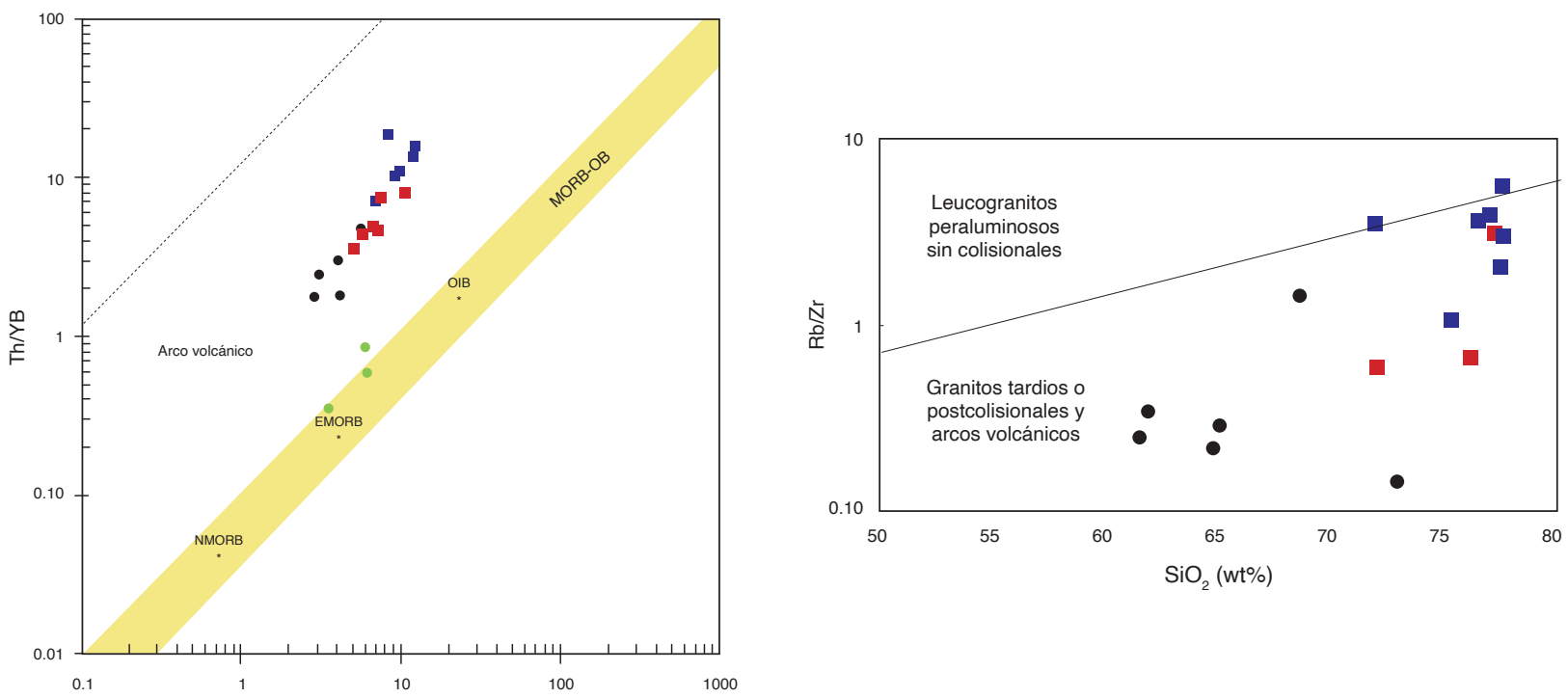

Figura 26. Discriminación de ambiente geotectónico correspondiente al Monzogranito de Rionegro. Símbolos como en la figura 17. A) Diagrama de discriminación tectónica de Pearce (2008). B) Diagrama de Harris et al. (1986)

A

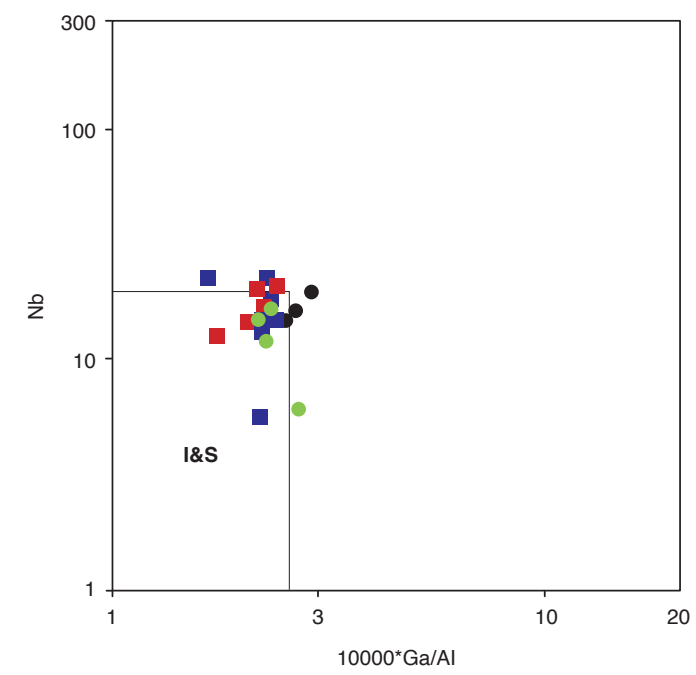

B

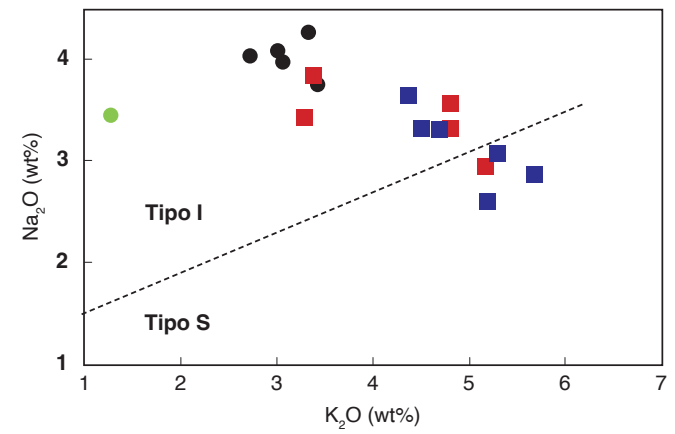

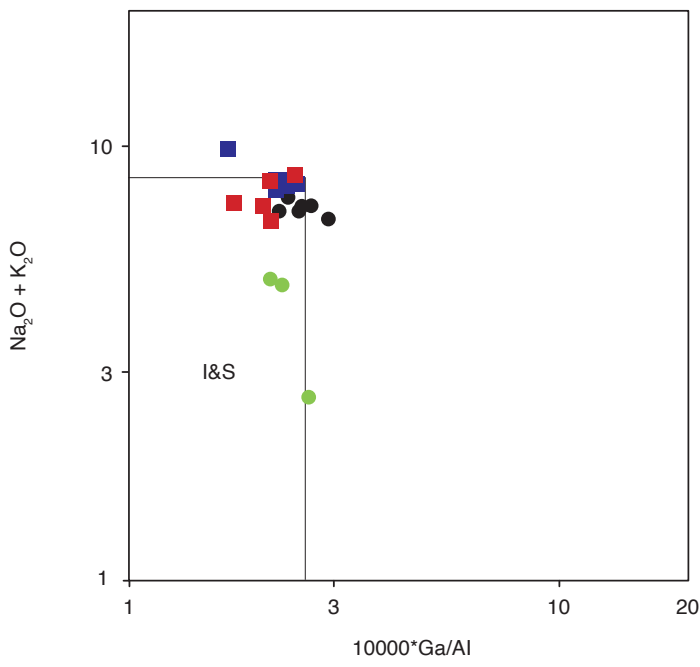

C

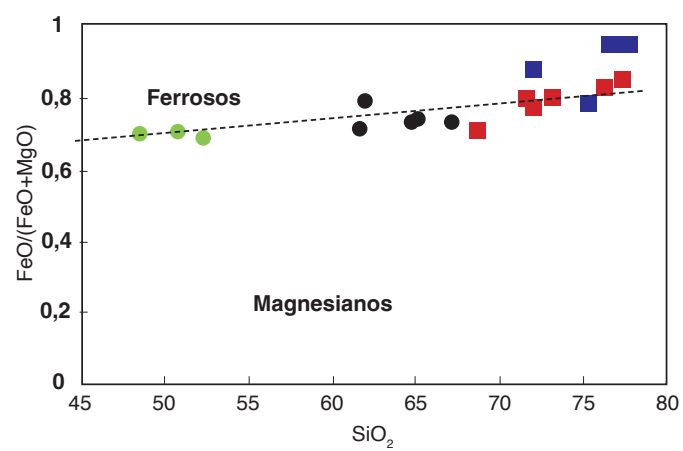

Figura 27. Diagramas discriminantes del tipo de granito correspondiente al Monzogranito de Rionegro. A) Diagrama de Whalen et al. (1987). B) Diagrama de Chappell y White (1974) (granitos tipo I, S, A). C) Diagrama de Frost et al. (2001) de discriminación de granitoides tipo I y S. D) Diagrama de Frost y Frost (2008) 


\section{Edad}

En el presente trabajo se realizaron nueve dataciones isotópicas U-Pb en circón del Monzogranito de Rionegro y diques asociados (tabla 11), en conjunto con los laboratorios de estudios isotópicos del Centro de Geociencias de la Universidad Nacional Autónoma de México (UNAM) y el Laboratorio de Ablación Láser del Servicio Geológico Colombiano, en Bogotá. La concentración de minerales pesados, separación de la fracción no magnética y selección de los circones se realizó en el Laboratorio Químico del Servicio Geológico Colombiano, sede Medellín, donde además se realizó el montaje de las probetas en la resina epóxica y el pulido de cristales de las muestras enviadas al Laboratorio de Ablación Láser del Servicio Geológico Colombiano.

En los trabajos de cartografía de las planchas 86 y 109 se correlacionan dos cuerpos de granodioritas asociadas al Monzogranito de Rionegro (Arias y Vargas, 1978; Ward et al., 1973); sin embargo, Van der Lelij (2013) reporta edades $\mathrm{U}-\mathrm{Pb}$ en circón en estas dos unidades: una edad de 443,4 $\pm 3,2$ Ma para el cuerpo de granodiorita expuesta en la plancha 86-Ábrego, y una edad de $196 \pm$ 1,1 Ma para el cuerpo de granodiorita cartografiado en la plancha 109, y muestra que se trata de cuerpos independientes sin relación alguna, por lo que en este trabajo los análisis petrográficos, químicos y geocronológicos de las facies granodioríticas se limitan a la unidad de la plancha 109, en cercanías del municipio de Rionegro.
Goldsmith et al. (1971) reporta dos dataciones por el método K-Ar, de $177 \pm 6$ Ma y $172 \pm 6$ Ma en rocas clasificadas como granodioritas porfiríticas localizadas unos $13 \mathrm{~km}$ hacia el noreste del municipio de Rionegro, en cercanías del municipio de Santa Cruz.

Por su parte, Daconte y Salinas (1980) asignan al Batolito de Rionegro un rango de edad Jurásico-Triásico, por correlación con otras rocas ígneas del Macizo de Santander en las que se identificó un evento térmico entre $198 \pm 8$ y $160 \pm 30 \mathrm{Ma}$.

Al sur del municipio de Ocaña, Van der Lelij (2013) obtuvo una edad U-Pb de 195,8 \pm 1,5 Ma en circón en un granito alcalino. Cerca del lugar de esta datación, Ordóñez Carmona (2001) obtuvo una edad isocrónica $\mathrm{Rb}$ Sr de $268 \pm 26 \mathrm{Ma}$, con una razón inicial de ${ }^{87} \mathrm{Sr} /{ }^{86} \mathrm{Sr}$ de $0,7007 \pm 0,003$, que, según el autor, no tiene validez geológica, porque la razón inicial tan baja de ${ }^{87} \mathrm{Sr} /{ }^{86} \mathrm{Sr}$ sugiere que la roca puede ser más joven que $268 \mathrm{Ma}$. Este autor también presentó los resultados de análisis isotópicos de los sistemas Nd y Sr de varias muestras del Batolito de Ocaña (tabla 12), con razones isotópicas iniciales calculadas para una edad de $268 \mathrm{Ma}$.

En el presente estudio se recalcularon las razones iniciales y los valores de $\varepsilon \mathrm{Nd}$ de las mismas muestras (tabla 13), tomando como base la edad de 196 Ma presentada por Van der Lelij (2013), que fue obtenida en una muestra ubicada al sureste de las muestras analizadas por Ordóñez Carmona (2001).

Tabla 11. Muestras del Monzogranito de Rionegro con análisis de geocronología

\begin{tabular}{|c|c|c|c|c|c|c|c|}
\hline IGM & N. campo & w & $\mathbf{N}$ & Localización & PL & Clasificación & Laboratorio \\
\hline \multicolumn{8}{|c|}{ Facies monzogranítica } \\
\hline \multirow[t]{2}{*}{900973} & GR-6743 & 1083832 & 1397462 & Ocaña-Ábrego & 86 & Monzogranito & UNAM \\
\hline & 10VDL54* & 1085710 & 1394475 & Ocaña & 86 & Granito alcalino & \\
\hline \multicolumn{8}{|c|}{ Facies granodiorítica } \\
\hline 900985 & GZ-6848A & 1094479 & 1337675 & Vía Primavera-Cáchira & 97 & Granodiorita & SGC \\
\hline \multirow[t]{2}{*}{ Saprolito } & JGB-462 & 1105322 & 1287011 & Rionegro, Qda. La Pajuda & 109 & Cuarzomonzonita & UNAM \\
\hline & 10VDL59* & 1102855 & 1297665 & Rionegro & 109 & Tonalita & \\
\hline 900952 & MIA-648B & 1104858 & 1301287 & Rionegro, vereda Valparaíso & 109 & Granodiorita & SGC \\
\hline \multicolumn{8}{|c|}{ Diques } \\
\hline 900951 & MIA-648A & 1104858 & 1301286 & Rionegro, vereda Valparaíso & 109 & Riolita porfídica & SGC \\
\hline 901011 & MIA-650B & 1099016 & 1313298 & Rionegro, vía Las Rocas & 109 & Sienogranito & UNAM \\
\hline Saprolito & MIA-657A & 1077093 & 1408339 & Ocaña-Río de Oro & 76 & Microdiorita & SGC \\
\hline 900998 & LMC-082 & 1087835 & 1343412 & Rionegro, vereda Pueblo Nuevo & 97 & Dique diorita & SGC \\
\hline \multicolumn{8}{|c|}{ Unidad diorita } \\
\hline 900999 & LMC-084 & 1088409 & 1339422 & Rionegro, vereda Pueblo Nuevo & 97 & Granodiorita con $\mathrm{Hbl}$ & SGC \\
\hline
\end{tabular}

* Van Der Lelij (2013) 
Tabla 12. Resultados isotópicos Rb-Sr y Sm-Nd de las rocas del Batolito de Ocaña

\begin{tabular}{|c|c|c|c|c|c|c|c|c|c|}
\hline Muestra & $143 \mathrm{Nd} / 144 \mathrm{Nd}$ & $147 \mathrm{Sm} / 144 \mathrm{Nd}$ & ECHUR(o) & $\operatorname{ECHUR}(\mathrm{T})$ & TDM(Ma) & $\mathrm{T}(\mathrm{Ma})$ & $87 \mathrm{Sr} / 86 \mathrm{Sr}$ & $87 \mathrm{Rb} / 86 \mathrm{Sr}$ & RiSr \\
\hline \multicolumn{10}{|c|}{ Batolito de Ocaña } \\
\hline BOC-1 & 0,512341 & 0,1291 & $-5,79$ & $-3,48$ & 1255 & 268 & 0,73750 & 9,6723 & 0,70062 \\
\hline BOC-2 & 0,512318 & 0,1264 & $-6,24$ & $-3,84$ & 1256 & 268 & 0,72874 & 7,4091 & 0,70049 \\
\hline BOC-3 & 0,512274 & 0,1222 & $-7,10$ & $-4,55$ & 1271 & 268 & 0,73118 & 7,8942 & 0,70108 \\
\hline BOC-4 & 0,512292 & 0,1186 & $-6,75$ & $-4,08$ & 1196 & 268 & 0,72917 & 7,4416 & 0,70080 \\
\hline
\end{tabular}

Fuente: Carmona (2001) y este trabajo

Tabla 13. Valores de ECHUR (T) y RiSr correspondientes a muestras de la tabla anterior recalculados a $196 \mathrm{Ma}$

\begin{tabular}{ccccccccccc}
\hline Muestra & 143Nd/144Nd & 147Sm/144Nd & ECHUR(o) & ECHUR(T) & TDM(Ma) & T (Ma) & 87Sr/86Sr & 87Rb/86Sr & RiSr \\
\hline BOC-1 & 0,512341 & 0,1291 & $-5,79$ & $-4,10$ & 1255 & 196 & 0,73750 & 9,6723 \\
\hline BOC-2 & 0,512318 & 0,1264 & $-6,24$ & $-4,49$ & 1256 & 196 & 0,72874 & 7,4091 & 0,70809 \\
\hline BOC-3 & 0,512274 & 0,1222 & $-7,10$ & $-5,24$ & 1271 & 196 & 0,73118 & 7,8942 & 0,70918 \\
\hline BOC-4 & 0,512292 & 0,1186 & $-6,75$ & $-4,80$ & 1196 & 196 & 0,72917 & 7,4416 & 0,70843 \\
\hline
\end{tabular}

Los valores de $\varepsilon N d$ a 196 Ma varían levemente con relación a los calculados con 268 Ma, haciéndose un poco más negativos, mientras que las razones iniciales de ${ }^{87} \mathrm{Sr} /{ }^{86} \mathrm{Sr}$ se incrementan significativamente, mostrando valores altos de esta razón, entre 0,70843 y 0,71054 a $196 \mathrm{Ma}$. Estas características isotópicas de Nd y Sr sugieren gran aporte de material cortical en los magmas a partir de los cuales cristalizaron las rocas de Batolito de Ocaña. Los valores recalculados de la razón inicial de Sr a 196 Ma confirman la interpretación realizada por Ordóñez Carmona (2001) de que las rocas podrían tener una edad menor de 268 Ma.

Las mediciones isotópicas y de elementos traza elaboradas en el Laboratorio de Estudios Isotópicos del Centro de Geociencias de la UNAM se lograron por medio de un espectrómetro de masa con plasma inductivamente acoplado (LA-ICPMS), siguiendo los procedimientos de Pérez et al. (2010). En el Laboratorio de Ablación Láser del Servicio Geológico Colombiano los análisis fueron realizados en un láser Photon Machines eximero de 193 nm y un espectrómetro ICP-MS Element 2. Los patrones de referencia utilizados fueron Plesovice, 91500 y M. Dromedry, y los resultados de ambos laboratorios se calcularon al 2 sigma absoluto (anexo 2).

Para la datación de las muestras, en primera instancia se realizó el análisis estadístico de los datos obtenidos teniendo en cuenta la relación $\left[{ }^{207} \mathrm{~Pb} /{ }^{235} \mathrm{U}\right)-\left({ }^{206} \mathrm{P}-\right.$ $\left.\left.\mathrm{b} /{ }^{238} \mathrm{U}\right)\right) /\left({ }^{207} \mathrm{~Pb} /{ }^{235} \mathrm{U}\right){ }^{*} 100$, con el fin de calcular valores concordantes en edades menores de $800 \mathrm{Ma}$. De esta manera se establecieron como parámetro de corte (cutoff) los cristales que en la mayoría de las muestras presentan dis- cordancia mayor del 10\% e incertidumbre mayor del 5\%. Los gráficos de concordia y edad promedio se elaboraron en el software Isoplot/Ex vers. 4.15 (Ludwig, 2008).

Bajo luz trasmitida, los circones presentan en general formas euhedrales a subeuhedrales. Predominan los cristales bipiramidales alargados, y algunos son prismáticos cortos, tienen tonalidades amarillo a incoloro y son poco frecuentes los que contienen inclusiones. Los tamaños de los cristales varían entre 80 y $120 \mu \mathrm{m}$, pero la mayoría son de alrededor de $100 \mu \mathrm{m}$. Bajo CL (figura 28), los circones exhiben buena luminiscencia; son comunes los zonamientos oscilatorios asociados con crecimientos magmáticos (Corfu et al., 2003), como se presenta en el punto 22 de la muestra MIA-657 A. Algunas zonaciones son interrumpidas por crecimientos más recientes. Algunos cristales muestran xenocristales o núcleos heredados de formas redondeadas y menos luminiscentes rodeados por zonamientos (punto 2 de la muestra GZ$6848 \mathrm{~A})$.

La muestra 900973 (GR-6743) es una roca de monzogranito colectada sobre la vía que conduce de Ábrego a Ocaña. Se tomaron 35 circones, de los cuales en el procesamiento de los datos fueron descartados tres análisis de circones con discordancias mayores del 10\% y errores mayores del $5 \%$, así que finalmente se trabajó con 32 análisis. El contenido de U está entre 62,8 y 630 ppm y de Th entre 64,8 y $1.240 \mathrm{ppm}$; la relación Th/U varía entre 0,61 y 1,94 . El diagrama de concordia (figura 29), muestra una concentración de análisis concordantes cerca de los $200 \mathrm{Ma}$, un circón discordante con una edad de 212,7 Ma y otro con una edad 230,9 Ma, posiblemente 
heredado. El diagrama de la media ponderada arroja una edad de 195,9 \pm 1,6 Ma con un MSWD = 4, considerada como la edad representativa de cristalización de la roca (figura 29).

La muestra 900985 (GZ-6848A) corresponde a una granodiorita tomada en el sector de la vereda La Primavera, sobre la vía hacia el municipio de Cáchira. Se analizaron 38 circones, de los cuales fueron retirados siete análisis por presentar valores de discordancia mayores del $10 \%$ y errores mayores del $5 \%$, así que finalmente se interpretaron 31 circones. Cinco de ellos reportan eda- des del Ordovícico (451 Ma), Neoproterozoico (877,9 y 993,40 Ma) y Mesoproterozoico (1.035,21 y $1.143,33$ $\mathrm{Ma}$ ), con relaciones menores de $\mathrm{Th} / \mathrm{U}$ entre 0,04 y 0,2

La mayoría de los circones son concordantes, se concentran en el rango de edades de 190 a $210 \mathrm{Ma}$ (figura 30) y muestran una relación de $\mathrm{Th} / \mathrm{U}$ mayor que los granos heredados (entre 0,55 a 2,8). En el diagrama del cálculo de la media por la desviación estándar, la edad promedio de cristalización es de 196,6 $\pm 2,1 \mathrm{Ma}$, con un MSWD de 2,7 (figura 30).

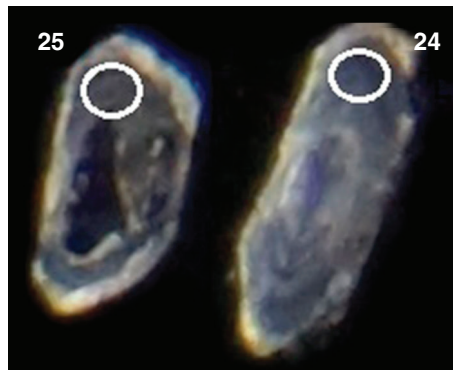

GR-6743

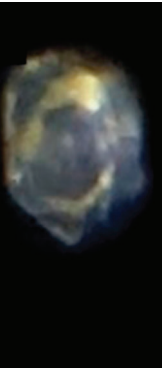

GZ-6848 A

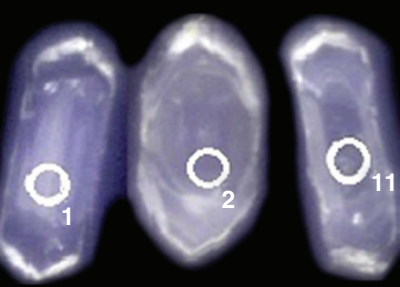

MIA-648 B
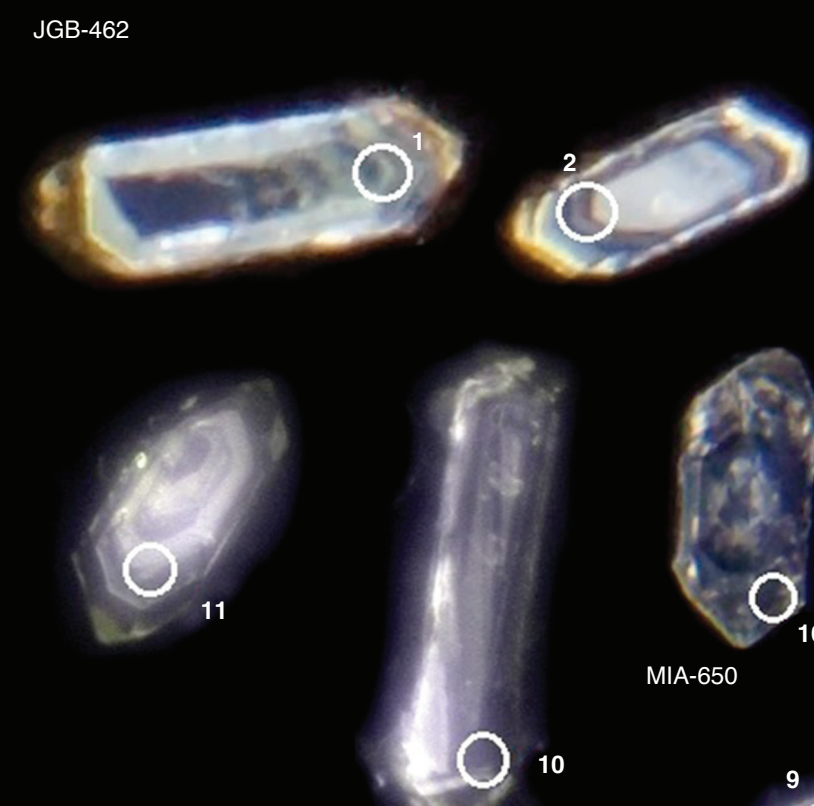

10

MIA-648 A

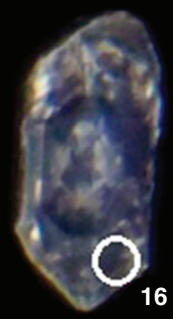

MIA-650

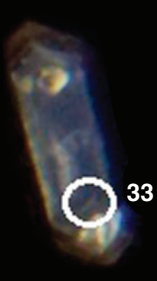

33

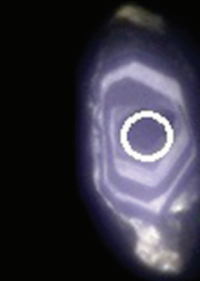

MIA-657 A
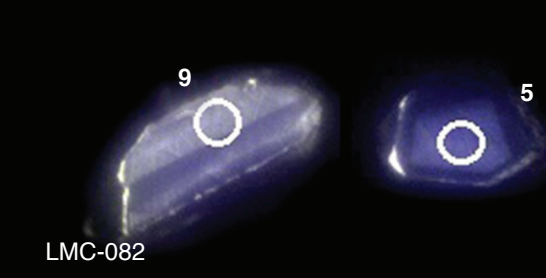

Figura 28. Imágenes de catodoluminiscencia $(\mathrm{CL})$ correspondientes a diferentes muestras de circones de rocas del Monzogranito de Rionegro y diques Se muestra la estructura concéntrica de los circones, la forma prismática y los puntos de ablación. 
A

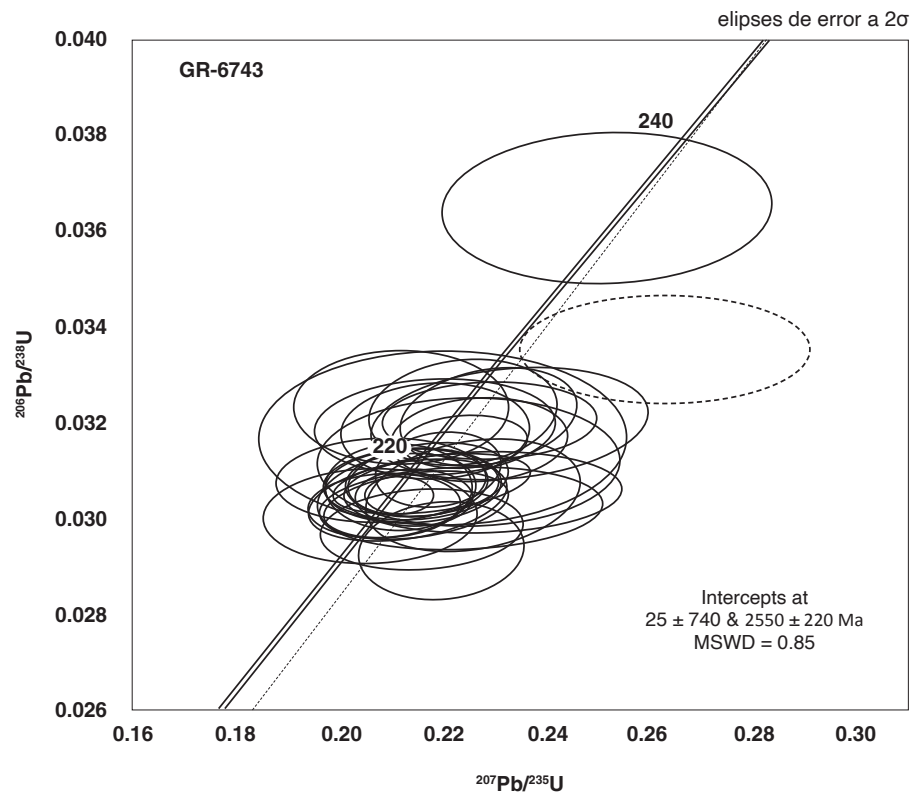

B

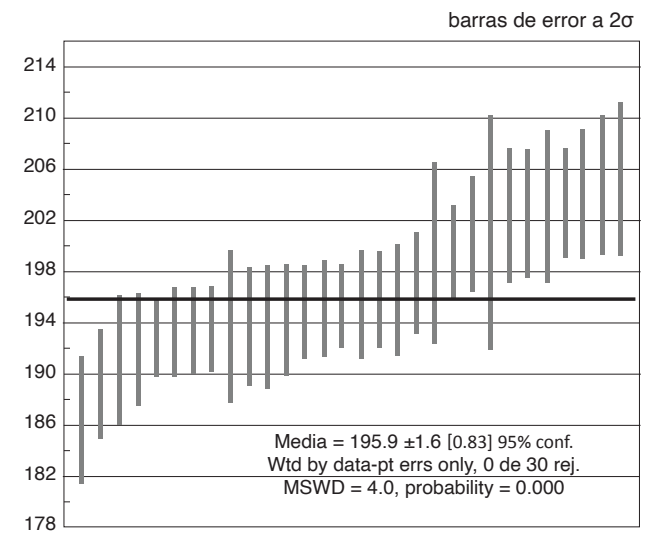

C

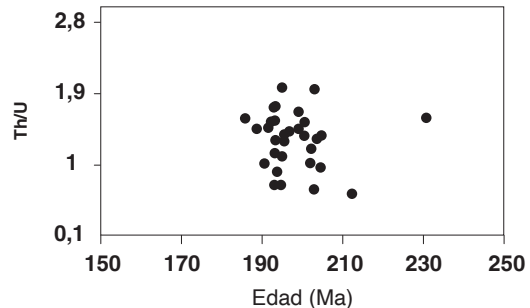

Figura 29. Edad de la Muestra 900973 (GR-6743). A) Diagrama de concordia correspondiente a la muestra B) Edad promedio ponderada. C) Gráfico de relación Th/U vs. edad

(A)

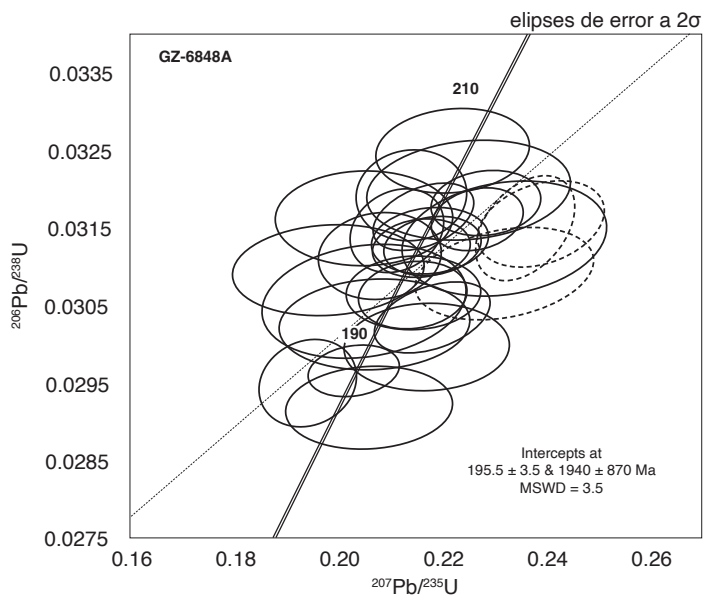

C

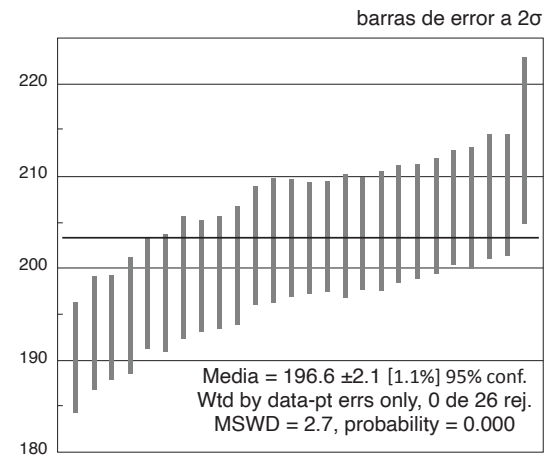

B

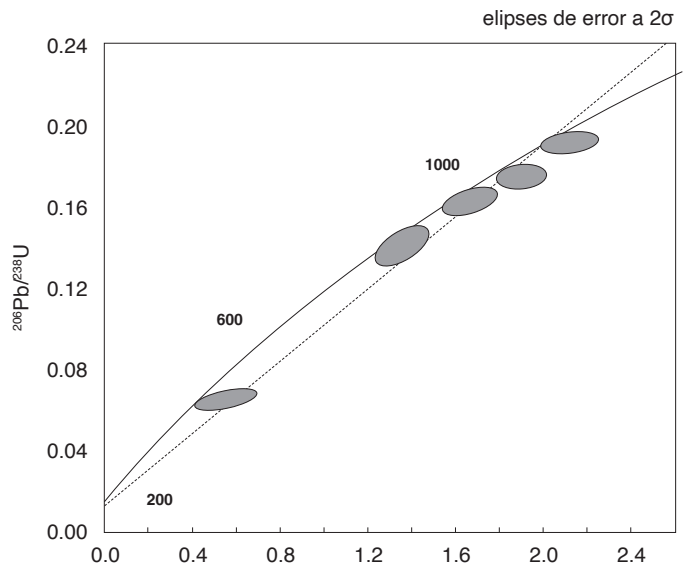

(D)

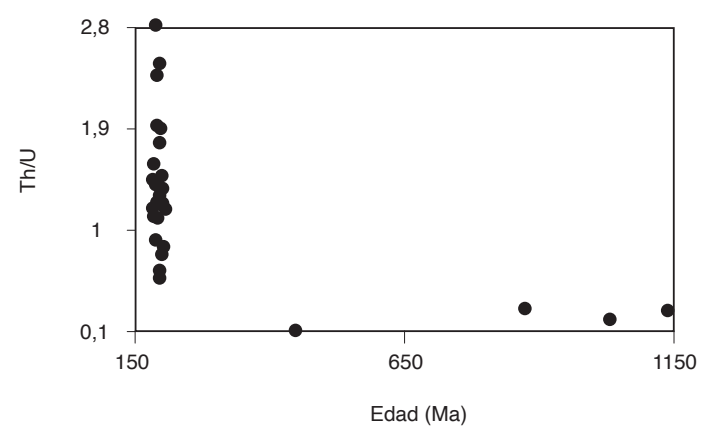

Figura 30. Edad de la muestra 900985 (GZ-6848A). A) Diagrama de concordia. B) Gráfico de concordia correspondiente a la muestra GZ-6848A. C) Edad promedio ponderada de la muestra GZ-6848A. D) Gráfico de relación Th/U vs. edad correspondiente a la muestra GZ-6848A 
La muestra JGB-462 corresponde a un saprolito de cuarzomonzonita colectado sobre la vía Bucaramanga-Rionegro, cerca de la escuela San Cayetano. Fueron seleccionados 35 circones, de los cuales ocho fueron retirados durante el procesamiento de los datos por presentar discordancias mayores del 10\% y errores que superaban el 5\%. Los 27 circones restantes se concentraron de manera concordante en la curva de Wetherill, en un rango de edad de entre 187 y 205 Ma (figura 31). Tienen concentraciones de U entre 53 y 1.021 , y Th entre 66 y 858 ; presentan relaciones $\mathrm{Th} / \mathrm{U}$ entre 0,62 y 3,1. El diagrama del cálculo de la media muestra una edad promedio de cristalización de 197,2 \pm 1,5 Ma, con un MSWD de 3 .

Para constituir la muestra MIA-648B, colectada en la vereda Valparaíso, municipio de Rionegro, fueron seleccionados 64 circones, de los cuales 50 tienen valores de discordancia menor del $15 \%$ y errores menores del $5,6 \%$. Las edades arrojadas por los circones varían entre 197 y $320 \mathrm{Ma}$; la edad promedio ponderada que arroja la muestra 900952 (MIA-648B), clasificada como granodiorita, es de 21 4,5 $\pm 2,7 \mathrm{Ma}(\mathrm{n}=44)$, con MSWD de 1,15, que se considera de cristalización de esta roca, aunque el gráfico de densidad de probabilidad forma dos picos; el primero de ellos corresponde a una edad promedio de 207,3 $\pm 1,6 \mathrm{Ma}(\mathrm{n}=23)$, con un MSWD de 0,67, que podría corresponder a la edad ponderada final de cristalización de la roca; el segundo pico arroja una edad ponderada de 221,8 $\pm 2,0(n=23)$, con MSWD de 1,19, que podría tomarse como la edad promedio ponderada de inicio de cristalización de los núcleos de circón. Seis circones reportan edades del Triásico Medio a Inferior, que corresponden a núcleos heredados (238 a $249 \mathrm{Ma})$, dos $(\mathrm{n}=2)$ del Pérmico (267 y $288 \mathrm{Ma})$ y uno $(\mathrm{n}=1)$ del Carbonífero (320 Ma). Solo un análisis presenta relación $\mathrm{Th} / \mathrm{U}<0,1$ y arrojó una edad de 223,8 Ma, mientras que la relación Th/U de los datos que definen la edad están entre 0,7 y 2,2 (figura 32).
A

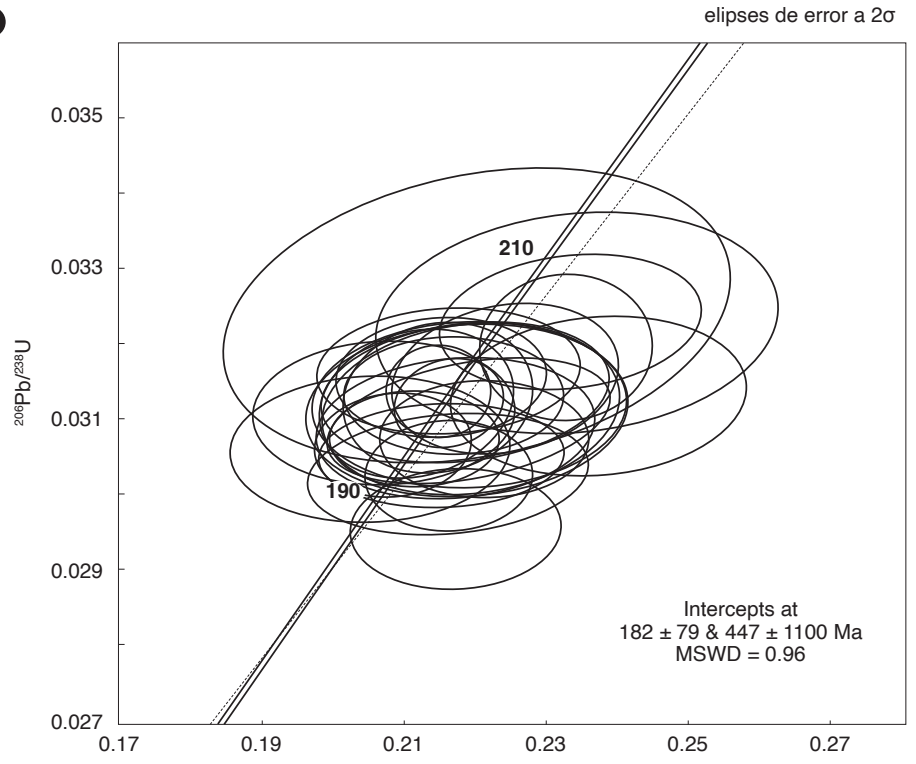

B

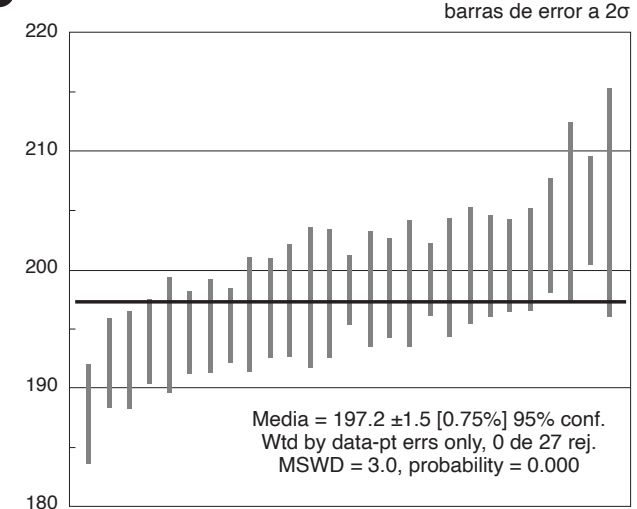

C

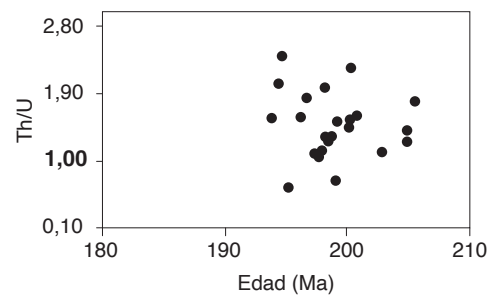

Figura 31. Edad de la muestra JGB-462. A) Diagrama de concordia. B) Diagrama del cálculo de la edad promedio ponderada correspondiente a la muestra JGB-462. C) Gráfico de relación Th/U vs. edad correspondiente a la muestra JGB-462 

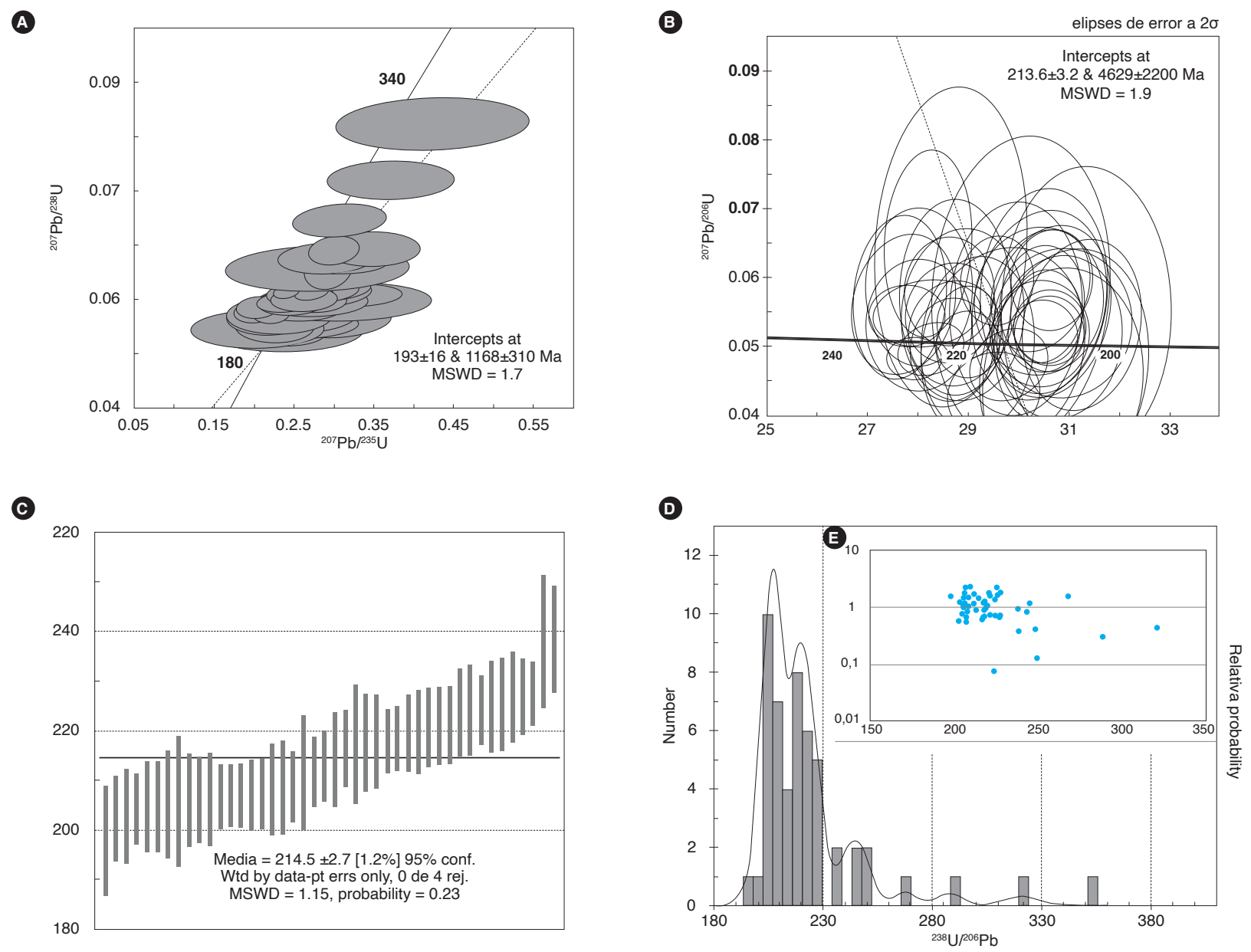

Figura 32. Edad de la muestra MIA-648B (granodiorita). A) Gráfico de concordia. B) Gráfico Tera-Wasserburg correspondiente a la muestra MIA-648B (granodiorita). C) Edad promedio ponderada correspondiente a la muestra MIA-648B (granodiorita). D) Histograma de densidad de probabilidad correspondiente a la muestra MIA-648B (granodiorita). E) Gráfico de relación Th/U vs. edad

Observando las edades individuales obtenidas por $\mathrm{U}-\mathrm{Pb}$ en circón de todas las rocas y el saprolito, queda en evidencia que las edades más antiguas corresponden a la facies granodiorita $(900985,900973$, JGB-462 y 900952), mientras que la facies monzogranito (900973) tiene una edad ligeramente más joven.

La muestra 900951 (MIA-648A) corresponde a una roca de dique clasificada como riolita porfídica, que se encuentra atravesando la granodiorita (900952-MIA648B). Se separaron 47 cristales de circón, de los cuales nueve presentaban errores mayores del $5 \%$ y discordancias mayores del $10 \%$. Los circones restantes muestran relaciones $\mathrm{Th} / \mathrm{U}$ entre 0,82 a 2,48, y se concentran en el rango de edad entre 180 y $210 \mathrm{Ma}$ (figura 33). Un circón arroja una edad mesoproterozoica de 1.021,67 Ma, con una relación $\mathrm{Th} / \mathrm{U}$ de 0,48 , y es interpretado como un cristal heredado. La edad media ponderada es de 194,5 $\pm 1,2 \mathrm{Ma}$, y se considera como edad de cristalización de esta roca, con MSWD de 0,95.

La roca 901011 (MIA-650B) corresponde a un dique de sienogranito tomado cerca de la escuela Las Rocas, en el municipio de Rionegro. Se separaron 35 circones, de los cuales seis fueron retirados por presentar discordancias y errores mayores del $10 \%$ y $5 \%$, respectivamente. Los resultados isotópicos arrojaron datos que muestran circones heredados $(n=3)$ concordantes a ligeramente discordantes, con edades neoproterozoicas de 924, 934 y $1.005 \mathrm{Ma}$ (figura 34) y relaciones $\mathrm{Th} / \mathrm{U}$ entre 1,10 y 1,60; una edad mesoproterozoica de $1.485 \mathrm{Ma}$ se registró en un circón discordante, con una relación Th/U de 1,33 y cantidades de U y Th muy altas (1.390 y $1.850 \mathrm{ppm})$. 
A

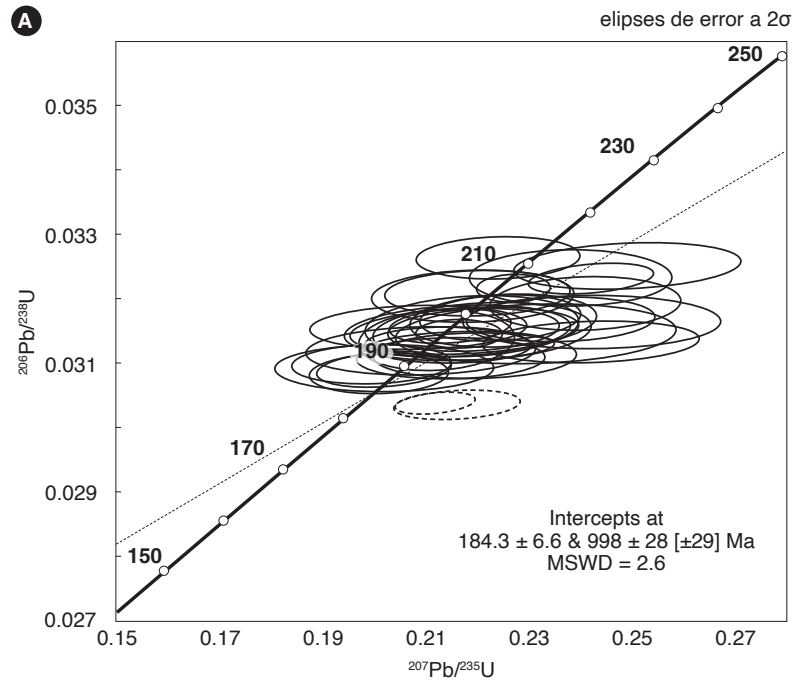

C

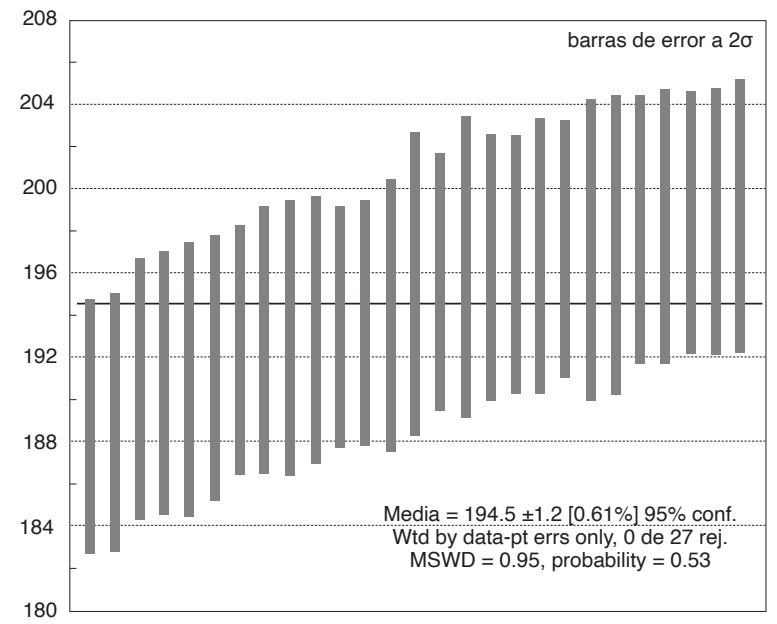

B

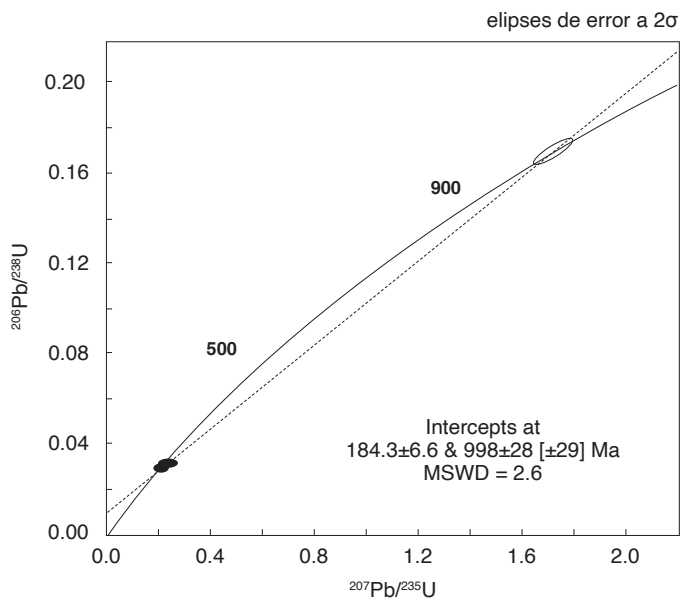

D

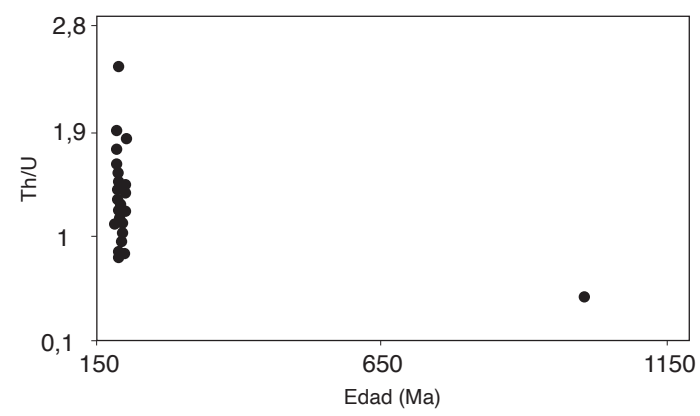

Figura 33. Edad de la la muestra 900951 (MIA-648A). A) Diagrama de concordia que detalla la edad. B) Gráfico de concordia. C) Edad promedio ponderada D) Gráfico de relación Th/U vs. edad

Asimismo, se observa una concentración de datos en el rango de 167 a $209 \mathrm{Ma}$, que se divide en dos poblaciones de circones: los más jóvenes $(n=5)$, con edades de $167,1,172,6,174,5,177,6$ y 177,7 Ma, y edades agrupadas $(\mathrm{n}=19)$ entre 182,2 y 196,2 Ma. Un circón presenta una edad de 209 Ma. La edad media ponderada de cristalización de la roca es de 184,1 × 2,3 Ma, con MSWD de 3,6.

En el saprolito de dique microdiorítico MIA-657A, tomado sobre la vía que de Rio de Oro conduce a Ocaña, se separaron 43 cristales de circón y se retiraron dos circones del procesamiento de datos por presentar discordancias mayores del 10\%. Los cristales, agrupados en un rango de edades situado entre 173,99 y 205,94 Ma, se comportan entre concordantes y discordantes, y tienen relaciones Th/U entre 0,78 y 4,35. Varios circones muestran concentraciones mayores de 1.000 ppm de U. La edad ponderada es de 186,7 $\pm 1,9 \mathrm{Ma}$, y el MSWD, de 5 (figura 35). 


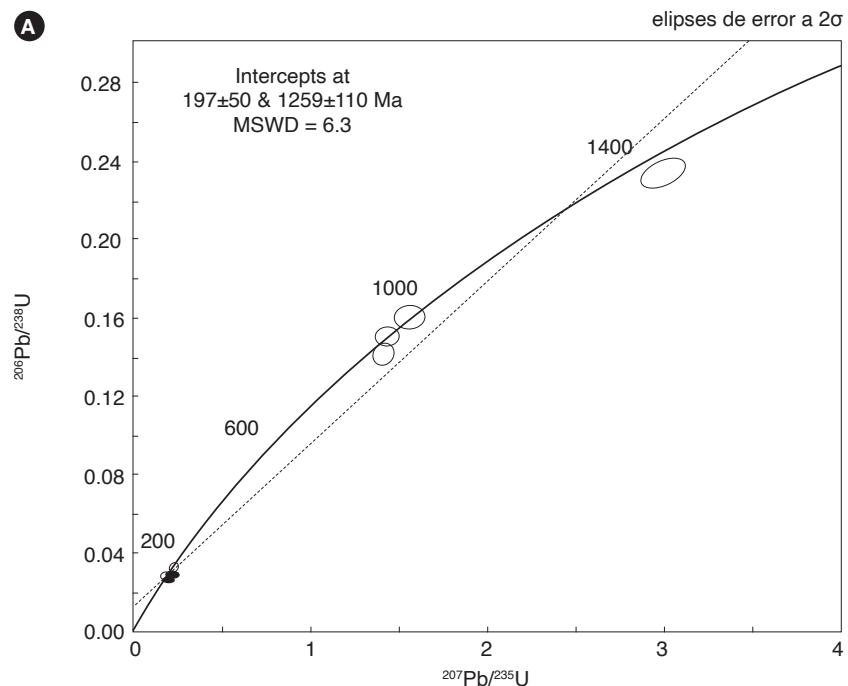

B
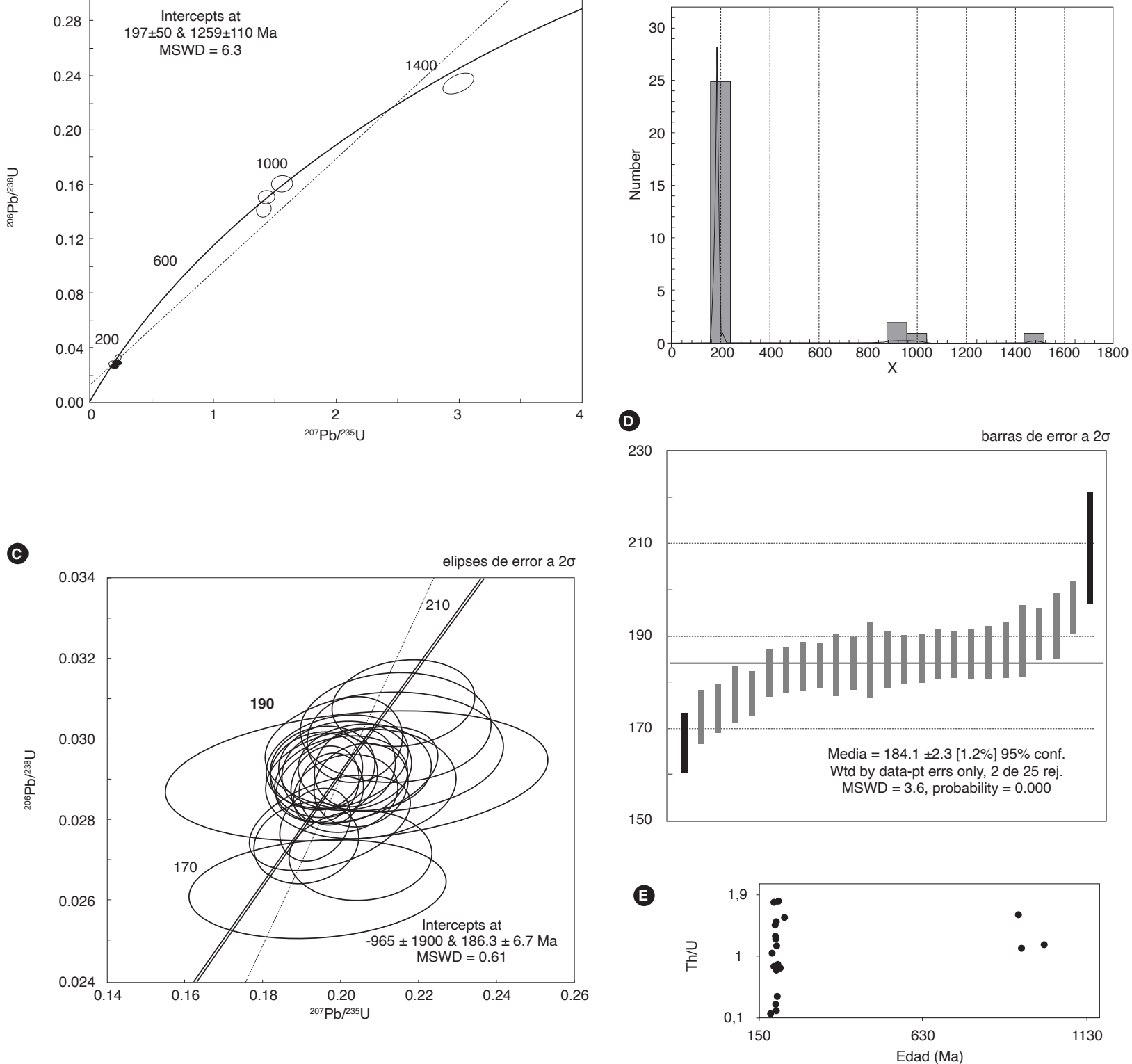

Figura 34. Edad de la muestra de dique 901011 (MIA-650B). A) Diagrama de concordia completo. B) Histograma de densidad de probabilidad C) Gráfico de concordia detallado. D) Edad promedio ponderada. E) Gráfico de relación Th/U vs. edad 

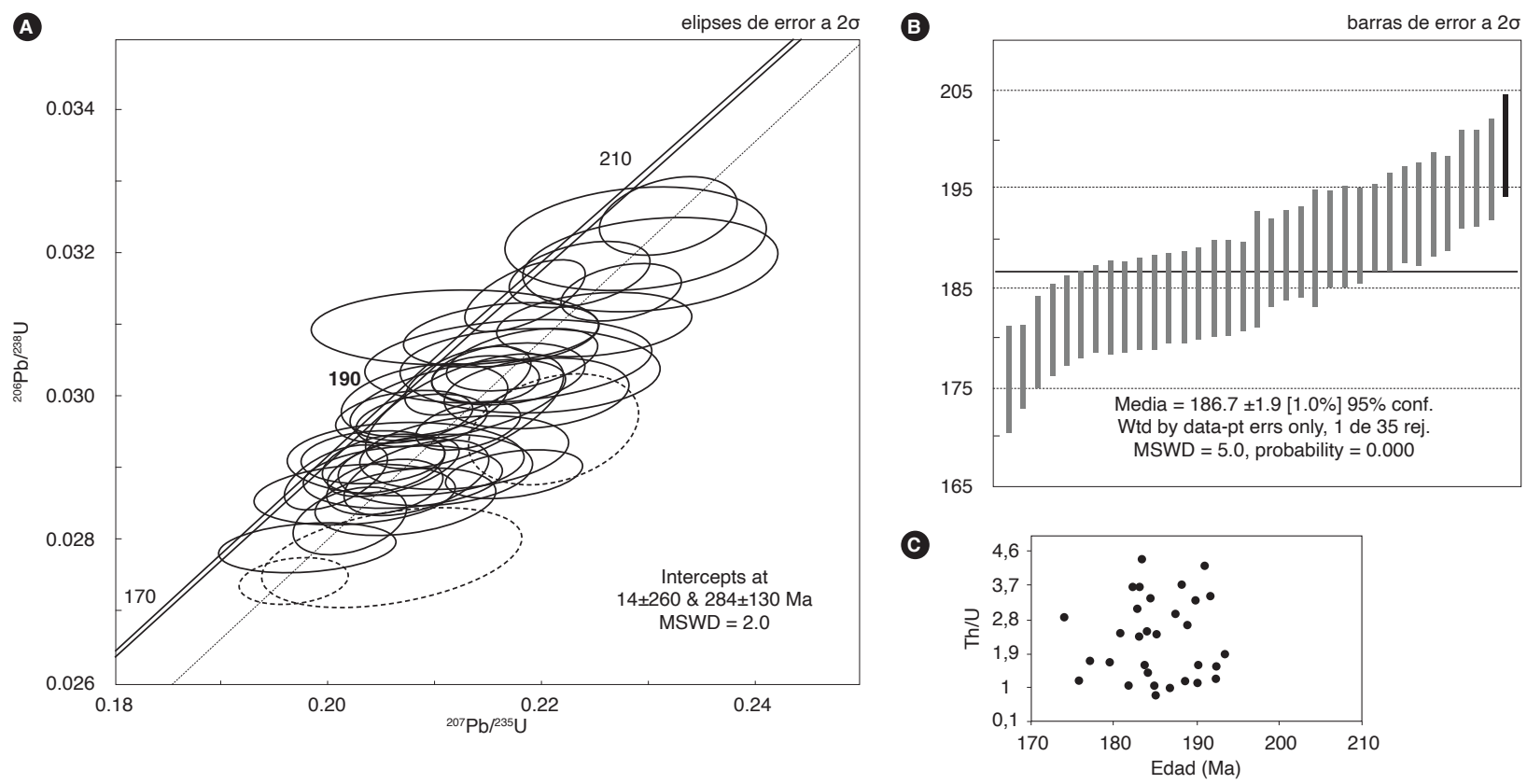

Figura 35. Edad de la muestra de dique MIA-657 ${ }^{\text {a }}$ A) Diagrama de concordia. B) Diagrama del cálculo de la edad promedio ponderada. C) Gráfico de relación $\mathrm{Th} / \mathrm{U}$ vs. edad

La roca 900998 (LMC-082) corresponde a un dique de diorita tomada en la vereda Pueblo Nuevo, municipio de Rionegro. Se separaron 45 circones. Discordancias mayores del $10 \%$ y errores mayores del $5 \%$ se reportaron en 18 circones, que fueron retirados del procesamiento de los datos. Las relaciones Th/U varían entre 0,72 y 2,78. De los circones restantes, nueve son discordantes; los demás se agrupan de manera concordante a ligeramente discordante en el rango de edad de 184,33 a 200,5 Ma. En el diagrama de la edad media ponderada se presenta una edad de 189,9 $\pm 1,6 \mathrm{Ma}$ (figura 36).

La muestra 900999 (LMC-084) se colectó cerca de la roca LMC-082 anteriormente descrita, en el sector centro-occidental del Monzogranito de Rionegro. Por sus características petrográficas y geoquímicas difiere de las rocas granodioríticas del plutón y es considerada como parte de la unidad cuarzomonzodiorita, teniendo en cuenta las observaciones de campo (figura 3); esta relación es corroborada por la edad U-Pb obtenida, como se muestra en la figura 37.

Se separaron cincuenta cristales de circón, y se retiraron del procesamiento e interpretación aquellos datos con discordancias mayores del $15 \%$ y errores mayores del $5 \%(n=9)$. Los circones restantes muestran una relación Th/U entre 0,88 y 3,77 , tienen un comportamiento concordante a ligeramente discordante en un rango de edad de 190 a 211 Ma. Diez circones fueron catalogados como discordantes. Un circón tiene una edad concordante de 231,89 Ma. El gráfico de la media ponderada arroja una edad de 200,8 $\pm 1,9 \mathrm{Ma}$, que se interpreta como la edad de cristalización.

Los datos de geocronología U-Pb en circón correspondientes al Monzogranito de Rionegro se resumen en la tabla 14. 

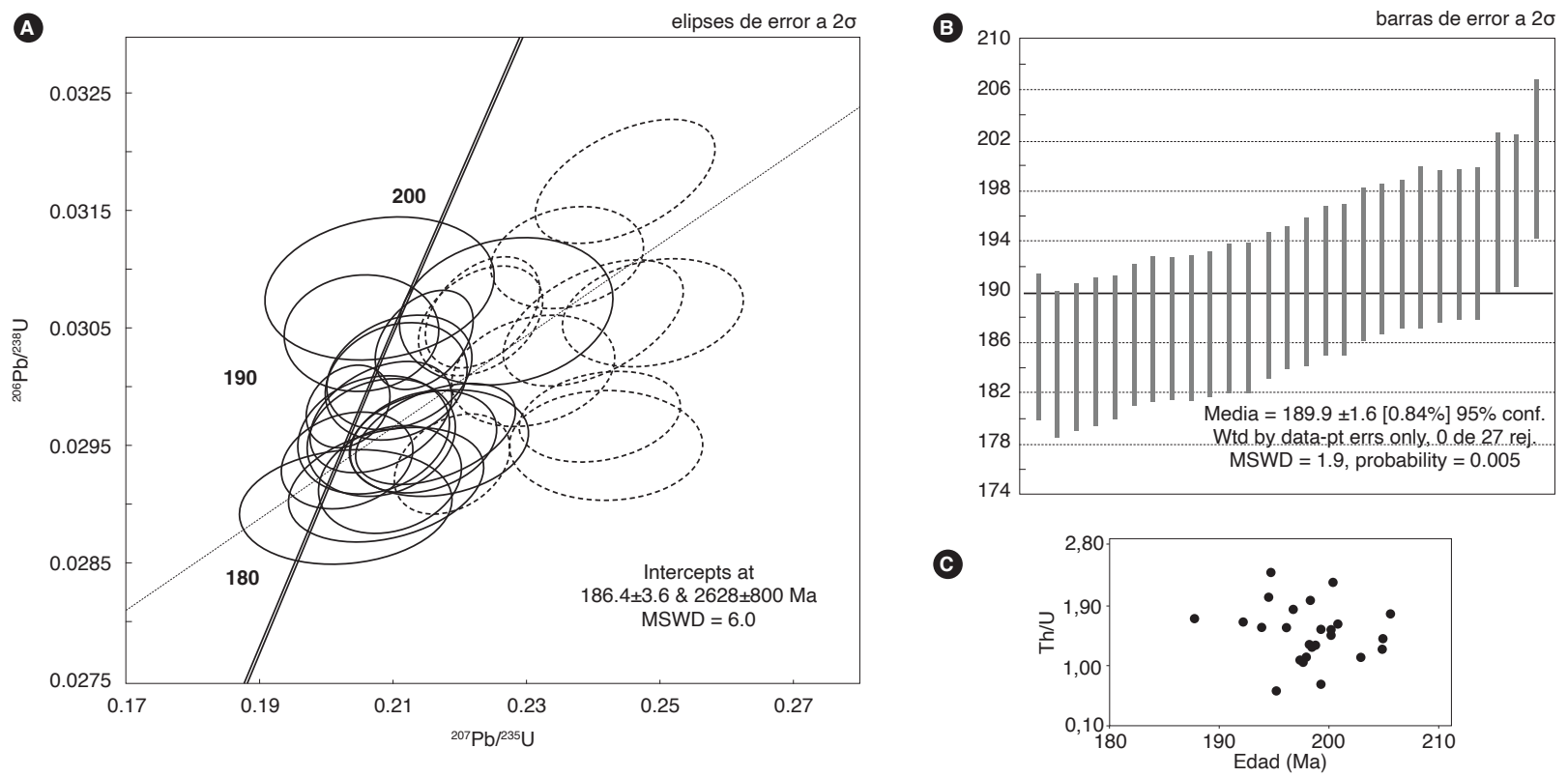

Figura 36. Edad de la muestra de dique LMC-082. A) Diagrama de concordia. B) Diagrama del cálculo de la edad promedio ponderada. C) Gráfico de relación $\mathrm{Th} / \mathrm{U}$ vs. edad
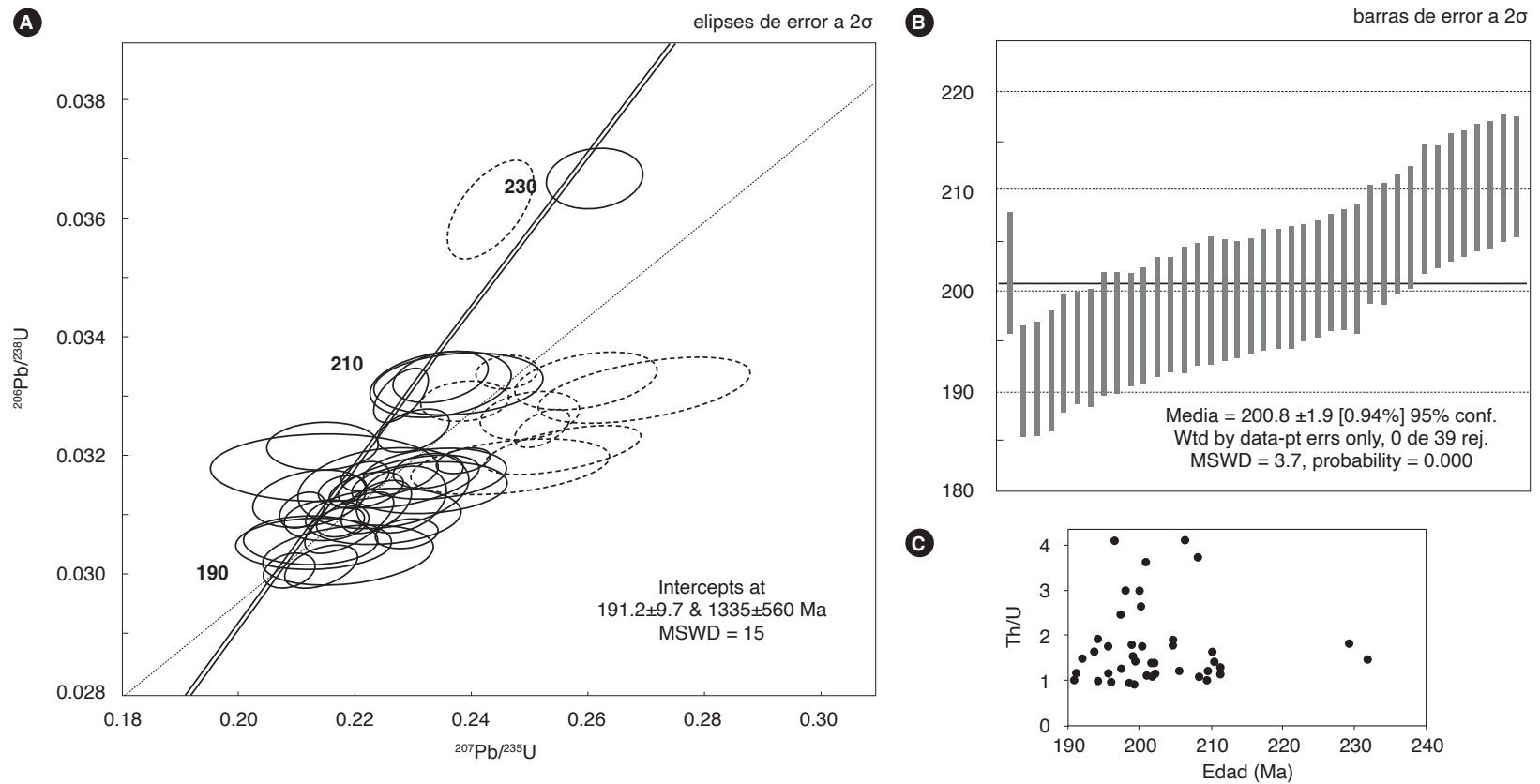

Figura 37. Edad de la la roca LMC-084. A) Diagrama de concordia y circones típicos de esta muestra. Las líneas punteadas corresponden a edades discordantes eliminadas. B) Diagrama del cálculo de la edad promedio ponderada. C) Gráfico de relación Th/U vs. edad 
Tabla 14. Dataciones U-Pb en circón del Monzogranito de Rionegro

\begin{tabular}{cccc}
\hline IGM & N. campo & Edad (Ma) & Edad heredada \\
\hline 900973 & GR-6743 & $195,9 \pm 1,6$ & $451-877,9-993,40-1035,21-1143,33$ Ma \\
\hline 900985 & 10VDL54* & $195,8 \pm 1,5$ & $196,6 \pm 2,1$ \\
\hline Saprolito & GZ-6848A & $197,2 \pm 1,5$ & $238-249,267,288,320$ \\
\hline 900952 & JGB-462 & $196 \pm 1,1$ & 1021,67 Ma \\
\hline 900951 & 10VDL59* & $214,5 \pm 2,7$ & $924-934-1005-1485$ Ma \\
\hline 901011 & MIA-648B & $194,5 \pm 1,2$ & $184,1 \pm 2,3$ \\
\hline Saprolito & MIA-648A & $186,7 \pm 1,9$ & \\
\hline 900998 & MIA-650B & $189,9 \pm 1,6$ & \\
\hline 900999 & MIA-657A & $200,8 \pm 1,9$ &
\end{tabular}

Fuente: este trabajo, * Van des Lelij (2013)

\subsection{Geoquímica de elementos traza en circones}

El análisis de ICP-MS de los circones enviados al Laboratorio de Geocronología de la UNAM determinó la abundancia de los elementos traza en cada circón (anexo 3 y figura 38). Los valores de REE se normalizaron a condrito (McDonough y Sun, 1995) y se calcularon las relaciones Pm* y Tm* de cada uno de ellos.

En general, los valores de Th y Pb en ppm de los circones de las muestras GR-6743, JGB 462 y MIA-650B están en los rangos característicos de granitos tipo I, que según Wang et al. (2012) se caracterizan por presentan bajas concentraciones de $\mathrm{Pb}$ y altas relaciones $\mathrm{Th} / \mathrm{Pb}$. Los circones 040 y 036 de la roca GR-6743 se sitúan en el borde del campo de granitos tipo A, correspondientes a circones con edades de 21 2,7 y 203,1 Ma, mayores que la media ponderada de esta roca.

Asimismo, los circones 010 y 05 de la muestra MIA$650 B$ se dispersan del conjunto de datos con menores valores de Th. Estos circones corresponden a cristales con edades heredadas de 924 y 1485 Ma, respectivamente.

Hay concentraciones menores en las REE desde La, $\mathrm{Pr}, \mathrm{Nd}, \mathrm{Pm}^{*}$ y Sm, excepto en el Ce, que describe una anomalía positiva, de acuerdo con Nardi et al. (2013), y que se debe a la incorporación de $\mathrm{Ce}^{4+}$ en sustitución de $\mathrm{Zr}^{4+}$ en la estructura cristalina del circón, ligeras anomalías negativas de Eu y enriquecimientos hacia las REE pesadas. 

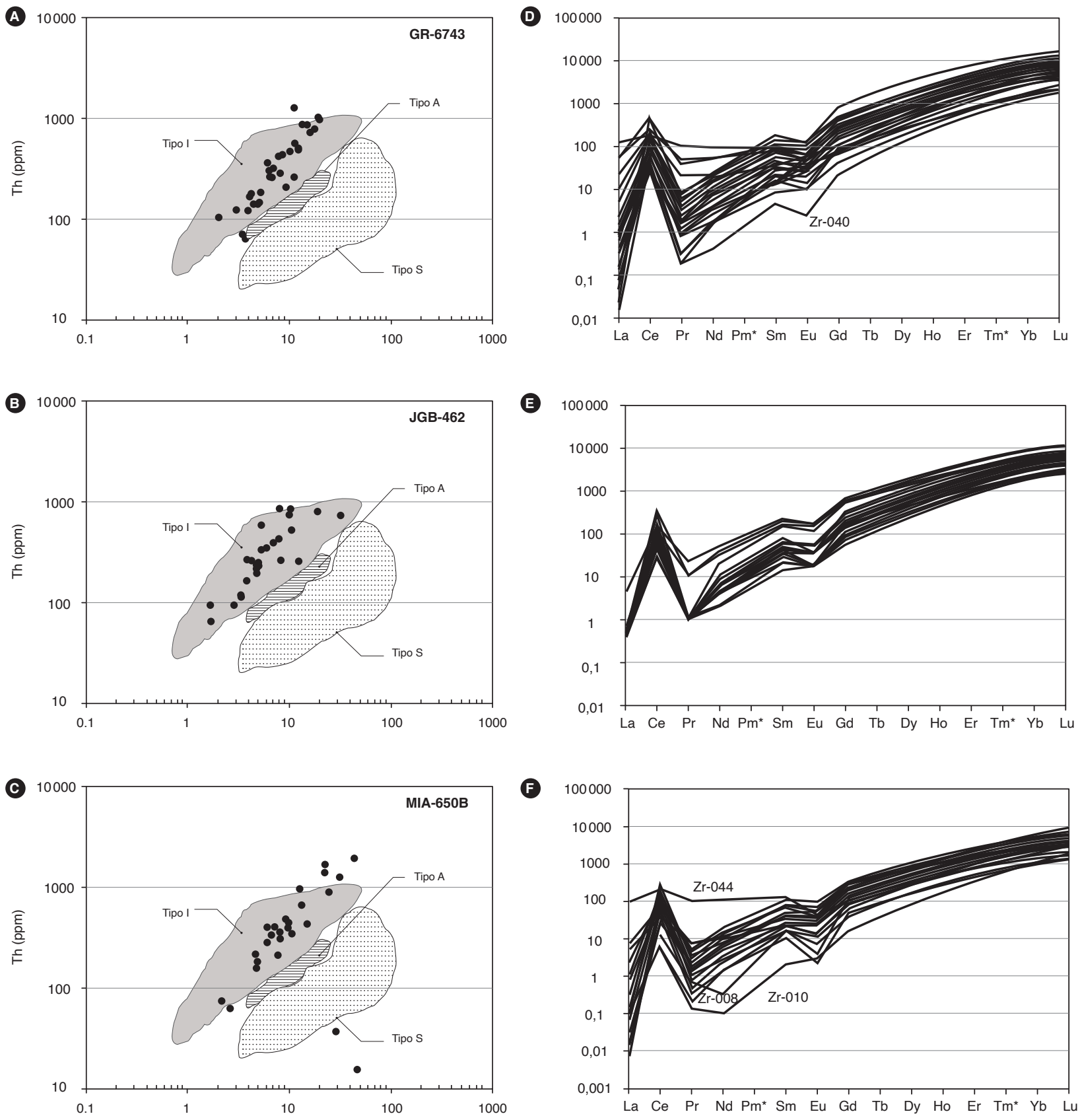

Figura 38. Diagramas de clasificación de granitos y diagramas multielementales a partir de la química del circón. A, B, C) Tipo de magma según los valores de Th y $\mathrm{Pb}$ (diagrama de Wang et al., 2012), en circones de las muestras GR-6743, JGB-462 y MIA-650B, respectivamente, del Monzogranito de Rionegro. D, E, F) Patrones de los elementos de las tierras raras REE normalizados según el condrito de McDonough y Sun (1995) en circones de las muestras GR-6743, JGB-462 y MIA-650B, respectivamente 


\section{Correlaciones}

El Monzogranito de Rionegro hace parte del magmatismo triásico-jurásico que se emplazó en el basamento metamorfo del Macizo de Santander y cuya correlación se extiende tanto a los cuerpos subvolcánicos porfídicos como a cuerpos plutónicos de composición granítica, entre los que se encuentra el Monzogranito de La Corcova (Goldsmith et al., 1971; Rodríguez et al., 2016), la tonalita y Granodiorita de Páramo Rico (Ward et al., 1973), el Batolito de Mogotes (Ward et al., 1973, Correa et al., 2016), el Granito de Pescadero (Ward et al., 1973, Zapata et al., 2016) y pequeños plutones subvolcánicos, como las Riolitas de El Uvo (Zapata et al., 2018), la Riolita de San Joaquín (Rodríguez et al., 2018) y la Riolita del Alto Los Cacaos (Correa et al., 2018).

\section{Localidad tipo}

La sección tipo del Monzogranito de Rionegro se encuentra en la vía que conduce del municipio de La Esperanza hacia La Vega, en la plancha 97. Se proponen como secciones alternas las expuestas en las vías caserío La Ceiba-El Filo y vereda El Mambo-Misijuay, en la plancha 109.

\section{Génesis}

El Monzogranito de Rionegro presenta mineralogía característica de granitoides tipo I, como son la presencia de feldespato potásico de color rosado, biotita parda, hornblenda con núcleos de clinopiroxeno y presencia de magnetita e ilmenita; además, presenta gabarros (xenolitos) de rocas ígneas intermedias con presencia de hornblenda. La química de rocas lo clasifica en el campo de los granitos tipo I, peraluminosos, y la geoquímica de elementos traza en circones lo sitúa en el campo de los granitos tipo I.

Las características macroscópicas y microscópicas del Monzogranito de Rionegro, como texturas equigranulares e inequigranulares, son indicativas de un emplazamiento epizonal del cuerpo, en un basamento metamórfico.

Los monzogranitos están constituidos por ortosa pasando a microclina pertítica, característica en rocas plutónicas que se forman en ambientes de temperaturas intermedias.

La química mineral obtenida en cristales de biotita, relacionada a una roca de monzogranito de la facies principal del plutón, se asocia a rocas de series calcoalcalinas orogénicas, de acuerdo con el diagrama de Abdel
Rahman (1994), resultado que es concordante con la química de óxidos mayores que clasifica las rocas como subalcalinas de la serie calcoalcalina alta en $\mathrm{K}$ y peraluminosas.

El Monzogranito de Rionegro presenta al menos tres facies, y predominan los monzogranitos sobre las granodioritas y las cuarzomonzodioritas. Las dataciones $\mathrm{U} / \mathrm{Pb}$ sugieren que algunas de estas facies representan pulsos y cuerpos de diferente edad, que podrían ser separados de la unidad principal, como es el caso del cuerpo de granodiorita que aflora en los alrededores del municipio de Rionegro, que arrojó una edad de 214 Ma. Presenta diques de monzogranitos, riolitas, andesitas y microdioritas, indicativos de eventos magmáticos posteriores a la cristalización de la masa principal del plutón con edades más jóvenes, cercanas a $184 \mathrm{Ma}$.

El Monzogranito de Rionegro presenta enriquecimiento en tierras raras livianas (LREE) de más de cien veces respecto al valor del condrito, que se va empobreciendo progresivamente hacia las tierras raras pesadas (HREE), comportamiento normal en rocas generadas en ambientes de subducción. Las diferentes litologías del Monzogranito de Rionegro en los diagramas multielementales de elementos traza normalizados al NMORB presentan anomalías negativas de $\mathrm{P}$, Ti y Nb y enriquecimientos en las LILE (Cs, $\mathrm{Rb}, \mathrm{Ba})$, algo típico en rocas ígneas generadas en ambientes de arco.

La presencia de circones heredados del Proterozoico en rocas monzograníticas indica aporte de corteza continental a los fundidos que dieron origen al Monzogranito de Rionegro. Además, los valores de $\varepsilon N d$ a 196 Ma y las razones iniciales de ${ }^{87} \mathrm{Sr} /{ }^{86} \mathrm{Sr}$ muestran valores altos, entre 0,70843 y 0,71054 , que corresponden a características isotópicas que apoyan el aporte de material cortical a los magmas que dieron origen a las rocas del Monzogranito de Rionegro.

\section{Recursos minerales}

No se conocen mineralizaciones asociadas al Monzogranito de Rionegro, aunque el desarrollo de saprolito espeso de contextura arenosa permite la extracción local de material que se utiliza en la construcción como arena de pega.

\section{Conclusiones}

Este catálogo, que constituye un aporte al conocimiento cartográfico del cuerpo plutónico, presenta nueva infor- 
mación del Monzogranito de Rionegro en los aspectos petrográfico, químico, mineral, litogeoquímico y geocronológico.

Se determinó que el cuerpo es un granito formado por varios pulsos magmáticos, que incluye diques más jóvenes y cuerpos de granodioritas más antiguos que la litología granítica principal.

El Monzogranito de Rionegro está constituido por monzogranitos granodioritas, sienogranitos, cuarzosienitas y tonalitas. Se encuentra intruido por diques de riolitas, monzogranitos, andesitas y microdioritas; además, tiene enclaves de andesitas y dioritas.

Es un plutón subalcalino de la serie calcoalcalina alta en $\mathrm{K}$, peraluminoso, con valores de $\mathrm{A} / \mathrm{NK}>1$ y valores de $\mathrm{A} / \mathrm{CNK}>1$, con valores de $\mathrm{Al}_{2} \mathrm{O}_{3}>\mathrm{CaO}+\mathrm{Na}_{2} \mathrm{O}+\mathrm{K}_{2} \mathrm{O}$.

En los diagramas multielementales se reconocen varios patrones con edades de cristalización, $\mathrm{U} / \mathrm{Pb}$ en circón, desde 21 4,5 $\pm 2,7$ Ma para un cuerpo de granodiorita que aflora al sur del Monzogranito de Rionegro, hasta edades que varía entre 197,2 \pm 1,5 y 195,8 $\pm 1,5 \mathrm{Ma}$, que representan la masa principal del cuerpo intrusivo en rocas de la facies monzogranítica. Las rocas de dique arrojaron edades entre 184,1 $\pm 2,3$ y $189,9 \pm 1,6 \mathrm{Ma}$, lo que sugiere que se trata de un cuerpo formado por varios pulsos magmáticos generados en un ambiente de arco continental.

La química de rocas y la química de circones clasifican el Monzogranito de Rionegro como un granito tipo I.

La presencia de núcleos de circones heredados del Paleozoico al Mesoproterozoico, en rocas monzograníticas y sienograníticas, son indicativas de la fusión de rocas de la corteza continental que aportaron material a los pulsos magmáticos.

\section{Referencias}

Abdel-Rahman, A. F. M. (1994). Nature of biotites from alkaline, calc-alkaline, and peraluminous magmas. Journal of Petrology, 35 (2), 525-541. https://doi. org/10.1093/petrology/35.2.525.

Arias, A. y Morales C., J. (2003). Mapa geológico generalizado del departamento del Cesar. Memoria explicativa. Escala 1:250.000. Bogotá: Ingeominas.

Arias, A. y Vargas, R. (1978). Geología de las planchas 86 Ábrego y 97 Cáchira. Departamento de Santander. Memoria explicativa. Escala 1:100.000. Bogotá: Ingeominas.

Best, M. G. (2003). Igneous and metamorphic petrology. Oxford: Wiley-Blackwell.
Chappell, B. W. y White, A. J. (2001). Two contrasting granite types: 25 years later. Australian Journal of Earth Sciences, 48 (4), 489-499. https://doi.org/10.1046/j.1440-0952.2001.00882.x.

Clavijo, J. (1994). Mapa geológico generalizado de Norte de Santander. Escala 1:250.000. Mapa interno. Bucaramanga: Ingeominas.

Clavijo, J., Mantilla, F. L. C., Pinto, J., Bernal, L. y Pérez, A. (2008). Evolución geológica de la serranía de San Lucas, norte del valle medio del Magdalena y noroeste de la cordillera Oriental. Boletín de Geología, 30 (1), 45-62.

Cordani, U. G., Cardona, A., Jiménez, D. M., Liu, D. y Nutran, A. P. (2005). Geochronology of Proterozoic basement inliers from the Colombian Andes: Tectonic history of remnants from a fragmented Grenville belt. Londres: Geological Society.

Corfu, F., Hanchar, J. M., Hoskin, P. W. O. y Kinny, P. (2003). Atlas of Zircon Textures. Zircon. Reviews in Mineralogy and Geochemistry, 53 (1), 469-500. https://doi.org/1 0.2113/0530469.

Correa Martínez, A. M., Rodríguez, G., Arango, M. I., Zapata, G. y Bermúdez, J. G. (2016). Catálogo de unidades litoestratigráficas de Colombia. Batolito de Mogotes. Medellín: Servicio Geológico Colombiano.

Correa Martínez, A. M., Rodríguez, G., Arango, M. I., Zapata, G. y Bermúdez, J. G. (2018). Catálogo de unidades litoestratigráficas de Colombia. Riolitas del alto Los Cacaos. Medellín: Servicio Geológico Colombiano.

Daconte, R. y Salinas, R. (1980). Geología de las planchas 66 Miraflores y 76 Ocaña. Departamento Norte de Santander. Memoria Explicativa. Escala 1:100.000. Bucaramanga: Ingeominas.

Debon, F. y Le Fort, P. (1983). A chemical-mineralogical classification of common plutonic rocks and associations. Earth and Environmental Science Transactions of The Royal Society of Edinburgh, 73 (3), 153-149. https://doi.org/10.1017/S0263593300010117.

Etayo Serna, F., Barrero, D., Lozano, H., Espinosa, A., González, H., Orrego, A., Ballesteros, I., Forero, H., Ramírez, C., Zambrano Ortiz, F., Duque Caro, H., Vargas, R., Núñez, A., Álvarez, J., Ropaín, C., Cardozo, E., Galvis, N., Sarmiento, L., Alberts, J. P., Case, J. E., Singer, D. A., Bowen, R. W., Berger, B.R., Cox, D. P. y Hodges, C. A. (1985). Mapa de terrenos geológicos de Colombia. Publicaciones Geológicas Especiales del Ingeominas 14, Bogotá: Ingeominas. 
Frost, B. R. y Frost, C. D. (2008). A geochemical classification for feldspathic igneous rocks. Journal of Petrology, 49 (11), 1955-1969. https://doi.org/10.1093/ petrology/egn054.

Frost, R. B., Barnes, C. G., Collins, W. J., Arculus, R. J., Ellis, D. J. y Frost, C. D. (2001). A geochemical classification for granitic rocks. Journal of Petrology, 42 (11), 20332048. https://doi.org/10.1093/petrology/42.11.2033.

Fuquen, J., Ceballos, L., Pedraza, A. y Marín, E. (2010). Geología de la plancha 98 Durania. Escala 1:100.000. Bogotá: Ingeominas.

García, C. y Ríos, C. (1 999). Metamorfismo y metalogénia asociada del Macizo de Santander, cordillera Oriental, Colombia. Informe final Proyecto de Investigación 1102-05-083-95. Bucaramanga: Colciencias y Universidad Industrial de Santander.

Goldsmith, R., Marvin, R. F. y Mehnert, H. H. (1971). Radiometric ages in the Santander Massif, Eastern Cordillera, Colombian Andes. U. S. Geological Survey Professional Paper 750-D, D44-D49.

Harris, N. B. W., Pearce, J. A. y Tindle, A. G. (1986). Geochemical characteristics of collision zone magmatism. En M. P. Coward y A. C. Ries (eds.), Collision tectonics (pp. 67-81). Special publication 19. London: Geological Society of London. http:/dx.doi. org/1 0.1 0.1 144/GSL.SP.1986.019.01.04.

Janoušek, V., Farrow, C. M. y Erban, V. (2006). Interpretation of whole-rock geochemical data in igneous geochemistry: Introducing geochemical data toolkit (GCDkit). Journal of Petrology, 47 (6), 1255-1259. https://doi.org/10.1093/petrology/egl013.

Leal-Mejía, H. (2011). Phanerozoic gold metallogeny in the Colombian Andes: A tectono-magmatic approach (tesis de doctorado). Universitat de Barcelona, España.

Ludwig, K. (2008). Isoplot version 4.15: A geochronological toolkit for Microsoft Excel. Berkeley Geochronology Center, Special Publication (4).

Mantilla Figueroa, L. C., Bissig, T., Valencia. V. y Hart, C. (2013). The magmatic history of the Vetas-California mining district, Santander Massif Eastern Cordillera, Colombia. Journal of South American Earth Sciences, 45, 235-249. https://doi.org/10.1016/j. jsames.2013.03.006.

McDonough, W. F. y Sun, S. S. (1995). The composition of the Earth. Chemical Geology, 120 (3), 223-253. https://doi.org/1 0.1016/0009-2541(94)00140-4.
Middlemost, E. A. K. (1985). Magmas and magmatic rocks. London: Longman.

Middlemost, E. A. K. (1994). Naming materials in the magma/igneous rock system. Earth-Science Reviews, 37 (3-4), 215-224. https://doi.org/10.1016/00128252(94)90029-9.

Nakamura, N. (1 974). Determination of REE, Ba, Fe, Mg, $\mathrm{Na}$ and $\mathrm{K}$ in carbonaceous and ordinary chondrites. Geochimical et Cosmochimical Acta, 38 (5), 757-775. https://doi.org/10.1016/0016-7037(74)90149-5.

Nardi, L. V. S., Formoso, M. L. L., Müller, I. F., Fontana, E., Jarvis, K. y Lamarão, C. (2013). Zircon/rock partition coefficients of REEs, Y, Th, U, Nb, and Ta in granitic rocks: Uses for provenance and mineral exploration purposes. Chemical Geology, 335, 1-7. https:/doi.org/10.1016/j.chemgeo.2012.10.043.

Ordóñez Cardona, O., Restrepo Álvarez, J. J. y Pimentel, M. M. (2006). Geochronological and isotopical review of pre-Devonian crustal basement of the Colombian Andes. Journal of South American Earth Sciences, 21 (4), 372-382. https://doi.org/10.1016/j. jsames.2006.07.005.

Ordóñez Carmona, O. (2001). Caracterização isotópica $\mathrm{Rb}-\mathrm{Sr}$ e Sm-Nd dos principais eventos magmáticos nos Andes colombianos (tesis de doctorado). Universidade de Brasilia.

Pearce, J. A. (2008). Geochemical fingerprinting of oceanic basalts with applications to ophiolite classification and the search for Archean oceanic crust. Lithos, 100 (1-4), 14-48. https://doi.org/10.1016/j. lithos.2007.06.016.

Peccerillo, A. y Taylor, S. R. (1976). Geochemistry of Eocene calc-alkaline volcanic rocks from the Kastamonu area, Northern Turkey. Contributions to Mineralogy and Petrology, 58 (1), 63-81. https://doi. org/10.1007/BF00384745.

Pérez Arvizu, O., Ortega Obregón, C., Solari, L. y Gómez Tuena, A. (2010). Aplicaciones del sistema LAICPMS del Centro de Geociencias de la UNAM. Simposio de Metrología 201 0, Querétaro, México.

Restrepo, J. J. y Toussaint, J. F. (1988). Terranes and continental accretion in the Colombian Andes. Episodes, 11 (3), 189-193.

Restrepo, J. J., Ordóñez Carmona, O., Armstrong, R. y Pimentel, M. (2011). Triassic metamorphism in the northern part of the Tahamí Terrane of the Central Cordillera of Colombia. Journal of South Amer- 
ican Earth Sciences, 32 (4), 497-507. https://doi. org/10.1016/j.jsames.2011.04.009.

Restrepo-Pace, P., Ruiz, J., Gehrels, G. y Cosca, M. (1997). Geochronology and Nd isotopic data of the Grenville-age rocks in the Colombian Andes: New constraints for Late Proterozoic-Early Paleozoic paleocontinental reconstructions of the Americas. Earth and Planetary Science Letters, 150 (3-4), 427-441. https://doi.org/10.101 6/S001 2-821 X(97)00091-5.

Rieder, M., Cavazzini, G., D’Yakonov, Y., Frank Kamenetskii, V., Gottardi, G., Guggenheim, S., Koval, P. W., Müller, G., Neiva, A. M. R., Radoslovich, E. W., Robert, J.-L., Sassi, F. P., Takeda, H., Weiss, Z. y Wones, D. R. (1998). Nomenclature of the micas. Clays and Clay Minerals, 46 (5): 586-595. https:/doi. org/10.1346/CCMN.1998.0460513.

Ríos, C., García, C. y Takusa, A. (2003). Tectono-metamorphic evolution of the Silgara Formation metamorphic rocks in the Southwestern Santander Massif, Colombian Andes. Journal of South American Earth Sciences, 16 (2), 133-154. https:/doi. org/10.1016/S0895-9811(03)00025-7.

Rodríguez, G., Arango, M. I., Correa Martínez, A. M. y Zapata, G. (2018). Catálogo de unidades litoestratigráficas de Colombia. Riolita de San Joaquín. Medellín: Servicio Geológico Colombiano.

Rodríguez, G., Correa Martínez, A. M., Zapata, G. y Arango, M. I. (2016). Catálogo de unidades litoestratigráficas de Colombia. Monzogranito de La Corcova. Medellín: Servicio Geológico Colombiano.

Royero, J. M. y Clavijo, J. (2001). Mapa geológico generalizado del departamento de Santander. Escala 1:300.000. Memoria explicativa. Bogotá: Ingeominas.

Shand, S. J. (1943). Eruptive rocks: Their genesis, composition, classification, and their relation to ore-deposits with a chapter on meteorite. New York: John Wiley \& Sons.

Smith, J. V. y Brown, W. L. (1988). Feldspar minerals. I. Crystal structures, physical, chemical and microtextural properties (2. ${ }^{\mathrm{a}} \mathrm{ed}$.). Berlin: Springer-Verlag.

Streckeisen, A. (1976). Classification and nomenclature of plutonic rocks: recommendations of the IUGS subcommission on the systematics of Igneous Rocks. Geologische Rundschau, 63 (2), 773-786. https:// doi.org/10.1007/BF01820841.
Streckeisen, A. (1978). Classification and nomenclature of volcanic rocks, lamprophyres, carbonatites and melilitic rocks; recommendation and suggestions. Neues Jahrbuch für Mineralogie, 134, 1-14.

Sun, S. S. y Mcdonough, W. S. (1989). Chemical and isotopic systematics of oceanic basalts: Implications for mantle composition and processes. Special Publications 42. London: Geological Society.

Van der Lelij, R. (2013). Reconstructing North-Western Gondwana with implications for the evolution of the Iapetus and Rheic Oceans: A geochronological, thermochronological and geochemical study (tesis de doctorado). Université de Genève.

Wang, Q., Zhu, D. C., Zhao, Z. D., Guan, Q., Zhang, X. Q., Sui, Q. L., Chu Hu, Z. y Mo, X. X. (2012). Magmatic zircons from I-, S- and A-type granitoids in Tibet: Trace element characteristics and their application to detrital zircon provenance study. Journal of Asian Earth Sciences, 53, 59-66. https://doi.org/10.1016/j. jseaes.2011.07.027.

Ward, D. E, Goldsmith, R., Jimeno, A., Cruz, J., Restrepo, H. y Gómez, E. (1973). Mapa geológico de Colombia, cuadrángulo H-12 Bucaramanga, planchas 109 Rionegro-120 Bucaramanga, cuadrángulo H-13, Pamplona, planchas 110 Pamplona-121 Cerrito. Departamento de Santander. Memoria Explicativa. Escala 1:100.000, Bogotá: Ingeominas.

Whalen, J. B., Currie, K. L. y Chappell, B. W. (1987). A-type granites: Geochemical characteristics, discrimination and petrogenesis. Contributions to Mineralogy and Petrology, 95 (4), 407-419. https:/doi. org/10.1007/BF00402202.

Winter, J. D. (2014). Principles of igneous and metamorphic petrology (2. a ed.). Harlow: Pearson.

Zapata, G., Arango, M. I., Rodríguez, G. y Correa Martínez, A. M. (2018). Catálogo de unidades litoestratigráficas de Colombia. Riolitas El Uvo. Medellín: Servicio Geológico Colombiano.

Zapata, G., Correa M, A. M., Rodríguez, G. y Arango, M. I. (2016). Catálogo de unidades litoestratigráficas de Colombia. Granito de Pescadero. Medellín: Servicio Geológico Colombiano. 


\section{ANEXOS}

Anexo 1. Contenido modal del Monzogranito de Rionegro

\begin{tabular}{|c|c|c|c|c|c|c|c|c|c|c|c|c|c|c|c|c|c|c|c|c|c|}
\hline IGM & N. campo & E & $\mathbf{N}$ & Qtz & PI & Fsp & Bt & Hbl & Cpx & Opx & Tr/Act & Ms & Chl & Op & Ap & Zrn & Ttn & Ep & Matriz & Textura & Clasificación \\
\hline 70801 & EA-717 & 1103352 & 1328059 & 37 & 16 & 46 & 1 & & & & & & $\mathrm{x}$ & $x$ & $\mathrm{x}$ & & $\mathrm{x}$ & & & $\begin{array}{c}\text { Holocristalina } \\
\text { alotriomorfa }\end{array}$ & Granito félsico \\
\hline 70807 & EA-736 & 1096402 & 1323699 & 32 & 20 & 47 & 0,5 & & & & & 0,5 & $\mathrm{x}$ & $x$ & & & & $\mathrm{x}$ & & $\begin{array}{c}\text { Holocristalina } \\
\text { alotriomorfa }\end{array}$ & Granito félsico \\
\hline 70808 & EA-738 & 1095482 & 1323399 & 34 & 20 & 45 & 0,5 & & & & & 0,5 & & $<1$ & & & & $\mathrm{x}$ & & $\begin{array}{c}\text { Holocristalina } \\
\text { alotriomorfa }\end{array}$ & Granito félsico \\
\hline 70811 & EA-754 & 1096342 & 1320749 & 18 & 15 & 65 & $<1$ & & & & & & $\mathrm{x}$ & $\mathrm{x}$ & $\operatorname{Tr}$ & & & & & $\begin{array}{c}\text { Holocristalina, } \\
\text { alotriomorfa }\end{array}$ & Granito félsico \\
\hline 10888 & $\mathrm{HCH} 1$ & 1098572 & 1311069 & 33,2 & 49,1 & 15,5 & 2,2 & & & & & & & & & & $\operatorname{Tr}$ & & & $\begin{array}{c}\text { Holocristalina, } \\
\text { hipidiomorfa } \\
\text { inequigranular }\end{array}$ & Brecha (monzogranito) \\
\hline 10941 & $\mathrm{HCH} 53$ & 1105372 & 1340599 & 11,1 & 46,6 & 22,2 & & & & & & & 2,2 & $\operatorname{Tr}$ & & & & 3,1 & 14,8 & Cataclástica & $\begin{array}{c}\text { Brecha cataclástica } \\
\text { (cuarzomonzodiorita) }\end{array}$ \\
\hline 10942 & $\mathrm{HCH} 54$ & 1104972 & 1340259 & 15,6 & 46,3 & 30,5 & 2,2 & & & & & & & & & & & 2,2 & 3,2 & Cataclástica & $\begin{array}{l}\text { Brecha cataclástica } \\
\text { (cuarzomonzonita) }\end{array}$ \\
\hline 10936 & $\mathrm{HCH} 48$ & 1091702 & 1337019 & 9,2 & 41,5 & 4,6 & 2,5 & 2 & & & & & & & & $\operatorname{Tr}$ & $\operatorname{Tr}$ & & 40,2 & Cataclástica & Cataclasita \\
\hline 70839 & LJM-411 & 1091622 & 1334399 & 23,8 & 29,7 & 4,5 & & & & & & & 0,5 & & $\operatorname{Tr}$ & $\operatorname{Tr}$ & & 1,9 & 39,6 & Cataclástica & Cataclasita \\
\hline 72056 & HM-253 & 1094822 & 1340059 & 37 & 40 & 15 & $\mathrm{x}$ & & & & & & $x$ & $x$ & & $\operatorname{Tr}$ & 2 & $\mathrm{x}$ & & Cataclástica & $\begin{array}{l}\text { Cataclasita de } \\
\text { granodiorita }\end{array}$ \\
\hline 70840 & LJM-411A & 1091623 & 1334400 & 16,2 & 28,6 & 11,9 & & & & & & 0,5 & & $\operatorname{Tr}$ & & $\operatorname{Tr}$ & & & 42,8 & Cataclástica & $\begin{array}{c}\text { Cataclasita/brecha } \\
\text { cataclástica }\end{array}$ \\
\hline 70884 & LJM-452 & 1091582 & 1337199 & 19,2 & 63,4 & 7,4 & & & & & & & 7,8 & & $\mathrm{x}$ & & $\mathrm{x}$ & 1,6 & & Hipidiomorfa granular & Cuarzodiorita \\
\hline 72054 & HM-246 & 1094632 & 1342919 & 23 & 55 & 5 & & 15 & $\operatorname{Tr}$ & & & & $x$ & 0,5 & $\operatorname{Tr}$ & $\operatorname{Tr}$ & 1 & 0,5 & & $\begin{array}{l}\text { Hipidiomorfa } \\
\text { micrográfica } \\
\end{array}$ & Cuarzodiorita \\
\hline 74443 & OP-432 & 1093043 & 1373559 & 20 & 54 & $<1$ & & 18 & & & & & $x$ & 3 & $x$ & $\mathrm{x}$ & 2 & 3 & & $\begin{array}{l}\text { Holocristalina, } \\
\text { hipidiomorfa }\end{array}$ & Cuarzodiorita \\
\hline 72051 & HM-235 & 1092722 & 1340789 & 15 & 60 & 8 & & & & & & & 15 & & & & 2 & 3 & & Hipidiomorfa & Cuarzodiorita \\
\hline 74108 & HM-1100 & 1089122 & 1334939 & 15 & 30 & 5 & & 44 & & & & & $\operatorname{Tr}$ & $\operatorname{Tr}$ & $\mathrm{x}$ & 1 & 2 & 3 & & $\begin{array}{l}\text { Holocristalina } \\
\text { hipidiomorfa }\end{array}$ & $\begin{array}{l}\text { Cuarzodiorita } \\
\text { hornblenda }\end{array}$ \\
\hline 900997 & LMC-081 & 1088010 & 1344458 & 5 & 45 & 9 & 11 & 20 & 3 & & & & & 3 & 0,5 & $\operatorname{Tr}$ & 3 & & & $\begin{array}{l}\text { Alotriomorfa, } \\
\text { equigranular }\end{array}$ & Cuarzomonzodiorita \\
\hline 70837 & HM-163 & 1103872 & 1326279 & 15 & 33 & 38 & 4 & & & & & $x$ & 5 & $x$ & & & & 4 & & $\begin{array}{c}\text { Holocristalina } \\
\text { alotriomorfa, con } \\
\text { efectos cataclásticos }\end{array}$ & Cuarzomonzonita \\
\hline 70841 & LJM-412 & 1091622 & 1334859 & 23 & 43 & 30 & & & & & & & 5 & $\mathrm{x}$ & $\mathrm{x}$ & $\mathrm{x}$ & $\mathrm{x}$ & $\mathrm{x}$ & & $\begin{array}{c}\text { Holocristalina } \\
\text { alotriomorfa }\end{array}$ & Cuarzomonzonita \\
\hline 70859 & LJM-428 & 1100392 & 1337879 & 14 & 52 & 32 & 1 & & & & & $\mathrm{x}$ & $\mathrm{x}$ & $x$ & $x$ & & $x$ & $\mathrm{x}$ & & $\begin{array}{c}\text { Holocristalina, } \\
\text { alotriomorfa }\end{array}$ & Cuarzomonzonita \\
\hline 70863 & LJM-432 & 1103242 & 1337039 & 32 & 37 & 25 & 6 & & & & & & & $\mathrm{x}$ & $\mathrm{x}$ & & & & & $\begin{array}{c}\text { Holocristalina } \\
\text { alotriomorfa }\end{array}$ & Cuarzomonzonita \\
\hline 70892 & LJM-461 & 1094732 & 1337789 & 17,9 & 40,5 & 35 & & 3,1 & & & & & $\mathrm{x}$ & $\mathrm{x}$ & & & & $\mathrm{x}$ & & Hipidiomorfa granular & Cuarzomonzonita \\
\hline 70897 & LJM-466 & 1093682 & 1337569 & 14,5 & 34,5 & 43 & 5 & 1 & & & & & 3 & 1 & $\operatorname{Tr}$ & $\operatorname{Tr}$ & & $\mathrm{x}$ & & Hipidiomorfa & Cuarzomonzonita \\
\hline 900950 & MIA-647 & 1103873 & 1300073 & 12,4 & 40,7 & 31,5 & 12,7 & & & & & & $\mathrm{x}$ & 0,5 & 1 & $\operatorname{Tr}$ & 1,2 & $\mathrm{x}$ & & $\begin{array}{c}\text { Holocristalina } \\
\text { subidiomorfa } \\
\text { inequigranular }\end{array}$ & Cuarzomonzonita \\
\hline 70824 & $\mathrm{HM}-141$ & 1096412 & 1321359 & 19 & 35 & 45 & & & & & & $\mathrm{x}$ & $\mathrm{x}$ & 1 & $\mathrm{x}$ & $\mathrm{x}$ & & $x$ & & $\begin{array}{l}\text { Holocristalina } \\
\text { alotriomorfa con } \\
\text { deformación }\end{array}$ & $\begin{array}{l}\text { Cuarzomonzonita con } \\
\text { efectos cataclásticos }\end{array}$ \\
\hline 11196 & JA 84 & 1113692 & 1307579 & 16 & 13 & 70 & $\operatorname{Tr}$ & & & & & 1 & $\mathrm{x}$ & & & & & & & $\begin{array}{c}\text { Hipidiomorfa } \\
\text { inequigranular }\end{array}$ & Cuarzosienita \\
\hline 72053 & $\mathrm{HM}-243$ & 1096672 & 1340859 & & 40 & & & 20 & 15 & & $\mathrm{x}$ & & 10 & 10 & & & 1 & 1 & & $\begin{array}{l}\text { Porfirítica con matriz } \\
\text { fanerítica }\end{array}$ & Diorita \\
\hline 900998 & LMC-082 & 1087836 & 1343412 & & 47 & & 10 & 35 & & & & & & 4 & 1 & $\operatorname{Tr}$ & 3 & $\mathrm{x}$ & & $\begin{array}{l}\text { Alotriomorfa } \\
\text { equigranular } \\
\end{array}$ & Diorita \\
\hline 71244 & EA-765 & 1088372 & 1339369 & & 44 & & $\operatorname{Tr}$ & & 11 & & 43 & & & 1 & & & $\operatorname{Tr}$ & $\mathrm{x}$ & & Hipidiomorfa granular & Diorita anfibólica \\
\hline 72032 & HM-185A & 1094443 & 1345819 & 10 & 30 & & & 25 & & & & & 10 & 3 & 2 & & 8 & 10 & & Hipiomorfica granular & Diorita hornbléndica, \\
\hline 31183 & EV 10 & 1082603 & 1357309 & 2,1 & 23,2 & & $\operatorname{Tr}$ & 70 & & & & & & & & & 1,1 & 3,3 & & $\begin{array}{l}\text { Holocristalina } \\
\text { hipidiomorfa }\end{array}$ & Diorita hornbléndica \\
\hline 74446 & OP-460 & 1095093 & 1368029 & 8 & 80 & & 9 & & & & & & $\mathrm{x}$ & 1 & $\mathrm{x}$ & $\mathrm{x}$ & $\mathrm{x}$ & 2 & & $\begin{array}{c}\text { Holocristalina } \\
\text { hipidiomorfa con } \\
\text { orientación }\end{array}$ & Diorita néisica \\
\hline 74463 & OP-559 & 1089403 & 1350199 & 5 & 68 & & 13 & 12 & & & & & $x$ & $x$ & & & $\mathrm{x}$ & $\mathrm{x}$ & & Holocristalina & Diorita \\
\hline 70861 & LJM-430 & 1102272 & 1337119 & $\mathrm{x}$ & $x$ & $\mathrm{x}$ & & & & & & $\mathrm{x}$ & $x$ & $x$ & $x$ & $\mathrm{x}$ & $x$ & $\mathrm{x}$ & & Esquistosa & $\begin{array}{c}\text { Esquisto } \\
\text { cuarzomicáceo }\end{array}$ \\
\hline 31147 & & 1093712 & 1373551 & 7,6 & 0,7 & & & 59 & & & & & 2,6 & 6,9 & & & & 23 & & $\begin{array}{l}\text { Holocristalina } \\
\text { inequigranular }\end{array}$ & Gabro propilitizado \\
\hline 31146 & & 1093636 & 1373369 & 1,1 & 36,9 & 0,6 & & & & 23,6 & 26,4 & & & 10,3 & $\mathrm{Tr}$ & & 1,1 & & & $\begin{array}{l}\text { Subidiomorfa } \\
\text { inequigranular }\end{array}$ & $\begin{array}{l}\text { Gabronorita px- } \\
\text { hornbléndica }\end{array}$ \\
\hline 70842 & LJM-413 & 1092542 & 1337239 & 15 & 52 & 25 & & & & & & & 3 & $\mathrm{x}$ & & & $\mathrm{x}$ & 6 & & $\begin{array}{c}\text { Holocristalina } \\
\text { alotriomorfa }\end{array}$ & Granodiorita \\
\hline 70813 & HM-101 & 1100312 & 1327599 & 36 & 20 & 43 & $<1$ & & & & & & $\mathrm{x}$ & $<1$ & $x$ & & & $\mathrm{x}$ & & $\begin{array}{c}\text { Holocristalina } \\
\text { alotriomorfa }\end{array}$ & Granito \\
\hline 70820 & HM-128 & 1092102 & 1323979 & 16 & 19 & 65 & $\operatorname{Tr}$ & & & & & & $\mathrm{x}$ & $\operatorname{Tr}$ & & $x$ & & $x$ & & $\begin{array}{c}\text { Holocristalina } \\
\text { alotriomorfa }\end{array}$ & Granito \\
\hline 70823 & HM-139 & 1096382 & 1322199 & 32 & 21 & 45 & $x$ & & & & & $x$ & $\mathrm{x}$ & 1 & & $x$ & $\mathrm{x}$ & $x$ & & $\begin{array}{c}\text { Holocristalina } \\
\text { alotriomorfa }\end{array}$ & Granito \\
\hline 70838 & HM-164 & 1104582 & 1327129 & 16 & 22 & 60 & 2 & & & & & & $\mathrm{x}$ & & $\mathrm{x}$ & & & & & $\begin{array}{c}\text { Holocristalina } \\
\text { alotriomorfa }\end{array}$ & Granito \\
\hline 70865 & LJM-434 & 1104392 & 1338179 & 26 & 24 & 50 & $x$ & & & & & & $\mathrm{x}$ & $\mathrm{x}$ & $\mathrm{x}$ & & & $\mathrm{x}$ & & $\begin{array}{c}\text { Holocristalina } \\
\text { alotriomorfa }\end{array}$ & Granito \\
\hline 70872 & LJM-441 & 1105112 & 1340559 & 25 & 17,5 & 44,5 & & & & & & 7,5 & 1 & $x$ & & 0,1 & & & & $\begin{array}{l}\text { Alotriomorfa } \\
\text { cataclástica }\end{array}$ & Granito \\
\hline 71253 & EA-782 & 1089742 & 1335959 & 42,5 & 8 & 43,5 & 2 & & & & & & 2 & 1 & & & & & & Granofírica & Granito \\
\hline 72029 & HM-169 & 1093653 & 1349679 & 15 & 28 & 55 & & & & & & & 2 & 1 & $\operatorname{Tr}$ & & $\operatorname{Tr}$ & $\operatorname{Tr}$ & & Holocristalina & Granito \\
\hline 72052 & $\mathrm{HM}-240$ & 1096262 & 1341649 & 10 & 20 & 60 & & & & & & & 3 & & & $\operatorname{Tr}$ & 4 & 4 & & $\begin{array}{l}\text { Hipidiomorfa, } \\
\text { micrográfica, } \\
\text { mirmequítica }\end{array}$ & Granito \\
\hline
\end{tabular}




\begin{tabular}{|c|c|c|c|c|c|c|c|c|c|c|c|c|c|c|c|c|c|c|c|c|c|}
\hline IGM & N. campo & E & $\mathrm{N}$ & Qtz & PI & Fsp & Bt & $\mathrm{Hbl}$ & $\mathrm{Cpx}$ & Opx & Tr/Act & Ms & $\mathrm{Chl}$ & Op & Ap & Zrn & Ttn & Ep & Matriz & Textura & Clasificación \\
\hline 74440 & OP-428 & 1092203 & 1374959 & 24 & 23 & 51 & $\mathrm{x}$ & & & & & $\mathrm{x}$ & $\mathrm{x}$ & $\mathrm{x}$ & & $\mathrm{x}$ & & $\mathrm{x}$ & & $\begin{array}{c}\text { Holocristalina } \\
\text { alotriomorfa }\end{array}$ & Granito \\
\hline 74864 & LJM-1356 & 1076733 & 1396729 & 39 & 20 & 40 & $\mathrm{x}$ & & & & & & & $x$ & & & & $\mathrm{x}$ & & $\begin{array}{c}\text { Holocristalina } \\
\text { hipidiomorfa }\end{array}$ & Granito \\
\hline 70895 & LJM-464 & 1104802 & 1338299 & 25,3 & 10 & 60 & & & & & & & $\operatorname{Tr}$ & 1 & $\operatorname{Tr}$ & & & $\operatorname{Tr}$ & & Alotriomorfa & Granito (alasquita) \\
\hline 70925 & JR-843 & 1105252 & 1336499 & 23,5 & 19,5 & 49,5 & & & & & & & 3 & 0,3 & $x$ & & & & & Alotriomorfa & Granito (alasquita) \\
\hline 71249 & EA-774 & 1089792 & 1335379 & 20 & 8 & 70 & & & & & & & & & & $\operatorname{Tr}$ & $\operatorname{Tr}$ & 2 & & $\begin{array}{c}\text { Alotriomorfa, pertítica } \\
\text { gráfica }\end{array}$ & Granito (alasquita) \\
\hline 71250 & EA-777 & 1088702 & 1333309 & 27 & 10 & 60 & $\operatorname{Tr}$ & & & & & 1 & 1 & 1 & & & $\operatorname{Tr}$ & $\operatorname{Tr}$ & & Alotriomorfa, pertítica & Granito (alasquita) \\
\hline 72047 & HM-223A & 1103692 & 1327989 & 25 & 19 & 55 & & & & & & & 1 & & & & & $\operatorname{Tr}$ & & Hipidiomorfa & Granito (alasquita) \\
\hline 72048 & $\mathrm{HM}-223 \mathrm{~B}$ & 1103432 & 1327319 & 30 & 20 & 50 & & & & & & & & & & & & 3 & & $\begin{array}{l}\text { Hipiomorfica con } \\
\text { deformación }\end{array}$ & $\begin{array}{c}\begin{array}{c}\text { Granito cataclástico } \\
\text { (alasquita) }\end{array} \\
\end{array}$ \\
\hline 72045 & HM-221 & 1102652 & 1327759 & 15 & & 50 & & & & & 1 & & & 6 & & & & 30 & & Cristaloblástica & $\begin{array}{c}\text { Granito con venas de } \\
\text { epidota }\end{array}$ \\
\hline 72044 & HM-220 & 1090972 & 1329549 & 30 & 10 & 60 & & & & & & & & $\operatorname{Tr}$ & & & & & & Hipidiomorfa & $\begin{array}{c}\text { Granito gráfico } \\
\text { (alasquita) }\end{array}$ \\
\hline 70866 & LJM-435 & 1104712 & 1338479 & 33 & 6 & 61 & $x$ & & & & & & $\mathrm{x}$ & $\mathrm{x}$ & $x$ & & $\mathrm{x}$ & $\mathrm{x}$ & & Micrográfica & Granito micrográfico \\
\hline 70893 & LJM-462 & 1105952 & 1340269 & 15 & 10 & 70 & 1 & & & & & $\operatorname{Tr}$ & & 2 & & & & $\operatorname{Tr}$ & & Perfirítica con matriz & $\begin{array}{c}\text { Granito porfirítico } \\
\text { (alasquita) }\end{array}$ \\
\hline 10937 & $\mathrm{HCH} 49$ & 1095102 & 1337699 & 34,8 & 39,9 & 15,2 & 9,5 & & & & & & & $\operatorname{Tr}$ & & & 0,5 & & & $\begin{array}{l}\text { Holocristalina } \\
\text { inequigranular }\end{array}$ & Granodiorita \\
\hline 70806 & EA-731 & 1095122 & 1330109 & 20 & 56 & 23 & 1 & & & & & $\mathrm{x}$ & $\mathrm{x}$ & $\mathrm{x}$ & $\mathrm{x}$ & & & $x$ & & $\begin{array}{c}\text { Holocristalina } \\
\text { alotriomorfa }\end{array}$ & Granodiorita \\
\hline 70875 & LJM-443 & 1097732 & 1337839 & 32 & 43 & 21,2 & & & & & & & 2,5 & 0,1 & & & 0,2 & 1 & & $\begin{array}{c}\text { Hipidiomorfa, en parte } \\
\text { brechoide }\end{array}$ & Granodiorita \\
\hline 70877 & LJM-445 & 1096422 & 1337779 & 4,5 & 62,5 & 20 & & & & & & & 3,8 & & & & & 9,2 & & Hipidiomorfa granular & Granodiorita \\
\hline 70878 & LJM-446 & 1095512 & 1337719 & 42,5 & 29 & 12 & & & & & & & 7 & & & & 1,2 & 5,6 & & Hipidiomorfa granular & Granodiorita \\
\hline 70891 & LJM-460 & 1095952 & 1337509 & 11 & 54 & 30 & & & & & & & 2 & 1 & $\operatorname{Tr}$ & & & 2 & & Hipidiomorfa & Granodiorita \\
\hline 70979 & AG-2262A & 1097722 & 1337839 & 31 & 42,5 & 18 & & $\operatorname{Tr}$ & & & & $\operatorname{Tr}$ & 7,4 & 1 & $\operatorname{Tr}$ & & & & & Hipidiomorfa & Granodiorita \\
\hline 72034 & HM-192 & 1095133 & 1347059 & 28,5 & 48,5 & 18,4 & 2,5 & & & & & & & & & $x$ & 1 & 0,8 & & $\begin{array}{c}\text { Porfirítica con matriz } \\
\text { fanerítica }\end{array}$ & Granodiorita \\
\hline 72035 & HM-193 & 1095803 & 1347189 & 19,7 & 47,4 & 20 & & & & & & & 11 & 1 & & 1 & $\operatorname{Tr}$ & 0,9 & & $\begin{array}{l}\text { Porfirítica con matriz } \\
\text { fanerítica }\end{array}$ & Granodiorita \\
\hline 72055 & HM-252 & 1095572 & 1340069 & 5,6 & 53,8 & 20 & 10 & 5,6 & & & & & $\mathrm{x}$ & 2 & & $\operatorname{Tr}$ & 1 & & & Hipidiomorfa & Granodiorita \\
\hline 74869 & LJM-1403 & 1077503 & 1399199 & 20,1 & 54,4 & 16,1 & 9,4 & & & & & & & $\operatorname{Tr}$ & $\operatorname{Tr}$ & $\operatorname{Tr}$ & & & & $\begin{array}{c}\text { Holocristalina } \\
\text { alotriomorfa }\end{array}$ & Granodiorita \\
\hline 120046 & OP-908A & 1106973 & 1391619 & 19 & 51 & 11 & 19 & & & & & & $\mathrm{x}$ & $\mathrm{x}$ & $\mathrm{x}$ & & $\mathrm{x}$ & & & $\begin{array}{c}\text { Holocristalina } \\
\text { alotriomorfa }\end{array}$ & Granodiorita \\
\hline 900949 & MIA-646B & 1102880 & 1297649 & 21,9 & 46,6 & 15,6 & 14,3 & & & & & & & 1,1 & & & 0,5 & & & $\begin{array}{l}\text { Holocristalina } \\
\text { inequigranular }\end{array}$ & Granodiorita \\
\hline 900952 & MIA-648B & 1104858 & 1301287 & 21,1 & 36,9 & 19,4 & 11,7 & 1,5 & & & & & & 1,2 & 1,6 & 2,1 & 4,5 & $\operatorname{Tr}$ & & Hipidiomorfa & Granodiorita \\
\hline 900999 & LMC-084 & 1088410 & 1339422 & 14 & 40 & 15 & & 29 & & & & & & $\operatorname{Tr}$ & $\operatorname{Tr}$ & $\operatorname{Tr}$ & 2 & $\mathrm{x}$ & & $\begin{array}{c}\text { Alotriomorfa } \\
\text { inequigranular, } \\
\text { ligeramente orientada }\end{array}$ & $\begin{array}{l}\text { Granodiorita con } \\
\text { hornblenda }\end{array}$ \\
\hline 70876 & LJM-444 & 1097152 & 1337629 & 22,5 & 46 & 20,5 & & & & & & & & $x$ & & & & 12 & & Hipidiomorfa granular & Granodiorita porfirítica \\
\hline 900954 & MIA-649B & 1107525 & 1305963 & 27 & 47,5 & 9,7 & 13,2 & & & & & $\mathrm{x}$ & $\mathrm{x}$ & 1,1 & 1 & 0,5 & & $\mathrm{x}$ & & $\begin{array}{l}\text { Holocristalina } \\
\text { inequigranular }\end{array}$ & Granodiorita \\
\hline 74926 & LJM-1404 & 1080473 & 1388019 & 27 & 55 & 18 & & & & & & & $\mathrm{x}$ & & $x$ & $\mathrm{x}$ & $\mathrm{x}$ & $\mathrm{x}$ & & Cataclástica & $\begin{array}{c}\text { Granodiorita? } \\
\text { Transformada en } \\
\text { partes en milonita-neis } \\
\text { por cataclasis }\end{array}$ \\
\hline 900985 & GZ-6848A & 1094480 & 1337675 & 19,5 & 56,3 & 10,4 & 12,1 & & & & & & & & & & 1,7 & & & Hipidiomorfa granular & Granodiorita \\
\hline 10943 & $\mathrm{HCH} 55$ & 1101712 & 1338699 & 34,6 & 25,6 & 37,1 & 2,3 & & & & & 0,2 & & 0,2 & & & & & & Granoblástica & $\begin{array}{c}\text { Granofels } \\
\text { (metamonzogranito) } \\
\text { facies anfibolita }\end{array}$ \\
\hline 31179 & EV 777 & 1088242 & 1340739 & 47,9 & 19,2 & 24,9 & 2,3 & & & & & 2,6 & & $\operatorname{Tr}$ & $\operatorname{Tr}$ & & & 3,1 & & Granoblástica & $\begin{array}{c}\text { Granofels } \\
\text { (metamonzogranito) } \\
\text { facies anfibolita }\end{array}$ \\
\hline 31178 & EV 778 & 1088442 & 1340559 & 20 & 35 & 18 & & 23 & & & & & & 1 & $\operatorname{Tr}$ & $\operatorname{Tr}$ & 3 & $x$ & & $\begin{array}{c}\text { Granonematoblástica } \\
\text { ligeramente } \\
\text { porfiroblástica }\end{array}$ & $\begin{array}{c}\text { Granofels de } \\
\text { cuarzofeldespatos } \\
\text { y hornblenda facies } \\
\text { anfibolita } \\
\end{array}$ \\
\hline 900973 & GR- 6743 & 1083832 & 1397463 & 36,5 & 38,9 & 21,6 & 2,3 & & & & & & & 0,6 & $\operatorname{Tr}$ & $\mathrm{Tr}$ & $\mathrm{Tr}$ & & & Alotriomorfa & $\begin{array}{c}\text { Límite granodiorita- } \\
\text { monzogranito }\end{array}$ \\
\hline 31160 & $\mathrm{RV} 2$ & 1089732 & 1335869 & 39,5 & 26 & 32 & 2 & & & & & & $\mathrm{x}$ & $\operatorname{Tr}$ & $\operatorname{Tr}$ & & & 0,5 & & Hipidiomorfa & Metamonzogranito \\
\hline 70889 & LJM-458 & 1103142 & 1337699 & 34 & 39,5 & 21 & & 3,1 & & & & & $\operatorname{Tr}$ & 1 & $\operatorname{Tr}$ & $\operatorname{Tr}$ & $\operatorname{Tr}$ & 1 & & $\begin{array}{c}\text { Brechoide con } \\
\text { cohesión primaria }\end{array}$ & Microbrecha \\
\hline 70890 & LJM-459 & 1098352 & 1337399 & 29,5 & 22,5 & 39 & & & & & & 1 & 4,7 & & & & & 2 & & $\begin{array}{l}\text { Brechoide con } \\
\text { porfiroclastos }\end{array}$ & $\begin{array}{l}\text { Microbrecha } \\
\text { monzogranito }\end{array}$ \\
\hline 70826 & $\mathrm{HM}-143$ & 1098302 & 1320109 & 36 & 20 & 43 & $\mathrm{x}$ & & & & & $x$ & & $x$ & & & & $x$ & & $\begin{array}{c}\text { Holocristalina } \\
\text { alotriomorfa }\end{array}$ & Microgranito \\
\hline 10870 & EA 167 & 1106802 & 1316379 & 31,7 & 35,8 & 29,8 & 2 & & & & & & & 0,7 & $\operatorname{Tr}$ & $\operatorname{Tr}$ & $\operatorname{Tr}$ & & & Alotriomorfa & Monzogranito \\
\hline 10889 & $\mathrm{HCH} 2$ & 1098642 & 1310819 & 26,7 & 39,6 & 32,2 & 0,8 & & & & & & & 0,7 & & & & & & $\begin{array}{l}\text { Holocristalina } \\
\text { inequigranular }\end{array}$ & Monzogranito \\
\hline 10893 & $\mathrm{HCH} 5$ & 1099342 & 1310319 & 22,6 & 27,5 & 42,5 & 5,8 & & & & & & & 1,6 & & & & & & $\begin{array}{c}\text { Holocristalina } \\
\text { hipidiomorfa }\end{array}$ & Monzogranito \\
\hline 10938 & $\mathrm{HCH} 50$ & 1099932 & 1337959 & 53,3 & 18,1 & 26,7 & 0,6 & & & & & & & 1,3 & & & & & & $\begin{array}{l}\text { Holocristalina } \\
\text { inequigranular }\end{array}$ & Monzogranito \\
\hline 10974 & & 1083776 & 1397131 & 29,5 & 31,7 & 37,4 & 0,7 & & & & & & & 0,7 & $\operatorname{Tr}$ & $\operatorname{Tr}$ & $\operatorname{Tr}$ & & & Alotriomorfa & Monzogranito \\
\hline 10975 & & 1084708 & 1395616 & 37 & 30,2 & 32,8 & $\operatorname{Tr}$ & & & & & $\operatorname{Tr}$ & & $\operatorname{Tr}$ & & $\operatorname{Tr}$ & & & & Alotriomorfa & Monzogranito \\
\hline 10976 & & 1086477 & 1393163 & 41,1 & 31,8 & 24 & 3,1 & & & & & $\operatorname{Tr}$ & & $\operatorname{Tr}$ & $\operatorname{Tr}$ & $\operatorname{Tr}$ & $\operatorname{Tr}$ & & & Alotriomorfa & Monzogranito \\
\hline 10977 & & 1087250 & 1392618 & 31,8 & 32,6 & 35,6 & $\mathrm{Tr}$ & & & & & $\operatorname{Tr}$ & & $\operatorname{Tr}$ & & & $\mathrm{Tr}$ & & & Alotriomorfa & Monzogranito \\
\hline 10979 & & 1087477 & 1392921 & 48,8 & 20,3 & 30,1 & 0,8 & & & & & $\mathrm{Tr}$ & & $\mathrm{Tr}$ & & $\mathrm{Tr}$ & & & & Alotriomorfa & Monzogranito \\
\hline 10980 & & 1096023 & 1372028 & 35,4 & 33,1 & 31,5 & $\operatorname{Tr}$ & & & & & $\mathrm{Tr}$ & & $\operatorname{Tr}$ & & $\operatorname{Tr}$ & & & & Alotriomorfa & Monzogranito \\
\hline 11172 & JA 60 & 1116392 & 1302489 & 31 & 25 & 34 & 10 & & & & & & $x$ & $\operatorname{Tr}$ & $\operatorname{Tr}$ & $\operatorname{Tr}$ & & $x$ & & $\begin{array}{l}\text { Alotriomorfa } \\
\text { inequigranular }\end{array}$ & Monzogranito \\
\hline
\end{tabular}




\begin{tabular}{|c|c|c|c|c|c|c|c|c|c|c|c|c|c|c|c|c|c|c|c|c|}
\hline IGM & N. campo & $E$ & $\mathrm{~N}$ & Qtz & PI & Fsp & Bt & $\mathrm{Hbl}$ & Cpx & Opx & Tr/Act & Ms & Chl & Op & Ap & Zrn & Ttn & Ep & Textura & Clasificación \\
\hline 11197 & JA 85 & 1113992 & 1307669 & 31 & 26 & 36,5 & 6,5 & & & & & $\mathrm{x}$ & $\mathrm{x}$ & $\operatorname{Tr}$ & $\operatorname{Tr}$ & $\operatorname{Tr}$ & $\mathrm{x}$ & $\mathrm{x}$ & $\begin{array}{c}\text { Alotriomorfa } \\
\text { inequigranular }\end{array}$ & Monzogranito \\
\hline 70653 & AG-2167A & 1139473 & 1333679 & 30 & 35 & 35 & 2 & & & & & 2 & & & & $\mathrm{Tr}$ & & & Hipidiomorfa & Monzogranito \\
\hline 70656 & AG-2174 & 1141472 & 1330738 & 25 & 30 & 37 & 4 & & & & & & 2 & & & & 1 & 1 & Hipidiomorfa & Monzogranito \\
\hline 70707 & AG-2176A & 1150862 & 1320268 & 35 & 35 & 25 & $<1$ & & & & & 5 & $\mathrm{x}$ & $\operatorname{Tr}$ & $\operatorname{Tr}$ & & $<1$ & $\mathrm{x}$ & $\begin{array}{c}\text { Holocristalina } \\
\text { alotriomorfa }\end{array}$ & Monzogranito \\
\hline 70798 & EA-707 & 1104412 & 1328939 & 27 & 40 & 21 & 5 & & & & & 5 & $\mathrm{x}$ & $\mathrm{x}$ & $\mathrm{x}$ & & $\mathrm{x}$ & $x$ & $\begin{array}{l}\text { Holocristalina } \\
\text { alotriomorfa, } \\
\text { micrográfica }\end{array}$ & Monzogranito \\
\hline 70800 & EA-714 & 1101902 & 1327639 & 38 & 34 & 21 & 4 & & & & & & $\mathrm{x}$ & 2 & $\mathrm{x}$ & $\mathrm{x}$ & & & $\begin{array}{c}\text { Holocristalina } \\
\text { alotriomorfa }\end{array}$ & Monzogranito \\
\hline 70802 & EA-719 & 1103372 & 1328379 & 26 & 37 & 27 & 8 & & & & & & & 1 & $\mathrm{x}$ & $\mathrm{x}$ & & $\mathrm{x}$ & $\begin{array}{c}\text { Holocristalina } \\
\text { alotriomorfa }\end{array}$ & Monzogranito \\
\hline 70805 & EA-729 & 1096022 & 1329249 & 25 & 27 & 45 & 3 & & & & & & $\mathrm{x}$ & $\mathrm{x}$ & $\mathrm{x}$ & $\mathrm{x}$ & & $x$ & $\begin{array}{c}\text { Holocristalina } \\
\text { alotriomorfa }\end{array}$ & Monzogranito \\
\hline 70810 & EA-751 & 1094572 & 1323599 & 43 & 22 & 35 & 0,5 & & & & & 0,5 & & $<1$ & & & & & $\begin{array}{c}\text { Holocristalina } \\
\text { alotriomorfa }\end{array}$ & Monzogranito \\
\hline 70812 & $\mathrm{HM}-100$ & 1100782 & 1327719 & 32 & 32 & 35 & $\mathrm{x}$ & & & & & & $\mathrm{x}$ & $\mathrm{x}$ & $\mathrm{x}$ & & $\mathrm{x}$ & $\mathrm{x}$ & $\begin{array}{c}\text { Holocristalina } \\
\text { alotriomorfa }\end{array}$ & Monzogranito \\
\hline 70814 & HM-108 & 1097402 & 1328479 & 32 & 33 & 34 & & & & & & $\mathrm{x}$ & $\mathrm{x}$ & $\mathrm{x}$ & & $\operatorname{Tr}$ & & $\mathrm{x}$ & $\begin{array}{c}\text { Holocristalina } \\
\text { alotriomorfa }\end{array}$ & Monzogranito \\
\hline 70815 & HM-111 & 1097102 & 1328719 & 22 & 43 & 33 & 2 & & & & & & $x$ & $\mathrm{x}$ & $\mathrm{x}$ & $\mathrm{x}$ & $\mathrm{x}$ & & $\begin{array}{c}\text { Holocristalina } \\
\text { alotriomorfa }\end{array}$ & Monzogranito \\
\hline 70817 & $\mathrm{HM}-114$ & 1095402 & 1326199 & 27 & 37 & 33 & 1 & & & & & 1 & & 1 & & $\mathrm{x}$ & $\operatorname{Tr}$ & $\mathrm{x}$ & $\begin{array}{c}\text { Holocristalina } \\
\text { alotriomorfa }\end{array}$ & Monzogranito \\
\hline 70818 & HM-115 & 1096302 & 1326829 & 34 & 25 & 37 & 1 & & & & & & $x$ & $\operatorname{Tr}$ & & & & & $\begin{array}{c}\text { Holocristalina } \\
\text { alotriomorfa }\end{array}$ & Monzogranito \\
\hline 70819 & $\mathrm{HM}-116$ & 1097682 & 1327659 & 22 & 37 & 40 & 1 & & & & & & $\mathrm{x}$ & 1 & $\mathrm{x}$ & $x$ & $x$ & $x$ & $\begin{array}{c}\text { Holocristalina } \\
\text { alotriomorfa }\end{array}$ & Monzogranito \\
\hline 70822 & HM-136 & 1095522 & 1322989 & 35 & 24 & 39 & 1 & & & & & $\mathrm{x}$ & & 1 & & $\mathrm{x}$ & & $\mathrm{x}$ & $\begin{array}{c}\text { Holocristalina } \\
\text { alotriomorfa }\end{array}$ & Monzogranito \\
\hline 70828 & HM-146 & 1101152 & 1320839 & 36 & 31 & 30 & 2,5 & & & & & & $\mathrm{x}$ & $\mathrm{x}$ & & $\mathrm{x}$ & $\mathrm{x}$ & & $\begin{array}{c}\text { Holocristalina } \\
\text { alotriomorfa }\end{array}$ & Monzogranito \\
\hline 70829 & HM-150 & 1090932 & 1327329 & 21 & 19 & 59 & 1 & & & & & & $\mathrm{x}$ & $\mathrm{x}$ & & & $\mathrm{x}$ & & $\begin{array}{c}\text { Holocristalina } \\
\text { alotriomorfa }\end{array}$ & Monzogranito \\
\hline 70830 & HM-152 & 1091712 & 1328739 & 32 & 31 & 37 & $<1$ & & & & & $\mathrm{x}$ & & $\operatorname{Tr}$ & & ? & & $\mathrm{x}$ & $\begin{array}{c}\text { Holocristalina } \\
\text { alotriomorfa }\end{array}$ & Monzogranito \\
\hline 70831 & HM-153 & 1096002 & 1329299 & 25 & 36 & 32 & 5 & & & & & & $\mathrm{x}$ & 1 & & & & $\mathrm{x}$ & $\begin{array}{c}\text { Holocristalina } \\
\text { alotriomorfa }\end{array}$ & Monzogranito \\
\hline 70832 & HM-154 & 1095722 & 1329549 & 22 & 32 & 44 & & & & & & 2 & & $\mathrm{x}$ & & & & & $\begin{array}{c}\text { Holocristalina } \\
\text { alotriomorfa }\end{array}$ & Monzogranito \\
\hline 70833 & HM-155 & 1095432 & 1329839 & 34 & 30 & 35 & 1 & & & & & & $x$ & $\operatorname{Tr}$ & $x$ & $\mathrm{x}$ & & $x$ & $\begin{array}{c}\text { Holocristalina } \\
\text { alotriomorfa }\end{array}$ & Monzogranito \\
\hline 70834 & HM-4159 & 1101932 & 1327099 & 29 & 25 & 44 & $\mathrm{x}$ & & & & & 1 & $\mathrm{x}$ & $\mathrm{x}$ & $\mathrm{x}$ & & $\mathrm{x}$ & $\mathrm{x}$ & $\begin{array}{c}\text { Holocristalina } \\
\text { alotriomorfa }\end{array}$ & Monzogranito \\
\hline 70855 & LJM-425 & 1105532 & 1340279 & 41 & 26 & 31 & & & & & & & $\mathrm{x}$ & $\mathrm{x}$ & $\mathrm{x}$ & $\mathrm{x}$ & $\mathrm{x}$ & $\mathrm{x}$ & $\begin{array}{c}\text { Holocristalina } \\
\text { alotriomorfa }\end{array}$ & Monzogranito \\
\hline 70856 & LJM-426 & 1098772 & 1337669 & 31 & 42 & 24 & & & & & & & $\mathrm{x}$ & $\mathrm{x}$ & $\mathrm{x}$ & $\mathrm{x}$ & $\mathrm{x}$ & $\mathrm{x}$ & $\begin{array}{c}\text { Holocristalina } \\
\text { alotriomorfa }\end{array}$ & Monzogranito \\
\hline 70858 & LJM-427 & 1099852 & 1337779 & 44 & 31 & 24 & & & & & & & $\mathrm{x}$ & $\mathrm{x}$ & $\mathrm{x}$ & & & $\mathrm{x}$ & $\begin{array}{c}\text { Holocristalina } \\
\text { alotriomorfa }\end{array}$ & Monzogranito \\
\hline 70860 & LJM-429 & 1101802 & 1338039 & 36 & 35 & 24 & $\mathrm{x}$ & & & & & $\mathrm{x}$ & & $\mathrm{x}$ & $\mathrm{x}$ & & & $\mathrm{x}$ & $\begin{array}{c}\text { Holocristalina } \\
\text { alotriomorfa }\end{array}$ & Monzogranito \\
\hline 70864 & LJM-433 & 1103722 & 1328469 & 27 & 34 & 35 & 3 & & & & & & $\mathrm{x}$ & $x$ & $\mathrm{x}$ & $\mathrm{x}$ & $\mathrm{x}$ & $\mathrm{x}$ & $\begin{array}{c}\text { Holocristalina } \\
\text { alotriomorfa }\end{array}$ & Monzogranito \\
\hline 70867 & LJM-436 & 1105002 & 1338679 & 28 & 30 & 41 & 1 & & & & $x$ ? & & $\mathrm{x}$ & $\mathrm{x}$ & $\mathrm{x}$ & $\mathrm{x}$ & & $\mathrm{x}$ & $\begin{array}{c}\text { Holocristalina } \\
\text { alotriomorfa con } \\
\text { efectos cataclásticos }\end{array}$ & Monzogranito \\
\hline 70868 & LJM-437 & 1104782 & 1339729 & 16 & 40 & 44 & & & & & & & $\mathrm{x}$ & $x$ & & & & $\mathrm{x}$ & Hipidiomorfa & Monzogranito \\
\hline 70874 & LJM-442 & 1098802 & 1337949 & 38,5 & 29,5 & 24,5 & & $\operatorname{Tr}$ & & & & & 5 & & $\operatorname{Tr}$ & & 1 & 2,1 & $\begin{array}{l}\text { Hipidiomorfa } \\
\text { poiquilítica con } \\
\text { antipertitas }\end{array}$ & Monzogranito \\
\hline 70894 & LJM-463 & 1105242 & 1338659 & 31 & 29,7 & 36,2 & & & & & & & 2,4 & $\mathrm{x}$ & $\mathrm{x}$ & & & $\mathrm{x}$ & Hipidiomorfa & Monzogranito \\
\hline 70896 & LJM-465 & 1093682 & 1337199 & 26,7 & 32 & 32 & & 1 & & & & & & $\operatorname{Tr}$ & & & $\operatorname{Tr}$ & $\operatorname{Tr}$ & Hipidiomorfa & Monzogranito \\
\hline 70921 & JR-839 & 1105082 & 1338179 & 29,3 & 29 & 36,5 & & & & & & & 0,5 & & & & & & Alotriomorfa & Monzogranito \\
\hline 70922 & JR-840 & 1105192 & 1337879 & 33,5 & 41 & 23,2 & 1,7 & $\operatorname{Tr}$ & & & & & $x$ & $\mathrm{x}$ & & & & 0,6 & Holocristalina & Monzogranito \\
\hline 70924 & JR-842 & 1105252 & 1336859 & 22 & 39 & 32 & 0,9 & & & & & & 3,1 & 0,7 & $\operatorname{Tr}$ & & & 2,4 & Alotriomorfa & Monzogranito \\
\hline 70927 & JR-845 & 1105902 & 1338489 & 31,5 & 25 & 38,5 & & & & & & 0,2 & 3,8 & & & & & 0,6 & $\begin{array}{l}\text { Hipidiomorfa con } \\
\text { protoclasis }\end{array}$ & Monzogranito \\
\hline 70928 & JR-846 & 1106242 & 1338389 & 35 & 25,5 & 36 & 0,5 & & & & & & 3,3 & 0,5 & $\operatorname{Tr}$ & & & & $\begin{array}{l}\text { Porfirítica con matriz } \\
\text { fanerítica }\end{array}$ & Monzogranito \\
\hline 70929 & JR-847 & 1106212 & 1338379 & 27,5 & 29 & 42 & & & & & & & $\mathrm{x}$ & 0,5 & & & & 1 & $\begin{array}{l}\text { Alotriomorfa de } \\
\text { grano fino }\end{array}$ & Monzogranito \\
\hline 70966 & AG-2253B & 1105172 & 1340689 & 30,5 & 25,5 & 38 & & & & & & & 5 & 1 & & $\operatorname{Tr}$ & & & Hipidiomorfa & Monzogranito \\
\hline 70969 & AG-2255 & 1104472 & 1338479 & 30,5 & 27,5 & 34 & 6 & & & & & & 2 & 1 & & & & & Hipidiomorfa & Monzogranito \\
\hline 72039 & HM-206 & 1099952 & 1321999 & 40,5 & 32,5 & 24 & & & & & & $\mathrm{Tr}$ & 2 & 0,2 & & $\operatorname{Tr}$ & & 0,2 & $\begin{array}{c}\text { Fanerítica, } \\
\text { mirmequítica y } \\
\text { pertítica }\end{array}$ & Monzogranito \\
\hline 72041 & HM-214 & 1102412 & 1328779 & 20 & 20 & 35 & 10 & & & & & & 2 & 1 & $\operatorname{Tr}$ & $\operatorname{Tr}$ & 2 & 5 & $\begin{array}{c}\text { Holocristalina pertítica } \\
\text { y poiquilítica }\end{array}$ & Monzogranito \\
\hline 72059 & HM-262 & 1098152 & 1340339 & 43 & 32 & 22,5 & & & & & & & 2,3 & & & $\mathrm{x}$ & & & Hipidiomorfa & Monzogranito \\
\hline 72062 & $\mathrm{HM}-272 \mathrm{~B}$ & 1100083 & 1341160 & 32 & 23 & 41 & & & & & & & 1 & 1 & & & & $\mathrm{x}$ & Hipidiomorfa pertítica & Monzogranito \\
\hline 72063 & HM-287 & 1102422 & 1343409 & 42,5 & 23 & 32,5 & & & & & & & 1 & 1 & & & & & Hipidiomorfa & Monzogranito \\
\hline 74341 & LJM 1001 & 1103423 & 1357969 & 20 & 40 & 30 & 2 & 3 & & & & & $\operatorname{Tr}$ & 1 & 1 & $\operatorname{Tr}$ & 1 & & Hipidiomorfa & Monzogranito \\
\hline 74344 & LJM 1010 & 1103103 & 1356279 & 30 & 25 & 35 & 1,5 & 1,5 & & & & & 2,5 & & & & & 1 & Hipidiomorfa & Monzogranito \\
\hline 74429 & & 1099961 & 1363609 & 20,1 & 36,2 & 40,5 & 2,2 & & & & & 0,8 & & 0,2 & & & & & Hipidiomorfa & Monzogranito \\
\hline 74459 & OP-539 & 1095263 & 1353079 & 38 & 26 & 35 & 1 & & & & & & $\mathrm{x}$ & $\mathrm{x}$ & & $\mathrm{x}$ & & & $\begin{array}{c}\text { Holocristalina } \\
\text { alotriomorfa }\end{array}$ & Monzogranito \\
\hline 900953 & MIA-649A & 1107525 & 1305963 & 23,8 & 26,5 & 41,9 & 6,1 & & & & & $\mathrm{x}$ & $\mathrm{x}$ & 1,2 & 0,5 & $\operatorname{Tr}$ & & $\mathrm{x}$ & $\begin{array}{l}\text { Subidiomorfa } \\
\text { equigranular }\end{array}$ & Monzogranito \\
\hline
\end{tabular}




\begin{tabular}{|c|c|c|c|c|c|c|c|c|c|c|c|c|c|c|c|c|c|c|c|c|c|}
\hline IGM & N. campo & E & $\mathbf{N}$ & Qtz & PI & Fsp & Bt & $\mathrm{Hbl}$ & Cpx & Opx & Tr/Act & Ms & $\mathrm{Chl}$ & Op & Ap & Zrn & Ttn & Ep & Matriz & Textura & Clasificación \\
\hline 900969 & GR-6736 & 1107549 & 1318415 & 39,1 & 24,5 & 35,8 & 0,7 & & & & & $\operatorname{Tr}$ & & $\operatorname{Tr}$ & $\operatorname{Tr}$ & $\operatorname{Tr}$ & & & & Alotriomorfa & Monzogranito \\
\hline 900971 & GR-6740 & 1105544 & 1340405 & 32,7 & 30,8 & 34,3 & 1,3 & & & & & & & 0,6 & & $\operatorname{Tr}$ & & & & Alotriomorfa & Monzogranito \\
\hline 900974 & GR-6744 & 1084623 & 1395986 & 30,8 & 25,3 & 38,3 & 4,9 & & & & & & & 0,7 & $\operatorname{Tr}$ & $\operatorname{Tr}$ & & & & $\begin{array}{c}\text { Subidiomorfa } \\
\text { inequigranular }\end{array}$ & Monzogranito \\
\hline 70803 & EA-723 & 1100352 & 1326799 & 36 & 32 & 29 & & & & & & 1 & & 1 & & & & & & $\begin{array}{c}\text { Holocristalina } \\
\text { alotriomorfa }\end{array}$ & Monzogranito aplítico \\
\hline 70799 & EA-712 & 1103762 & 1328759 & 40 & 25 & 32 & & & & & & & $\mathrm{x}$ & $x$ & $\mathrm{x}$ & & $\mathrm{x}$ & 2 & & $\begin{array}{l}\text { Holocristalina } \\
\text { alotriomorfa, con } \\
\text { efectos cataclásticos }\end{array}$ & $\begin{array}{l}\text { Monzogranito con } \\
\text { efectos cataclásticos }\end{array}$ \\
\hline 70654 & AG-2167B & 1139472 & 1333678 & 40 & 25 & 31 & 4 & & & & & & & & & & & & & Hipidiomorfa & $\begin{array}{c}\text { Monzogranito } \\
\text { porfirítico }\end{array}$ \\
\hline 11198 & JA 86 & 1114102 & 1307559 & 23,5 & 25,5 & 45 & 6 & & & & & $\mathrm{x}$ & $\mathrm{x}$ & $\operatorname{Tr}$ & $\operatorname{Tr}$ & $\operatorname{Tr}$ & $\mathrm{x}$ & $x$ & & $\begin{array}{c}\text { Alotriomorfa } \\
\text { inequigranular }\end{array}$ & $\begin{array}{l}\text { Monzogranito límite } \\
\text { con sienogranito }\end{array}$ \\
\hline 70923 & JR-841 & 1105252 & 1337279 & 5,3 & 40,5 & 40 & $\mathrm{x}$ & & & & & & 1,5 & 0,5 & $\operatorname{Tr}$ & & & 5,1 & & $\begin{array}{c}\text { Hipidiomorfa } \\
\text { con deformación } \\
\text { cataclástica } \\
\end{array}$ & Monzonita \\
\hline 72042 & HM-215 & 1102012 & 1328729 & 8 & 35 & 30 & & 10 & & & & & & $x$ & & $x$ & 5 & 10 & & Hipiomorfa & Monzonita \\
\hline 70926 & JR-844 & 1105582 & 1338329 & 0,7 & 35,5 & 53,5 & & & & & & & 3,8 & 0,3 & & & & 5,4 & & Alotriomorfa & Monzonita brechada \\
\hline 70816 & HM-112 & 1094922 & 1326399 & 1 & 53 & 45 & 1 & & & & & $x$ & $\mathrm{x}$ & $x$ & $\mathrm{x}$ & $\mathrm{x}$ & & & & $\begin{array}{c}\text { Holocristalina } \\
\text { alotriomorfa con } \\
\text { efectos cataclásticos }\end{array}$ & $\begin{array}{l}\text { Monzonita con } \\
\text { cataclasis }\end{array}$ \\
\hline 70873 & LJM-441A & 1105113 & 1340560 & 9 & & & & & & & & & 80 & & & & 1 & & & Holocristalina & Roca cloritizada \\
\hline 70809 & EA-739 & 1094572 & 1326629 & 54 & & 29 & $\mathrm{x}$ & & & & & & & & & $<1$ & & 16 & & $\begin{array}{c}\text { Holocristalina } \\
\text { alotriomorfa }\end{array}$ & Granito \\
\hline 10939 & $\mathrm{HCH} 51$ & 1103672 & 1338299 & 34,2 & 21,2 & 41,4 & 3,2 & & & & & & & $\operatorname{Tr}$ & & & & & & $\begin{array}{c}\text { Holocristalina } \\
\text { inequigranular }\end{array}$ & Sienogranito \\
\hline 10981 & & 1096790 & 1368704 & 31,3 & 22,9 & 45 & 0,8 & & & & & $\operatorname{Tr}$ & & $\operatorname{Tr}$ & & $\operatorname{Tr}$ & & & & Alotriomorfa & Sienogranito \\
\hline 11177 & JA 65 & 1114922 & 1300209 & 23,5 & 22,5 & 46 & 7 & & & & & & $\mathrm{x}$ & 1 & $\operatorname{Tr}$ & $\operatorname{Tr}$ & & $\mathrm{x}$ & & $\begin{array}{c}\text { Hipidiomorfa } \\
\text { inequigranular }\end{array}$ & Sienogranito \\
\hline 11461 & EA 280 & 1107222 & 1314129 & 30,6 & 21,3 & 46,3 & 0,8 & & & & & & & 1 & & $\operatorname{Tr}$ & & & & Alotriomorfa & Sienogranito \\
\hline 72040 & HM-211 & 1097772 & 1322639 & 37 & 19,6 & 41 & & & & & & 2 & $\mathrm{x}$ & 0,1 & 0,2 & 0,2 & 0,2 & & & Hipidiomorfa & Sienogranito \\
\hline 72043 & HM-219 & 1091882 & 1329999 & 20 & 22 & 54 & 4 & & & & & & $x$ & $x$ & & $x$ & $\mathrm{x}$ & $x$ & & $\begin{array}{c}\text { Alotriomorfa, gráfica, } \\
\text { pertítica }\end{array}$ & Sienogranito \\
\hline 72060 & HM-267 & 1100542 & 1340539 & 30 & 20 & 46 & 2,5 & & & & & 1 & $\mathrm{x}$ & 0,5 & & & & $x$ & & Hipidiomorfa, pertítica & Sienogranito \\
\hline 74425 & & 1101736 & 1362608 & 45,1 & 6,9 & 47,1 & 0,9 & & & & & & & $\operatorname{Tr}$ & & & & & & Hipidiomorfa & Sienogranito \\
\hline 901011 & MIA-650B & 1099016 & 1313299 & 26,5 & 21 & 45,4 & 4,8 & & & & & $\operatorname{Tr}$ & & 1,6 & & 0,7 & & & & $\begin{array}{c}\text { Alotriomorfa } \\
\text { inequigranular }\end{array}$ & Sienogranito \\
\hline 901028 & TCR-388 & 1089344 & 1335770 & 28 & 14 & 53,5 & 2 & & & & & & $x$ & 1,5 & & & 0,5 & $x$ & & $\begin{array}{c}\text { Hipidiomorfa gráfica, } \\
\text { pertítica }\end{array}$ & Sienogranito \\
\hline 10874 & EA 171 & 1105102 & 1317149 & 37,2 & 54,5 & 0,8 & 7,3 & & & & & & $x$ & $\operatorname{Tr}$ & 0,2 & $\operatorname{Tr}$ & $\operatorname{Tr}$ & $\mathrm{x}$ & & Subidiomorfa & Tonalita \\
\hline 31180 & EV 2 & 1081873 & 1354259 & 24 & 52 & & 10 & 12 & & & & & & $\operatorname{Tr}$ & $\operatorname{Tr}$ & & 2 & $\mathrm{x}$ & & Hipidiomorfa & Tonalita \\
\hline 74932 & LJM-1419 & 1081573 & 1388019 & 21 & 41 & 4,5 & 23 & 9 & & & & & & 0,5 & 0,3 & 0,5 & 0,2 & $\mathrm{x}$ & & Hipidiomorfa & Tonalita \\
\hline
\end{tabular}

Símbolos de minerales: Qtz: cuarzo; PI: plagioclasa; Fsp: feldespato; Bt: biotita; Hbl: hornblenda; Cpx: clinopiroxeno, Opx: ortopiroxeno; Tr: tremolita, Act: actinolita; Ms: moscovita; Chl: clorita; Op: opacos; Ap: apatito; Zrn: circón, Ttn: titanita; Ep: epidota.

E: este; N: norte 


\section{Anexo 2. Análisis isotópicos U-Pb en circón} GR-6743, análisis isotópicos U-Pb en circón

\begin{tabular}{|c|c|c|c|c|c|c|c|c|c|c|c|c|c|c|c|c|c|c|c|c|c|c|}
\hline $\mathrm{Zr}$ & $\underset{(p p m) 1}{U}$ & $\begin{array}{c}\text { Th } \\
(\mathrm{ppm}) 1\end{array}$ & $\mathrm{Th} / \mathrm{U}$ & ${ }^{207} \mathrm{~Pb} /{ }^{206} \mathrm{~Pb}$ & $\begin{array}{l} \pm 2 s \\
\text { abs }\end{array}$ & ${ }^{207} \mathrm{~Pb} /{ }^{235} \mathrm{U}$ & $\begin{array}{l} \pm 2 s \\
\text { abs }\end{array}$ & ${ }^{206} \mathrm{~Pb} /{ }^{238} \mathrm{U}$ & $\begin{array}{l} \pm 2 s \\
\text { abs }\end{array}$ & $\begin{array}{l}\text { Correlación } \\
\text { de errores }\end{array}$ & ${ }^{208} \mathrm{~Pb} /{ }^{232} \mathrm{Th}$ & $\begin{array}{l} \pm 2 s \\
\text { abs }\end{array}$ & Disc\% & Error & ${ }^{206} \mathrm{~Pb} / 238 \mathrm{U}$ & $\begin{array}{c} \pm \\
2 s\end{array}$ & ${ }^{207} \mathrm{~Pb} /{ }^{235} \mathrm{U}$ & $\begin{array}{c} \pm \\
2 \mathrm{~s}\end{array}$ & ${ }^{207} \mathrm{~Pb} /{ }^{206} \mathrm{~Pb}$ & $\begin{array}{c} \pm \\
2 \mathrm{~s}\end{array}$ & $\begin{array}{l}\text { Mejor } \\
\text { edad } \\
\text { (Ma) }\end{array}$ & $\begin{array}{c} \pm \\
2 \mathrm{~s}\end{array}$ \\
\hline Zr-017 & 156,9 & 177 & 1,1 & 0,0976 & 0,007 & 0,403 & 0,02 & 0,0306 & 0,0007 & 0,083 & 0,013 & 0,0006 & 43,382 & $8,33 \%$ & 194,2 & 4,5 & 343 & 17 & 1.560 & 130 & 1.560 & 130 \\
\hline Zr-028 & 243 & 327 & 1,3 & 0,0922 & 0,008 & 0,442 & 0,04 & 0,0346 & 0,0011 & 0,293 & 0,013 & 0,0016 & 40,863 & $9,66 \%$ & 219,4 & 6,7 & 371 & 29 & 1.450 & 140 & 1.450 & 140 \\
\hline Zr-012 & 267 & 625 & 2,3 & 0,059 & 0,021 & 0,24 & 0,11 & 0,0303 & 0,0012 & 0,536 & 0,01 & 0,0013 & 13,288 & $3,84 \%$ & 192,5 & 7,4 & 222 & 69 & 540 & 310 & 192,5 & 7,4 \\
\hline Zr-031 & 268,9 & 420 & 1,6 & 0,0543 & 0,004 & 0,22 & 0,01 & 0,0293 & 0,0008 & 0,114 & 0,009 & 0,0004 & 7,264 & $2,68 \%$ & 186,4 & 5 & 201 & 11 & 400 & 150 & 186,4 & 5 \\
\hline Zr-043 & 207,8 & 299,4 & 1,4 & 0,0536 & 0,004 & 0,216 & 0,02 & 0,0298 & 0,0007 & 0,11 & 0,009 & 0,0004 & 4,444 & $2,27 \%$ & 189,2 & 4,3 & 198 & 13 & 350 & 150 & 189,2 & 4,3 \\
\hline Zr-011 & 123,5 & 122,7 & 1 & 0,0489 & 0,004 & 0,206 & 0,02 & 0,0301 & 0,0008 & 0,078 & 0,009 & 0,0005 & $-1,111$ & $2,67 \%$ & 191,1 & 5,1 & 189 & 14 & 140 & 180 & 191,1 & 5,1 \\
\hline Zr-039 & 302 & 437 & 1,4 & 0,054 & 0,005 & 0,224 & 0,02 & 0,0302 & 0,0007 & 0,14 & 0,009 & 0,0007 & 6,390 & $2,29 \%$ & 191,9 & 4,4 & 205 & 18 & 340 & 170 & 191,9 & 4,4 \\
\hline Zr-038 & 630 & 956 & 1,5 & 0,0501 & 0,003 & 0,206 & 0,01 & 0,0304 & 0,0005 & 0,29 & 0,009 & 0,0004 & $-1,634$ & $1,56 \%$ & 192,8 & 3 & 189,7 & 8,5 & 200 & 120 & 192,8 & 3 \\
\hline Zr-020 & 499 & 856 & 1,7 & 0,0509 & 0,002 & 0,2133 & 0,01 & 0,0304 & 0,0006 & 0,023 & 0,009 & 0,0004 & 1,478 & $1,81 \%$ & 193,3 & 3,5 & 196,2 & 6,8 & 220 & 100 & 193,3 & 3,5 \\
\hline Zr-013 & 349,4 & 259 & 0,7 & 0,0517 & 0,003 & 0,217 & 0,01 & 0,0305 & 0,0005 & 0,087 & 0,01 & 0,0004 & 2,814 & $1,76 \%$ & 193,4 & 3,4 & 199 & 11 & 240 & 140 & 193,4 & 3,4 \\
\hline Zr-016 & 358 & 552 & 1,5 & 0,0505 & 0,003 & 0,212 & 0,01 & 0,0305 & 0,0006 & 0,062 & 0,01 & 0,0004 & 1,627 & $1,76 \%$ & 193,5 & 3,4 & 196,7 & 9,3 & 220 & 120 & 193,5 & 3,4 \\
\hline Zr-029 & 437 & 498 & 1,1 & 0,0522 & 0,004 & 0,226 & 0,02 & 0,0305 & 0,001 & 0,215 & 0,01 & 0,0006 & 6,425 & $3,10 \%$ & 193,7 & 6 & 207 & 13 & 320 & 120 & 193,7 & 6 \\
\hline Zr-018 & 202 & 261 & 1,3 & 0,0515 & 0,004 & 0,214 & 0,02 & 0,0305 & 0,0008 & 0,222 & 0,009 & 0,0005 & 2,172 & $2,43 \%$ & 193,7 & 4,7 & 198 & 12 & 230 & 160 & 193,7 & 4,7 \\
\hline Zr-021 & 582 & 1.000 & 1,7 & 0,0513 & 0,003 & 0,21 & 0,01 & 0,0305 & 0,0008 & 0,33 & 0,009 & 0,0005 & 1,173 & $2,53 \%$ & 193,7 & 4,9 & 196 & 11 & 230 & 140 & 193,7 & 4,9 \\
\hline Zr-041 & 158,6 & 142,6 & 0,9 & 0,0539 & 0,005 & 0,228 & 0,02 & 0,0306 & 0,0007 & 0,051 & 0,009 & 0,0005 & 5,728 & $2,27 \%$ & 194,2 & 4,4 & 206 & 19 & 310 & 220 & 194,2 & 4,4 \\
\hline Zr-033 & 350,5 & 1240 & 3,5 & 0,0499 & 0,004 & 0,214 & 0,01 & 0,0307 & 0,0006 & 0,026 & 0,01 & 0,0006 & 0,612 & $1,90 \%$ & 194,8 & 3,7 & 196 & 12 & 180 & 150 & 194,8 & 3,7 \\
\hline Zr-034 & 282,5 & 206,2 & 0,7 & 0,051 & 0,004 & 0,213 & 0,01 & 0,0307 & 0,0006 & 0,021 & 0,01 & 0,0005 & 0,964 & $1,95 \%$ & 195,1 & 3,8 & 197 & 11 & 200 & 150 & 195,1 & 3,8 \\
\hline Zr-032 & 444 & 865 & 1,9 & 0,0535 & 0,004 & 0,221 & 0,01 & 0,0308 & 0,0005 & 0,394 & 0,01 & 0,0004 & 3,317 & $1,69 \%$ & 195,3 & 3,3 & 202 & 10 & 310 & 140 & 195,3 & 3,3 \\
\hline Zr-044 & 261,2 & 284,4 & 1,1 & 0,0497 & 0,003 & 0,212 & 0,01 & 0,0308 & 0,0007 & 0,128 & 0,009 & 0,0004 & $-0,360$ & $2,20 \%$ & 195,4 & 4,3 & 194,7 & 9,6 & 160 & 130 & 195,4 & 4,3 \\
\hline Zr-025 & 380,1 & 485 & 1,3 & 0,0514 & 0,003 & 0,217 & 0,01 & 0,0308 & 0,0006 & 0,23 & 0,01 & 0,0004 & 1,111 & $1,94 \%$ & 195,8 & 3,8 & 198 & 11 & 240 & 140 & 195,8 & 3,8 \\
\hline Zr-023 & 124,4 & 169,6 & 1,4 & 0,0492 & 0,005 & 0,21 & 0,02 & 0,0308 & 0,0007 & 0,07 & 0,01 & 0,0005 & $-1,451$ & $2,25 \%$ & 195,8 & 4,4 & 193 & 15 & 160 & 180 & 195,8 & 4,4 \\
\hline Zr-014 & 554 & 780 & 1,4 & 0,0518 & 0,003 & 0,219 & 0,01 & 0,0311 & 0,0006 & 0,174 & 0,01 & 0,0004 & 2,522 & $2,03 \%$ & 197,1 & 4 & 202,2 & 8,6 & 250 & 120 & 197,1 & 4 \\
\hline Zr-015 & 62,8 & 104 & 1,7 & 0,0524 & 0,006 & 0,225 & 0,02 & 0,0312 & 0,0011 & 0,018 & 0,01 & 0,0006 & 2,206 & $3,56 \%$ & 199,5 & 7,1 & 204 & 20 & 200 & 220 & 199,5 & 7,1 \\
\hline Zr-010 & 491 & 708 & 1,4 & 0,0513 & 0,003 & 0,223 & 0,01 & 0,0315 & 0,0006 & 0,245 & 0,01 & 0,0005 & 2,157 & $1,85 \%$ & 199,6 & 3,7 & 204 & 8,9 & 240 & 120 & 199,6 & 3,7 \\
\hline Zr-037 & 305 & 466 & 1,5 & 0,0525 & 0,003 & 0,227 & 0,01 & 0,0317 & 0,0007 & 0,121 & 0,01 & 0,0005 & 2,947 & $2,29 \%$ & 200,9 & 4,6 & 207 & 11 & 300 & 140 & 200,9 & 4,6 \\
\hline Zr-042 & 235 & 318 & 1,4 & 0,0509 & 0,006 & 0,22 & 0,03 & 0,0317 & 0,0015 & 0,021 & 0,01 & 0,0013 & 0,000 & $4,58 \%$ & 201 & 9,2 & 201 & 22 & 210 & 220 & 201 & 9,2 \\
\hline Zr-022 & 138,1 & 140,1 & 1 & 0,0493 & 0,004 & 0,216 & 0,02 & 0,0319 & 0,0009 & 0,052 & 0,01 & 0,0006 & $-2,690$ & $2,62 \%$ & 202,3 & 5,3 & 197 & 14 & 120 & 170 & 202,3 & 5,3 \\
\hline Zr-019 & 155 & 184 & 1,2 & 0,0516 & 0,004 & 0,221 & 0,02 & 0,0319 & 0,0008 & 0,101 & 0,01 & 0,0005 & $-0,746$ & $2,52 \%$ & 202,5 & 5,1 & 201 & 14 & 210 & 170 & 202,5 & 5,1 \\
\hline Zr-036 & 104,3 & 71,1 & 0,7 & 0,0515 & 0,005 & 0,233 & 0,02 & 0,032 & 0,001 & 0,194 & 0,012 & 0,0008 & 3,744 & $2,95 \%$ & 203,1 & 6 & 211 & 18 & 220 & 210 & 203,1 & 6 \\
\hline Zr-026 & 183,5 & 355 & 1,9 & 0,0536 & 0,005 & 0,229 & 0,02 & 0,0321 & 0,0007 & 0,081 & 0,01 & 0,0005 & 2,679 & $2,11 \%$ & 203,4 & 4,3 & 209 & 15 & 290 & 180 & 203,4 & 4,3 \\
\hline Zr-035 & 195,5 & 257,1 & 1,3 & 0,0517 & 0,003 & 0,229 & 0,01 & 0,0322 & 0,0008 & 0,258 & 0,01 & 0,0005 & 2,810 & $2,50 \%$ & 204,1 & 5,1 & 210 & 11 & 260 & 130 & 204,1 & 5,1 \\
\hline Zr-024 & 154,7 & 147 & 1 & 0,0507 & 0,004 & 0,224 & 0,02 & 0,0323 & 0,0009 & 0,131 & 0,011 & 0,0007 & 0,631 & $2,69 \%$ & 204,7 & 5,5 & 206 & 12 & 220 & 170 & 204,7 & 5,5 \\
\hline Zr-027 & 130,6 & 176 & 1,3 & 0,0486 & 0,004 & 0,212 & 0,02 & 0,0324 & 0,001 & 0,013 & 0,01 & 0,0006 & $-5,773$ & $2,92 \%$ & 205,2 & 6 & 194 & 14 & 120 & 180 & 205,2 & 6 \\
\hline Zr-040 & 105,2 & 64,8 & 0,6 & 0,0563 & 0,005 & 0,263 & 0,02 & 0,0336 & 0,0009 & 0,01 & 0,012 & 0,0008 & 9,873 & $2,73 \%$ & 212,7 & 5,8 & 236 & 19 & 410 & 190 & 212,7 & 5,8 \\
\hline Zr-030 & 77 & 122 & 1,6 & 0,051 & 0,005 & 0,252 & 0,03 & 0,0365 & 0,0013 & 0,049 & 0,015 & 0,0009 & $-2,622$ & $3,42 \%$ & 230,9 & 7,9 & 225 & 20 & 150 & 200 & 230,9 & 7,9 \\
\hline
\end{tabular}


GZ-6848A, análisis isotópicos U-Pb en circón

\begin{tabular}{|c|c|c|c|c|c|c|c|c|c|c|c|c|c|}
\hline $\mathrm{Zr}$ & $\begin{array}{l}\text { Relación final } \\
{ }^{207} \mathrm{~Pb} /{ }^{235} \mathrm{U}\end{array}$ & $\begin{array}{c}\text { Error interno } \\
\text { relación final } \\
{ }^{207} \mathrm{~Pb} / 235 \mathrm{U} \text { a } 2 \\
\text { D. E. }\end{array}$ & $\begin{array}{l}\text { Relación final } \\
{ }^{206 \mathrm{~Pb} / 238 \mathrm{U}}\end{array}$ & $\begin{array}{c}\text { Error interno } \\
\text { relación final } \\
{ }^{206} \mathrm{~Pb} / 235 \mathrm{U} \text { a } 2 \\
\text { D. E. }\end{array}$ & $\begin{array}{l}\text { Ajuste error } \\
\text { de correlación } \\
\text { (datos } \\
\text { negativos) }\end{array}$ & $\begin{array}{c}\text { Error de } \\
\text { correlación } \\
{ }^{206} \mathrm{~Pb} /{ }^{238} \mathrm{U} \text { vs. } \\
{ }^{207} \mathrm{~Pb} /{ }^{235} \mathrm{U} \\
\end{array}$ & $\begin{array}{c}\text { Edad } \\
{ }^{207} \mathrm{~Pb} /{ }^{235} \mathrm{U} \\
(\mathrm{Ma})\end{array}$ & $\%$ disc & $\begin{array}{l}\text { Edad corregida } \\
{ }^{206} \mathrm{~Pb} /{ }^{238} \mathrm{U}(\mathrm{Ma})\end{array}$ & $\begin{array}{c} \pm \text { Error edad } \\
\text { corregida (Ma) }\end{array}$ & Error & $\begin{array}{l}\text { Aproximación } \\
{ }^{238} \mathrm{U}(\mathrm{ppm})\end{array}$ & $\mathrm{Th} / \mathrm{U}$ \\
\hline Zr-4 & 0,415 & 0,022 & 0,032 & 0,00053 & 0,10722 & 0,107 & 352 & 83,579 & 191,743 & 7,319 & 3,817 & 335,8 & 1,552 \\
\hline Zr-22 & 0,369 & 0,03 & 0,03241 & 0,00081 & 0,1 & $-0,023$ & 318 & 61,289 & 197,161 & 8,299 & 4,209 & 121,6 & 0,939 \\
\hline Zr-28 & 0,229 & 0,019 & 0,02893 & 0,00076 & 0,1 & $-0,018$ & 217 & 19,282 & 181,921 & 7,299 & 4,012 & 244 & 1,914 \\
\hline $\mathrm{Zr}-6$ & 0,243 & 0,018 & 0,03095 & 0,00048 & 0,029091 & 0,029 & 219 & 12,483 & 194,696 & 6,610 & 3,395 & 315 & 0,733 \\
\hline $\mathrm{Zr}-7$ & 0,229 & 0,014 & 0,02964 & 0,0006 & 0,25141 & 0,251 & 209 & 11,919 & 186,742 & 6,664 & 3,569 & 415 & 1,313 \\
\hline Zr-26 & 0,233 & 0,015 & 0,03008 & 0,00048 & 0,040081 & 0,040 & 211 & 11,186 & 189,772 & 6,392 & 3,368 & 191,6 & 1,279 \\
\hline $\mathrm{Zr}-30$ & 0,2383 & 0,006 & 0,03107 & 0,00033 & 0,28881 & 0,289 & 217,3 & 10,822 & 196,079 & 6,075 & 3,098 & 1.581 & 2,549 \\
\hline Zr-33 & 0,206 & 0,013 & 0,02918 & 0,00044 & 0,1 & $-0,010$ & 191 & 3,090 & 185,275 & 6,036 & 3,258 & 259 & 1,425 \\
\hline $\mathrm{Zr}-1$ & 0,1942 & 0,0077 & 0,02951 & 0,00046 & 0,14735 & 0,147 & 180,7 & $-3,884$ & 188,002 & 6,118 & 3,254 & 988 & 1,180 \\
\hline Zr-23 & 0,203 & 0,0071 & 0,02966 & 0,00027 & 0,18995 & 0,190 & 187,8 & $-0,423$ & 188,597 & 5,710 & 3,028 & 582 & 1,120 \\
\hline Zr-27 & 0,217 & 0,013 & 0,02996 & 0,00046 & 0,042252 & 0,042 & 197 & 3,715 & 189,944 & 6,289 & 3,311 & 218,7 & 1,582 \\
\hline $\mathrm{Zr}-20$ & 0,2181 & 0,0091 & 0,03035 & 0,00037 & 0,40463 & 0,405 & 199,7 & 3,863 & 192,273 & 6,101 & 3,173 & 635 & 2,819 \\
\hline$Z r-18$ & 0,207 & 0,015 & 0,03025 & 0,00048 & 0,078746 & 0,079 & 190 & $-1,215$ & 192,336 & 6,355 & 3,304 & 173,3 & 0,910 \\
\hline Zr-9 & 0,205 & 0,016 & 0,03055 & 0,0006 & 0,18016 & 0,180 & 195 & 0,524 & 193,984 & 6,658 & 3,432 & 147 & 1,388 \\
\hline $\mathrm{Zr}-13$ & 0,2157 & 0,0096 & 0,03064 & 0,00037 & 0,11466 & 0,115 & 198,3 & 2,105 & 194,212 & 6,110 & 3,146 & 705 & 2,369 \\
\hline $\mathrm{Zr}-32$ & 0,2132 & 0,0095 & 0,03066 & 0,00038 & 0,070827 & 0,071 & 195,5 & 0,436 & 194,652 & 6,161 & 3,165 & 493 & 1,929 \\
\hline $\mathrm{Zr}-21$ & 0,232 & 0,014 & 0,03092 & 0,00048 & 0,29584 & 0,296 & 210 & 7,507 & 195,337 & 6,453 & 3,303 & 207 & 1,111 \\
\hline$Z r-19$ & 0,198 & 0,015 & 0,03095 & 0,00048 & 0,1 & $-0,017$ & 183 & $-7,341$ & 197,498 & 6,469 & 3,275 & 168,2 & 1,435 \\
\hline $\mathrm{Zr}-16$ & 0,232 & 0,016 & 0,03136 & 0,0006 & 0,19326 & 0,193 & 214 & 8,073 & 198,015 & 6,712 & 3,389 & 114,8 & 1,890 \\
\hline$Z r-14$ & 0,208 & 0,0096 & 0,03114 & 0,00046 & 0,080814 & 0,081 & 192,4 & $-2,942$ & 198,233 & 6,391 & 3,224 & 360 & 1,767 \\
\hline $\mathrm{Zr}-38$ & 0,2182 & 0,0076 & 0,03125 & 0,00033 & 0,1747 & 0,175 & 200,8 & 1,243 & 198,336 & 6,105 & 3,078 & 850 & 1,247 \\
\hline $\mathrm{Zr}-37$ & 0,216 & 0,0078 & 0,03124 & 0,00031 & 0,1054 & 0,105 & 199,3 & 0,419 & 198,469 & 6,034 & 3,040 & 715 & 0,636 \\
\hline $\mathrm{Zr}-15$ & 0,2361 & 0,0077 & 0,0315 & 0,00056 & 0,40221 & 0,402 & 214,3 & 7,950 & 198,518 & 6,677 & 3,364 & 1.290 & 2,457 \\
\hline $\mathrm{Zr}-12$ & 0,2177 & 0,0092 & 0,03134 & 0,00034 & 0,1238 & 0,124 & 199,9 & 0,552 & 198,802 & 6,113 & 3,075 & 428 & 1,150 \\
\hline $\mathrm{Zr}-36$ & 0,239 & 0,01 & 0,03155 & 0,00046 & 0,3109 & 0,311 & 217,7 & 9,313 & 199,153 & 6,504 & 3,266 & 651 & 0,556 \\
\hline $\mathrm{Zr}-11$ & 0,2112 & 0,0072 & 0,03147 & 0,00044 & 0,22741 & 0,227 & 196 & $-1,922$ & 199,842 & 6,399 & 3,202 & 1.630 & 1,196 \\
\hline $\mathrm{Zr}-24$ & 0,2267 & 0,0072 & 0,03161 & 0,00033 & 0,21961 & 0,220 & 206,7 & 3,298 & 200,100 & 6,184 & 3,091 & 693 & 1,486 \\
\hline$Z r-3$ & 0,2165 & 0,0079 & 0,03165 & 0,00035 & 0,41338 & 0,413 & 198 & $-1,369$ & 200,749 & 6,228 & 3,102 & 878 & 0,772 \\
\hline Zr-35 & 0,2283 & 0,0086 & 0,03182 & 0,00035 & 0,15201 & 0,152 & 209,1 & 3,725 & 201,591 & 6,243 & 3,097 & 746 & 1,165 \\
\hline $\mathrm{Zr}-17$ & 0,205 & 0,014 & 0,03162 & 0,0005 & 0,022745 & 0,023 & 187 & $-7,244$ & 201,605 & 6,596 & 3,272 & 163,6 & 1,346 \\
\hline Zr-34 & 0,225 & 0,016 & 0,03199 & 0,00053 & 0,16757 & 0,168 & 205 & 1,106 & 202,758 & 6,704 & 3,307 & 200 & 1,370 \\
\hline $\mathrm{Zr}-10$ & 0,2141 & 0,0087 & 0,03193 & 0,00048 & 0,061266 & 0,061 & 196,3 & $-3,305$ & 203,009 & 6,585 & 3,244 & 443 & 0,837 \\
\hline Zr-29 & 0,222 & 0,012 & 0,0325 & 0,00045 & 0,12248 & 0,122 & 206 & $-0,226$ & 206,467 & 6,609 & 3,201 & 318 & 1,189 \\
\hline $\mathrm{Zr}-25$ & 0,58 & 0,022 & 0,0726 & 0,0012 & 0,53091 & 0,531 & 462 & 2,432 & 451,029 & 14,998 & 3,325 & 396,8 & 0,110 \\
\hline $\mathrm{Zr}-31$ & 1,455 & 0,03 & 0,1465 & 0,0021 & 0,56489 & 0,565 & 910 & 3,650 & 877,951 & 28,822 & 3,283 & 421,9 & 0,293 \\
\hline $\mathrm{Zr}-2$ & 1,768 & 0,037 & 0,1677 & 0,0017 & 0,5154 & 0,515 & 1.036 & 4,288 & 993,407 & 31,254 & 3,146 & 531 & 0,046 \\
\hline Zr-8 & 1,879 & 0,042 & 0,175 & 0,0019 & 0,23974 & 0,240 & 1.073 & 3,650 & $1.035,214$ & 32,979 & 3,186 & 278 & 0,190 \\
\hline Zr-5 & 2,05 & 0,043 & 0,194 & 0,0018 & 0,33612 & 0,336 & 1.133 & $-0,904$ & $1.143,332$ & 36,040 & 3,152 & 290 & 0,282 \\
\hline
\end{tabular}


JGB-642, análisis isotópicos U-Pb en circón

\begin{tabular}{|c|c|c|c|c|c|c|c|c|c|c|c|c|c|c|c|c|c|c|c|c|c|c|}
\hline $\mathrm{Zr}$ & $\underset{(\mathrm{ppm}) 1}{U}$ & $\begin{array}{c}\text { Th } \\
(\mathrm{ppm}) 1\end{array}$ & $\mathrm{Th} / \mathrm{U}$ & ${ }^{207} \mathrm{~Pb} /{ }^{206} \mathrm{~Pb}$ & $\begin{array}{l} \pm 2 \mathrm{~s} \\
\text { abs }\end{array}$ & ${ }^{207} \mathrm{~Pb} /{ }^{235} \mathrm{U}$ & $\begin{array}{l} \pm 2 s \\
\text { abs }\end{array}$ & ${ }^{206} \mathrm{~Pb} /{ }^{238} \mathrm{U}$ & $\begin{array}{l} \pm 2 \mathrm{~s} \\
\text { abs }\end{array}$ & $\begin{array}{c}\text { Correlación } \\
\text { de errores }\end{array}$ & ${ }^{208} \mathrm{~Pb} /{ }^{232} \mathrm{Th}$ & $\begin{array}{l} \pm 2 s \\
\text { abs }\end{array}$ & Disc \% & Error & ${ }^{206} \mathrm{~Pb} /{ }^{238} \mathrm{U}$ & $\pm 2 \mathrm{~s}$ & ${ }^{207} \mathrm{~Pb} /{ }^{235} \mathrm{U}$ & $\pm 2 \mathrm{~s}$ & ${ }^{207} \mathrm{~Pb} /{ }^{206} \mathrm{~Pb}$ & $\begin{array}{l} \pm \\
2 s\end{array}$ & $\begin{array}{l}\text { Mejor } \\
\text { edad } \\
(\mathrm{Ma})\end{array}$ & $\pm 2 \mathrm{~s}$ \\
\hline Zr-058 & 110 & 186 & 1,69 & 0,0970 & 0,0130 & 0,4480 & 0,0610 & 0,0330 & 0,0010 & 0,43 & 0,0128 & 0,0008 & 43,82 & 16,55 & 209,0 & 5,9 & 372,0 & 42,0 & $1.450,0$ & 240 & $1.450,0$ & 240,0 \\
\hline Zr-067 & 102 & 136 & 1,33 & 0,0813 & 0,0063 & 0,3530 & 0,0320 & 0,0308 & 0,0011 & 0,51 & 0,0121 & 0,0008 & 36,90 & 3,43 & 195,6 & 6,7 & 310,0 & 23,0 & $1.240,0$ & 110 & 195,6 & 6,7 \\
\hline Zr-047 & 71 & 75 & 1,06 & 0,0683 & 0,0089 & 0,2870 & 0,0380 & 0,0316 & 0,0013 & 0,12 & 0,0120 & 0,0009 & 22,21 & 3,94 & 200,7 & 7,9 & 258,0 & 29,0 & 970,0 & 140 & 200,7 & 7,9 \\
\hline Zr-040 & 33 & 44 & 1,33 & 0,0650 & 0,0098 & 0,2840 & 0,0380 & 0,0308 & 0,0017 & 0,18 & 0,0112 & 0,0009 & 21,29 & 5,10 & 196,0 & 10,0 & 249,0 & 30,0 & 840,0 & 130 & 196,0 & 10,0 \\
\hline Zr-057 & 207 & 170 & 0,82 & 0,0620 & 0,0044 & 0,2510 & 0,0180 & 0,0291 & 0,0006 & 0,34 & 0,0100 & 0,0005 & 18,32 & 2,06 & 184,6 & 3,8 & 226,0 & 14,0 & 690,0 & 77 & 184,6 & 3,8 \\
\hline Zr-069 & 222 & 449 & 2,02 & 0,0471 & 0,0034 & 0,2010 & 0,0140 & 0,0309 & 0,0006 & 0,09 & 0,0100 & 0,0004 & $-6,11$ & 1,94 & 196,3 & 3,8 & 185,0 & 11,0 & 323,0 & 78 & 196,3 & 3,8 \\
\hline Zr-068 & 115 & 147 & 1,28 & 0,0466 & 0,0037 & 0,2150 & 0,0160 & 0,0336 & 0,0008 & 0,13 & 0,0101 & 0,0005 & $-8,17$ & 2,35 & 213,1 & 5,0 & 197,0 & 14,0 & 221,0 & 68 & 213,1 & 5,0 \\
\hline Zr-041 & 111 & 113 & 1,02 & 0,0430 & 0,0037 & 0,1970 & 0,0170 & 0,0327 & 0,0009 & 0,13 & 0,0104 & 0,0005 & 12,83 & 2,79 & 207,6 & 5,8 & 184,0 & 14,0 & 304,0 & 95 & 207,6 & 5,8 \\
\hline Zr-070 & 206 & 351 & 1,70 & 0,0519 & 0,0034 & 0,2170 & 0,0120 & 0,0296 & 0,0007 & 0,05 & 0,0089 & 0,0004 & 5,63 & 2,24 & 187,8 & 4,2 & 199,0 & 10,0 & 355,0 & 68 & 187,8 & 4,2 \\
\hline Zr-056 & 241 & 397 & 1,65 & 0,0494 & 0,0026 & 0,2161 & 0,0095 & 0,0303 & 0,0006 & 0,03 & 0,0096 & 0,0004 & 2,98 & 1,98 & 192,2 & 3,8 & 198,1 & 7,9 & 382,0 & 56 & 192,2 & 3,8 \\
\hline Zr-039 & 184 & 587 & 3,19 & 0,0508 & 0,0037 & 0,2160 & 0,0160 & 0,0303 & 0,0007 & 0,16 & 0,0100 & 0,0004 & 4,28 & 2,13 & 192,4 & 4,1 & 201,0 & 13,0 & 360,0 & 77 & 192,4 & 4,1 \\
\hline Zr-048 & 279 & 436 & 1,56 & 0,0500 & 0,0036 & 0,2150 & 0,0140 & 0,0305 & 0,0006 & 0,07 & 0,0094 & 0,0004 & 2,07 & 1,81 & 193,9 & 3,5 & 198,0 & 11,0 & 304,0 & 64 & 193,9 & 3,5 \\
\hline Zr-038 & 131 & 266 & 2,03 & 0,0477 & 0,0042 & 0,2050 & 0,0160 & 0,0306 & 0,0008 & 0,05 & 0,0098 & 0,0004 & $-3,46$ & 2,52 & 194,5 & 4,9 & 188,0 & 14,0 & 346,0 & 83 & 194,5 & 4,9 \\
\hline Zr-065 & 348 & 834 & 2,40 & 0,0495 & 0,0024 & 0,2083 & 0,0090 & 0,0307 & 0,0006 & 0,10 & 0,0095 & 0,0003 & $-0,88$ & 1,80 & 194,7 & 3,5 & 193,0 & 7,5 & 291,0 & 77 & 194,7 & 3,5 \\
\hline Zr-060 & 273 & 858 & 3,14 & 0,0517 & 0,0030 & 0,2210 & 0,0120 & 0,0308 & 0,0006 & 0,04 & 0,0092 & 0,0003 & 4,73 & 2,00 & 195,3 & 3,9 & 205,0 & 10,0 & 388,0 & 74 & 195,3 & 3,9 \\
\hline Zr-042 & 413 & 257 & 0,62 & 0,0495 & 0,0024 & 0,2110 & 0,0098 & 0,0308 & 0,0005 & 0,04 & 0,0097 & 0,0004 & $-0,62$ & 1,64 & 195,3 & 3,2 & 194,1 & 8,0 & 236,0 & 52 & 195,3 & 3,2 \\
\hline Zr-061 & 150 & 235 & 1,57 & 0,0517 & 0,0041 & 0,2170 & 0,0160 & 0,0309 & 0,0008 & 0,12 & 0,0094 & 0,0004 & 0,91 & 2,45 & 196,2 & 4,8 & 198,0 & 13,0 & 412,0 & 88 & 196,2 & 4,8 \\
\hline Zr-055 & 140 & 258 & 1,84 & 0,0509 & 0,0038 & 0,2190 & 0,0160 & 0,0310 & 0,0007 & 0,34 & 0,0099 & 0,0004 & 1,60 & 2,18 & 196,8 & 4,3 & 200,0 & 13,0 & 358,0 & 69 & 196,8 & 4,3 \\
\hline Zr-063 & 106 & 114 & 1,08 & 0,0480 & 0,0037 & 0,2070 & 0,0150 & 0,0311 & 0,0008 & 0,05 & 0,0098 & 0,0005 & $-3,89$ & 2,43 & 197,4 & 4,8 & 190,0 & 12,0 & 381,0 & 49 & 197,4 & 4,8 \\
\hline Zr-044 & 91 & 96 & 1,05 & 0,0509 & 0,0046 & 0,2190 & 0,0170 & 0,0311 & 0,0010 & 0,18 & 0,0093 & 0,0005 & 2,61 & 2,98 & 197,7 & 5,9 & 203,0 & 14,0 & 414,0 & 98 & 197,7 & 5,9 \\
\hline Zr-046 & 107 & 121 & 1,13 & 0,0528 & 0,0047 & 0,2190 & 0,0180 & 0,0312 & 0,0009 & 0,02 & 0,0100 & 0,0005 & 1,98 & 2,78 & 198,0 & 5,5 & 202,0 & 15,0 & 493,0 & 94 & 198,0 & 5,5 \\
\hline Zr-066 & 616 & 809 & 1,31 & 0,0503 & 0,0019 & 0,2161 & 0,0063 & 0,0312 & 0,0005 & 0,18 & 0,0097 & 0,0003 & 0,15 & 1,51 & 198,3 & 3,0 & 198,6 & 5,2 & 231,0 & 48 & 198,3 & 3,0 \\
\hline Zr-053 & 167 & 331 & 1,98 & 0,0489 & 0,0035 & 0,2120 & 0,0130 & 0,0312 & 0,0008 & 0,23 & 0,0100 & 0,0004 & $-1,69$ & 2,47 & 198,3 & 4,9 & 195,0 & 11,0 & 267,0 & 60 & 198,3 & 4,9 \\
\hline Zr-050 & 154 & 196 & 1,27 & 0,0498 & 0,0032 & 0,2150 & 0,0140 & 0,0313 & 0,0007 & 0,11 & 0,0100 & 0,0005 & $-0,76$ & 2,12 & 198,5 & 4,2 & 197,0 & 12,0 & 339,0 & 82 & 198,5 & 4,2 \\
\hline Zr-036 & 127 & 166 & 1,31 & 0,0549 & 0,0040 & 0,2370 & 0,0170 & 0,0313 & 0,0009 & 0,09 & 0,0101 & 0,0004 & 7,53 & 2,72 & 198,8 & 5,4 & 215,0 & 14,0 & 511,0 & 69 & 198,8 & 5,4 \\
\hline Zr-059 & 1.021 & 742 & 0,73 & 0,0494 & 0,0017 & 0,2147 & 0,0061 & 0,0314 & 0,0005 & 0,04 & 0,0096 & 0,0003 & $-0,91$ & 1,56 & 199,2 & 3,1 & 197,4 & 5,1 & 190,0 & 50 & 199,2 & 3,1 \\
\hline Zr-054 & 345 & 528 & 1,53 & 0,0496 & 0,0025 & 0,2131 & 0,0097 & 0,0313 & 0,0008 & 0,09 & 0,0101 & 0,0004 & $-1,79$ & 2,51 & 199,3 & 5,0 & 195,8 & 8,1 & 230,0 & 55 & 199,3 & 5,0 \\
\hline Zr-049 & 146 & 225 & 1,54 & 0,0508 & 0,0033 & 0,2240 & 0,0130 & 0,0316 & 0,0008 & 0,15 & 0,0095 & 0,0004 & 1,81 & 2,50 & 200,3 & 5,0 & 204,0 & 11,0 & 311,0 & 57 & 200,3 & 5,0 \\
\hline Zr-045 & 159 & 230 & 1,45 & 0,0506 & 0,0040 & 0,2190 & 0,0160 & 0,0314 & 0,0007 & 0,08 & 0,0102 & 0,0004 & $-0,15$ & 2,15 & 200,3 & 4,3 & 200,0 & 13,0 & 386,0 & 70 & 200,3 & 4,3 \\
\hline Zr-037 & 327 & 732 & 2,24 & 0,0496 & 0,0031 & 0,2150 & 0,0120 & 0,0316 & 0,0007 & 0,07 & 0,0098 & 0,0004 & $-1,62$ & 2,00 & 200,4 & 4,0 & 197,2 & 9,8 & 377,0 & 88 & 200,4 & 4,0 \\
\hline Zr-051 & 156 & 252 & 1,62 & 0,0487 & 0,0037 & 0,2160 & 0,0150 & 0,0317 & 0,0007 & 0,08 & 0,0098 & 0,0004 & $-1,46$ & 2,14 & 200,9 & 4,3 & 198,0 & 12,0 & 306,0 & 64 & 200,9 & 4,3 \\
\hline $\mathrm{Zr}-043$ & 243 & 270 & 1,11 & 0,0529 & 0,0027 & 0,2324 & 0,0099 & 0,0320 & 0,0008 & 0,03 & 0,0105 & 0,0004 & 4,16 & 2,41 & 202,9 & 4,9 & 211,7 & 8,1 & 354,0 & 65 & 202,9 & 4,9 \\
\hline Zr-064 & 53 & 66 & 1,25 & 0,0539 & 0,0057 & 0,2340 & 0,0230 & 0,0323 & 0,0012 & 0,14 & 0,0102 & 0,0006 & 4,25 & 3,71 & 204,9 & 7,6 & 214,0 & 20,0 & 557,0 & 97 & 204,9 & 7,6 \\
\hline Zr-062 & 151 & 211 & 1,40 & 0,0518 & 0,0037 & 0,2330 & 0,0150 & 0,0323 & 0,0007 & 0,18 & 0,0105 & 0,0005 & 3,30 & 2,24 & 205,0 & 4,6 & 212,0 & 12,0 & 358,0 & 69 & 205,0 & 4,6 \\
\hline Zr-052 & 54 & 96 & 1,78 & 0,0491 & 0,0058 & 0,2200 & 0,0290 & 0,0324 & 0,0016 & 0,24 & 0,0101 & 0,0006 & $-3,32$ & 4,72 & 205,6 & 9,7 & 199,0 & 23,0 & 478,0 & 93 & 205,6 & 9,7 \\
\hline
\end{tabular}


MIA-648B, análisis isotópicos U-Pb en circón

\begin{tabular}{|c|c|c|c|c|c|c|c|c|c|c|c|c|c|c|}
\hline $\mathrm{zr}$ & $\begin{array}{l}\text { Relación final } \\
{ }_{207} \mathrm{~Pb}^{2} / 25 \mathrm{U}\end{array}$ & 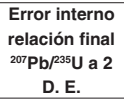 & 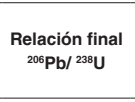 & $\begin{array}{c}\text { Error interno } \\
\text { relación final } \\
{ }^{206 \mathrm{~Pb} / 230 \mathrm{U} \text { a } 2} \\
\text { D. E. }\end{array}$ & $\begin{array}{c}\text { Ajuste error } \\
\text { de correlación } \\
\text { (datos } \\
\text { negativos) }\end{array}$ & 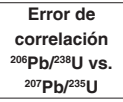 & $\begin{array}{c}\text { Edad } \\
{ }^{207} \mathrm{~Pb} / \\
{ }^{235} \mathrm{U}(\mathrm{Ma})\end{array}$ & $\begin{array}{l}\% \\
\text { disco }\end{array}$ & $\begin{array}{l}\text { Edad corregida } \\
{ }^{206 \mathrm{~Pb} / 238 \mathrm{U}} \text { (Ma) }\end{array}$ & $\begin{array}{l} \pm \text { Error edad } \\
\text { corregida (Ma) }\end{array}$ & $\begin{array}{l}\% \text { de } \\
\text { error? }\end{array}$ & $\begin{array}{l}\text { Relación } \\
\text { final } \\
{ }^{238} \mathrm{U} / \mathrm{P}^{232} \mathrm{Th}\end{array}$ & $\begin{array}{l}\text { Edad corregida } \\
200 \mathrm{~Pb} / 230 \mathrm{U} \text { (Ma) }\end{array}$ & $\mathrm{Th} / \mathrm{U}$ \\
\hline 1 & 14,02 & 0,74 & 0,17 & 0,01 & 0,50 & 0,50 & $2.744,00$ & 651,46 & 365,16 & 54,59 & 14,95 & 1,37 & 365,16 & 0,73 \\
\hline 10 & 1,10 & 0,10 & 0,04 & 0,00 & 0,20 & 0,20 & 711,00 & 206,22 & 232,18 & 11,02 & 4,75 & 1,09 & 232,18 & 0,92 \\
\hline 73 & 0,80 & 0,08 & 0,04 & 0,00 & 0,84 & 0,84 & 562,00 & 170,17 & 208,02 & 8,75 & 4,21 & 0,35 & 208,02 & 2,83 \\
\hline 58 & 0,50 & 0,08 & 0,04 & 0,00 & 0,11 & 0,11 & 427,00 & 109,48 & 203,83 & 11,50 & 5,64 & 1,04 & 203,83 & 0,96 \\
\hline 16 & 0,80 & 0,15 & 0,04 & 0,00 & 0,23 & 0,23 & 468,00 & 92,07 & 243,66 & 15,48 & 6,35 & 1,71 & 243,66 & 0,58 \\
\hline 13 & 0,59 & 0,11 & 0,04 & 0,00 & 0,10 & 0,00 & 391,00 & 78,29 & 219,30 & 12,98 & 5,92 & 0,64 & 219,30 & 1,57 \\
\hline 59 & 0,47 & 0,07 & 0,04 & 0,00 & 0,10 & $-0,04$ & 359,00 & 71,38 & 209,48 & 10,47 & 5,00 & 0,62 & 209,48 & 1,61 \\
\hline 50 & 0,36 & 0,07 & 0,03 & 0,00 & 0,10 & $-0,05$ & 313,00 & 58,30 & 197,73 & 10,64 & 5,38 & 1,25 & 197,73 & 0,80 \\
\hline 32 & 0,38 & 0,08 & 0,03 & 0,00 & 0,18 & 0,18 & 326,00 & 57,79 & 206,61 & 12,93 & 6,26 & 0,66 & 206,61 & 1,51 \\
\hline 56 & 0,39 & 0,08 & 0,04 & 0,00 & 0,15 & 0,15 & 340,00 & 57,53 & 215,83 & 11,40 & 5,28 & 1,30 & 215,83 & 0,77 \\
\hline 26 & 0,31 & 0,11 & 0,04 & 0,00 & 0,01 & 0,01 & 337,00 & 57,04 & 214,60 & 17,53 & 8,17 & 0,78 & 214,60 & 1,28 \\
\hline 31 & 0,52 & 0,08 & 0,04 & 0,00 & 0,01 & 0,01 & 409,00 & 56,97 & 260,56 & 12,33 & 4,73 & 1,31 & 260,56 & 0,76 \\
\hline 76 & 0,41 & 0,04 & 0,04 & 0,00 & 0,10 & $-0,02$ & 341,00 & 50,98 & 225,86 & 10,70 & 4,74 & 3,09 & 225,86 & 0,32 \\
\hline 64 & 0,40 & 0,04 & 0,04 & 0,00 & 0,05 & 0,05 & 337,00 & 48,81 & 226,46 & 8,28 & 3,65 & 0,80 & 226,46 & 1,25 \\
\hline 18 & 0,44 & 0,08 & 0,04 & 0,00 & 0,10 & $-0,04$ & 332,00 & 41,76 & 234,20 & 12,17 & 5,20 & 1,25 & 234,20 & 0,80 \\
\hline 27 & 0,40 & 0,03 & 0,04 & 0,00 & 0,57 & 0,57 & 336,00 & 38,47 & 242,65 & 11,69 & 4,82 & 7,77 & 242,65 & 0,13 \\
\hline 33 & 0,31 & 0,05 & 0,03 & 0,00 & 0,10 & $-0,02$ & 279,00 & 32,44 & 210,66 & 9,24 & 4,39 & 0,76 & 210,66 & 1,31 \\
\hline 51 & 0,34 & 0,06 & 0,04 & 0,00 & 0,03 & 0,03 & 283,00 & 30,85 & 216,28 & 10,13 & 4,68 & 1,41 & 216,28 & 0,71 \\
\hline 53 & 0,28 & 0,04 & 0,03 & 0,00 & 0,10 & $-0,03$ & 253,00 & 24,83 & 202,67 & 7,82 & 3,86 & 0,57 & 202,67 & 1,75 \\
\hline 36 & 0,27 & 0,05 & 0,03 & 0,00 & 0,00 & 0,00 & 255,00 & 23,51 & 206,46 & 9,26 & 4,48 & 0,73 & 206,46 & 1,36 \\
\hline 12 & 0,33 & 0,05 & 0,04 & 0,00 & 0,18 & 0,18 & 269,00 & 22,40 & 219,78 & 9,20 & 4,19 & 0,63 & 219,78 & 1,59 \\
\hline 72 & 0,31 & 0,05 & 0,03 & 0,00 & 0,16 & 0,16 & 248,00 & 19,71 & 207,17 & 8,49 & 4,10 & 0,80 & 207,17 & 1,26 \\
\hline 15 & 0,30 & 0,03 & 0,04 & 0,00 & 0,21 & 0,21 & 265,00 & 19,67 & 221,44 & 8,23 & 3,72 & 4,78 & 221,44 & 0,21 \\
\hline 71 & 0,32 & 0,03 & 0,04 & 0,00 & 0,26 & 0,26 & 278,00 & 19,14 & 233,33 & 10,08 & 4,32 & 3,04 & 233,33 & 0,33 \\
\hline 68 & 0,53 & 0,06 & 0,06 & 0,00 & 0,70 & 0,70 & 421,00 & 17,70 & 357,70 & 18,45 & 5,16 & 51,22 & 357,70 & 0,02 \\
\hline 29 & 0,29 & 0,04 & 0,03 & 0,00 & 0,10 & $-0,05$ & 254,00 & 17,46 & 216,25 & 8,40 & 3,88 & 1,27 & 216,25 & 0,78 \\
\hline 85 & 0,29 & 0,03 & 0,04 & 0,00 & 0,20 & 0,20 & 259,00 & 16,69 & 221,96 & 10,16 & 4,58 & 4,94 & 221,96 & 0,20 \\
\hline 60 & 0,38 & 0,03 & 0,04 & 0,00 & 0,30 & 0,30 & 322,00 & 16,53 & 276,32 & 13,06 & 4,73 & 2,80 & 276,32 & 0,36 \\
\hline 61 & 0,27 & 0,04 & 0,03 & 0,00 & 0,03 & 0,03 & 241,00 & 16,48 & 206,91 & 8,51 & 4,11 & 0,94 & 206,91 & 1,07 \\
\hline 11 & 0,26 & 0,09 & 0,03 & 0,00 & 0,04 & 0,04 & 248,00 & 15,77 & 214,23 & 13,42 & 6,26 & 0,63 & 214,23 & 1,59 \\
\hline 24 & 0,27 & 0,12 & 0,04 & 0,00 & 0,16 & 0,16 & 258,00 & 15,08 & 224,19 & 15,38 & 6,86 & 0,55 & 224,19 & $\begin{array}{r}1,82 \\
\end{array}$ \\
\hline 20 & 0,21 & 0,11 & 0,03 & 0,00 & 0,12 & 0,12 & 174,00 & $-12,67$ & 199,25 & 29,70 & 14,91 & 0,72 & 199,25 & 1,38 \\
\hline 7 & 0,29 & 0,12 & 0,04 & 0,00 & 0,09 & 0,09 & 217,00 & 5,32 & 206,04 & 17,81 & 8,64 & 0,61 & 206,04 & 1,64 \\
\hline 9 & 0,27 & 0,08 & 0,03 & 0,00 & 0,04 & 0,04 & 212,00 & 2,90 & 206,03 & 13,09 & 6,35 & 0,57 & 206,03 & 1,76 \\
\hline 47 & 0,20 & 0,08 & 0,03 & 0,00 & 0,18 & 0,18 & 163,00 & $-18,22$ & 199,32 & 11,98 & 6,01 & 0,53 & 199,32 & 1,90 \\
\hline 39 & 0,24 & 0,08 & 0,03 & 0,00 & 0,14 & 0,14 & 224,00 & 13,16 & 197,95 & 11,04 & 5,58 & 0,64 & 197,95 & 1,57 \\
\hline 67 & 0,24 & 0,04 & 0,03 & 0,00 & 0,01 & 0,01 & 202,00 & $-0,22$ & 202,44 & 8,51 & 4,21 & 1,74 & 202,44 & 0,57 \\
\hline 63 & 0,22 & 0,06 & 0,03 & 0,00 & 0,07 & 0,07 & 198,00 & $-2,45$ & 202,97 & 9,45 & 4,65 & 0,80 & 202,97 & 1,25 \\
\hline 78 & 0,27 & 0,03 & 0,03 & 0,00 & 0,09 & 0,09 & 234,00 & 14,41 & 204,52 & 7,04 & 3,44 & 1,30 & 204,52 & 0,77 \\
\hline 82 & 0,24 & 0,04 & 0,03 & 0,00 & 0,16 & 0,16 & 217,00 & 5,89 & 204,92 & 9,08 & 4,43 & 0,98 & 204,92 & 1,02 \\
\hline 83 & 0,25 & 0,05 & 0,03 & 0,00 & 0,01 & 0,01 & 213,00 & 3,94 & 204,92 & 9,13 & 4,46 & 0,88 & 204,92 & 1,13 \\
\hline 70 & 0,20 & 0,06 & 0,03 & 0,00 & 0,08 & 0,08 & 184,00 & $-10,40$ & 205,35 & 10,83 & 5,27 & 0,67 & 205,35 & 1,49 \\
\hline 17 & 0,26 & 0,05 & 0,03 & 0,00 & 0,01 & 0,01 & 226,00 & 9,62 & 206,16 & 9,31 & 4,52 & 0,95 & 206,16 & 1,05 \\
\hline 84 & 0,23 & 0,04 & 0,03 & 0,00 & 0,03 & 0,03 & 191,00 & $-7,38$ & 206,21 & 8,55 & 4,15 & 0,83 & 206,21 & 1,21 \\
\hline 54 & 0,26 & 0,05 & 0,03 & 0,00 & 0,06 & 0,06 & 236,00 & 14,39 & 206,32 & 9,25 & 4,48 & 0,45 & 206,32 & 2,23 \\
\hline 75 & 0,25 & 0,02 & 0,03 & 0,00 & 0,23 & 0,23 & 219,00 & 5,85 & 206,90 & 6,42 & 3,10 & 1,80 & 206,90 & 0,56 \\
\hline 66 & 0,24 & 0,02 & 0,03 & 0,00 & 0,31 & 0,31 & 211,00 & 1,90 & 207,07 & 6,25 & 3,02 & 1,11 & 207,07 & 0,90 \\
\hline 48 & 0,24 & 0,02 & 0,03 & 0,00 & 0,04 & 0,04 & 220,00 & 6,20 & 207,16 & 6,39 & 3,08 & 1,46 & 207,16 & 0,68 \\
\hline 41 & 0,26 & 0,03 & 0,03 & 0,00 & 0,01 & 0,01 & 225,00 & 8,54 & 207,30 & 7,08 & 3,42 & 0,65 & 207,30 & 1,54 \\
\hline 77 & 0,23 & 0,02 & 0,03 & 0,00 & 0,07 & 0,07 & 206,00 & $-0,70$ & 207,46 & 7,06 & 3,40 & 1,16 & 207,46 & 0,86 \\
\hline 80 & 0,25 & 0,05 & 0,03 & 0,00 & 0,06 & 0,06 & 213,00 & 2,24 & 208,34 & 9,20 & 4,42 & 0,96 & 208,34 & 1,04 \\
\hline 49 & 0,26 & 0,06 & 0,03 & 0,00 & 0,10 & $-0,04$ & 225,00 & 7,79 & 208,74 & 9,40 & 4,51 & 0,66 & 208,74 & 1,52 \\
\hline 22 & 0,24 & 0,03 & 0,03 & 0,00 & 0,15 & 0,15 & 210,00 & 0,55 & 208,85 & 7,08 & 3,39 & 0,44 & 208,85 & 2,30 \\
\hline
\end{tabular}




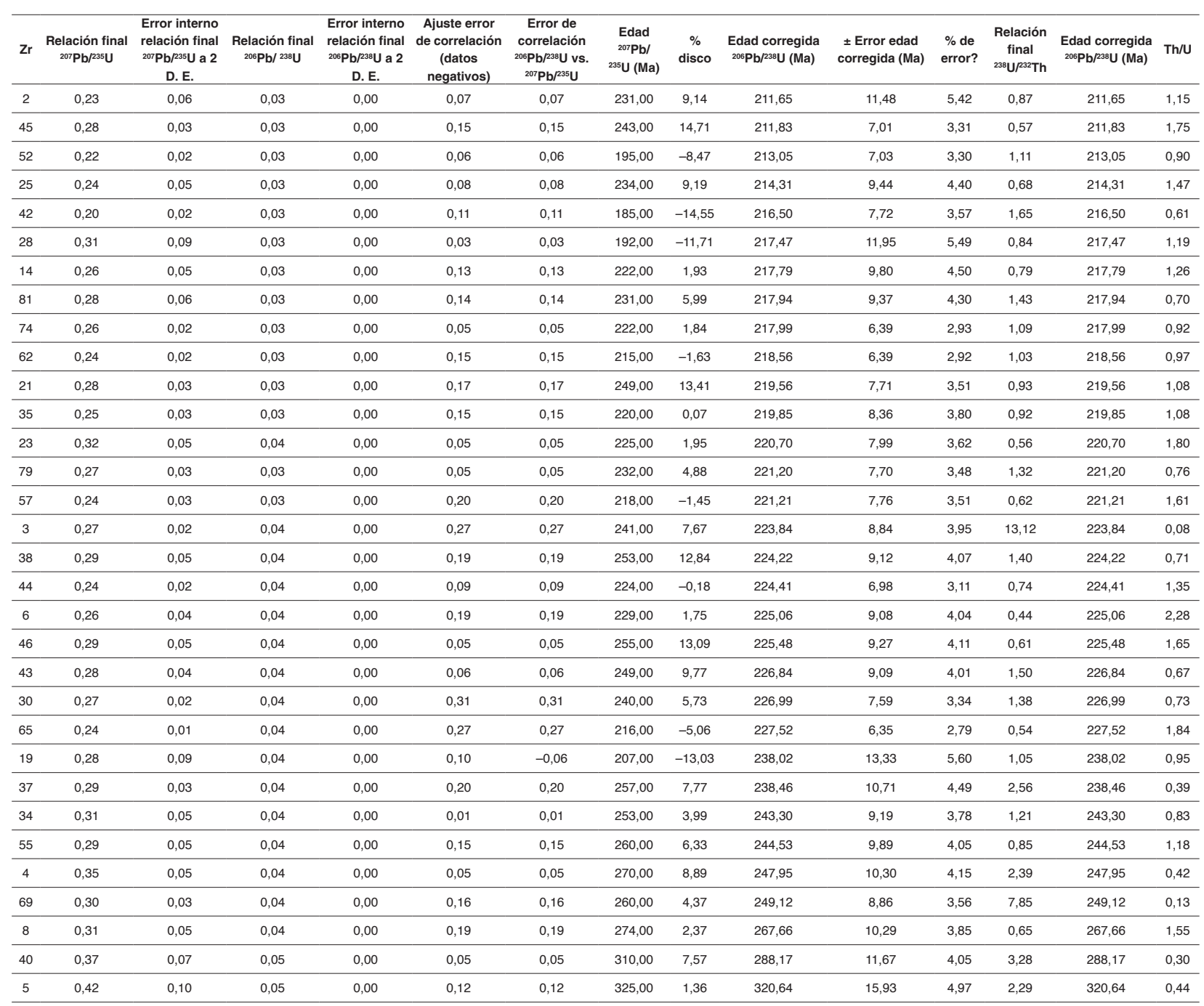


MIA-648A, análisis isotópicos U-Pb en circón

\begin{tabular}{|c|c|c|c|c|c|c|c|c|c|c|c|c|c|}
\hline $\mathrm{Zr}$ & $\begin{array}{l}\text { Relación final } \\
{ }^{207} \mathrm{~Pb} /{ }^{235} \mathrm{U}\end{array}$ & $\begin{array}{c}\text { Error interno } \\
\text { relación final } \\
{ }^{207} \mathrm{~Pb} / 235 \mathrm{U} \text { a } 2 \\
\text { D. E. } \\
\end{array}$ & $\begin{array}{c}\text { Relación final } \\
{ }^{206} \mathrm{~Pb} / 238 \mathrm{U}\end{array}$ & $\begin{array}{c}\text { Error interno } \\
\text { relación final } \\
{ }^{206 \mathrm{~Pb} / 235 \mathrm{U} \text { a } 2} \\
\text { D. E. } \\
\end{array}$ & $\begin{array}{c}\text { Ajuste error } \\
\text { de correlación } \\
\text { (datos } \\
\text { negativos) } \\
\end{array}$ & $\begin{array}{c}\text { Error de } \\
\text { correlación } \\
{ }^{206} \mathrm{~Pb} / 238 \mathrm{U} \text { vs. } \\
{ }^{207} \mathrm{~Pb} /{ }^{235} \mathrm{U} \\
\end{array}$ & $\begin{array}{c}\operatorname{Edad}^{207} \mathrm{~Pb} /{ }^{235} \mathrm{U} \\
(\mathrm{Ma})\end{array}$ & $\%$ disc & $\begin{array}{l}\text { Edad corregida } \\
{ }^{206} \mathrm{~Pb} /{ }^{238} \mathrm{U}(\mathrm{Ma})\end{array}$ & $\begin{array}{l} \pm \text { Error edad } \\
\text { corregida (Ma) }\end{array}$ & Error & $\begin{array}{l}\text { Aproximación } \\
{ }^{238} \mathrm{U}(\mathrm{ppm})\end{array}$ & Th/U \\
\hline Zr-36 & 0,694 & 0,036 & 0,03456 & 0,00056 & 0,65699 & 0,657 & 530 & 173,0 & 194,127 & 7,208 & 3,71 & 767 & 2,55 \\
\hline Zr-45 & 0,332 & 0,028 & 0,02989 & 0,00062 & 0,51654 & 0,517 & 281 & 53,8 & 182,717 & 6,426 & 3,52 & 313 & 1,98 \\
\hline $\mathrm{Zr}-19$ & 0,275 & 0,016 & 0,03077 & 0,00044 & 0,32724 & 0,327 & 247 & 28,9 & 191,636 & 5,902 & 3,08 & 343 & 1,19 \\
\hline Zr-46 & 0,284 & 0,024 & 0,03072 & 0,00066 & 0,60041 & 0,600 & 246 & 28,8 & 190,964 & 6,425 & 3,36 & 417 & 0,62 \\
\hline $\mathrm{Zr}-6$ & 0,286 & 0,032 & 0,03101 & 0,00067 & 0,571 & 0,571 & 242 & 25,2 & 193,361 & 7,095 & 3,67 & 230,7 & 2,05 \\
\hline Zr-23 & 0,279 & 0,018 & 0,03186 & 0,00053 & 0,237 & 0,237 & 248 & 24,8 & 198,785 & 6,341 & 3,19 & 254 & 1,51 \\
\hline $\mathrm{Zr}-10$ & 0,263 & 0,018 & 0,03109 & 0,00047 & 0,28041 & 0,280 & 231 & 18,7 & 194,565 & 6,045 & 3,11 & 263 & 0,99 \\
\hline $\mathrm{Zr}-1$ & 0,263 & 0,024 & 0,03085 & 0,00061 & 0,41714 & 0,417 & 227 & 17,4 & 193,368 & 6,455 & 3,34 & 192 & 2,44 \\
\hline Zr-9 & 0,2271 & 0,0076 & 0,02982 & 0,00046 & 0,40393 & 0,404 & 207,4 & 10,1 & 188,312 & 5,812 & 3,09 & 707 & 0,81 \\
\hline Zr-47 & 0,2161 & 0,0099 & 0,02872 & 0,00037 & 0,25377 & 0,254 & 197,7 & 8,9 & 181,520 & 5,396 & 2,97 & 481 & 1,59 \\
\hline Zr-37 & 0,2119 & 0,0062 & 0,02877 & 0,00028 & 0,30878 & 0,309 & 195 & 7,1 & 182,105 & 5,195 & 2,85 & 850 & 2,06 \\
\hline $\mathrm{Zr}-25$ & 0,201 & 0,011 & 0,02969 & 0,0005 & 0,11835 & 0,118 & 185,4 & $-1,8$ & 188,857 & 5,975 & 3,16 & 250 & 1,59 \\
\hline $\mathrm{Zr}-27$ & 0,206 & 0,014 & 0,02974 & 0,00051 & 0,13769 & 0,138 & 189 & 0,0 & 188,984 & 6,050 & 3,20 & 200,7 & 1,12 \\
\hline Zr-42 & 0,198 & 0,014 & 0,02991 & 0,00053 & 0,14238 & 0,142 & 182 & $-4,5$ & 190,596 & 6,115 & 3,21 & 157,5 & 1,53 \\
\hline Zr-32 & 0,222 & 0,014 & 0,03018 & 0,00055 & 0,17942 & 0,179 & 202 & 5,8 & 190,873 & 6,164 & 3,23 & 199,1 & 1,33 \\
\hline $\mathrm{Zr}-11$ & 0,206 & 0,018 & 0,03008 & 0,00059 & 0,23444 & 0,234 & 185 & $-3,1$ & 191,005 & 6,391 & 3,35 & 126,3 & 0,83 \\
\hline Zr-28 & 0,215 & 0,015 & 0,03018 & 0,00054 & 0,086791 & 0,087 & 200 & 4,4 & 191,586 & 6,180 & 3,23 & 190 & 1,43 \\
\hline Zr-22 & 0,212 & 0,01 & 0,03031 & 0,00045 & 0,14431 & 0,144 & 193,9 & 0,8 & 192,404 & 5,839 & 3,03 & 353 & 1,36 \\
\hline$Z r-14$ & 0,241 & 0,018 & 0,03065 & 0,00053 & 0,18821 & 0,188 & 210 & 8,9 & 192,923 & 6,240 & 3,23 & 210 & 1,60 \\
\hline Zr-33 & 0,205 & 0,015 & 0,03036 & 0,0006 & 0,059634 & 0,060 & 187 & $-3,1$ & 192,981 & 6,430 & 3,33 & 336 & 1,66 \\
\hline $\mathrm{Zr}-16$ & 0,214 & 0,014 & 0,03048 & 0,00056 & 0,043066 & 0,043 & 196 & 1,3 & 193,400 & 6,297 & 3,26 & 190 & 1,45 \\
\hline $\mathrm{Zr}-3$ & 0,2106 & 0,0098 & 0,03049 & 0,00037 & 0,064632 & 0,065 & 191,6 & $-1,0$ & 193,535 & 5,660 & 2,92 & 539 & 1,91 \\
\hline Zr-29 & 0,2121 & 0,0099 & 0,03052 & 0,00041 & 0,098861 & 0,099 & 195,1 & 0,7 & 193,676 & 5,777 & 2,98 & 326 & 1,77 \\
\hline Zr-44 & 0,219 & 0,013 & 0,03064 & 0,00057 & 0,065436 & 0,065 & 201 & 3,6 & 194,044 & 6,348 & 3,27 & 173 & 1,24 \\
\hline $\mathrm{Zr}-30$ & 0,229 & 0,024 & 0,03095 & 0,00079 & 0,1 & $-0,001$ & 202 & 3,3 & 195,549 & 7,108 & 3,63 & 95,1 & 1,41 \\
\hline Zr-26 & 0,211 & 0,011 & 0,03081 & 0,00047 & 0,18079 & 0,181 & 193,2 & $-1,2$ & 195,643 & 6,033 & 3,08 & 387 & 1,61 \\
\hline $\mathrm{Zr}-20$ & 0,22 & 0,018 & 0,03098 & 0,00075 & 0,19287 & 0,193 & 200 & 1,9 & 196,297 & 7,054 & 3,59 & 143 & 1,46 \\
\hline Zr-43 & 0,221 & 0,014 & 0,031 & 0,00051 & 0,21576 & 0,216 & 201 & 2,4 & 196,301 & 6,233 & 3,18 & 175 & 1,47 \\
\hline $\mathrm{Zr}-17$ & 0,211 & 0,013 & 0,03093 & 0,00048 & 0,099898 & 0,100 & 191 & $-2,8$ & 196,446 & 6,050 & 3,08 & 197,9 & 1,63 \\
\hline $\mathrm{Zr}-40$ & 0,215 & 0,017 & 0,03102 & 0,00062 & 0,19778 & 0,198 & 193 & $-2,0$ & 196,890 & 6,442 & 3,27 & 121 & 0,88 \\
\hline $\mathrm{Zr}-4$ & 0,216 & 0,011 & 0,03106 & 0,00047 & 0,1352 & 0,135 & 198,9 & 0,9 & 197,166 & 6,033 & 3,06 & 527 & 2,48 \\
\hline Zr-31 & 0,239 & 0,023 & 0,03126 & 0,00068 & 0,052165 & 0,052 & 210 & 6,5 & 197,168 & 7,088 & 3,59 & 120 & 0,85 \\
\hline Zr-39 & 0,219 & 0,017 & 0,03111 & 0,0008 & 0,14289 & 0,143 & 202 & 2,4 & 197,358 & 7,053 & 3,57 & 145 & 1,00 \\
\hline $\mathrm{Zr}-18$ & 0,219 & 0,014 & 0,03127 & 0,00052 & 0,1072 & 0,107 & 200 & 1,0 & 198,092 & 6,293 & 3,18 & 193 & 1,49 \\
\hline $\mathrm{Zr}-21$ & 0,236 & 0,015 & 0,0314 & 0,00057 & 0,05797 & 0,058 & 211 & 6,4 & 198,240 & 6,418 & 3,24 & 194 & 1,54 \\
\hline $\mathrm{Zr}-8$ & 0,2286 & 0,0094 & 0,03138 & 0,00046 & 0,27254 & 0,273 & 208,9 & 5,3 & 198,436 & 6,079 & 3,06 & 431 & 1,14 \\
\hline Zr-34 & 0,207 & 0,016 & 0,03118 & 0,00052 & 0,20091 & 0,201 & 187 & $-5,8$ & 198,485 & 6,260 & 3,15 & 130,2 & 1,40 \\
\hline $\mathrm{Zr}-15$ & 0,226 & 0,014 & 0,03141 & 0,00059 & 0,1 & $-0,043$ & 205 & 3,2 & 198,698 & 6,425 & 3,23 & 147 & 1,41 \\
\hline $\mathrm{Zr}-24$ & 0,241 & 0,015 & 0,03187 & 0,00068 & 0,1 & $-0,045$ & 217 & 8,0 & 200,852 & 7,031 & 3,50 & 191 & 1,86 \\
\hline $\mathrm{Zr}-41$ & 0,219 & 0,016 & 0,0321 & 0,00064 & 0,16464 & 0,165 & 211 & 3,6 & 203,700 & 7,057 & 3,46 & 111 & 1,12 \\
\hline $\mathrm{Zr}-13$ & 0,218 & 0,013 & 0,03222 & 0,00056 & 0,14733 & 0,147 & 201 & $-1,7$ & 204,454 & 6,417 & 3,14 & 171,8 & 0,87 \\
\hline $\mathrm{Zr}-12$ & 0,2288 & 0,0073 & 0,03235 & 0,00036 & 0,11214 & 0,112 & 208,4 & 1,7 & 204,889 & 5,889 & 2,87 & 1080 & 1,84 \\
\hline $\mathrm{Zr}-7$ & 0,242 & 0,0099 & 0,03264 & 0,00038 & 0,35118 & 0,351 & 218,5 & 6,1 & 205,937 & 6,019 & 2,92 & 859 & 1,49 \\
\hline $\mathrm{Zr}-35$ & 0,238 & 0,016 & 0,03267 & 0,0007 & 0,00070785 & 0,001 & 215 & 4,0 & 206,792 & 7,039 & 3,40 & 318 & 1,23 \\
\hline Zr-38 & 0,249 & 0,018 & 0,03302 & 0,00058 & 0,22552 & 0,226 & 219 & 5,1 & 208,362 & 6,435 & 3,09 & 174 & 1,25 \\
\hline $\mathrm{Zr}-2$ & 0,224 & 0,013 & 0,03327 & 0,00056 & 0,1 & $-0,125$ & 203 & $-4,1$ & 211,647 & 6,439 & 3,04 & 436 & 1,40 \\
\hline$Z r-5$ & 1,717 & 0,058 & 0,1717 & 0,0046 & 0,87025 & 0,870 & 1011 & $-1,0$ & $1.021,673$ & 38,044 & 3,72 & 1190 & 0,48 \\
\hline
\end{tabular}


MIA-650B, análisis isotópicos U-Pb en circón

\begin{tabular}{|c|c|c|c|c|c|c|c|c|c|c|c|c|c|c|c|c|c|c|c|c|c|c|}
\hline $\mathrm{Zr}$ & $\underset{(p p m) 1}{U}$ & $\begin{array}{c}\text { Th } \\
(\mathrm{ppm}) 1\end{array}$ & $\mathrm{Th} / \mathrm{U}$ & ${ }^{207} \mathrm{~Pb} /{ }^{206} \mathrm{~Pb}$ & $\begin{array}{l} \pm 2 s \\
\text { abs }\end{array}$ & ${ }^{207} \mathrm{~Pb} /{ }^{235} \mathrm{U}$ & $\begin{array}{l} \pm 2 \mathrm{~s} \\
\text { abs }\end{array}$ & ${ }^{206} \mathrm{~Pb} /{ }^{238} \mathrm{U}$ & $\begin{array}{l} \pm 2 s \\
\text { abs }\end{array}$ & $\begin{array}{l}\text { Correlación } \\
\text { de errores }\end{array}$ & ${ }^{208} \mathrm{~Pb} /{ }^{232} \mathrm{Th}$ & $\begin{array}{l} \pm 2 \mathrm{~s} \\
\text { abs }\end{array}$ & Disc.\% & Error & ${ }^{206} \mathrm{~Pb} /{ }^{238} \mathrm{U}$ & $\pm 2 \mathrm{~s}$ & ${ }^{207} \mathrm{~Pb} /{ }^{235} \mathrm{U}$ & $\pm 2 \mathrm{~s}$ & ${ }^{207} \mathrm{~Pb} /{ }^{206} \mathrm{~Pb}$ & $\pm 2 \mathrm{~s}$ & $\begin{array}{l}\text { Mejor } \\
\text { edad } \\
\text { (Ma) }\end{array}$ & $\pm 2 \mathrm{~s}$ \\
\hline Zr-025 & 72 & 74 & 1,03 & 0,0880 & 0,0260 & 0,3400 & 0,1900 & 0,0294 & 0,0026 & $-0,12$ & 0,011 & 0,0042 & 37,58 & 0,09 & 186,0 & 16,0 & 298,0 & 98,0 & 1340,0 & 250,0 & 186,0 & 16,0 \\
\hline Zr-030 & 420 & 362 & 0,86 & 0,0589 & 0,0033 & 0,2260 & 0,0150 & 0,0279 & 0,0011 & 0,20 & 0,009 & 0,0005 & 13,98 & 0,04 & 177,2 & 7,4 & 206,0 & 13,0 & 520,0 & 120,0 & 177,2 & 7,4 \\
\hline Zr-032 & 323 & 335 & 1,04 & 0,0579 & 0,0042 & 0,2270 & 0,0170 & 0,0288 & 0,0009 & 0,14 & 0,01 & 0,0006 & 11,16 & 0,03 & 183,9 & 5,8 & 207,0 & 14,0 & 470,0 & 160,0 & 183,9 & 5,8 \\
\hline Zr-029 & 147 & 208 & 1,41 & 0,0554 & 0,0043 & 0,2070 & 0,0210 & 0,0271 & 0,0010 & 0,35 & 0,009 & 0,0006 & 11,13 & 0,03 & 172,4 & 6,0 & 194,0 & 17,0 & 500,0 & 140,0 & 172,4 & 6,0 \\
\hline Zr-003 & 986 & 1.210 & 1,23 & 0,0570 & 0,0041 & 0,2240 & 0,0160 & 0,0293 & 0,0009 & 0,21 & 0,009 & 0,0005 & 10,43 & 0,03 & 186,3 & 5,7 & 208,0 & 13,0 & 480,0 & 140,0 & 186,3 & 5,7 \\
\hline Zr-019 & 321 & 435 & 1,36 & 0,0540 & 0,0290 & 0,2100 & 0,1800 & 0,0295 & 0,0019 & 0,02 & 0,01 & 0,0034 & 6 & 0,06 & 188,0 & 12,0 & 200,0 & 110,0 & 290,0 & 400,0 & 188,0 & 12,0 \\
\hline Zr-009 & 1.050 & 166 & 0,16 & 0,0536 & 0,0055 & 0,1940 & 0,0270 & 0,0263 & 0,0010 & 0,17 & 0,009 & 0,0005 & 8,187 & 0,04 & 167,1 & 6,4 & 182,0 & 22,0 & 360,0 & 210,0 & 167,1 & 6,4 \\
\hline Zr-022 & 149 & 156 & 1,05 & 0,0563 & 0,0037 & 0,2050 & 0,0150 & 0,0271 & 0,0009 & 0,06 & 0,009 & 0,0005 & 8,191 & 0,03 & 172,6 & 5,7 & 188,0 & 13,0 & 440,0 & 140,0 & 172,6 & 5,7 \\
\hline Zr-017 & 409 & 910 & 2,22 & 0,0516 & 0,0028 & 0,1910 & 0,0110 & 0,0274 & 0,0008 & 0,15 & 0,009 & 0,0004 & 1,69 & 0,03 & 174,5 & 5,1 & 177,5 & 9,2 & 300,0 & 120,0 & 174,5 & 5,1 \\
\hline Zr-033 & 357 & 297 & 0,83 & 0,0515 & 0,0037 & 0,1970 & 0,0170 & 0,0279 & 0,0010 & 0,42 & 0,009 & 0,0006 & 2,418 & 0,03 & 177,6 & 6,0 & 182,0 & 14,0 & 240,0 & 130,0 & 177,6 & 6,0 \\
\hline Zr-020 & 590 & 1.050 & 1,78 & 0,0509 & 0,0022 & 0,1934 & 0,0075 & 0,0279 & 0,0007 & 0,25 & 0,009 & 0,0004 & 0,948 & 0,03 & 177,7 & 4,7 & 179,4 & 6,4 & 240,0 & 96,0 & 177,7 & 4,7 \\
\hline Zr-007 & 192 & 277 & 1,44 & 0,0515 & 0,0031 & 0,2010 & 0,0110 & 0,0287 & 0,0008 & 0,15 & 0,009 & 0,0004 & 1,938 & 0,03 & 182,2 & 5,0 & 185,8 & 9,6 & 250,0 & 130,0 & 182,2 & 5,0 \\
\hline Zr-004 & 269 & 343 & 1,28 & 0,0498 & 0,0016 & 0,1974 & 0,0066 & 0,0288 & 0,0007 & 0,07 & 0,009 & 0,0004 & 0 & 0,03 & 182,8 & 4,7 & 182,8 & 5,6 & 179,0 & 73,0 & 182,8 & 4,7 \\
\hline Zr-013 & 500 & 105 & 0,21 & 0,0518 & 0,0022 & 0,2050 & 0,0100 & 0,0289 & 0,0008 & 0,13 & 0,01 & 0,0004 & 2,909 & 0,03 & 183,6 & 5,2 & 189,1 & 8,5 & 257,0 & 95,0 & 183,6 & 5,2 \\
\hline Zr-002 & 720 & 1.610 & 2,24 & 0,0494 & 0,0017 & 0,1958 & 0,0072 & 0,0289 & 0,0008 & 0,19 & 0,009 & 0,0004 & $-1,16$ & 0,03 & 183,6 & 4,8 & 181,5 & 6,1 & 161,0 & 78,0 & 183,6 & 4,8 \\
\hline Zr-015 & 429 & 640 & 1,49 & 0,0526 & 0,0045 & 0,2050 & 0,0200 & 0,0289 & 0,0011 & 0,09 & 0,009 & 0,0005 & 2,181 & 0,04 & 183,9 & 6,6 & 188,0 & 16,0 & 250,0 & 170,0 & 183,9 & 6,6 \\
\hline Zr-035 & 311 & 385 & 1,24 & 0,0506 & 0,0036 & 0,2000 & 0,0140 & 0,0290 & 0,0009 & 0,17 & 0,01 & 0,0005 & $-0,16$ & 0,03 & 184,3 & 5,6 & 184,0 & 12,0 & 180,0 & 150,0 & 184,3 & 5,6 \\
\hline Zr-023 & 264 & 205 & 0,78 & 0,0510 & 0,0096 & 0,2040 & 0,0400 & 0,0291 & 0,0013 & 0,25 & 0,011 & 0,0012 & $-0,49$ & 0,04 & 184,9 & 8,1 & 184,0 & 32,0 & 120,0 & 330,0 & 184,9 & 8,1 \\
\hline Zr-028 & 194 & 393 & 2,03 & 0,0503 & 0,0040 & 0,2040 & 0,0170 & 0,0291 & 0,0010 & 0,40 & 0,009 & 0,0005 & 1,016 & 0,03 & 185,1 & 6,1 & 187,0 & 14,0 & 270,0 & 150,0 & 185,1 & 6,1 \\
\hline Zr-018 & 274 & 349 & 1,27 & 0,0483 & 0,0026 & 0,1970 & 0,0100 & 0,0291 & 0,0008 & 0,04 & 0,01 & 0,0004 & $-0,43$ & 0,03 & 185,1 & 5,2 & 184,3 & 9,2 & 130,0 & 110,0 & 185,1 & 5,2 \\
\hline Zr-016 & 156 & 179 & 1,15 & 0,0484 & 0,0023 & 0,1934 & 0,0097 & 0,0292 & 0,0008 & 0,16 & 0,009 & 0,0004 & $-2,66$ & 0,03 & 185,4 & 5,2 & 180,6 & 8,3 & 120,0 & 100,0 & 185,4 & 5,2 \\
\hline Zr-014 & 784 & 880 & 1,12 & 0,0487 & 0,0025 & 0,1950 & 0,0110 & 0,0293 & 0,0008 & 0,10 & 0,009 & 0,0004 & $-2,99$ & 0,03 & 186,1 & 5,3 & 180,7 & 9,1 & 120,0 & 110,0 & 186,1 & 5,3 \\
\hline Zr-001 & & & & 0,0515 & 0,0020 & 0,2034 & 0,0084 & 0,0293 & 0,0008 & 0,14 & 0,009 & 0,0004 & 0,852 & 0,03 & 186,2 & 5,0 & 187,8 & 7,1 & 246,0 & 79,0 & 186,2 & 5,0 \\
\hline Zr-006 & 122 & 36,2 & 0,30 & 0,0516 & 0,0034 & 0,2060 & 0,0140 & 0,0293 & 0,0009 & 0,01 & 0,009 & 0,0004 & 1,947 & 0,03 & 186,3 & 5,4 & 190,0 & 11,0 & 250,0 & 140,0 & 186,3 & 5,4 \\
\hline Zr-011 & 279 & 15,1 & 0,05 & 0,0494 & 0,0035 & 0,2010 & 0,0140 & 0,0294 & 0,0009 & 0,06 & 0,01 & 0,0005 & $-0,86$ & 0,03 & 186,6 & 5,6 & 185,0 & 12,0 & 170,0 & 150,0 & 186,6 & 5,6 \\
\hline Zr-027 & 115 & 47,3 & 0,41 & 0,0489 & 0,0040 & 0,1990 & 0,0150 & 0,0295 & 0,0009 & 0,24 & 0,009 & 0,0004 & $-1,68$ & 0,03 & 187,1 & 5,9 & 184,0 & 13,0 & 160,0 & 170,0 & 187,1 & 5,9 \\
\hline $\mathrm{Zr}-024$ & 76 & 63 & 0,83 & 0,0524 & 0,0057 & 0,2110 & 0,0250 & 0,0297 & 0,0012 & 0,09 & 0,011 & 0,0008 & 1,615 & 0,04 & 188,9 & 7,7 & 192,0 & 21,0 & 170,0 & 210,0 & 188,9 & 7,7 \\
\hline Zr-031 & 368 & 325 & 0,88 & 0,0495 & 0,0026 & 0,2034 & 0,0099 & 0,0300 & 0,0009 & 0,08 & 0,01 & 0,0004 & $-1,55$ & 0,03 & 190,5 & 5,5 & 187,6 & 8,3 & 180,0 & 110,0 & 190,5 & 5,5 \\
\hline Zr-021 & 734 & 1.320 & 1,80 & 0,0513 & 0,0050 & 0,2140 & 0,0200 & 0,0303 & 0,0011 & 0,04 & 0,01 & 0,0005 & 2,879 & 0,04 & 192,3 & 7,0 & 198,0 & 17,0 & 240,0 & 200,0 & 192,3 & 7,0 \\
\hline Zr-034 & 506 & 415 & 0,82 & 0,0511 & 0,0036 & 0,2160 & 0,0150 & 0,0309 & 0,0009 & 0,14 & 0,011 & 0,0005 & 0,909 & 0,03 & 196,2 & 5,5 & 198,0 & 13,0 & 200,0 & 150,0 & 196,2 & 5,5 \\
\hline Zr-008 & 299 & 467 & 1,56 & 0,0522 & 0,0019 & 0,2250 & 0,0170 & 0,0329 & 0,0019 & 0,21 & 0,014 & 0,0012 & $-1,46$ & 0,06 & 209,0 & 12,0 & 206,0 & 14,0 & 269,0 & 84,0 & 209,0 & 12,0 \\
\hline $\mathrm{Zr}-010$ & 245 & 392 & 1,60 & 0,0701 & 0,0026 & 1,4300 & 0,0550 & 0,1503 & 0,0040 & 0,06 & 0,049 & 0,0039 & 0,221 & 0,08 & 903,0 & 22,0 & 905,0 & 22,0 & 924,0 & 72,0 & 924,0 & 72,0 \\
\hline Zr-026 & 221 & 244 & 1,10 & 0,0706 & 0,0029 & 1,5550 & 0,0660 & 0,1606 & 0,0046 & 0,08 & 0,046 & 0,0022 & $-1,05$ & 0,1 & 960,0 & 25,0 & 950,0 & 26,0 & 934,0 & 89,0 & 934,0 & 89,0 \\
\hline Zr-012 & 261 & 305 & 1,17 & 0,0728 & 0,0019 & 1,4130 & 0,0480 & 0,1416 & 0,0044 & 0,22 & 0,024 & 0,0012 & 4,474 & 0,06 & 854,0 & 25,0 & 894,0 & 21,0 & $1.005,0$ & 56,0 & $1.005,0$ & 56,0 \\
\hline Zr-005 & 1.390 & 1.850 & 1,33 & 0,0931 & 0,0028 & 2,9940 & 0,0990 & 0,2340 & 0,0061 & 0,50 & 0,073 & 0,0032 & 3,559 & 0,04 & $1.355,0$ & 32,0 & $1.405,0$ & 26,0 & $1.485,0$ & 57,0 & $1.485,0$ & 57,0 \\
\hline
\end{tabular}


MIA-657A, análisis isotópicos U-Pb en circón

\begin{tabular}{|c|c|c|c|c|c|c|c|c|c|c|c|c|c|}
\hline $\mathrm{Zr}$ & $\begin{array}{l}\text { Relación final } \\
{ }^{207} \mathrm{~Pb} /{ }^{235} \mathrm{U}\end{array}$ & $\begin{array}{c}\text { Error Interno } \\
\text { relación final } \\
{ }^{207 \mathrm{~Pb} / 235 \mathrm{U} \text { a } 2} \\
\text { D. E. }\end{array}$ & $\begin{array}{l}\text { Relación final } \\
{ }_{206 \mathrm{~Pb}} / 238 \mathrm{U}\end{array}$ & $\begin{array}{c}\text { Error Interno } \\
\text { relación final } \\
{ }^{206} \mathrm{~Pb} / 235 \mathrm{U} \text { a } 2 \\
\text { D. E. }\end{array}$ & $\begin{array}{c}\text { Ajuste error } \\
\text { de correlación } \\
\text { (datos } \\
\text { negativos) }\end{array}$ & $\begin{array}{c}\text { Error de } \\
\text { correlación } \\
{ }^{206} \mathrm{~Pb} /{ }^{238} \mathrm{U} \text { vs. } \\
{ }^{207} \mathrm{~Pb} /{ }^{235} \mathrm{U} \\
\end{array}$ & $\begin{array}{c}\text { Edad } \\
\text { corregida } \\
{ }^{206} \mathrm{~Pb} / 238 \mathrm{U} \\
(\mathrm{Ma})\end{array}$ & $\begin{array}{c}\text { Edad } \\
{ }^{207} \mathrm{~Pb} /{ }^{235} \mathrm{U} \\
(\mathrm{Ma})\end{array}$ & $\%$ disc & $\begin{array}{c}\text { Edad } \\
\text { corregida } \\
{ }^{206} \mathrm{~Pb} / 238 \mathrm{U} \\
(\mathrm{Ma})\end{array}$ & $\begin{array}{l} \pm \text { Error edad } \\
\text { corregida } \\
\text { (Ma) }\end{array}$ & $\begin{array}{l}\text { Aproximación } \\
{ }^{238} \mathrm{U}(\mathrm{ppm})\end{array}$ & $\mathrm{Th} / \mathrm{U}$ \\
\hline $\mathrm{Zr}-17$ & 0,2191 & 0,0074 & 0,02773 & 0,00043 & 0,38632 & 0,386 & 174,638 & 200,8 & 15 & 174,638 & 4,700 & 886 & 2,28 \\
\hline$Z r-5$ & 0,218 & 0,013 & 0,02854 & 0,00056 & 0,1 & $-0,029$ & 180,032 & 199 & 10,5 & 180,032 & 5,313 & 560 & 2,107 \\
\hline Zr-38 & 0,1969 & 0,0042 & 0,02744 & 0,00026 & 0,26453 & 0,265 & 173,999 & 182,5 & 4,89 & 173,999 & 4,156 & 1.443 & 2,814 \\
\hline $\mathrm{Zr}-11$ & 0,206 & 0,01 & 0,02776 & 0,00057 & 0,38805 & 0,388 & 175,813 & 190,5 & 8,35 & 175,813 & 5,301 & 579 & 1,15 \\
\hline Zr-30 & 0,1982 & 0,0068 & 0,02791 & 0,00028 & 0,24034 & 0,240 & 177,195 & 183,3 & 3,45 & 177,195 & 4,234 & 1.134 & 1,693 \\
\hline Zr-29 & 0,2021 & 0,0044 & 0,02828 & 0,00039 & 0,36701 & 0,367 & 179,545 & 186,6 & 3,93 & 179,545 & 4,663 & 1.618 & 1,65 \\
\hline $\mathrm{Zr}-16$ & 0,2073 & 0,0069 & 0,02855 & 0,00038 & 0,28724 & 0,287 & 180,928 & 190,9 & 5,51 & 180,928 & 4,602 & 1.107 & 2,43 \\
\hline $\mathrm{Zr}-41$ & 0,2026 & 0,0077 & 0,02865 & 0,00035 & 0,25422 & 0,254 & 181,760 & 187,1 & 2,94 & 181,760 & 4,548 & 729 & 1,044 \\
\hline $\mathrm{Zr}-20$ & 0,2054 & 0,0045 & 0,02875 & 0,00031 & 0,35795 & 0,358 & 182,388 & 189,3 & 3,79 & 182,388 & 4,408 & 1.715 & 3,621 \\
\hline $\mathrm{Zr}-40$ & 0,2175 & 0,0053 & 0,02893 & 0,00028 & 0,35183 & 0,352 & 182,926 & 199,8 & 9,22 & 182,926 & 4,395 & 1.330 & 3,038 \\
\hline Zr-26 & 0,2084 & 0,0056 & 0,02887 & 0,00042 & 0,48103 & 0,481 & 183,142 & 192,5 & 5,11 & 183,142 & 4,786 & 1.830 & 2,311 \\
\hline $\mathrm{Zr}-12$ & 0,2071 & 0,0077 & 0,02888 & 0,00036 & 0,19569 & 0,196 & 183,160 & 191,2 & 4,39 & 183,160 & 4,607 & 878 & 3,61 \\
\hline $\mathrm{Zr}-42$ & 0,2008 & 0,0039 & 0,02889 & 0,00037 & 0,56163 & 0,562 & 183,514 & 185,9 & 1,3 & 183,514 & 4,662 & 3.700 & 4,351 \\
\hline $\mathrm{Zr}-25$ & 0,2102 & 0,0074 & 0,02898 & 0,0004 & 0,18045 & 0,180 & 183,742 & 192,8 & 4,93 & 183,742 & 4,731 & 617 & 1,579 \\
\hline Zr-32 & 0,2055 & 0,0045 & 0,02901 & 0,00031 & 0,51812 & 0,518 & 184,137 & 189,4 & 2,86 & 184,137 & 4,472 & 2.024 & 2,451 \\
\hline Zr-39 & 0,2074 & 0,0064 & 0,02905 & 0,00035 & 0,21645 & 0,216 & 184,205 & 190,7 & 3,53 & 184,205 & 4,604 & 699 & 1,398 \\
\hline $\mathrm{Zr}-24$ & 0,2066 & 0,0046 & 0,02909 & 0,00035 & 0,44214 & 0,442 & 184,548 & 190,3 & 3,12 & 184,548 & 4,595 & 2.063 & 3,34 \\
\hline Zr-23 & 0,2073 & 0,0091 & 0,02914 & 0,00041 & 0,048993 & 0,049 & 185,023 & 191,9 & 3,72 & 185,023 & 4,807 & 361 & 1,042 \\
\hline Zr-35 & 0,2129 & 0,008 & 0,02923 & 0,00042 & 0,27071 & 0,271 & 185,174 & 195,5 & 5,58 & 185,174 & 4,854 & 554 & 0,782 \\
\hline $\mathrm{Zr}-21$ & 0,2043 & 0,0055 & 0,02917 & 0,00031 & 0,1737 & 0,174 & 185,212 & 189 & 2,05 & 185,212 & 4,479 & 1163 & 2,387 \\
\hline $\mathrm{Zr}-27$ & 0,2212 & 0,0065 & 0,02955 & 0,00064 & 0,30078 & 0,301 & 186,926 & 202,6 & 8,39 & 186,926 & 5,780 & 761 & 0,942 \\
\hline $\mathrm{Zr}-33$ & 0,2132 & 0,0041 & 0,0296 & 0,00027 & 0,41021 & 0,410 & 187,599 & 196,5 & 4,74 & 187,599 & 4,463 & 2.590 & 2,911 \\
\hline $\mathrm{Zr}-14$ & 0,2088 & 0,005 & 0,02968 & 0,0003 & 0,26359 & 0,264 & 188,349 & 193,2 & 2,58 & 188,349 & 4,536 & 1.890 & 3,704 \\
\hline Zr-36 & 0,2073 & 0,0053 & 0,02971 & 0,0003 & 0,31284 & 0,313 & 188,702 & 191,2 & 1,32 & 188,702 & 4,540 & 1.108 & 1,147 \\
\hline $\mathrm{Zr}-18$ & 0,2129 & 0,0076 & 0,02981 & 0,00066 & 0,62333 & 0,623 & 189,049 & 195 & 3,15 & 189,049 & 5,854 & 1.264 & 2,619 \\
\hline $\mathrm{Zr}-1$ & 0,2095 & 0,006 & 0,02992 & 0,00041 & 0,51135 & 0,511 & 189,975 & 192,6 & 1,38 & 189,975 & 4,916 & 1.500 & 3,273 \\
\hline $\mathrm{Zr}-43$ & 0,2119 & 0,0086 & 0,03 & 0,00046 & 0,37041 & 0,370 & 190,218 & 194 & 1,99 & 190,218 & 5,111 & 497 & 1,095 \\
\hline $\mathrm{Zr}-13$ & 0,2196 & 0,0071 & 0,03006 & 0,0004 & 0,23161 & 0,232 & 190,335 & 201 & 5,6 & 190,335 & 4,847 & 986 & 1,593 \\
\hline$Z r-15$ & 0,2137 & 0,0052 & 0,03012 & 0,00029 & 0,48635 & 0,486 & 191,114 & 196,3 & 2,71 & 191,114 & 4,532 & 2.350 & 4,179 \\
\hline $\mathrm{Zr}-19$ & 0,2132 & 0,0049 & 0,03023 & 0,00038 & 0,47831 & 0,478 & 191,758 & 196,5 & 2,47 & 191,758 & 4,844 & 2.019 & 3,388 \\
\hline Zr-28 & 0,217 & 0,0059 & 0,03033 & 0,00036 & 0,25737 & 0,257 & 192,458 & 199,7 & 3,76 & 192,458 & 4,787 & 1.021 & 1,528 \\
\hline $\mathrm{Zr}-22$ & 0,219 & 0,01 & 0,03038 & 0,00048 & 0,040979 & 0,041 & 192,509 & 200,3 & 4,05 & 192,509 & 5,183 & 254 & 1,224 \\
\hline $\mathrm{Zr}-6$ & 0,217 & 0,011 & 0,0305 & 0,00047 & 0,24837 & 0,248 & 193,454 & 198,5 & 2,61 & 193,454 & 5,185 & 499 & 1,84 \\
\hline Zr-31 & 0,2183 & 0,0058 & 0,03053 & 0,00035 & 0,43526 & 0,435 & 193,522 & 200 & 3,35 & 193,522 & 4,781 & 1.500 & 1,793 \\
\hline $\mathrm{Zr}-2$ & 0,2163 & 0,0075 & 0,03087 & 0,00037 & 0,28212 & 0,282 & 196,118 & 198,9 & 1,42 & 196,118 & 4,924 & 833 & 2,101 \\
\hline $\mathrm{Zr}-4$ & 0,2251 & 0,0075 & 0,03102 & 0,00036 & 0,24619 & 0,246 & 196,182 & 205,8 & 4,9 & 196,182 & 4,842 & 868 & 3,214 \\
\hline $\mathrm{Zr}-34$ & 0,212 & 0,011 & 0,03098 & 0,00042 & 0,045883 & 0,046 & 197,054 & 193,7 & $-1,7$ & 197,054 & 5,081 & 417 & 0,851 \\
\hline $\mathrm{Zr}-7$ & 0,2185 & 0,0046 & 0,03142 & 0,00041 & 0,60391 & 0,604 & 199,426 & 200,7 & 0,64 & 199,426 & 5,095 & 3.960 & 7,197 \\
\hline $\mathrm{Zr}-3$ & 0,2276 & 0,0046 & 0,03147 & 0,00032 & 0,33236 & 0,332 & 199,443 & 208,2 & 4,39 & 199,443 & 4,776 & 2.039 & 3,462 \\
\hline Zr-9 & 0,2237 & 0,0054 & 0,03172 & 0,00037 & 0,38438 & 0,384 & 201,139 & 204,5 & 1,67 & 201,139 & 4,968 & 1.880 & 3,138 \\
\hline Zr-37 & 0,2303 & 0,0098 & 0,03186 & 0,00053 & 0,25233 & 0,252 & 201,867 & 208,9 & 3,48 & 201,867 & 5,546 & 521 & 1,027 \\
\hline Zr-8 & 0,229 & 0,01 & 0,03221 & 0,00058 & 0,19029 & 0,190 & 204,290 & 207,4 & 1,52 & 204,290 & 5,739 & 497 & 1,787 \\
\hline $\mathrm{Zr}-10$ & 0,232 & 0,0053 & 0,03253 & 0,00045 & 0,3267 & 0,327 & 205,940 & 211,4 & 2,65 & 205,940 & 5,273 & 2.180 & 1,541 \\
\hline
\end{tabular}


LMC-082, análisis isotópicos U-Pb en circón

\begin{tabular}{|c|c|c|c|c|c|c|c|c|c|c|c|c|c|}
\hline $\mathrm{Zr}$ & $\begin{array}{l}\text { Relación final } \\
{ }^{207} \mathrm{~Pb} /{ }^{235} \mathrm{U}\end{array}$ & $\begin{array}{c}\text { Error Interno } \\
\text { relación final } \\
{ }^{207} \mathrm{~Pb} / 235 \mathrm{U} \\
\text { a 2 D. E. }\end{array}$ & $\begin{array}{l}\text { Relación final } \\
{ }^{206} \mathrm{~Pb} /{ }^{238} \mathrm{U}\end{array}$ & $\begin{array}{c}\text { Error Interno } \\
\text { relación final } \\
{ }^{206 \mathrm{~Pb} / 235 \mathrm{U}} \\
\text { a 2 D. E. }\end{array}$ & $\begin{array}{c}\text { Ajuste error } \\
\text { de correlación } \\
\text { (datos } \\
\text { negativos) }\end{array}$ & $\begin{array}{c}\text { Error de } \\
\text { correlación } \\
{ }^{206} \mathrm{~Pb} /{ }^{238} \mathrm{U} \text { vs. } \\
{ }^{207} \mathrm{~Pb} /{ }^{235} \mathrm{U}\end{array}$ & $\begin{array}{c}\text { Edad } \\
\text { corregida } \\
{ }^{206} \mathrm{~Pb} / 23 \mathrm{U} \\
(\mathrm{Ma})\end{array}$ & $\begin{array}{c}\text { Edad } \\
{ }^{207} \mathrm{~Pb} /{ }^{235} \mathrm{U} \\
(\mathrm{Ma})\end{array}$ & $\%$ disc & $\begin{array}{c}\text { Edad } \\
\text { corregida } \\
206 \mathrm{~Pb} / 238 \mathrm{U} \\
(\mathrm{Ma})\end{array}$ & $\begin{array}{l} \pm \text { Error edad } \\
\text { corregida } \\
\text { (Ma) }\end{array}$ & $\begin{array}{c}\text { Aproximación } \\
{ }_{238}(\mathrm{ppm})\end{array}$ & $\mathrm{Th} / \mathrm{U}$ \\
\hline Zr-43 & 0,674 & 0,039 & 0,03321 & 0,00066 & 0,1 & $-0,0066$ & 185,0039 & 515 & 178 & 185,00 & 7,09 & 185,00 & 1,0808 \\
\hline $\mathrm{Zr}-12$ & 0,546 & 0,049 & 0,03565 & 0,00082 & 0,21888 & 0,2189 & 209,433 & 427 & 104 & 209,43 & 8,27 & 209,43 & 0,7021 \\
\hline $\mathrm{Zr}-41$ & 0,424 & 0,037 & 0,03117 & 0,00086 & 0,30896 & 0,3090 & 185,977 & 355 & 90,9 & 185,98 & 7,68 & 185,98 & 0,7443 \\
\hline $\mathrm{Zr}-28$ & 0,367 & 0,023 & 0,03057 & 0,00065 & 0,21666 & 0,2167 & 185,054 & 318 & 71,8 & 185,05 & 6,91 & 185,05 & 0,8747 \\
\hline Zr-32 & 0,333 & 0,028 & 0,02975 & 0,00068 & 0,15076 & 0,1508 & 181,985 & 287 & 57,7 & 181,99 & 6,97 & 181,99 & 0,8544 \\
\hline $\mathrm{Zr}-23$ & 0,383 & 0,038 & 0,03287 & 0,00095 & 0,47843 & 0,4784 & 199,856 & 312 & 56,1 & 199,86 & 8,20 & 199,86 & 0,9389 \\
\hline $\mathrm{Zr}-18$ & 0,336 & 0,025 & 0,03191 & 0,00067 & 0,21016 & 0,2102 & 195,554 & 289 & 47,8 & 195,55 & 6,99 & 195,55 & 1,0583 \\
\hline Zr-35 & 0,311 & 0,02 & 0,03031 & 0,00056 & 0,63477 & 0,6348 & 187,507 & 268 & 42,9 & 187,51 & 6,32 & 187,51 & 0,7379 \\
\hline $\mathrm{Zr}-27$ & 0,302 & 0,02 & 0,03071 & 0,00044 & 0,58033 & 0,5803 & 190,540 & 265 & 39,1 & 190,54 & 6,09 & 190,54 & 1,6562 \\
\hline $\mathrm{Zr}-10$ & 0,276 & 0,016 & 0,02935 & 0,00046 & 0,36158 & 0,3616 & 181,945 & 247 & 35,8 & 181,95 & 5,90 & 181,95 & 1,1034 \\
\hline Zr-34 & 0,3 & 0,027 & 0,03033 & 0,00065 & 0,65762 & 0,6576 & 188,753 & 251 & 33 & 188,75 & 6,98 & 188,75 & 0,4404 \\
\hline$Z r-31$ & 0,27 & 0,013 & 0,02939 & 0,00041 & 0,51174 & 0,5117 & 183,234 & 240 & 31 & 183,23 & 5,82 & 183,23 & 1,2509 \\
\hline $\mathrm{Zr}-20$ & 0,26 & 0,014 & 0,02955 & 0,00043 & 0,2633 & 0,2633 & 184,945 & 233 & 26 & 184,95 & 5,97 & 184,95 & 1,0331 \\
\hline Zr-22 & 0,266 & 0,015 & 0,03002 & 0,00049 & 0,079926 & 0,0799 & 187,694 & 236 & 25,7 & 187,69 & 6,17 & 187,69 & 0,8988 \\
\hline $\mathrm{Zr}-6$ & 0,265 & 0,015 & 0,0303 & 0,00048 & 0,39549 & 0,3955 & 189,404 & 234 & 23,5 & 189,40 & 6,15 & 189,40 & 1,1355 \\
\hline $\mathrm{Zr}-36$ & 0,249 & 0,017 & 0,02888 & 0,00039 & 0,030231 & 0,0302 & 180,675 & 221 & 22,3 & 180,68 & 5,76 & 180,68 & 2,5034 \\
\hline $\mathrm{Zr}-3$ & 0,277 & 0,028 & 0,03161 & 0,00079 & 0,40385 & 0,4039 & 197,290 & 241 & 22,2 & 197,29 & 7,66 & 197,29 & 0,7419 \\
\hline $\mathrm{Zr}-19$ & 0,262 & 0,018 & 0,0308 & 0,00054 & 0,36073 & 0,3607 & 192,888 & 233 & 20,8 & 192,89 & 6,37 & 192,89 & 1,125 \\
\hline $\mathrm{Zr}-40$ & 0,242 & 0,012 & 0,02952 & 0,00038 & 0,0039886 & 0,0040 & 185,690 & 219,1 & 18 & 185,69 & 5,79 & 185,69 & 2,7685 \\
\hline $\mathrm{Zr}-5$ & 0,203 & 0,013 & 0,029 & 0,0004 & 0,12073 & 0,1207 & 184,326 & 186 & 0,91 & 184,33 & 5,78 & 184,33 & 1,0037 \\
\hline $\mathrm{Zr}-17$ & 0,209 & 0,012 & 0,02918 & 0,0004 & 0,29196 & 0,2920 & 184,860 & 191,5 & 3,59 & 184,86 & 5,82 & 184,86 & 1,2076 \\
\hline $\mathrm{Zr}-2$ & 0,2096 & 0,0087 & 0,02923 & 0,00038 & 0,21029 & 0,2103 & 185,290 & 192 & 3,62 & 185,29 & 5,80 & 185,29 & 1,082 \\
\hline Zr-42 & 0,2189 & 0,0073 & 0,02936 & 0,00034 & 0,35181 & 0,3518 & 185,596 & 201,2 & 8,41 & 185,60 & 5,60 & 185,60 & 2,3317 \\
\hline Zr-29 & 0,2031 & 0,008 & 0,02939 & 0,00033 & 0,23491 & 0,2349 & 186,619 & 188 & 0,74 & 186,62 & 5,62 & 186,62 & 1,1269 \\
\hline Zr-26 & 0,217 & 0,011 & 0,02954 & 0,00037 & 0,16963 & 0,1696 & 187,096 & 198,3 & 5,99 & 187,10 & 5,75 & 187,10 & 1,9619 \\
\hline Zr-38 & 0,241 & 0,01 & 0,02976 & 0,00031 & 0,2095 & 0,2095 & 187,116 & 218,8 & 16,9 & 187,12 & 5,66 & 187,12 & 1,8869 \\
\hline $\mathrm{Zr}-11$ & 0,211 & 0,012 & 0,02954 & 0,00039 & 0,20456 & 0,2046 & 187,166 & 193,6 & 3,44 & 187,17 & 5,75 & 187,17 & 1,1638 \\
\hline Zr-33 & 0,2164 & 0,0097 & 0,02962 & 0,00035 & 0,46938 & 0,4694 & 187,551 & 196,4 & 4,72 & 187,55 & 5,74 & 187,55 & 0,9815 \\
\hline Zr-45 & 0,2079 & 0,0087 & 0,0296 & 0,00042 & 0,25504 & 0,2550 & 187,846 & 191 & 1,68 & 187,85 & 5,93 & 187,85 & 1,4061 \\
\hline $\mathrm{Zr}-1$ & 0,2076 & 0,0097 & 0,0296 & 0,00041 & 0,14149 & 0,1415 & 187,940 & 192 & 2,16 & 187,94 & 5,93 & 187,94 & 1,1462 \\
\hline $\mathrm{Zr}-14$ & 0,2082 & 0,0087 & 0,02977 & 0,00038 & 0,35821 & 0,3582 & 188,915 & 190,7 & 0,95 & 188,91 & 5,80 & 188,91 & 1,5034 \\
\hline $\mathrm{Zr}-15$ & 0,2033 & 0,0052 & 0,02985 & 0,00028 & 0,25583 & 0,2558 & 189,582 & 187,4 & $-1,15$ & 189,58 & 5,61 & 189,58 & 2,9855 \\
\hline $\mathrm{Zr}-13$ & 0,231 & 0,01 & 0,03015 & 0,00039 & 0,23162 & 0,2316 & 190,044 & 210,8 & 10,9 & 190,04 & 5,86 & 190,04 & 2,7383 \\
\hline $\mathrm{Zr}-30$ & 0,2104 & 0,0088 & 0,03007 & 0,0004 & 0,19462 & 0,1946 & 190,919 & 193,1 & 1,14 & 190,92 & 5,87 & 190,92 & 1,2165 \\
\hline $\mathrm{Zr}-7$ & 0,2109 & 0,0088 & 0,03014 & 0,0004 & 0,27636 & 0,2764 & 191,002 & 193,7 & 1,41 & 191,00 & 5,93 & 191,00 & 1,5953 \\
\hline $\mathrm{Zr}-8$ & 0,24 & 0,011 & 0,03057 & 0,00044 & 0,49125 & 0,4913 & 192,208 & 218 & 13,4 & 192,21 & 6,04 & 192,21 & 0,893 \\
\hline Zr-24 & 0,249 & 0,011 & 0,03066 & 0,00038 & 0,21315 & 0,2132 & 192,624 & 225,2 & 16,9 & 192,62 & 5,91 & 192,62 & 2,2219 \\
\hline $\mathrm{Zr}-21$ & 0,2147 & 0,006 & 0,03042 & 0,00034 & 0,38937 & 0,3894 & 192,975 & 197,3 & 2,24 & 192,98 & 5,85 & 192,98 & 1,5447 \\
\hline $\mathrm{Zr}-16$ & 0,227 & 0,013 & 0,03066 & 0,00051 & 0,19048 & 0,1905 & 193,541 & 207 & 6,95 & 193,54 & 6,37 & 193,54 & 0,8018 \\
\hline Zr-9 & 0,2053 & 0,0095 & 0,03048 & 0,0004 & 0,050545 & 0,0505 & 193,568 & 190,7 & $-1,48$ & 193,57 & 6,00 & 193,57 & 1,5695 \\
\hline Zr-44 & 0,2232 & 0,0077 & 0,03059 & 0,00037 & 0,36643 & 0,3664 & 193,730 & 204,1 & 5,35 & 193,73 & 5,92 & 193,73 & 1,4549 \\
\hline $\mathrm{Zr}-25$ & 0,2232 & 0,0068 & 0,03063 & 0,00041 & 0,43445 & 0,4345 & 193,860 & 203,8 & 5,13 & 193,86 & 5,97 & 193,86 & 2,4045 \\
\hline $\mathrm{Zr}-4$ & 0,208 & 0,014 & 0,03085 & 0,0005 & 0,16829 & 0,1683 & 196,186 & 191 & $-2,64$ & 196,19 & 6,40 & 196,19 & 0,7296 \\
\hline Zr-37 & 0,2362 & 0,0093 & 0,03112 & 0,00035 & 0,17461 & 0,1746 & 196,416 & 214,6 & 9,26 & 196,42 & 5,98 & 196,42 & 2,0973 \\
\hline Zr-39 & 0,245 & 0,011 & 0,03177 & 0,00043 & 0,52319 & 0,5232 & 200,503 & 221,6 & 10,5 & 200,50 & 6,29 & 200,50 & 2,2989 \\
\hline
\end{tabular}


LMC-084, análisis isotópicos U-Pb en circón

\begin{tabular}{|c|c|c|c|c|c|c|c|c|c|c|c|c|c|}
\hline $\mathrm{Zr}$ & $\begin{array}{l}\text { Relación final } \\
{ }^{207} \mathrm{pb} / 235 \mathrm{U}\end{array}$ & $\begin{array}{c}\text { Error interno } \\
\text { relación final } \\
{ }^{207} \mathrm{~Pb} / 235 \mathrm{U} \\
\text { a 2 D. E. } \\
\end{array}$ & $\begin{array}{c}\text { Relación final } \\
{ }^{206} \mathrm{~Pb} / 238 \mathrm{U}\end{array}$ & $\begin{array}{c}\text { Error Interno } \\
\text { relación final } \\
{ }^{206 \mathrm{~Pb} / 235 \mathrm{~S}} \\
\text { a 2 D. E. } \\
\end{array}$ & $\begin{array}{c}\text { Ajuste error } \\
\text { de correlación } \\
\text { (datos } \\
\text { negativos) } \\
\end{array}$ & $\begin{array}{c}\text { Error de } \\
\text { correlación } \\
{ }^{206} \mathrm{~Pb} /{ }^{238} \mathrm{U} \text { vs. } \\
{ }^{207} \mathrm{~Pb} /{ }^{235} \mathrm{U} \\
\end{array}$ & $\begin{array}{l}\text { Edad corregida } \\
{ }^{206} \mathrm{~Pb} /{ }^{238} \mathrm{U}(\mathrm{Ma})\end{array}$ & $\begin{array}{c}\text { Edad }{ }^{207} \mathrm{~Pb} /{ }^{235} \mathrm{U} \\
\text { (Ma) }\end{array}$ & $\begin{array}{c}\% \\
\text { disc. }\end{array}$ & $\begin{array}{c}\text { Edad } \\
\text { corregida } \\
{ }^{206 \mathrm{~Pb} /}{ }^{238} \mathrm{U} \text { (Ma) }\end{array}$ & $\begin{array}{l} \pm \text { Error edad } \\
\text { corregida } \\
(\mathrm{Ma})\end{array}$ & $\begin{array}{l}\text { Aproximación } \\
{ }^{238} \mathrm{U}(\mathrm{ppm})\end{array}$ & $\mathrm{Th} / \mathrm{U}$ \\
\hline $\mathrm{Zr}-20$ & 0,3220 & 0,0120 & 0,03322 & 0,00034 & 0,5306 & 0,53058 & 205,72 & 282,60 & 37,37 & 205,72 & 6,23 & 0,69 & 1,441 \\
\hline $\mathrm{Zr}-21$ & 0,3620 & 0,0340 & 0,03690 & 0,00081 & 0,4867 & 0,48672 & 227,54 & 310,00 & 36,24 & 227,54 & 8,24 & 0,45 & 2,226 \\
\hline $\mathrm{Zr}-40$ & 0,2937 & 0,0099 & 0,03133 & 0,00032 & 0,3901 & 0,39011 & 194,10 & 260,70 & 34,31 & 194,10 & 5,86 & 1,63 & 0,615 \\
\hline Zr-35 & 0,2660 & 0,0150 & 0,02959 & 0,00053 & 0,1485 & 0,14848 & 183,84 & 240,00 & 30,55 & 183,84 & 6,20 & 0,68 & 1,477 \\
\hline Zr-50 & 0,2880 & 0,0150 & 0,03214 & 0,00041 & 0,2157 & 0,21571 & 199,76 & 258,00 & 29,16 & 199,76 & 6,27 & 0,43 & 2,341 \\
\hline Zr-25 & 0,2540 & 0,0120 & 0,03074 & 0,00045 & 0,4367 & 0,43673 & 192,47 & 228,20 & 18,57 & 192,47 & 6,15 & 0,47 & 2,137 \\
\hline $\mathrm{Zr}-11$ & 0,2552 & 0,0053 & 0,03102 & 0,00019 & 0,3950 & 0,39500 & 194,69 & 230,70 & 18,49 & 194,69 & 5,64 & 0,87 & 1,148 \\
\hline Zr-5 & 0,2560 & 0,0110 & 0,03122 & 0,00035 & 0,5190 & 0,51903 & 195,94 & 229,80 & 17,28 & 195,94 & 5,97 & 0,69 & 1,454 \\
\hline Zr-27 & 0,2660 & 0,0150 & 0,03269 & 0,00044 & 0,2429 & 0,24287 & 205,20 & 237,00 & 15,50 & 205,20 & 6,37 & 0,74 & 1,354 \\
\hline $\mathrm{Zr}-31$ & 0,2560 & 0,0110 & 0,03213 & 0,00034 & 0,6044 & 0,60442 & 201,79 & 229,80 & 13,88 & 201,79 & 6,10 & 0,75 & 1,325 \\
\hline $\mathrm{Zr}-45$ & 0,2088 & 0,0037 & 0,03010 & 0,00022 & 0,2098 & 0,20979 & 190,98 & 192,60 & 0,85 & 190,98 & 5,54 & 1,01 & 0,991 \\
\hline Zr-48 & 0,2143 & 0,0052 & 0,03017 & 0,00030 & 0,4558 & 0,45578 & 191,21 & 196,90 & 2,97 & 191,21 & 5,72 & 0,89 & 1,123 \\
\hline Zr-47 & 0,2190 & 0,0120 & 0,03035 & 0,00041 & 0,2675 & 0,26751 & 192,08 & 199,60 & 3,91 & 192,08 & 6,00 & 0,71 & 1,411 \\
\hline Zr-44 & 0,2130 & 0,0110 & 0,03056 & 0,00034 & 0,0879 & 0,08792 & 193,83 & 194,60 & 0,40 & 193,83 & 5,88 & 0,65 & 1,546 \\
\hline $\mathrm{Zr}-15$ & 0,2292 & 0,0043 & 0,03072 & 0,00020 & 0,2277 & 0,22769 & 194,28 & 209,80 & 7,99 & 194,28 & 5,60 & 1,05 & 0,957 \\
\hline Zr-39 & 0,2125 & 0,0094 & 0,03061 & 0,00034 & 0,0357 & 0,03566 & 194,34 & 195,40 & 0,55 & 194,34 & 5,88 & 0,56 & 1,797 \\
\hline Zr-37 & 0,2191 & 0,0062 & 0,03093 & 0,00044 & 0,6191 & 0,61909 & 195,76 & 201,40 & 2,88 & 195,76 & 6,16 & 0,90 & 1,113 \\
\hline Zr-42 & 0,2250 & 0,0110 & 0,03102 & 0,00038 & 0,1717 & 0,17168 & 195,77 & 208,60 & 6,56 & 195,77 & 6,06 & 0,60 & 1,676 \\
\hline $\mathrm{Zr}-13$ & 0,2178 & 0,0032 & 0,03092 & 0,00023 & 0,2810 & 0,28104 & 196,18 & 199,90 & 1,89 & 196,18 & 5,67 & 1,07 & 0,937 \\
\hline $\mathrm{Zr}-8$ & 0,2153 & 0,0060 & 0,03095 & 0,00028 & 0,1770 & 0,17698 & 196,57 & 197,80 & 0,62 & 196,57 & 5,80 & 0,26 & 3,774 \\
\hline $\mathrm{Zr}-18$ & 0,2239 & 0,0049 & 0,03118 & 0,00038 & 0,5498 & 0,54976 & 197,41 & 205,40 & 4,04 & 197,41 & 6,03 & 0,43 & 2,311 \\
\hline Zr-43 & 0,2110 & 0,0032 & 0,03112 & 0,00025 & 0,3964 & 0,39639 & 197,55 & 194,40 & $-1,60$ & 197,55 & 5,73 & 0,82 & 1,212 \\
\hline $\mathrm{Zr}-14$ & 0,2282 & 0,0064 & 0,03130 & 0,00047 & 0,2874 & 0,28744 & 198,06 & 208,90 & 5,47 & 198,06 & 6,28 & 0,36 & 2,789 \\
\hline Zr-49 & 0,2124 & 0,0081 & 0,03132 & 0,00040 & 0,3121 & 0,31208 & 198,73 & 196,50 & $-1,12$ & 198,73 & 6,11 & 1,10 & 0,909 \\
\hline Zr-46 & 0,2250 & 0,0120 & 0,03149 & 0,00054 & 0,1918 & 0,19181 & 199,08 & 206,00 & 3,48 & 199,08 & 6,37 & 0,59 & 1,691 \\
\hline $\mathrm{Zr}-7$ & 0,2330 & 0,0110 & 0,03150 & 0,00037 & 0,1659 & 0,16585 & 199,11 & 212,50 & 6,72 & 199,11 & 6,05 & 0,68 & 1,466 \\
\hline Zr-30 & 0,2220 & 0,0053 & 0,03146 & 0,00025 & 0,4585 & 0,45845 & 199,31 & 203,10 & 1,90 & 199,31 & 5,79 & 1,13 & 0,888 \\
\hline Zr-28 & 0,2178 & 0,0032 & 0,03146 & 0,00021 & 0,3836 & 0,38357 & 199,48 & 199,90 & 0,21 & 199,48 & 5,73 & 0,72 & 1,384 \\
\hline Zr-34 & 0,2300 & 0,0096 & 0,03163 & 0,00036 & 0,4972 & 0,49716 & 200,08 & 208,70 & 4,31 & 200,08 & 6,05 & 0,36 & 2,792 \\
\hline Zr-38 & 0,2340 & 0,0100 & 0,03173 & 0,00035 & 0,2335 & 0,23352 & 200,20 & 214,60 & 7,19 & 200,20 & 6,05 & 0,40 & 2,47 \\
\hline $\mathrm{Zr}-1$ & 0,2470 & 0,0140 & 0,03183 & 0,00037 & 0,4138 & 0,41380 & 200,38 & 222,00 & 10,79 & 200,38 & 6,12 & 0,60 & 1,667 \\
\hline Zr-22 & 0,2328 & 0,0050 & 0,03178 & 0,00024 & 0,2854 & 0,28536 & 200,87 & 212,40 & 5,74 & 200,87 & 5,84 & 0,30 & 3,35 \\
\hline $\mathrm{Zr}-17$ & 0,2219 & 0,0034 & 0,03170 & 0,00020 & 0,3020 & 0,30202 & 201,12 & 203,80 & 1,33 & 201,12 & 5,79 & 0,93 & 1,075 \\
\hline $\mathrm{Zr}-10$ & 0,2389 & 0,0037 & 0,03195 & 0,00019 & 0,3510 & 0,35099 & 201,92 & 217,50 & 7,72 & 201,92 & 5,78 & 0,94 & 1,065 \\
\hline $\mathrm{Zr}-12$ & 0,2502 & 0,0058 & 0,03209 & 0,00031 & 0,1794 & 0,17935 & 202,15 & 227,00 & 12,29 & 202,15 & 6,02 & 0,90 & 1,108 \\
\hline Zr-29 & 0,2150 & 0,0160 & 0,03183 & 0,00047 & 0,0324 & 0,03239 & 202,23 & 196,00 & $-3,08$ & 202,23 & 6,42 & 0,76 & 1,317 \\
\hline $\mathrm{Zr}-6$ & 0,2525 & 0,0038 & 0,03250 & 0,00026 & 0,4482 & 0,44817 & 204,67 & 228,40 & 11,59 & 204,67 & 5,96 & 0,59 & 1,702 \\
\hline $\mathrm{Zr}-19$ & 0,2146 & 0,0079 & 0,03221 & 0,00032 & 0,0511 & 0,05107 & 204,72 & 196,90 & $-3,82$ & 204,72 & 6,06 & 0,56 & 1,779 \\
\hline $\mathrm{Zr}-4$ & 0,2303 & 0,0050 & 0,03246 & 0,00029 & 0,4283 & 0,42825 & 205,68 & 210,10 & 2,15 & 205,68 & 6,04 & 0,86 & 1,161 \\
\hline Zr-9 & 0,2504 & 0,0069 & 0,03272 & 0,00032 & 0,3044 & 0,30436 & 206,39 & 226,60 & 9,79 & 206,39 & 6,15 & 0,27 & 3,772 \\
\hline Zr-26 & 0,2700 & 0,0150 & 0,03315 & 0,00045 & 0,5556 & 0,55559 & 208,21 & 237,00 & 13,83 & 208,21 & 6,35 & 0,29 & 3,444 \\
\hline $\mathrm{Zr}-41$ & 0,2393 & 0,0062 & 0,03297 & 0,00026 & 0,1486 & 0,14864 & 208,36 & 216,70 & 4,00 & 208,36 & 6,10 & 0,94 & 1,061 \\
\hline Zr-33 & 0,2600 & 0,0100 & 0,03330 & 0,00040 & 0,3837 & 0,38370 & 209,40 & 232,20 & 10,89 & 209,40 & 6,34 & 1,00 & 0,999 \\
\hline $\mathrm{Zr}-16$ & 0,2281 & 0,0038 & 0,03306 & 0,00037 & 0,5584 & 0,55839 & 209,67 & 208,60 & $-0,51$ & 209,67 & 6,29 & 0,85 & 1,181 \\
\hline Zr-23 & 0,2380 & 0,0120 & 0,03324 & 0,00042 & 0,1756 & 0,17561 & 210,31 & 215,90 & 2,66 & 210,31 & 6,37 & 0,64 & 1,552 \\
\hline $\mathrm{Zr}-2$ & 0,2350 & 0,0100 & 0,03325 & 0,00045 & 0,2807 & 0,28070 & 210,61 & 214,60 & 1,90 & 210,61 & 6,37 & 0,74 & 1,343 \\
\hline Zr-24 & 0,2350 & 0,0067 & 0,03337 & 0,00036 & 0,3554 & 0,35540 & 211,28 & 214,50 & 1,52 & 211,28 & 6,35 & 0,81 & 1,233 \\
\hline $\mathrm{Zr}-3$ & 0,2463 & 0,0042 & 0,03346 & 0,00022 & 0,1712 & 0,17121 & 211,43 & 223,60 & 5,75 & 211,43 & 6,09 & 0,91 & 1,099 \\
\hline Zr-32 & 0,2436 & 0,0061 & 0,03620 & 0,00069 & 0,6118 & 0,61181 & 229,39 & 221,20 & $-3,57$ & 229,39 & 7,59 & 0,58 & 1,721 \\
\hline Zr-36 & 0,2615 & 0,0067 & 0,03672 & 0,00042 & 0,1485 & 0,14854 & 231,90 & 236,00 & 1,77 & 231,90 & 6,97 & 0,71 & 1,403 \\
\hline
\end{tabular}




\section{Anexo 3. Análisis isotópicos de elementos traza en circón}

\section{GZ-6743, análisis isotópicos de elementos traza en circón}

\begin{tabular}{|c|c|c|c|c|c|c|c|c|c|c|c|c|c|c|c|c|c|c|c|c|c|}
\hline (ppm) & $\mathbf{P}$ & $\mathrm{Ti}$ & $Y$ & $\mathrm{Nb}$ & La & $\mathrm{Ce}$ & $\mathrm{Pr}$ & $\mathrm{Nd}$ & Sm & Eu & Gd & Tb & Dy & Ho & Er & Yb & Lu & $\mathrm{Hf}$ & $\mathrm{Pb}$ & Th & u \\
\hline Zr-012 & 1.080 & 16,4 & 6.080 & 8,66 & 0,5 & 159 & 1,25 & 18,2 & 30,4 & 10,35 & 160 & 52 & 577 & 211 & 893 & 1.530 & 308 & 8.280 & 7,825 & 625 & 267 \\
\hline Zr-017 & 560 & 39,2 & 1.910 & 13,63 & 0,62 & 39 & 0,479 & 5,85 & 7,85 & 2,99 & 41,2 & 13,2 & 160 & 63,9 & 297 & 617 & 134,4 & 9.800 & 4,773 & 177 & 156,9 \\
\hline Zr-028 & 520 & 36,1 & 1.820 & 15,4 & 0,299 & 80,6 & 0,257 & 3,69 & 5,9 & 1,84 & 34,1 & 11,9 & 149 & 60,7 & 277 & 558 & 117,2 & 10.910 & 8,375 & 327 & 243 \\
\hline Zr-010 & 810 & 9,17 & 3.110 & 13,76 & 1,19 & 118,4 & 0,81 & 8,1 & 10,6 & 2,81 & 62,6 & 21,3 & 260 & 100,5 & 466 & 941 & 194,8 & 10.630 & 16,3 & 708 & 491 \\
\hline Zr-011 & 390 & 9,3 & 1.005 & 1,19 & 0 & 22,57 & 0,088 & 1,29 & 2,24 & 2,07 & 13,15 & 4,95 & 65,5 & 29,19 & 157,7 & 421 & 105 & 5.712 & 3,988 & 122,7 & 123,5 \\
\hline Zr-013 & 417 & 6,53 & 1.811 & 14,89 & 0,026 & 58,2 & 0,022 & 0,75 & 2,96 & 0,738 & 21,7 & 9,55 & 131,7 & 58,51 & 295,8 & 675 & 148,7 & 11.800 & 11,13 & 259 & 349,4 \\
\hline Zr-014 & 2.770 & 26,2 & 2.719 & 16,01 & 13,5 & 155 & 4,7 & 25 & 11,1 & 2,95 & 50,7 & 17,69 & 218,3 & 88,2 & 419,2 & 902 & 196,9 & 9.980 & 18,25 & 780 & 554 \\
\hline Zr-015 & 480 & 14,7 & 1.930 & 2,29 & 0,074 & 36,4 & 0,73 & 10,9 & 15 & 5,77 & 57,7 & 17,6 & 188 & 66 & 290 & 538 & 112 & 8.230 & 2,095 & 104 & 62,8 \\
\hline Zr-016 & 1.870 & 12,76 & 3.190 & 12,3 & 5,4 & 123,8 & 1,9 & 10,2 & 10,7 & 3,94 & 56,8 & 20,85 & 259 & 104,2 & 503 & 1.034 & 222,3 & 9.860 & 11,38 & 552 & 358 \\
\hline Zr-018 & 440 & 7,86 & 1.680 & 7,02 & 0,08 & 58,3 & 0,118 & 2,07 & 5,2 & 1,36 & 30,7 & 11,3 & 138 & 54,8 & 258 & 530 & 108 & 11.580 & 6,8 & 261 & 202 \\
\hline Zr-019 & 230 & 8,03 & 1.170 & 5,32 & 0,095 & 46,6 & 0,52 & 5,28 & 6,46 & 2,18 & 23,5 & 7,88 & 90,8 & 36,5 & 176 & 408 & 91,6 & 9.220 & 5,375 & 184 & 155 \\
\hline Zr-020 & 830 & 8,72 & 3.090 & 11,67 & 0,154 & 108,9 & 0,329 & 5,48 & 10,6 & 2,99 & 59,1 & 20,9 & 255 & 100 & 459 & 933 & 194 & 9.640 & 15,48 & 856 & 499 \\
\hline Zr-021 & 1.000 & 10,7 & 4.750 & 9,97 & 0,04 & 149 & 0,47 & 9,2 & 16,5 & 5,9 & 86,6 & 31,1 & 382 & 149 & 710 & 1.500 & 308 & 8.860 & 19,78 & 1.000 & 582 \\
\hline Zr-022 & 526 & 10,66 & 1.641 & 4,25 & 0,004 & 31,77 & 0,096 & 1,84 & 4,75 & 1,73 & 28,1 & 9,87 & 122,5 & 51,7 & 255,4 & 583 & 130,3 & 9.570 & 4,633 & 140,1 & 138,1 \\
\hline Zr-023 & 470 & 11,11 & 1.257 & 3,04 & 0,009 & 39,74 & 0,076 & 2,35 & 4,12 & 1,55 & 23,4 & 8,37 & 104,2 & 41,34 & 200,8 & 407,6 & 86,5 & 8.955 & 4,145 & 169,6 & 124,4 \\
\hline Zr-024 & 290 & 8,1 & 1.063 & 5,33 & 0,38 & 31,9 & 0,163 & 1,64 & 2,42 & 0,86 & 15,5 & 5,91 & 81 & 34,5 & 170,5 & 401 & 88,4 & 10.970 & 5,175 & 147 & 154,7 \\
\hline Zr-025 & 560 & 10,27 & 2.269 & 10,34 & 0,153 & 68,4 & 0,18 & 2,68 & 6,1 & 2,04 & 38 & 14,03 & 177,2 & 73,5 & 356,6 & 784 & 172 & 10.040 & 12,43 & 485 & 380,1 \\
\hline Zr-026 & 2.740 & 18,3 & 3.570 & 18,2 & 12,2 & 270 & 3,7 & 22,8 & 15,8 & 4,36 & 66,9 & 21,9 & 266 & 105 & 490 & 1.040 & 221 & 10.070 & 6,225 & 355 & 183,5 \\
\hline Zr-027 & 390 & 11,57 & 1.950 & 4,15 & 0,048 & 45,4 & 0,405 & 7,1 & 10,6 & 3,72 & 49 & 15,7 & 179 & 65,8 & 295 & 582 & 123,3 & 9.050 & 4,225 & 176 & 130,6 \\
\hline Zr-029 & 780 & 11,9 & 4.080 & 17,55 & 2,37 & 103,9 & 0,9 & 7,56 & 13,9 & 3,79 & 77 & 29,19 & 355 & 140,2 & 653 & 1.283 & 260 & 11.200 & 12,55 & 498 & 437 \\
\hline Zr-030 & 210 & 7,87 & 670 & 2,38 & 0,02 & 28,7 & 0,159 & 2,25 & 3,24 & 1,13 & 16,1 & 4,6 & 58 & 21,8 & 104 & 219 & 48,2 & 10.370 & 3 & 122 & 77 \\
\hline Zr-031 & 710 & 11,13 & 4.170 & 5,68 & 0,205 & 79,3 & 0,73 & 12 & 20,6 & 7,33 & 97,6 & 31,6 & 363,9 & 138,9 & 630 & 1.277 & 266,2 & 8.530 & 8,043 & 420 & 268,9 \\
\hline Zr-032 & 1.820 & 9,87 & 7.360 & 39,4 & 0,062 & 262 & 0,511 & 10,6 & 26,9 & 6,91 & 151,1 & 54 & 648 & 246,6 & 1073 & 1.910 & 361 & 9.140 & 13,68 & 865 & 444 \\
\hline Zr-033 & 6.500 & 10,1 & 2.366 & 16,37 & 8800 & 14300 & 1340 & 4500 & 470 & 30,3 & 303 & 32,8 & 229 & 77,4 & 361,6 & 795 & 173,7 & 11.500 & 11,4 & 1.240 & 350,5 \\
\hline Zr-034 & 399 & 7,52 & 1.358 & 9,96 & 0,267 & 42,8 & 0,078 & 0,84 & 2,26 & 0,618 & 17,6 & 7,13 & 99,3 & 43,1 & 217,3 & 510 & 110,8 & 11.560 & 9,325 & 206,2 & 282,5 \\
\hline Zr-035 & 671 & 12,53 & 2.505 & 7,3 & 0,013 & 69,6 & 0,167 & 3,47 & 6,09 & 2,51 & 41,1 & 15,39 & 197,7 & 81,4 & 387,6 & 806 & 174,3 & 8.110 & 6,55 & 257,1 & 195,5 \\
\hline Zr-036 & 140 & 6,76 & 621 & 2,03 & 0 & 21,83 & 0,033 & 0,9 & 1,28 & 0,61 & 8,42 & 3,28 & 43,1 & 18,75 & 100 & 260 & 62,4 & 11.140 & 3,485 & 71,1 & 104,3 \\
\hline Zr-037 & 510 & 10,2 & 2.060 & 5,27 & 0,138 & 55,1 & 0,229 & 3,87 & 7,04 & 2,62 & 34,5 & 12,28 & 151,9 & 61,5 & 312 & 729 & 165,2 & 9.920 & 10,3 & 466 & 305 \\
\hline Zr-038 & 571 & 9,12 & 2.106 & 14,99 & 0,018 & 86,7 & 0,117 & 1,87 & 5,26 & 1,47 & 33,3 & 13,18 & 168,9 & 68,2 & 326 & 671 & 143,8 & 10.950 & 20,05 & 956 & 630 \\
\hline Zr-039 & 570 & 8,7 & 2.350 & 6,16 & 0,01 & 66,3 & 0,189 & 4,7 & 7,7 & 2,8 & 42,4 & 15,1 & 186 & 74,6 & 362 & 818 & 179,6 & 9.820 & 8,775 & 437 & 302 \\
\hline Zr-040 & 400 & 7,08 & 454 & 3,74 & 0,025 & 16,49 & 0,019 & 0,2 & 0,71 & 0,152 & 4,46 & 2,08 & 31,1 & 14,44 & 75,3 & 192,5 & 43,9 & 11.330 & 3,725 & 64,8 & 105,2 \\
\hline Zr-041 & 3.110 & 19,1 & 1.933 & 6,29 & 29,1 & 115 & 9,6 & 43 & 13,1 & 2,25 & 38 & 13,09 & 157,1 & 63,9 & 303,1 & 641,7 & 138,2 & 10.670 & 5,088 & 142,6 & 158,6 \\
\hline Zr-042 & 200 & 8,52 & 1.953 & 2,01 & 0,028 & 38,7 & 0,321 & 4,6 & 8,25 & 3,76 & 43,3 & 13,68 & 168,6 & 64,9 & 298 & 623 & 136,7 & 9.790 & 7,075 & 318 & 235 \\
\hline Zr-043 & 730 & 12,94 & 3.054 & 4,65 & 0,53 & 59,4 & 0,61 & 7,72 & 12,4 & 4,73 & 66 & 21,76 & 259,3 & 100,5 & 468,3 & 952 & 204,8 & 8.120 & 6,31 & 299,4 & 207,8 \\
\hline Zr-044 & 534 & 9,97 & 2.707 & 10,78 & 0 & 76,1 & 0,083 & 2,09 & 5,88 & 2,26 & 42,4 & 16,58 & 214,3 & 88,9 & 434 & 933 & 203 & 9.960 & 8,478 & 284,4 & 261,2 \\
\hline
\end{tabular}


JGB-462, análisis isotópicos de elementos traza en circón

\begin{tabular}{|c|c|c|c|c|c|c|c|c|c|c|c|c|c|c|c|c|c|c|c|c|c|}
\hline (ppm) & $\mathbf{P}$ & $\mathrm{Ti}$ & $Y$ & $\mathrm{Nb}$ & La & $\mathrm{Ce}$ & $\mathrm{Pr}$ & $\mathrm{Nd}$ & $\mathrm{Sm}$ & $\mathrm{Eu}$ & Gd & Tb & Dy & Ho & $\mathrm{Er}$ & $\mathrm{Yb}$ & Lu & $\mathrm{Hf}$ & $\mathrm{Pb}$ & Th & u \\
\hline Zr-058 & 332 & 53 & 1.720 & 5 & 0 & 39 & 0 & 6 & 10 & 4 & 48 & 15 & 167 & 60 & 263 & 490 & 99 & 6.538 & 3,75 & 186 & 110 \\
\hline Zr-067 & 382 & 10 & 1.132 & 3 & 0 & 32 & 0 & 3 & 6 & 2 & 27 & 9 & 99 & 38 & 181 & 359 & 77 & 7.014 & 3,5 & 136 & 102 \\
\hline Zr-047 & 6.224 & 57 & 1.021 & 3 & 2 & 27 & 2 & 11 & 5 & 1 & 17 & 6 & 80 & 33 & 160 & 316 & 66 & 7.060 & 2,25 & 75 & 71 \\
\hline $\mathrm{Zr}-040$ & 212 & 10 & 565 & 1 & 0 & 14 & 0 & 1 & 2 & 1 & 11 & 4 & 48 & 19 & 89 & 196 & 45 & 7.490 & 1 & 44 & 33 \\
\hline Zr-057 & 348 & 11 & 937 & 6 & 0 & 41 & 0 & 1 & 3 & 1 & 15 & 6 & 70 & 30 & 152 & 338 & 73 & 9.237 & 6,5 & 170 & 207 \\
\hline Zr-069 & 600 & 8 & 2.184 & 7 & 0 & 71 & 0 & 4 & 9 & 3 & 47 & 16 & 189 & 74 & 336 & 674 & 138 & 6.996 & 7,25 & 449 & 222 \\
\hline Zr-068 & 489 & 10 & 1.582 & 6 & 0 & 50 & 0 & 2 & 4 & 2 & 27 & 10 & 125 & 53 & 260 & 558 & 119 & 7.295 & 3,75 & 147 & 115 \\
\hline Zr-041 & 402 & 10 & 1.043 & 5 & 0 & 38 & 0 & 1 & 3 & 1 & 16 & 6 & 76 & 33 & 171 & 394 & 89 & 10.754 & 3,75 & 113 & 111 \\
\hline Zr-036 & 328 & 8 & 936 & 4 & 0,1 & 40 & 0,1 & 1 & 3 & 1 & 16 & 6 & 75 & 31 & 151 & 330 & 72 & 9.715 & 4 & 166 & 127 \\
\hline Zr-037 & 608 & 10 & 1.842 & 9 & 0,1 & 87 & 0,1 & 3 & 7 & 2 & 39 & 13 & 158 & 60 & 283 & 565 & 120 & 9.162 & 10,5 & 732 & 327 \\
\hline Zr-038 & 525 & 14 & 2.852 & 3 & 0,1 & 58 & 1 & 15 & 23 & 8 & 91 & 27 & 280 & 100 & 432 & 786 & 158 & 8.634 & 4 & 266 & 131 \\
\hline Zr-039 & 731 & 11 & 3.309 & 5 & 0,1 & 95 & 2 & 23 & 30 & 9 & 105 & 33 & 331 & 119 & 503 & 889 & 173 & 7.484 & 5,5 & 587 & 184 \\
\hline Zr-042 & 891 & 9 & 2.087 & 9 & 0,1 & 40 & 0,1 & 2 & 5 & 1 & 33 & 13 & 168 & 68 & 333 & 698 & 148 & 8.404 & 13 & 257 & 413 \\
\hline $\mathrm{Zr}-043$ & 402 & 8 & 1.939 & 12 & 0,1 & 87 & 0,1 & 3 & 6 & 2 & 35 & 12 & 160 & 65 & 320 & 659 & 142 & 10.036 & 8,5 & 270 & 243 \\
\hline Zr-044 & 347 & 11 & 1.111 & 2 & 0,1 & 17 & 0,1 & 2 & 3 & 1 & 18 & 7 & 88 & 36 & 180 & 410 & 91 & 7.990 & 3 & 96 & 91 \\
\hline Zr-045 & 611 & 10 & 2.030 & 7 & 0,1 & 62 & 0,1 & 3 & 6 & 2 & 34 & 13 & 166 & 68 & 321 & 675 & 144 & 7.815 & 5,25 & 230 & 159 \\
\hline Zr-046 & 356 & 9 & 1.301 & 5 & 0,1 & 43 & 0,1 & 2 & 3 & 1 & 21 & 8 & 101 & 43 & 215 & 490 & 109 & 8.396 & 3,5 & 121 & 107 \\
\hline Zr-048 & 761 & 9 & 2.000 & 9 & 1 & 76 & 0,1 & 4 & 6 & 2 & 36 & 12 & 152 & 62 & 305 & 739 & 160 & 8.418 & 8,25 & 436 & 279 \\
\hline Zr-049 & 494 & 8 & 1.544 & 7 & 0,1 & 67 & 0,1 & 2 & 5 & 2 & 27 & 10 & 128 & 51 & 255 & 539 & 114 & 8.003 & 5 & 225 & 146 \\
\hline $\mathrm{Zr}-050$ & 416 & 8 & 1.761 & 7 & 0,1 & 64 & 0,1 & 2 & 4 & 2 & 26 & 10 & 133 & 58 & 283 & 606 & 132 & 7.821 & 5 & 196 & 154 \\
\hline Zr-051 & 498 & 11 & 2.203 & 8 & 0,1 & 75 & 0,1 & 3 & 6 & 2 & 37 & 14 & 180 & 73 & 352 & 732 & 157 & 7.609 & 5,25 & 252 & 156 \\
\hline Zr-052 & 330 & 11 & 1.141 & 2 & 0,1 & 28 & 0,1 & 3 & 5 & 2 & 30 & 10 & 109 & 40 & 179 & 340 & 70 & 7.286 & 1,75 & 96 & 54 \\
\hline Zr-053 & 538 & 11 & 2.685 & 9 & 0,1 & 99 & 0,1 & 3 & 9 & 3 & 53 & 18 & 231 & 91 & 422 & 839 & 173 & 7.161 & 5,5 & 331 & 167 \\
\hline $\mathrm{Zr}-054$ & 395 & 8 & 1.622 & 15 & 0,1 & 92 & 0,1 & 2 & 6 & 1 & 31 & 11 & 142 & 55 & 255 & 508 & 103 & 7.959 & 11 & 528 & 345 \\
\hline Zr-055 & 510 & 10 & 2.137 & 6 & 0,1 & 71 & 0,1 & 4 & 8 & 3 & 42 & 15 & 185 & 71 & 333 & 681 & 144 & 7.308 & 4,5 & 258 & 140 \\
\hline Zr-056 & 684 & 11 & 3.400 & 4 & 0,1 & 79 & 1 & 17 & 29 & 9 & 114 & 33 & 352 & 123 & 515 & 898 & 178 & 7.793 & 7,25 & 397 & 241 \\
\hline Zr-059 & 866 & 7 & 2.637 & 13 & 0,1 & 53 & 0,1 & 2 & 7 & 1 & 47 & 18 & 227 & 87 & 410 & 809 & 163 & 9.647 & 33,5 & 742 & 1.021 \\
\hline Zr-060 & 1.008 & 10 & 4.560 & 13 & 0,1 & 188 & 0,1 & 9 & 20 & 6 & 111 & 38 & 431 & 162 & 718 & 1271 & 250 & 7.367 & 8,5 & 858 & 273 \\
\hline $\mathrm{Zr}-061$ & 385 & 9 & 1.429 & 5 & 0,1 & 52 & 0,1 & 2 & 4 & 2 & 27 & 10 & 118 & 47 & 227 & 483 & 104 & 7.686 & 5 & 235 & 150 \\
\hline Zr-062 & 282 & 9 & 1.250 & 7 & 0,1 & 61 & 0,1 & 2 & 4 & 1 & 22 & 8 & 104 & 42 & 199 & 421 & 90 & 8.327 & 5 & 211 & 151 \\
\hline Zr-063 & 257 & 7 & 740 & 4 & 0,1 & 29 & 0,1 & 1 & 2 & 1 & 11 & 4 & 59 & 25 & 120 & 271 & 59 & 8.005 & 3,5 & 114 & 106 \\
\hline Zr-064 & 319 & 7 & 771 & 2 & 0,1 & 27 & 0,1 & 1 & 2 & 1 & 14 & 5 & 63 & 26 & 126 & 272 & 60 & 8.160 & 1,75 & 66 & 53 \\
\hline Zr-065 & 815 & 8 & 4.133 & 11 & 0,1 & 164 & 1 & 15 & 22 & 8 & 102 & 33 & 376 & 142 & 637 & 1253 & 255 & 6.228 & 10,8 & 834 & 348 \\
\hline Zr-066 & 1.033 & 8 & 2.877 & 12 & 0,1 & 94 & 0,1 & 5 & 11 & 2 & 60 & 22 & 261 & 100 & 455 & 860 & 170 & 7.552 & 20 & 809 & 616 \\
\hline Zr-070 & 389 & 7 & 1.464 & 8 & 0,1 & 75 & 0,1 & 2 & 5 & 2 & 28 & 10 & 127 & 50 & 233 & 468 & 96 & 8.160 & 6,25 & 351 & 206 \\
\hline Zr-025 & 530 & 110 & 1.560 & 10,8 & 3,7 & 60 & 0,8 & 4,6 & 5,7 & 1,86 & 21,5 & 9,7 & 125 & 50 & 245 & 560 & 123 & 8.900 & 7,375 & 244 & 221 \\
\hline $\mathrm{Zr}-030$ & 910 & 10,7 & 2.100 & 16,5 & 1,23 & 109 & 0,6 & 4,9 & 5,5 & 3,47 & 34,5 & 13,2 & 171 & 71 & 348 & 790 & 162 & 10.500 & 10,48 & 325 & 368 \\
\hline $\mathrm{Zr}-032$ & 330 & 15,7 & 1.660 & 14,1 & 0,102 & 52,5 & 0,044 & 0,97 & 2,31 & 1,04 & 19,5 & 8,2 & 117 & 51,5 & 265 & 636 & 144 & 10.900 & 10,38 & 297 & 357 \\
\hline Zr-029 & 890 & 13,1 & 1.770 & 15,7 & 0 & 57 & 0,105 & 1,4 & 3,07 & 1,09 & 27,3 & 10,5 & 113,8 & 56 & 297 & 650 & 144 & 6.200 & 12,75 & 362 & 420 \\
\hline Zr-003 & 660 & 10,1 & 1.350 & 8,8 & 0 & 48,3 & 0,05 & 1,33 & 3,97 & 1,09 & 22,8 & 8,2 & 109 & 44,3 & 215 & 464 & 98 & 10.200 & 8,725 & 343 & 269 \\
\hline Zr-019 & 1.270 & 15,3 & 3.500 & 16,8 & 0,31 & 123 & 0,29 & 6,2 & 12,8 & 3 & 77 & 24,6 & 300 & 116 & 540 & 1.060 & 219 & 12.000 & 20 & 1.050 & 590 \\
\hline Zr-001 & 730 & 12,2 & 3.250 & 26,9 & 0,01 & 211 & 0,281 & 6,3 & 13,7 & 3,3 & 72 & 25 & 291 & 111 & 500 & 950 & 193 & 9.500 & 22,5 & 1.610 & 720 \\
\hline Zr-002 & 1.280 & 9,3 & 3.840 & 56,3 & 0,011 & 101 & 0,097 & 2,31 & 7,63 & 1,89 & 59,3 & 24,5 & 312 & 128 & 601 & 1.240 & 244 & 10.080 & 30,5 & 1.210 & 986 \\
\hline Zr-004 & 6.000 & 30,5 & 3.500 & 51 & 24,1 & 149 & 10,4 & 59 & 21,9 & 2,47 & 71,3 & 24,7 & 308 & 121 & 559 & 1.090 & 215 & 13.100 & 42,75 & 1.850 & 1.390 \\
\hline Zr-005 & 500 & 9,4 & 670 & 1,81 & 0,026 & 4,02 & 0,016 & 0,63 & 1,5 & 0,118 & 10,2 & 4,26 & 53,5 & 22,4 & 105 & 206 & 40 & 8.980 & 28,5 & 36,2 & 122 \\
\hline Zr-006 & 720 & 11,4 & 1.970 & 8,5 & 0,003 & 85 & 0,15 & 3,25 & 6,6 & 2,12 & 36,1 & 12,9 & 163 & 66,5 & 311 & 647 & 132 & 8.810 & 5,925 & 277 & 192 \\
\hline Zr-007 & 610 & 11,2 & 2.270 & 10,7 & 0,003 & 96 & 0,122 & 3,21 & 7,4 & 3,16 & 46,9 & 16,5 & 202 & 78,8 & 362 & 746 & 150 & 8.710 & 9,15 & 467 & 299 \\
\hline Zr-008 & 1.000 & 12,3 & 2.440 & 5,2 & 0 & 8,4 & 0,052 & 0,13 & 2,5 & 0,21 & 22,4 & 12,3 & 189 & 79 & 410 & 960 & 204 & 14.200 & 39 & 166 & 1.050 \\
\hline Zr-009 & 590 & 11,7 & 3.530 & 6 & 0,055 & 89 & 0,51 & 9,4 & 17,9 & 5,97 & 83 & 27,4 & 319 & 121 & 544 & 1.010 & 203 & 10.700 & 7,125 & 392 & 245 \\
\hline $\mathrm{Zr}-010$ & 10 & 9,6 & 388 & 2,84 & 0 & 3,01 & 0,01 & 0,04 & 0,28 & 0,161 & 3,12 & 1,32 & 22,2 & 10,6 & 62 & 236 & 74 & 13.700 & 46,25 & 15,1 & 279 \\
\hline $\mathrm{Zr}-011$ & 790 & 14 & 2.620 & 10,7 & 0 & 81,5 & 0,125 & 3,37 & 7,4 & 2,76 & 45,1 & 17,8 & 228 & 89 & 423 & 890 & 176 & 9.800 & 8,075 & 305 & 261 \\
\hline Zr-012 & 330 & 9,6 & 960 & 4,4 & 0,02 & 25 & 0,039 & 0,97 & 3,3 & 0,75 & 18 & 7 & 81 & 32 & 148 & 294 & 60 & 12.400 & 77 & 105 & 500 \\
\hline $\mathrm{Zr}-013$ & 660 & 10,8 & 3.350 & 29,2 & 0,057 & 103 & 0,064 & 1,56 & 3,93 & 1,56 & 36,1 & 15,2 & 214 & 99 & 525 & 1.350 & 309 & 11.900 & 24 & 880 & 784 \\
\hline Zr-014 & 890 & 14 & 2.500 & 17,8 & 0,002 & 111 & 0,119 & 3,2 & 6,8 & 2,19 & 45,1 & 16,8 & 213 & 85 & 399 & 840 & 176 & 12.400 & 13,05 & 640 & 429 \\
\hline Zr-015 & 940 & 16,3 & 1.750 & 5,51 & 1,8 & 46,2 & 0,67 & 5,5 & 5,4 & 1,73 & 30,2 & 11,1 & 144 & 58,6 & 281 & 582 & 125 & 8.520 & 4,75 & 179 & 156 \\
\hline
\end{tabular}




\begin{tabular}{|c|c|c|c|c|c|c|c|c|c|c|c|c|c|c|c|c|c|c|c|c|c|}
\hline (ppm) & $\mathbf{P}$ & $\mathrm{Ti}$ & $Y$ & $\mathrm{Nb}$ & La & $\mathrm{Ce}$ & $\mathrm{Pr}$ & Nd & Sm & $\mathrm{Eu}$ & Gd & Tb & Dy & Ho & Er & $\mathrm{Yb}$ & Lu & $\mathrm{Hf}$ & $\mathrm{Pb}$ & Th & U \\
\hline Zr-016 & 950 & 13,6 & 2.280 & 10,7 & 0,217 & 107 & 0,214 & 3,87 & 8 & 3,43 & 49,8 & 16,9 & 207 & 78,3 & 351 & 655 & 133 & 9.800 & 12,35 & 910 & 409 \\
\hline Zr-017 & 540 & 9,4 & 1.490 & 10,5 & 0,011 & 66,8 & 0,084 & 1,57 & 3,46 & 1,18 & 23,4 & 8,8 & 114 & 47,3 & 237 & 499 & 110 & 10.200 & 7,95 & 349 & 274 \\
\hline Zr-018 & 460 & 9,7 & 1.050 & 2,33 & 0,015 & 41 & 0,294 & 4,03 & 6,4 & 1,87 & 25,1 & 7,87 & 91 & 34,8 & 161 & 357 & 77 & 9.050 & 9,7 & 435 & 321 \\
\hline Zr-020 & 1.230 & 12 & 3.660 & 27,5 & 0,002 & 158 & 0,165 & 4,86 & 12,1 & 4,33 & 77 & 26 & 337 & 134 & 599 & 1.170 & 223 & 10.100 & 21,75 & 1.320 & 734 \\
\hline Zr-021 & 620 & 12,8 & 1.900 & 5,3 & 0,001 & 51,6 & 0,159 & 2,85 & 6,3 & 2,38 & 33,8 & 12,6 & 157 & 63 & 301 & 630 & 134 & 11.500 & 4,7 & 156 & 149 \\
\hline $\mathrm{Zr}-022$ & 600 & 8,5 & 1.280 & 11,5 & 0 & 32,7 & 0,026 & 0,53 & 2,3 & 0,63 & 13,7 & 6,02 & 87 & 38,2 & 207 & 484 & 110 & 9.500 & 7,575 & 205 & 264 \\
\hline Zr-023 & -600 & 10,5 & 630 & 1,64 & 0 & 17,1 & 0,09 & 1,2 & 2,4 & 0,38 & 8 & 4 & 49 & 21,2 & 101 & 212 & 46 & 5.700 & 2,575 & 63 & 76 \\
\hline Zr-024 & 270 & 10,8 & 592 & 2,31 & 1,17 & 24,3 & 0,75 & 4,58 & 3,43 & 1,37 & 12,3 & 3,9 & 46,7 & 18,2 & 87 & 192 & 43 & 9.100 & 2,125 & 74 & 72 \\
\hline Zr-026 & 290 & 14,6 & 1.570 & 2,52 & 0,012 & 13,8 & 0,389 & 7,3 & 11,3 & 2,24 & 51,7 & 15,8 & 164 & 55,5 & 220 & 359 & 68 & 10.300 & 19 & 47,3 & 115 \\
\hline Zr-027 & 330 & 13,5 & 1.540 & 5,82 & 0,51 & 61,5 & 0,333 & 3,4 & 6,31 & 2,21 & 32,6 & 11,4 & 135 & 51,3 & 230 & 448 & 94 & 8.920 & 5,975 & 393 & 194 \\
\hline Zr-028 & 370 & 8,59 & 1.400 & 5,47 & 0 & 54 & 0,1 & 2,11 & 4,38 & 1,5 & 25,2 & 9,2 & 119 & 44,6 & 221 & 440 & 97 & 9.520 & 4,525 & 208 & 147 \\
\hline Zr-031 & 700 & 10,6 & 2.530 & 13,5 & 0,005 & 98 & 0,107 & 2,75 & 5,85 & 2,34 & 39,9 & 14,8 & 204 & 84 & 406 & 840 & 173 & 10.100 & 10,58 & 335 & 323 \\
\hline Zr-033 & 960 & 172 & 2.090 & 12 & 0,158 & 53,2 & 0,102 & 1,59 & 4,33 & 1,49 & 28,7 & 11,5 & 155 & 65,7 & 328 & 789 & 169 & 9.290 & 15,03 & 415 & 506 \\
\hline Zr-034 & 580 & 9,1 & 1.680 & 13,3 & 0,5 & 85 & 0,207 & 2,2 & 4,29 & 1,28 & 26,3 & 10,2 & 136 & 55,4 & 260 & 551 & 112 & 10.400 & 9,6 & 385 & 311 \\
\hline $\mathrm{Zr}-035$ & 510 & 16 & 3.070 & 8,48 & 0,02 & 86,4 & 0,24 & 3,81 & 8,2 & 3,41 & 52,3 & 19,8 & 261 & 99,4 & 473 & 882 & 181 & 8.500 & 6,625 & 328 & 223 \\
\hline
\end{tabular}

